\title{
Progress in understanding of Indian Ocean circulation, variability, air-sea exchange, and impacts on biogeochemistry
}

Helen E. Phillips ${ }^{1,2}$, Amit Tandon ${ }^{3}$, Ryo Furue ${ }^{4}$, Raleigh Hood ${ }^{5}$, Caroline C. Ummenhofer ${ }^{6,7}$, Jessica A. Benthuysen ${ }^{8}$, Viviane Menezes $^{6}$, Shijian $\mathrm{Hu}^{9}$, Ben Webber ${ }^{10}$, Alejandra Sanchez-Franks ${ }^{11}$, Deepak Cherian ${ }^{12}$, Emily Shroyer ${ }^{13}$, Ming Feng ${ }^{14,15}$, Hemantha Wijesekera ${ }^{16}$, Abhisek Chatterjee ${ }^{17}$, Lisan Yu ${ }^{6}$, Juliet Hermes ${ }^{18}$, Raghu Murtugudde ${ }^{19}$, Tomoki Tozuka ${ }^{20,4}$, Danielle Su ${ }^{21}$, Arvind Singh ${ }^{22}$, Luca Centurioni ${ }^{23}$, Satya Prakash ${ }^{17, \boldsymbol{t}}$, and Jerry Wiggert ${ }^{24}$

${ }^{1}$ Institute for Marine and Antarctic Studies, University of Tasmania, Hobart, 7005, Australia

${ }^{2}$ Australian Antarctic Program Partnership, Institute for Marine and Antarctic Studies,

University of Tasmania, Hobart, 7005, Australia

${ }^{3}$ Department of Mechanical Engineering, College of Engineering, University of Massachusetts, Dartmouth, 02747, USA

${ }^{4}$ APL/JAMSTEC, Yokohama, 236-0001, Japan

${ }^{5}$ Horn Point Laboratory, University of Maryland Center for Environmental Science, Cambridge, 21613, USA

${ }^{6}$ Department of Physical Oceanography, Woods Hole Oceanographic Institution, Woods Hole, 02543, USA

${ }^{7}$ ARC Centre of Excellence for Climate Extremes, University of New South Wales, Sydney, 2052, Australia

${ }^{8}$ Australian Institute of Marine Science, Indian Ocean Marine Research Centre, Crawley, 6009, Australia

${ }^{9}$ Institute of Oceanology, Chinese Academy of Sciences, Qingdao, China

${ }^{10}$ School of Environmental Sciences, University of East Anglia, Norwich, NR4 7TJ, UK

${ }^{11}$ National Oceanography Centre, Southampton, SO 15 UK

${ }^{12}$ National Center for Atmospheric Research, Boulder, 80305, USA

${ }^{13}$ College of Earth, Ocean and Atmospheric Sciences, Oregon State University, Corvallis, 97331, USA

${ }^{14}$ CSIRO Oceans and Atmosphere, Indian Ocean Marine Research Centre, Crawley, 6009, Australia

${ }^{15}$ Centre for Southern Hemisphere Oceans Research, Hobart, 7004, Australia

${ }^{16}$ U.S. Naval Research Laboratory, Stennis Space Center, 39529, USA

${ }^{17}$ Indian National Centre for Ocean Information Services, Ministry of Earth Sciences, Hyderabad, India

${ }^{18}$ South African Environmental Observation Network, Cape Town, South Africa

${ }^{19}$ Department of Atmospheric and Oceanic Science, University of Maryland, College Park, 20742, USA

${ }^{20}$ Department of Earth and Planetary Science, Graduate School of Science, The University of Tokyo, Tokyo, 113-0033, Japan

${ }^{21}$ Sorbonne Universités, UPMC Université Paris 06, CNRS, UMR 7159 LOCEAN-IPSL, Paris, France

${ }^{22}$ Physical Research Laboratory, Ahmedabad, India

${ }^{23}$ Scripps Institution of Oceanography, University of California San Diego, La Jolla, 92093, USA

${ }^{24}$ Marine Science Department, University of Southern Mississippi, Hattiesburg, 399406, USA

$\boldsymbol{t}_{\text {deceased, } 22 \text { July } 2021}$

Correspondence: Helen E. Phillips (h.e.phillips@utas.edu.au)

Received: 4 January 2021 - Discussion started: 29 March 2021

Revised: 10 September 2021 - Accepted: 15 September 2021 - Published: 26 November 2021 
Abstract. Over the past decade, our understanding of the Indian Ocean has advanced through concerted efforts toward measuring the ocean circulation and air-sea exchanges, detecting changes in water masses, and linking physical processes to ecologically important variables. New circulation pathways and mechanisms have been discovered that control atmospheric and oceanic mean state and variability. This review brings together new understanding of the oceanatmosphere system in the Indian Ocean since the last comprehensive review, describing the Indian Ocean circulation patterns, air-sea interactions, and climate variability. Coordinated international focus on the Indian Ocean has motivated the application of new technologies to deliver higherresolution observations and models of Indian Ocean processes. As a result we are discovering the importance of small-scale processes in setting the large-scale gradients and circulation, interactions between physical and biogeochemical processes, interactions between boundary currents and the interior, and interactions between the surface and the deep ocean. A newly discovered regional climate mode in the southeast Indian Ocean, the Ningaloo Niño, has instigated more regional air-sea coupling and marine heatwave research in the global oceans. In the last decade, we have seen rapid warming of the Indian Ocean overlaid with extremes in the form of marine heatwaves. These events have motivated studies that have delivered new insight into the variability in ocean heat content and exchanges in the Indian Ocean and have highlighted the critical role of the Indian Ocean as a clearing house for anthropogenic heat. This synthesis paper reviews the advances in these areas in the last decade.

Dedication. Dedicated to Dr. Satya Prakash (1979-2021). This paper was written during the COVID-19 pandemic while many juggled family and health issues under lockdown. Satya, our co-author and friend, passed away on 22 July 2021. Satya was the coordinator of the International Indian Ocean Expedition (IIOE-2) at the Indian National Centre for Ocean Information Services (INCOIS). He played an integral part in Indian Ocean research. He is remembered for his enthusiasm, commitment, and smile. His passing is a massive loss to the Indian Ocean community, but there will be much that will still be carried on in his memory thanks to his hard work and passion.

\section{Introduction}

The physical processes taking place in the Indian Ocean and overlying atmosphere underpin the variability evident in monsoons, extreme events, marine biogeochemical cycles, ecosystems, and ultimately human experience. The Indian Ocean rim countries, accounting for one-third of the Earth's human population, depend on this ocean for food and resources and are dramatically impacted by its variability (Hermes et al., 2019). Increasing our understanding of in- teractions between geologic, oceanic, and atmospheric processes that control the complex physical dynamics of the Indian Ocean region is a priority for many national, bilateral, and international programmes, including the Indian Ocean Observing System (IndOOS; Beal et al., 2020), the Climate and Ocean: Variability, Predictability and Change (CLIVAR)/Intergovernmental Oceanographic Commission (IOC) - Indian Ocean Region Panel (https://www.clivar.org/ sites/default/files/documents/indian/135_IOP5.pdf, last access: 22 October 2021), and the second International Indian Ocean Expedition (IIOE-2), to name a few. While initiated through IIOE-2 (Hood et al., 2015), this review draws on the collective results of all of the programmes and individual efforts. We focus, in particular, on questions about the Indian Ocean circulation, climate variability and change, such as (1) how have the atmospheric and oceanic circulation of the Indian Ocean changed in the past and how will they change in the future; (2) how do these changes relate to geography and connectivity with the Pacific, Atlantic, and Southern oceans; and (3) what impact does the circulation, variability, and change have on biological productivity and fisheries.

Recent focus on the Indian Ocean has motivated new international efforts in field campaigns and modelling studies and leveraged advances in global observations that contribute to the Indian Ocean Observing System (IndOOS; Beal et al., 2020). The Argo profiling float array (Roemmich et al., 2012) reached full coverage in the Indian Ocean in 2006, the Research Moored Array for African-Asian-Australian Monsoon Analysis and Prediction (RAMA) moored buoy array (McPhaden et al., 2009) has now delivered multi-year time series of tropical oceanic and atmospheric variability, with some sites dating back to 2000. GO-SHIP continues to provide global, repeat, full-depth hydrographic surveys (Talley et al., 2016, 2017). Satellite systems continue to provide observations vital to interpreting spatial and temporal variability in the in situ observations, and new technology is now enabling high-resolution observations of boundary current variability and small-scale processes. Thus, since the reviews of Schott and McCreary (2001) and Schott et al. (2009), the spatial coverage of observations and length of time series have increased substantially such that the signals of many previously unresolved processes are now able to be observed.

These new higher-resolution observations and companion improvements in model simulations have highlighted the importance of small-scale processes in setting the large-scale gradients and circulation, interactions between physical and biogeochemical processes, interactions between boundary currents and the interior, and interactions between the surface and the deep ocean. Overlaid on these interior Indian Ocean processes, ocean warming due to increasing greenhouse gas concentrations has been shown to be pervasive and relentless (Wijffels et al., 2016) and extend to abyssal depths (Johnson et al., 2008; Desbruyères et al., 2017).

The Indian Ocean plays a key role in the global climate system, enabling upwelling of the lower cell of the merid- 
ional overturning circulation from abyssal to upper-deep and intermediate waters through diffusive mixing (Schmitz, 1995; Lumpkin and Speer, 2007; McDonagh et al., 2008; Talley, 2013; Hernández-Guerra and Talley, 2016) and exporting the largest poleward heat flux of all Southern Hemisphere basins (Roxy et al., 2014). In recent decades, the upper $700 \mathrm{~m}$ of the entire Indian Ocean has warmed rapidly (Desbruyères et al., 2017). In the southern Indian Ocean, the warming was directly linked primarily to heat advection from a strengthened Indonesian Throughflow (ITF) and secondly to a decrease in mean air-sea flux cooling ( $\mathrm{Li}$ et al., 2017b; L. Zhang et al., 2018). This coupling between the ocean and atmosphere in the Indian Ocean and Pacific Ocean shifted the balance of global warming, accelerating ocean warming and causing a hiatus in the warming of Earth's surface atmosphere (Sect. 6). Marine heatwaves have emerged as an increasing threat to marine ecosystems as ocean temperatures warm (e.g. Oliver et al., 2018). Increasingly vulnerable populations need more reliable monsoon predictions, a task complicated by variability across timescales from intraseasonal to interannual, decadal, and beyond in a tightly coupled ocean-atmosphere system (Hazra et al., 2017).

The starting point for this synthesis report are the reviews by Schott and McCreary (2001) and Schott et al. (2009), describing the circulation patterns, air-sea interactions and climate variability on timescales from intraseasonal to interannual and relatively large spatial scales. We begin with a description of the large-scale setting that has been well established since Schott et al. (2009) (Sect. 2). We then consider the structure and propagation of variability in air-sea interactions at seasonal and intra-seasonal scales, including the contribution of the mesoscale and the ocean's role in airsea interaction (Sect. 3). Section 4 discusses new advances in understanding of the upper-ocean circulation, organized by region (southern basin, equatorial and northern basin). This section includes an update of the near-surface circulation maps of Talley et al. (2011), including recent work on boundary currents around Australia and Madagascar, and a discussion of the biogeochemical variability observed in each region. The inter-ocean connections with the Pacific, Atlantic, and Southern Oceans are discussed in Sect. 5. Section 6 describes the variability of the Indian Ocean circulation with the recent advances in understanding the warming across the basin, climate modes such as the Indian Ocean Dipole, connections with the El Niño-Southern Oscillation (ENSO), and Indian Ocean marine heatwaves. Section 7 focuses on multiscale processes in the Bay of Bengal as an "ocean laboratory", since there have been multiple international programmes in this bay in the last decade. Recent advances from the larger scales $(>100 \mathrm{~km})$ down to submesoscales $(100 \mathrm{~m}$ to $10 \mathrm{~km})$ and further down to mixing scales (mm) are discussed. We then link back from mixing to large scales via salinity budgets and coupled phenomena such as the Madden-Julian Oscillation (MJO) to understand the complexity of these processes across multiple scales. We end with a short summary and open questions that will need to be addressed over the next decade.

\section{Large-scale setting}

The oceanic and atmospheric circulations of the Indian Ocean are unlike those in the Pacific and Atlantic oceans, largely due to geography. The Asian landmass limits the northern extent of the Indian Ocean to around $25^{\circ} \mathrm{N}$ so that there is no high-latitude cooling of the ocean and consequently no dense water formation such as that seen in the North Atlantic and, to some extent, the North Pacific. The intense seasonal variation in temperature over Asia drives the seasonal monsoons: the southwest monsoon in boreal summer and northeast monsoon in boreal winter. The timing of the onset of the monsoon, and associated wet and dry periods in the Indian Ocean rim countries, varies considerably depending on a range of large-scale climate modes and smallerscale coupled ocean-atmosphere interactions. The seasonally reversing winds drive seasonally reversing ocean currents in the northern Indian Ocean (Sect. 4.4), e.g. the southwest and northeast monsoon current and the Somali Current. Equatorial currents in the Indian Ocean, eastward near the surface above westward undercurrents (Sect. 4.3), provide rapid connection between the western and eastern basin and are also subject to monsoon dynamics.

In the southern Indian Ocean (Sect. 4.2), the connection of the Indian and Pacific Oceans through the Indonesian seas also contributes to the unique circulation patterns. The very warm and fresh ITF water is funnelled into the tropical southern Indian Ocean and carried westward by the South Equatorial Current. The warm, fresh waters are much lighter than those further south, creating a north-south density (pressure) gradient that drives near-surface broad, eastward geostrophic currents between 16 and $32^{\circ} \mathrm{S}$ and between Madagascar and Australia (Niiler et al., 2003). This pressure gradient also generates the Leeuwin Current, a unique poleward-flowing eastern boundary current (Godfrey and Ridgway, 1985) that is a downwelling region but is also, counter-intuitively, highly productive (Waite et al., 2007b). These two features are not found in the southeastern Atlantic and Pacific oceans. There, the eastern basin currents are characterized by a clear subtropical gyre circulation with weak, equatorward flow and upwelling against the coast.

The tropical Indian Ocean (Sect. 4.3) is home to the largest fraction of sea surface temperature (SST) warmer than $28^{\circ} \mathrm{C}$ (the tropical warm pool), and is therefore a key region for deep atmospheric convection: the upward part of the Walker Circulation that drives cloud formation and precipitation over the tropical Indo-Pacific. Variation in SST is the primary driver of variation in exchanges between the ocean and atmosphere and is thus a key focus in this paper. Sea surface salinity effects on ocean-atmosphere exchanges have become bet- 
ter understood and are discussed throughout and in particular in Sect. 7.

The tropical Indian Ocean SST has warmed faster over the period since 1950 than either the tropical Pacific or Atlantic (Alory et al., 2007; Han et al., 2014; Fox-Kemper et al., 2021), with implications for primary productivity (Roxy et al., 2014, 2016). The Indian Ocean accounts for 50\%-70\% of the total ocean heat uptake in the global upper $(700 \mathrm{~m})$ ocean over the last decade, associated with anthropogenic warming (Lee et al., 2015). The deeper ocean (700-2000 m) is warming across the globe with a robust signature of anthropogenic warming evident even in the short Argo record since 2005 (Wijffels et al., 2016; Rathore et al., 2020). Warming in the abyss is detectable and widespread, communicated from the surface of the ocean along pathways from Antarctic Bottom Water formation regions (Purkey and Johnson, 2012). Considerable variability in the Indian Ocean climate system exists on the backdrop of this strong, long-term warming trend.

An extensive debate erupted in recent years about whether there was hiatus or a reduced rate of global warming (Lewandowsky et al., 2018). However, persistent cold anomalies in the eastern Pacific have been argued to have enhanced oceanic heat uptake, and the strengthened trade winds are consistent with this argument (Kosaka and Xie, 2013; England et al., 2014). It has further been argued that the excess heat taken up by the tropical Pacific has been pumped into the Indian Ocean via the Indonesian throughflow (Lee et al., 2015). The tropical Indian Ocean is likely affected by the Southern Ocean trends at a rapid timescale on the order of a decade (Yang et al., 2020), and the Indian Ocean warming may accelerate the Atlantic meridional overturning circulation (Hu et al., 2019) and the Pacific response to anthropogenic forcing (Zhang et al., 2019). Based on these oceanic tunnels and atmospheric bridges into and out of the Indian Ocean, one could hypothesize that the Indian Ocean may be acting as the clearing house for oceanic warming under anthropogenic forcing.

Variability in the oceanic and atmospheric circulation of the Indian Ocean is the result of complex interactions that are both internal and external to the Indian Ocean. The recent review of the IndOOS plan (Beal et al., 2019, 2020) summarizes the major scientific drivers, of which we still have limited understanding (Fig. 1). The overarching signal is anthropogenic climate change, causing a background trend of ocean warming and increasing acidity due to uptake of heat and carbon dioxide and affecting the nature of large- and small-scale variability mechanisms.

A net poleward flow of heat out of the Indian Ocean is accomplished by a combination of the horizontal circulation along the boundaries, coupled with the Indian Ocean's part of the global meridional overturning circulation (MOC) and shallow overturning cells. The ITF delivers heat from the Pacific Ocean into the Indian Ocean. The Agulhas Current moves heat rapidly southward at surface and interme- diate depths (Bryden and Beal, 2001), with $30 \%$ of Indian Ocean heat export thought to be carried across $32^{\circ} \mathrm{S}$ by this gyre circulation (Talley, 2008). The shallow Leeuwin Current makes a smaller direct contribution to the poleward flow of heat (Smith et al., 1991; Feng et al., 2003; Furue et al., 2017) but generates a rich field of mesoscale eddies that carry heat and momentum into the Indian Ocean interior, contributing to heat export across $32^{\circ} \mathrm{S}$ (Domingues et al., 2006; Feng et al., 2007; Dilmahamod et al., 2018).

In the upper ocean, the shallow overturning consists of the cross-equatorial cell (Miyama et al., 2003; Schott et al., 2004) and the subtropical cell (Schott et al., 2004). The ascending branches of these cells connect to different upwelling zones in the southern and northern Indian Ocean and therefore play an important role in regulating the climatological mean, seasonal, and interannual heat balance in the tropical Indian Ocean (Lee, 2004; Lee and McPhaden, 2008). At intermediate depths (500-2000 m), mode waters of varying density enter the Indian Ocean from the Southern Ocean. Along their northward path they mix with lighter waters above, progressively upwelling to the sea surface in a range of locations north of $10^{\circ} \mathrm{S}$ to then return south in a widespread southward Ekman transport of near-surface waters (Schott et al., 2009). The lower part of the mode water layer mixes with denser waters below and joins the southward-flowing deep waters (2000-4000 m). This southward flow also has a contribution from transformed abyssal waters: Antarctic Bottom Water moves northward at abyssal depths, mixing with lighter waters above, progressively upwelling along its path from the Southern Ocean to the Indian Ocean to return southward at shallower depths (Talley, 2013). Cross-equatorial flow is accomplished both at abyssal levels and via the East Africa Coastal Current, seasonally reversing Somali Current (Schott et al., 2009), and southward Ekman transport (Schott and McCreary, 2001).

The remaining elements of Fig. 1 refer to oxygen minimum zones (OMZs) in the Arabian Sea and Bay of Bengal and the range of mechanisms that drive strong variations in sea surface temperature leading to shifts in atmospheric convection and precipitation with major effects on rim countries. These mechanisms include the Madden-Julian oscillation (MJO) and Monsoon Intraseasonal Oscillation (MISO), Indian Ocean Dipole (IOD), Indian Ocean Basin Mode, Subtropical IOD, and Ningaloo Niño, which are discussed further in Sect. 6. Cyclogenesis is not discussed in this synthesis. For discussion of OMZs, the reader is referred to the review papers of McCreary et al. (2013) and Rixen et al. (2020).

Extreme precipitation in the Bay of Bengal and evaporation in the Red Sea and Arabian Sea lead to strong variability in ocean salinity that in turn impacts ocean circulation and air-sea interaction. The surface salinity gradient in the northern Indian Ocean decreases from the Arabian Sea in the west to the Bay of Bengal in the east. Strong evaporation over the Arabian Sea results in highly saline surface waters (Antonov 

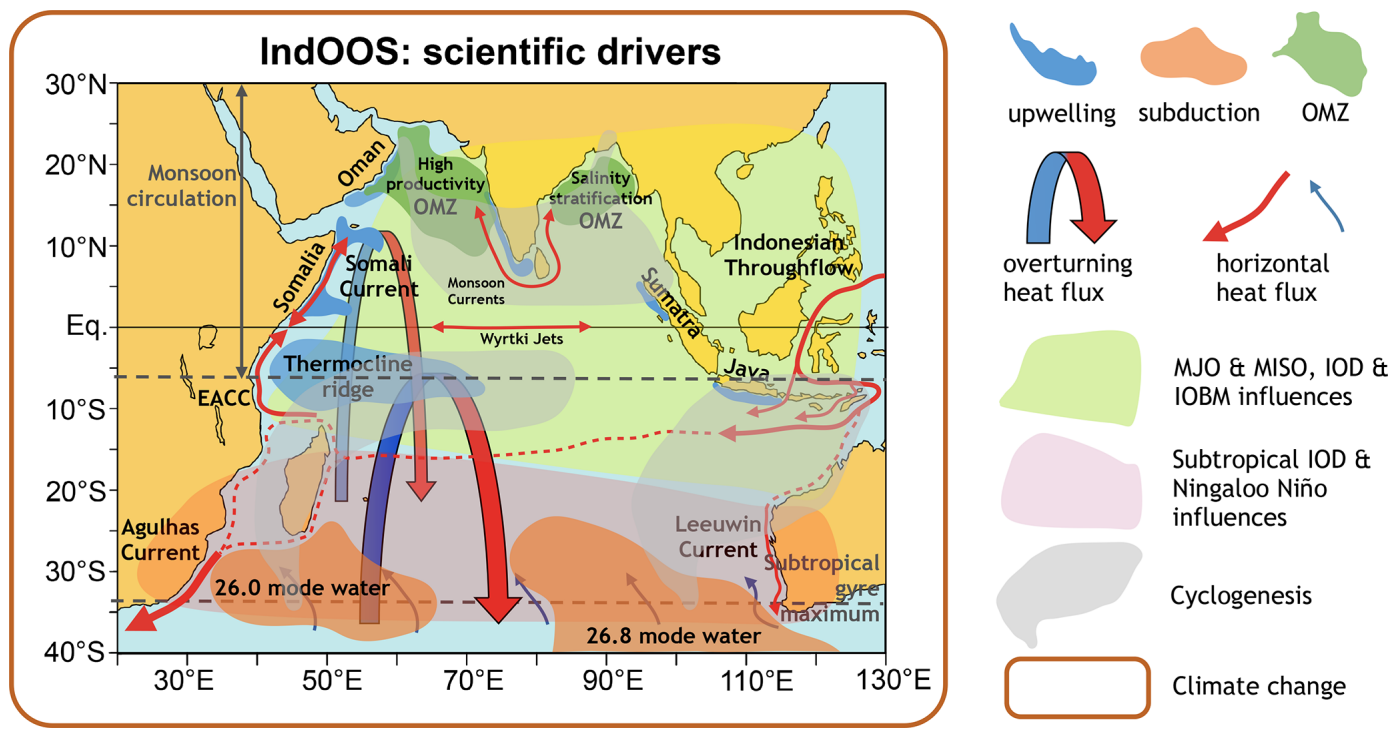

Figure 1. Schematic view of key phenomena in the Indian Ocean (from Beal et al., 2019). The main scientific drivers of the Indian Ocean Observing System, including the oxygen minimum zones (OMZs), upwelling and subduction zones, major heat flux components, the tropical modes of the Madden-Julian Oscillation (MJO), the Monsoon Intra-Seasonal Oscillation (MISO), the Indian Ocean Dipole (IOD) and Indian Ocean Basin Mode (IOBM), the subtropical modes of Ningaloo Niño and subtropical IOD, cyclogenesis, and climate change.

et al., 2010; Chatterjee et al., 2012), while surface waters in the Bay of Bengal are comparatively fresh and highly stratified as a result of monsoon precipitation and outflow from river systems such as the Ganges-Brahmaputra (Shetye et al., 1996; Vinayachandran et al., 2002). The surface forcing is balanced by the seasonally reversing monsoon currents to maintain the climatological distribution of salinity.

\section{Air-sea interactions}

The tropical Indian Ocean is highly variable across multiple scales, all of which involve atmosphere-ocean interaction: from the locally intense heat and moisture fluxes that drive tropical cyclones to large-scale convection in the ascending branch of the Hadley circulation and basin-scale ocean heat transport carried by overturning cells that contribute to decadal variability and trends. At intermediate timescales, the intraseasonal oscillations involve strong air-sea coupling (e.g. DeMott et al., 2015). The Indian Ocean Dipole (IOD) is an example of an inherently coupled mode of variability (Saji et al., 1999; Webster et al., 1999; Murtugudde et al., 2000). The monsoonal rainfall around the Indian Ocean is largely fuelled by warm SSTs and strong sea-to-air moisture fluxes. These phenomena emphasize the need to understand the mechanisms of air-sea interaction within the Indian Ocean, with a particular focus on how these processes can be better represented in models to aid predictions of variability in the Earth system.

\subsection{Seasonal cycle and the monsoons}

In the open ocean south of $10^{\circ} \mathrm{S}$, the wind pattern throughout the year is southeasterly trade winds across the tropics and subtropics and westerlies south of $35^{\circ} \mathrm{S}$ (Fig. 2). The evaporative cooling of the ocean surface by the trade winds leads to high salinity throughout the subtropics. The curl of the wind stress drives year-round Ekman pumping (downwelling) south of around $15^{\circ} \mathrm{S}$ (Fig. 2). Downwelling of these denser, high-salinity surface waters supplies the downward limb of the shallow Subtropical Cell (STC) and CrossEquatorial Cell (CEC) (Schott et al., 2002; Miyama et al., 2003; Schott et al., 2004; Lee, 2004; Schott et al., 2009). The subsurface path of the shallow overturning is not well known, and the return to the surface is in any of a number of upwelling zones including the Seychelles-Chagos Thermocline Ridge for the STC and along Somalia, Oman, and the west coast of India for the CEC. North of around $10^{\circ} \mathrm{S}$, the winds over the Indian Ocean are characterized by seasonal reversals due to the monsoons (Fig. 2), which in turn cause most of the near-surface currents in these regions to seasonally reverse (Schott et al., 2009; Shankar et al., 2002, Sect. 4.4).

A strong positive correlation between seasonal net heat fluxes into the ocean and SST variability (Fig. 3) suggests that the seasonal cycle of SST is largely due to the seasonal cycle of winds and cloud cover (Yu et al., 2007). One prominent exception is the Seychelles-Chagos Thermocline Ridge (located between 5 and $10^{\circ} \mathrm{S}$ and east of $50^{\circ} \mathrm{E}$ ), where upwelling and horizontal advection exhibit substantial seasonal variations that in turn contribute to the seasonal cycle of SST 

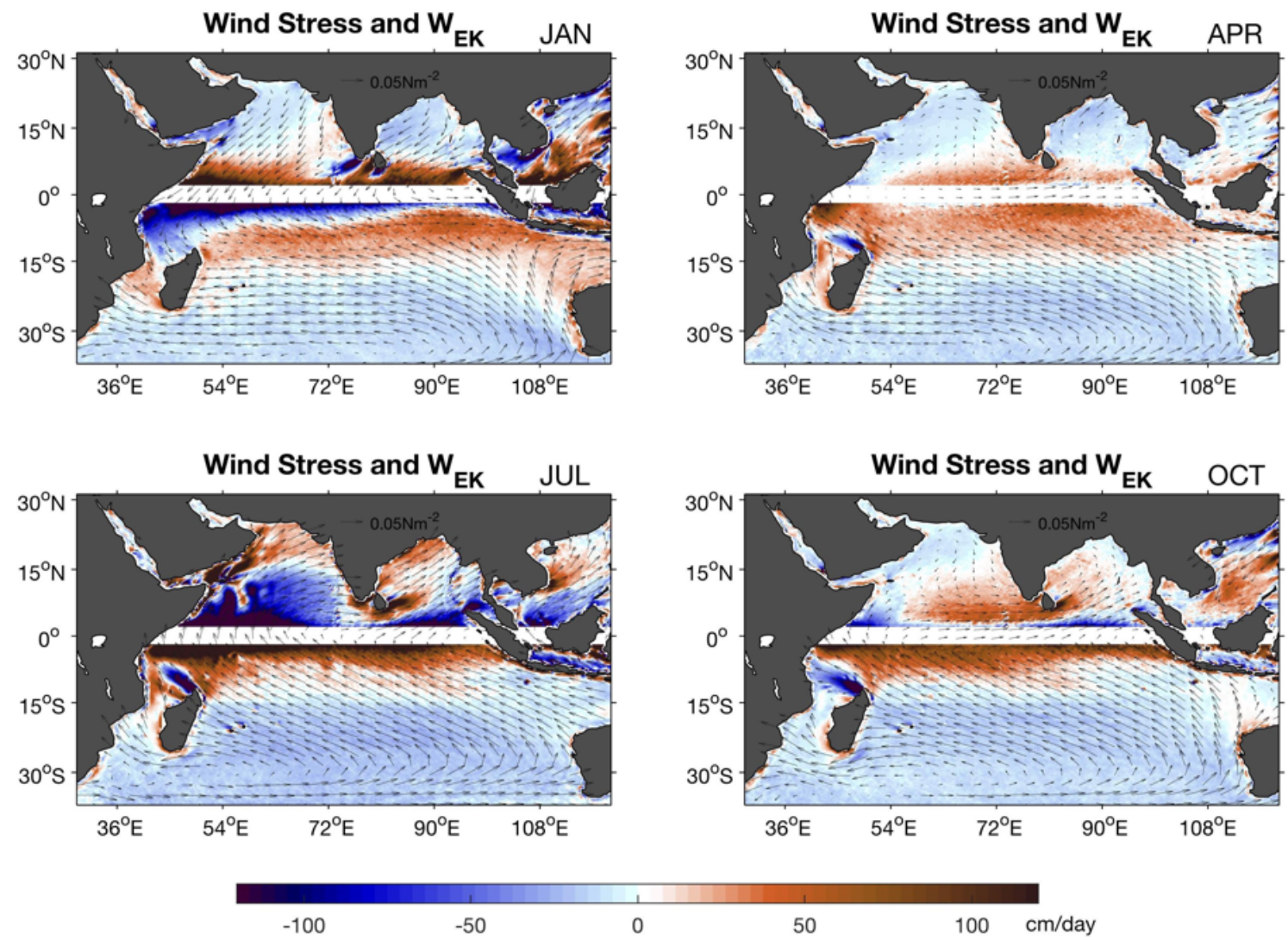

Figure 2. Climatology (2001-2018) of monsoon wind stress (vectors) and Ekman pumping rate (colour shaded) with positive values denoting Ekman suction (upwelling) and negative values Ekman pumping (downwelling) for (a) January - NE monsoon, (b) April - transition, (c) July - SW monsoon, and (d) October - transition. The climatology was constructed by the Objectively Analyzed air-sea Flux High-Resolution (OAFlux-HR) analysis (adapted from Yu, 2019).

(Hermes and Reason, 2008; Foltz et al., 2010). On the Equator and to the north, seasonally reversing winds drive complex patterns of upwelling and downwelling that lead to complex SST variability.

In the Bay of Bengal and Arabian Sea, surface heat fluxes dominate the seasonal cycle of SST, with the exception of the upwelling zone along the western boundary of the Arabian Sea (Chowdary et al., 2015; Yu et al., 2007). However, salinity effects and subsurface processes (barrier layers, vertical entrainment, variations in the depth of penetration of solar radiation and zonal advection) also influence SST variability (Thangaprakash et al., 2016). Rainfall variability driven by the monsoons creates near-surface salinity variability, most notably in the Bay of Bengal where there is a pronounced annual cycle of sea surface salinity (SSS; Fig. 4, Akhil et al., 2014). Freshwater input at the northern end of the bay forms a shallow mixed layer stratified by low salinity and is advected southwards along the east coast of India, where it is eventually eroded by vertical mixing (Akhil et al., 2014). The variability in freshwater input contributes to the seasonal cycle of barrier layer thickness in the Bay of Bengal (Howden and Murtugudde, 2001; Thadathil et al., 2007), which in turn modulates how strongly SST responds to surface forcing ( $\mathrm{Li}$ et al., 2017a). The seasonally reversing currents that connect the salty Arabian Sea and fresh Bay of Bengal also strongly influence sea surface salinity patterns (Sect. 4.1.3).

The seasonal cycles in the atmosphere and ocean circulation strongly influence the biological productivity of the near-surface Indian Ocean (Wiggert et al., 2006). Figure 5 shows the seasonal cycle of satellite chlorophyll $a$ and surface currents. The dramatically low productivity in the subtropics, where wind stress curl drives large-scale downwelling (Fig. 2), and highly productive coastal boundaries where wind-driven upwelling occurs, highlights the impact of the circulation and atmosphere-ocean interaction on biological productivity. In turn, the chlorophyll $a$ distribution has important implications for air-sea interaction, since higher concentrations of phytoplankton lead to increased absorption of solar radiation (e.g. Morel and Antoine, 1994; Murtugudde et al., 2002; Giddings et al., 2021). Organization of chlorophyll $a$ at intraseasonal timescales has also been reported (Sect. 3.2.1). 

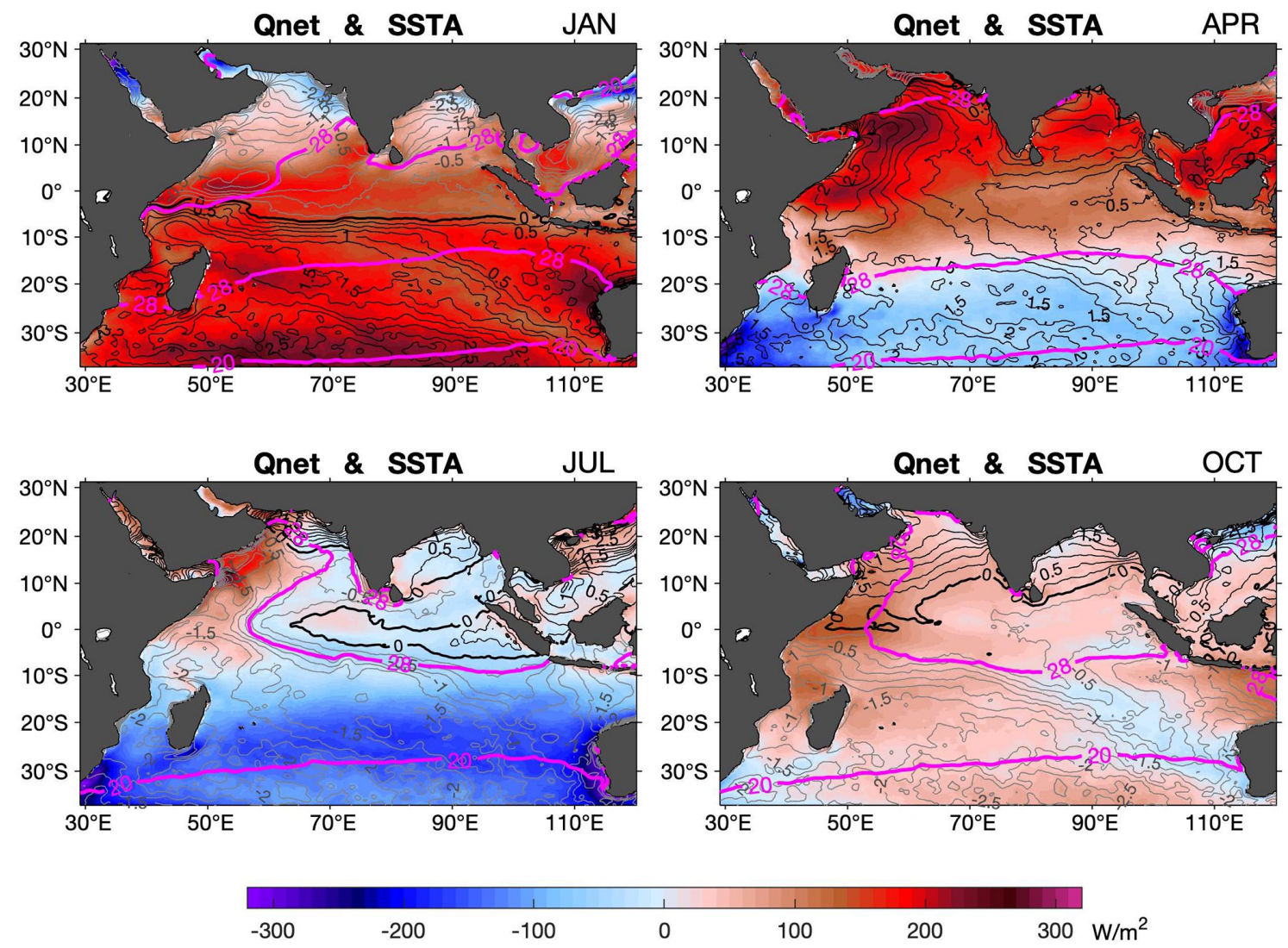

Figure 3. Climatology (2001-2018) of ocean surface net heat input (colour shaded; positive values denote ocean heat gain and negative values ocean heat loss), SST anomaly (black contours) and 20 and $28^{\circ}$ SST contours (pink) for (a) January - NE monsoon, (b) April - transition, (c) July - SW monsoon, and (d) October - transition (adapted from Yu, 2019). Net heat flux is the sum of solar radiation, longwave radiation, and turbulent latent and sensible heat fluxes. The turbulent heat flux climatology was constructed by the OAFlux-HR analysis, and surface radiation climatology was constructed by the NASA CERES EBAF (Kato et al., 2013).

\subsection{Intraseasonal air-sea interaction}

\subsubsection{Madden-Julian Oscillation - MJO}

The Madden-Julian Oscillation (MJO; Madden and Julian, $1972,1971)$ is the dominant mode of variability in the Indian Ocean at subseasonal timescales. The MJO (Fig. 6) is characterized by eastward-propagating features of enhanced and reduced convection over distances of more than $10000 \mathrm{~km}$ and with a periodicity of around 30-60 d (Zhang, 2005). The MJO propagates slowly $\left(\sim 5 \mathrm{~m} \mathrm{~s}^{-1}\right)$ through the portion of the Indian Ocean and Pacific Ocean where the sea surface is warm, constantly interacting with the underlying ocean and influencing many weather and climate systems. Within the large-scale envelopes of enhanced convection, smaller-scale clusters of clouds propagate westward and can produce local extremes in rainfall. Air-sea interaction is believed to sustain and perhaps amplify the patterns of enhanced and reduced convection as the MJO propagates eastward (DeMott et al., 2015). Indo-Pacific warming trends are warping the life cycle of the MJO, which is spending less time over the
Indian Ocean and more time over the Pacific Ocean and altering mean rainfall trends in parts of the globe (Roxy et al., 2019).

The MJO-related pattern of winds results in anomalous westerly (easterly) winds to the west (east) of the region of convergence, convection, and enhanced rainfall (Fig. 6). These winds generate Kelvin and Rossby waves along the Equator. The Kelvin waves generated by the MJO have been hypothesized (Kessler et al., 1995; McPhaden, 1999; Bergman et al., 2001) to trigger ENSO events in the Pacific. In the Indian Ocean, there is a distinctive sequence of basin-scale ocean waves generated by the MJO. Eastwardpropagating equatorial ocean Kelvin waves strike the coast of Sumatra, where they generate coastally trapped Kelvin waves that propagate northward and southward away from the generation site. Kelvin waves also propagate into the Indonesian seas where they affect the ITF (Pujiana and McPhaden, 2020). Westward-propagating equatorial ocean Rossby waves are also formed, either due to direct intraseasonal wind forcing or through reflection of Kelvin waves at the eastern boundary (Oliver and Thompson, 2010; Web- 

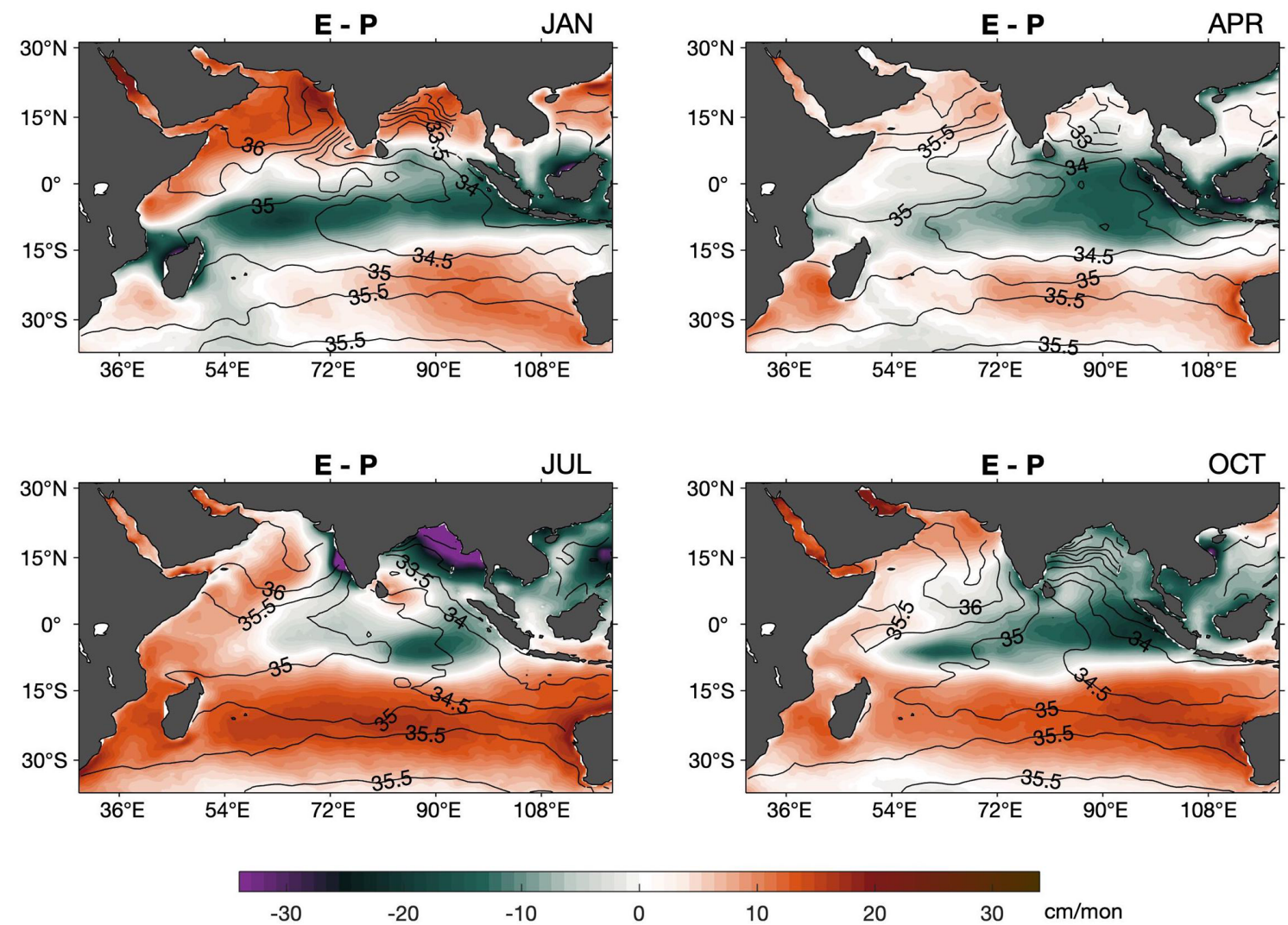

Figure 4. Climatology (2001-2018) of evaporation minus precipitation (colour shaded; positive values denote freshwater leaving the ocean and negative values addition of fresh water to the ocean) and sea surface salinity (black contours) for (a) January - NE monsoon, (b) April transition, (c) July - SW monsoon, and (d) October - transition (adapted from Yu, 2019).

ber et al., 2010; Nagura and McPhaden, 2012; Pujiana and McPhaden, 2020). These waves influence local upwelling and currents; they have been linked to variability in coastal currents around the Bay of Bengal (Vialard et al., 2009b), to enhancement of the spring Wyrtki jets in the eastern equatorial Indian Ocean (Prerna et al., 2019), to changes in subsurface equatorial currents in the central Indian Ocean (Iskandar and McPhaden, 2011), and to changes in upwelling and chlorophyll $a$ concentration in the off-equatorial central Indian Ocean (Webber et al., 2014). Such waves also propagate energy downwards into the deep ocean (e.g. Pujiana and McPhaden, 2020), contributing to deep ocean variability at multiple timescales (e.g. Matthews et al., 2007). Downwelling Rossby waves in the western Indian Ocean create positive SST anomalies through a combination of reduced entrainment of cooler water from below and zonal advection (Rydbeck et al., 2017; Webber et al., 2012a). These waves therefore act as a triggering mechanism for new MJO events (Rydbeck and Jensen, 2017; Webber et al., 2010, 2012a, b) and may also play a role in amplifying existing MJO events.

MJO-related winds also lead to variability in mixing within and at the bottom of the mixed layer. Westerly wind bursts generate zonal currents that create strong vertical cur- rent shear (Moum et al., 2014). These currents and the associated mixing persist after the passage of the atmospheric disturbance. Cooler waters from below the surface are mixed with surface waters, leading to a reduction in available ocean heat content for the next MJO event and thus reducing its potential amplitude (Moum et al., 2016). By examining the causes of SST variability in two separate MJO events, McPhaden and Foltz (2013) showed that the presence or absence of barrier layers may play a crucial role in determining how strongly mixing and vertical entrainment influence SST. They also found that zonal advection plays a relatively strong role when a barrier layer is present. Chi et al. (2014) confirmed the importance of barrier layers in influencing the turbulent heat flux but found that thin barrier layers can be eroded by strong current shear that occurs during active phases of the MJO. Wind mixing and surface heat and freshwater fluxes both contribute in roughly equal proportions to intraseasonal variability in mixed-layer depth (Keerthi et al., 2016).

Various studies have investigated the relative importance of surface heat fluxes and subsurface ocean processes for the evolution of SST at intraseasonal timescales. The Seychelles-Chagos Thermocline Ridge (SCTR), is a region 

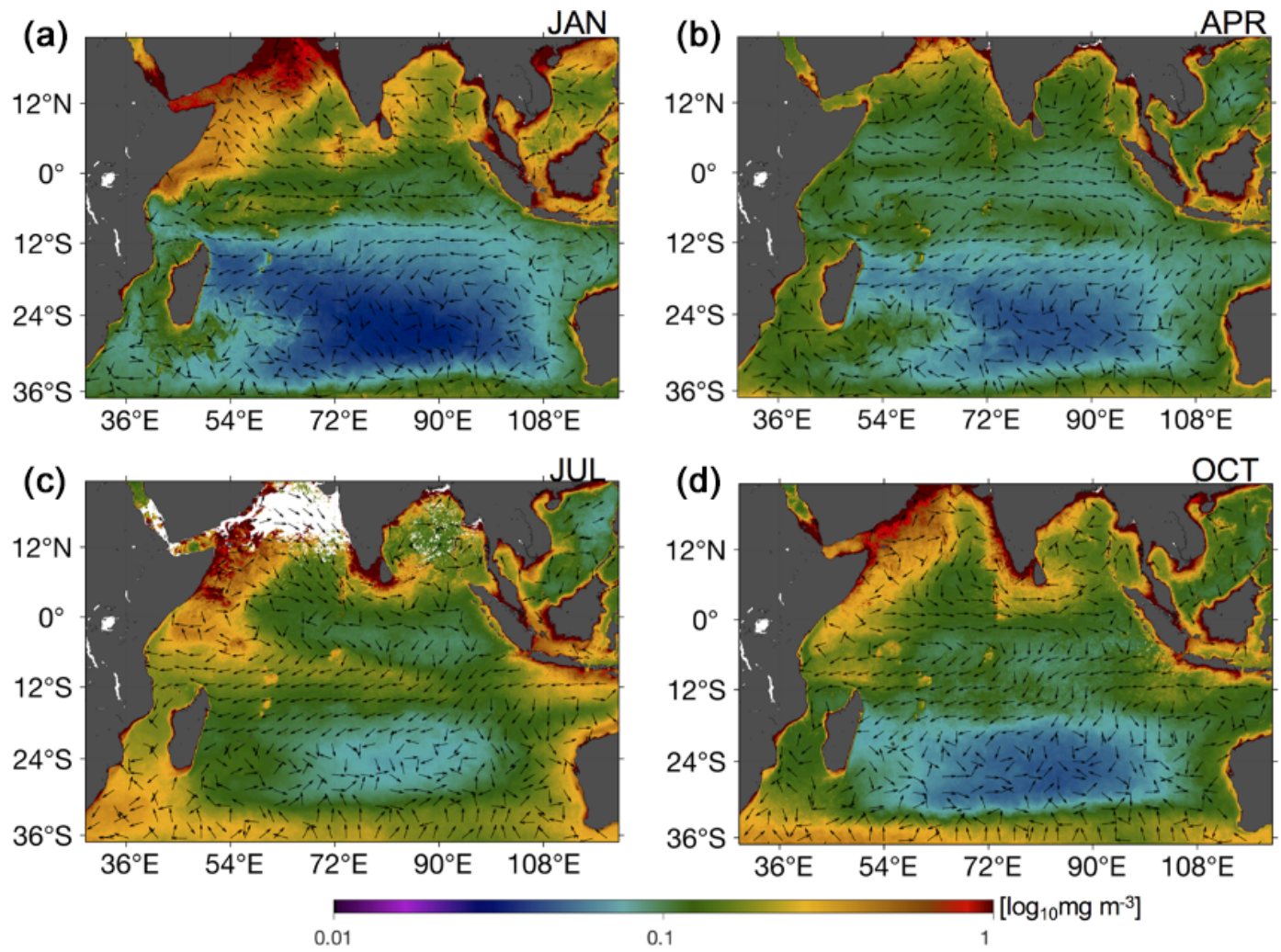

Figure 5. Climatology (2002-2018) of chlorophyll a concentrations (colour map) and current velocities (arrows) for (a) January, (b) April, (c) July, and (d) October. Chlorophyll $a$ climatology was obtained from the MODIS-Aqua product, and current velocities were obtained from the third-degree Ocean Surface Current Analysis Real-time (OSCAR) product.

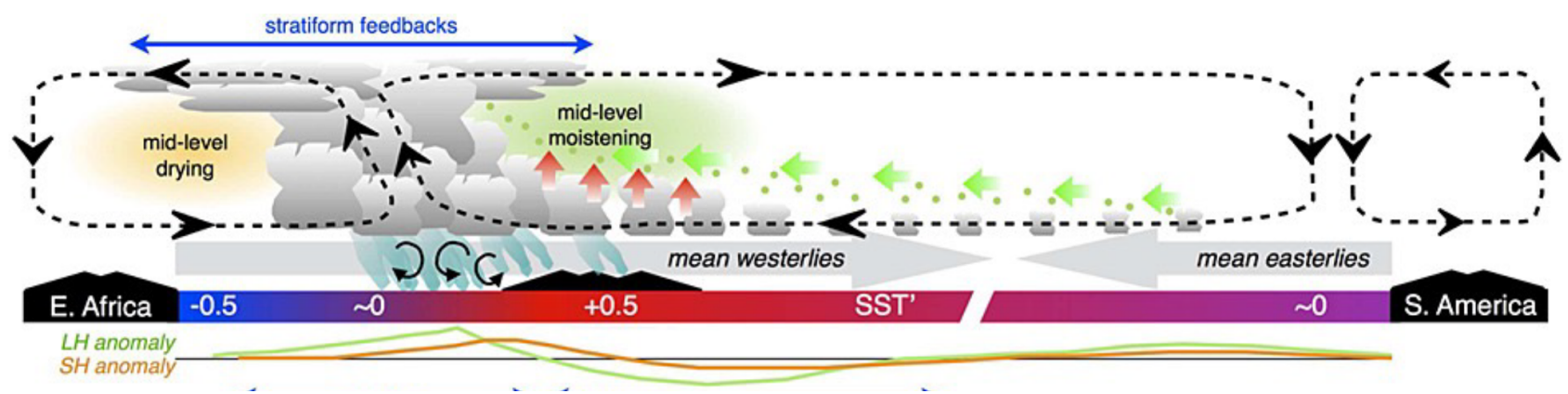

Figure 6. Schematic depiction of Indian Ocean and Pacific Ocean feedbacks to the MJO when convection (grey cloud elements) is maximized in the eastern Indian Ocean. Rainfall (aquamarine), circulation anomalies (dashed black cells), convective downdrafts (black rotor arrows), mean winds (faint grey arrows), moistening by convective detrainment (small green dots), and horizontal and vertical advection (thick green and red arrows, respectively) are overlaid. Net moistening (drying) is shaded green (orange). Positive (red) and negative (blue) SST anomalies for a strong event are shaded, while latent (sensible) heat flux anomalies are shown with green (orange) curves. The central and eastern Pacific spatial scales are compressed relative to the Pacific Warm Pool. Adapted from DeMott et al. (2015).

of high intraseasonal SST variability (Saji et al., 2006; Hermes and Reason, 2008). Several observational studies have concluded that the SST variability here is predominantly generated by variability in surface heat fluxes (Jayakumar et al., 2011; Vialard et al., 2008), while Drushka et al. (2012) suggest this finding applies across most of the tropical Indian Ocean. Such studies, however, typically exhibit large uncer- tainty in the subsurface ocean terms. The shallow thermocline and strong high-frequency winds in the SCTR region enhance near-inertial waves and lead to strong mixing at the base of the mixed layer and in the thermocline (e.g. Cuypers et al., 2013; Sabu et al., 2021). Modelling studies have shown that ocean dynamics play an important role in generating SST variability (Halkides et al., 2015; Han et al., 2007). For 
(a) heat fluxes (Q) vs ocean dynamics (D)

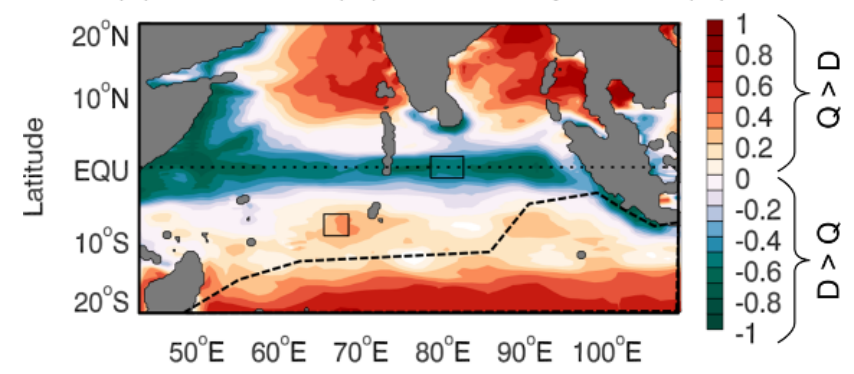

(b) horizontal $(\mathrm{H})$ vs vertical $(\mathrm{V})$ dynamics

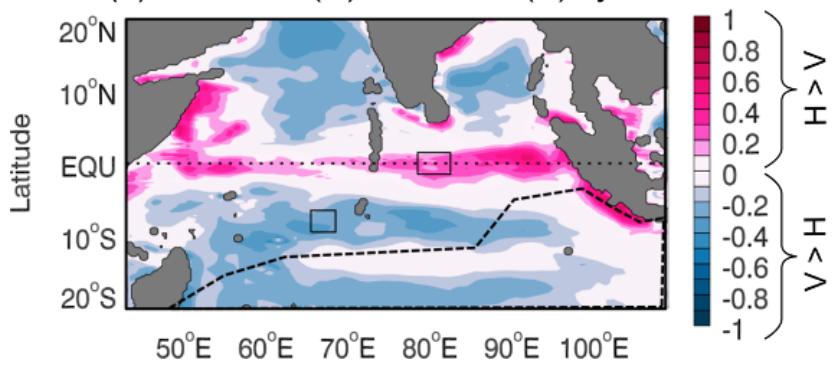

Figure 7. Modelled balance of processes driving intraseasonal SST variability. (a) Relative role of heat fluxes $(Q)$ and ocean dynamics $(D)$ in driving SST variability, with red (green) colours implying $Q(D)$ dominates forcing. (b) Relative role of horizontal $(\mathrm{H})$ and vertical (V) processes in the dynamical forcing, with pink (blue) colours implying that $\mathrm{H}(\mathrm{V})$ processes dominate. All fields are derived from the ECCO-JPL ocean state estimate. The dotted line marks the Equator, the dashed line in the Southern Hemisphere outlines a region in which the model does not fully resolve the ocean heat budget, and the boxes on the Equator and at $10^{\circ} \mathrm{S}$ mark regions for further analysis not described here. Modified from Halkides et al. (2015).

example, Fig. 7 from the study of Halkides et al. (2015) shows the relative contribution of modelled ocean dynamical processes and thermodynamical processes (i.e. surface heat fluxes) in forcing intraseasonal SST variability. Figure 7a shows that ocean dynamical processes (green shading), including horizontal and vertical advection, are the dominant source of intraseasonal SST variability on the Equator and in upwelling regions off Indonesia, Sri Lanka, and along the western boundary. The ocean dynamical processes are in turn dominated by horizontal advection along the Equator and tropical coastlines (Fig. 7b, pink shading) and vertical advection (blue shading) in the off-equatorial ocean interior.

Organization of chlorophyll $a$ at intraseasonal timescales has also been reported, with model studies indicating potential biophysical feedbacks due to the variability of penetrative radiation into the water column (Waliser et al., 2005; Jin et al., 2013a; Giddings et al., 2021). In the Bay of Bengal, the proportion of incoming solar radiation absorbed within the mixed layer varies between $60 \%$ and $97 \%$ due to a combination of variability in chlorophyll $a$ concentration and mixed- layer depth (Lotliker et al., 2016), and an increase in chlorophyll of $0.3 \mathrm{mg} \mathrm{m}^{-3}$ can lead to SST increase of up to $0.35^{\circ} \mathrm{C}$ on intraseasonal timescales (Giddings et al., 2021). Representing the seasonal cycle of chlorophyll $a$ concentration in the Arabian Sea in a coupled model led to substantial changes in the simulated SST and monsoon rainfall over India (Turner et al., 2012), suggesting that incorporating this process into coupled models may be important to improve simulation of monsoon rainfall and circulation around the Indian Ocean.

Figure 8 illustrates propagation of surface patterns in an MJO composite constructed by Jin et al. (2013a). In each panel the peak in outgoing longwave radiation (OLR, a proxy for convection) is indicated by a diagonal red line. The MJO generates substantial surface heat flux anomalies that create a pattern of surface heat fluxes and SST anomalies such that warm (cool) SSTs lead enhanced (reduced) convection by a quarter of a phase (e.g. Shinoda et al., 1998). The MJO also leads to low-frequency rectifications in the mean state of physical and ecosystem responses (Fig. 8, Waliser et al., 2003; Jin et al., 2013a, b).

\subsubsection{Monsoon Intraseasonal Oscillation - MISO}

While the MJO dominates intraseasonal variability during October to April, during May to September (boreal summer, southwest monsoon), the Monsoon Intraseasonal Oscillation (MISO; Goswami, 2012; Suhas et al., 2013) dominates. The dominant timescale for MISOs is $30-60 \mathrm{~d}$ but MISOs can also occur on 10-20 d timescales (Goswami et al., 2016) and there are studies that have identified a 3$7 \mathrm{~d}$ timescale for MISOs (e.g. Roman-Stork et al., 2020). MISOs can be seen as low-pressure systems laden with moisture that deliver rain from atmospheric instabilities (Fig. 9). The MISO is also known as the Boreal Summer Intraseasonal Oscillation (BSISO; Lau and Waliser, 2012; Lee et al., 2013). The MISO oscillations are dynamically linked to the equatorial MJO (e.g. Sperber and Annamalai, 2008) but exhibit northeastward- and northwestward-propagating features, with the main centre of action being the Bay of Bengal. These northward-propagating bands of enhanced and reduced rainfall exhibit a similar relationship with SST to the MJO: warm SST leading to increased rainfall (cool SST leading to reduced rainfall) that then determine the wet or dry (or active or break) cycles of the South Asian monsoon (Vecchi and Harrison, 2002; Roxy et al., 2013; Suhas et al., 2013; L. Zhang et al., 2018). These SST anomalies are primarily forced by variations in surface heat fluxes in the Bay of Bengal (Girishkumar et al., 2017; Vialard et al., 2012), while variations in wind-induced mixing, Ekman pumping, and entrainment drive SST variability in the Arabian Sea (Duncan and Han, 2012; Vialard et al., 2012).

Simulations of the MISO are still generally poor in state-of-the-art coupled models (e.g. Goswami et al., 2013; Jayakumar et al., 2017; Sabeerali et al., 2013; Sharmila et al., 2013) and re-analysis products (e.g. Sanchez-Franks et 


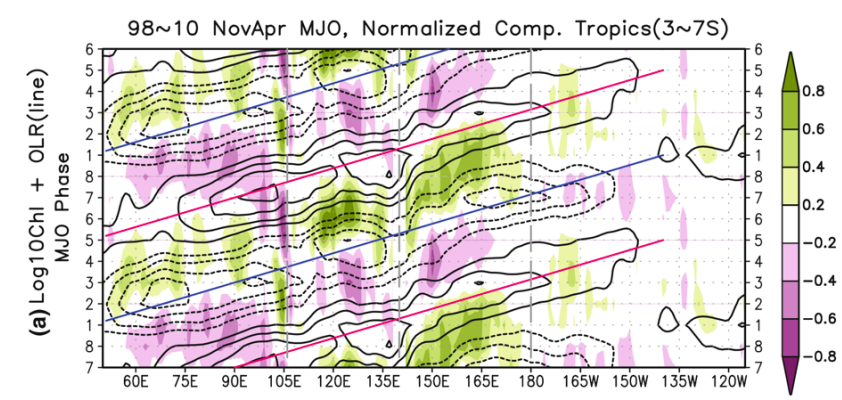

tude smaller than the scales of the propagating atmospheric systems (Waliser et al., 1999; Zhou and Murtugudde, 2009). Including air-sea coupling in simulations of the MISO has been identified as key to improving simulation of this oscillation in some models (e.g. Jayakumar et al., 2017; Li et al., 2018a, b; Roxy et al., 2013; Sharmila et al., 2013) and has been shown to improve aspects of simulation in others (e.g. Bellon et al., 2008; Peatman and Klingaman, 2018).

While new theories continue to be proposed for MJOs (e.g. Wang et al., 2016), MISOs have not received similar attention, likely due to their more local nature compared to the global impacts of MJOs (e.g. their impact on ENSO). The mechanism that causes the northward propagation of the MISO is still a topic of research. The most recent theory for MISOs proposed by L. Zhou et al. (2017a, b) invokes an explicit coupling between the ocean and the atmosphere in a so-called Central Indian Ocean mode. Zonal winds at intraseasonal timescales over the Indian Ocean are argued to be coupled to SSTs to produce a barotropic instability in the meridional gradient of the zonal winds. The horizontal atmospheric eddy fluxes generated by the barotropic instability are invoked to explain the northward propagation and the advection of momentum and moisture as a coupled phenomenon. Key questions remain about the oceanic and air-sea interaction processes that reorganize the SSTs in the Central Indian Ocean mode and the respective roles of the vertical and horizontal shears in driving northward propagation of MISOs.

Observations and models indicate that MISOs may be slowing down because of the warming in the Indian Ocean (Sabeerali et al., 2013), which needs to be understood better for providing reliable monsoon predictions and projections in this climate-vulnerable region. This is underscored by the observational evidence that climate variability and change are increasing the frequency of dry spells and the intensity of wet spells in the Indian summer monsoon, which are directly related to MISO (Singh et al., 2014).

lies (shaded) and AVISO mean sea level anomaly (contour). AIl contour intervals match shading levels in (c), and a solid (dashed) line indicates positive (negative) values. All variables are normalized, and the same MJO composite is repeated for two cycles for convenience. There are between 127 and 227 events in the composite for each MJO phase. Diagonal red lines indicate peak signals of positive OLR, and blue lines indicate negative OLR peak; these are guides for the MJO propagation. The relative location of each propagation line in all panels is the same. The left and centre dashed vertical grey lines indicate the western and eastern boundary of the Maritime Continent, respectively, and the right grey line is on the International Date Line where chlorophyll $a$ propagation stops. From Jin et al. (2013a).

al., 2018). Evidence exists from observations of low-level convergence and OLR, as well as from forced atmospheric and coupled ocean-atmosphere model experiments, that both MJOs and MISOs are phenomena that require coupling between the ocean and atmosphere to exist. This is even though the scales of SST anomalies tend to be an order of magni-

\subsubsection{Intraseasonal drivers of heavy rainfall}

As the MJO season begins to wind down in April, northwardpropagating MISOs begin to become dominant in the northern Indian Ocean, north of around $5^{\circ} \mathrm{N}$. While the southwesterlies produce some of the strongest coastal upwelling off Somalia and cool the Arabian Sea, the Bay of Bengal remains warm and largely above the convective threshold $\left(28^{\circ} \mathrm{C}\right)$ owing to the freshwater input from rainfall and rivers discharging into the bay (Roxy and Tanimoto, 2007). The freshwater input creates a shallow density stratification (barrier layer) within the temperature mixed layer and thereby weakens the upwelling of cold water from the thermocline. MISOs deliver rain from atmospheric instabilities, but what controls the rainfall at intraseasonal timescales during the summer can be expected to be region specific, with moisture supply determining the rainfall variability over land (Pathak et al., 2017). 


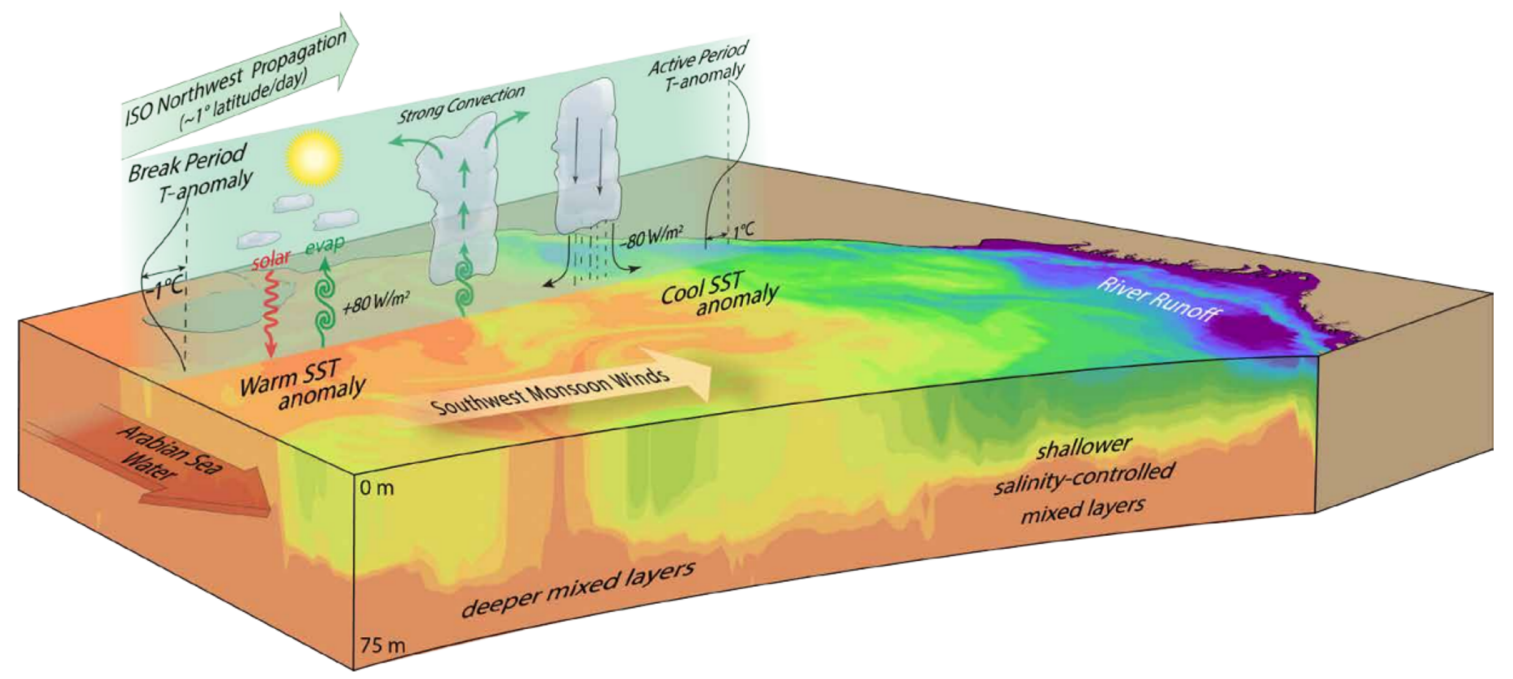

Figure 9. A schematic of the Monsoon Intraseasonal Oscillation (MISO) in the Bay of Bengal, showing the coupled ocean-atmosphere 30-60 d mode northwestward propagation and associated processes in the atmosphere and the ocean (from Mahadevan et al., 2016a).

Over the ocean, the largely evaporative Arabian Sea is relatively cool, but the southwesterlies begin to slow down as they approach the Western Ghats mountain range on the west coast of India, leading to maximum rainfall there during the boreal summer monsoon season (Xi et al., 2015). Rather counterintuitively, the warm SST in the Bay of Bengal remains above the convective threshold (Gadgil et al., 1984; Roxy et al., 2013), and yet the ocean is not in direct control of the intraseasonal rainfall events. Once the SSTs are warm enough to support atmospheric convection, it is baroclinic instabilities and not static instabilities induced by warm SSTs that drive the majority of rainfall over the Bay of Bengal (Xi et al., 2015).

\subsection{Ocean internal variability impacts on air-sea interaction}

Mesoscale eddies are ubiquitous in the ocean. In the tropical Indian Ocean, however, linear dynamics dominate and the impacts of eddies are (or seem) small. While the Indian Ocean has the largest SST variability occurring at seasonal timescales, strong mesoscale variability is also observed along the Somali coast where the western boundary current crosses the Equator. The slope of the East African coastline and the equatorial crossing of the low-latitude jet produce multiple eddies (Nof and Olson, 1993), which are shown to generate strong air-sea coupling at mesoscales (Schott and McCreary, 2001; Schott et al., 2009; Vecchi et al., 2004; Seo et al., 2008). Some intraseasonal oscillations in the ocean were reported in the southwestern tropical Indian Ocean (Kindle and Thompson, 1989), but generally the impact of ocean internal variability on SSTs in the tropical Indian Ocean has not been widely studied. At the eastern boundary of the subtropical Indian Ocean, instability of the poleward Leeuwin Current generates a rich field of mesoscale eddies that carry heat into the Indian Ocean interior, contributing to air-sea exchange of heat and the oceanic interior poleward heat transport (Domingues et al., 2006; Feng et al., 2007; Dilmahamod et al., 2018). In the subtropical southeastern Indian Ocean, mesoscale eddies and possibly annual and semiannual Rossby waves propagating from the eastern boundary were found to influence the seasonal variation of the surface layer heat balance through horizontal advection (Cyriac et al., 2019).

Low-frequency internal variability is also possible. Jochum and Murtugudde (2005) performed forced ocean model experiments with climatological forcing alone to demonstrate that significant low-frequency variability at interannual timescales is generated in the Indian Ocean by mesoscale eddies and other types of non-linearity. The role of internal variability in regional coupled climate variability, as well as ecosystem and biogeochemistry, remain interesting problems for this already warm ocean, in which even small SST anomalies can be important for generating largescale ocean-atmosphere interactions (Palmer and Mansfield, 1994).

\section{Upper-ocean circulation and biogeochemical variability}

\subsection{Overview}

The near-surface circulation in the Indian Ocean consists of the monsoon-dominated, seasonally reversing currents north of around $10^{\circ} \mathrm{S}$ and the steady currents to the south, as illustrated in Fig. 10a for the southwest monsoon (July-August) and Fig. 10b for the northeast monsoon (January-February). Figure 10 has been updated from Talley et al. (2011) to rec- 
ognize recent advances in understanding of circulation patterns. In the northern Indian Ocean, additions are a revision of the Red Sea circulation (Menezes et al., 2019). In the southern Indian Ocean, moving in an anticlockwise direction from the Maritime Continent, additions are (1) the seasonally reversing flows in the Java Sea; (2) the Holloway Current along Australia's North West Shelf (Holloway and Nye, 1985; Holloway, 1995; Bahmanpour et al., 2016); (3) the revised position of the salinity-driven Eastern Gyral Current that flows eastward from around $90^{\circ} \mathrm{E}$ along approximately $15^{\circ} \mathrm{S}$ that recirculates Indonesian Throughflow Water from the South Equatorial Current and supplies the polewardflowing Leeuwin Current (Meyers et al., 1995; Domingues et al., 2007; Menezes et al., 2013, 2014a); (4) the near-surface South Indian Countercurrent, with three distinct branches (northern, central, and southern) flowing from the southern tip of Madagascar to Australia where they merge with the poleward-flowing Leeuwin Current (Menezes et al., 2014a, and references therein); and (5) the splitting of the Flinders Current near $110^{\circ} \mathrm{E}$, with one branch recirculating back toward Australia and the other being a westward continuation of the Flinders Current, previously not shown (Duran et al., 2020).

The intermediate and deep circulation and overturning cells will not be examined in this synthesis. The reader is referred to Talley et al. (2011) and references therein and, in addition, Nagura and McPhaden (2018), who used Argo and CTD data to map out the circulation and water masses in density classes associated with the shallow overturning circulation, with emphasis on the Southern Hemisphere. There has been some progress in the understanding of circulation at intermediate and deeper depths in the equatorial band, which is summarized in Huang et al. (2018).

\subsection{Southern Indian Ocean}

\subsubsection{South Equatorial Current}

The South Equatorial Current (SEC), the northern limb of the southern Indian Ocean subtropical gyre, carries ITF Water into the interior Indian Ocean, flowing westward between 10 and $20^{\circ} \mathrm{S}$ (Fig. 10a and b). Upon reaching the northern tip of eastern Madagascar, it bifurcates and supplies the Northeast Madagascar Current (NEMC; Schott and McCreary, 2001; Song et al., 2004; Valsala and Ikeda, 2007) and the Southeast Madagascar Current (SEMC) and contributes to the development of Mozambique Channel eddies. The mean flow through the Mozambique Channel is weak (Song et al., 2004), although there is an indication from ocean model results that the eddy-dominated flow contributes on the order of $20 \mathrm{~Sv}$ southward (Durgadoo et al., 2013). The Mozambique Channel eddies, eddies from the SEMC, and recirculation combine to feed into the Agulhas Current (Schott and McCreary, 2001).

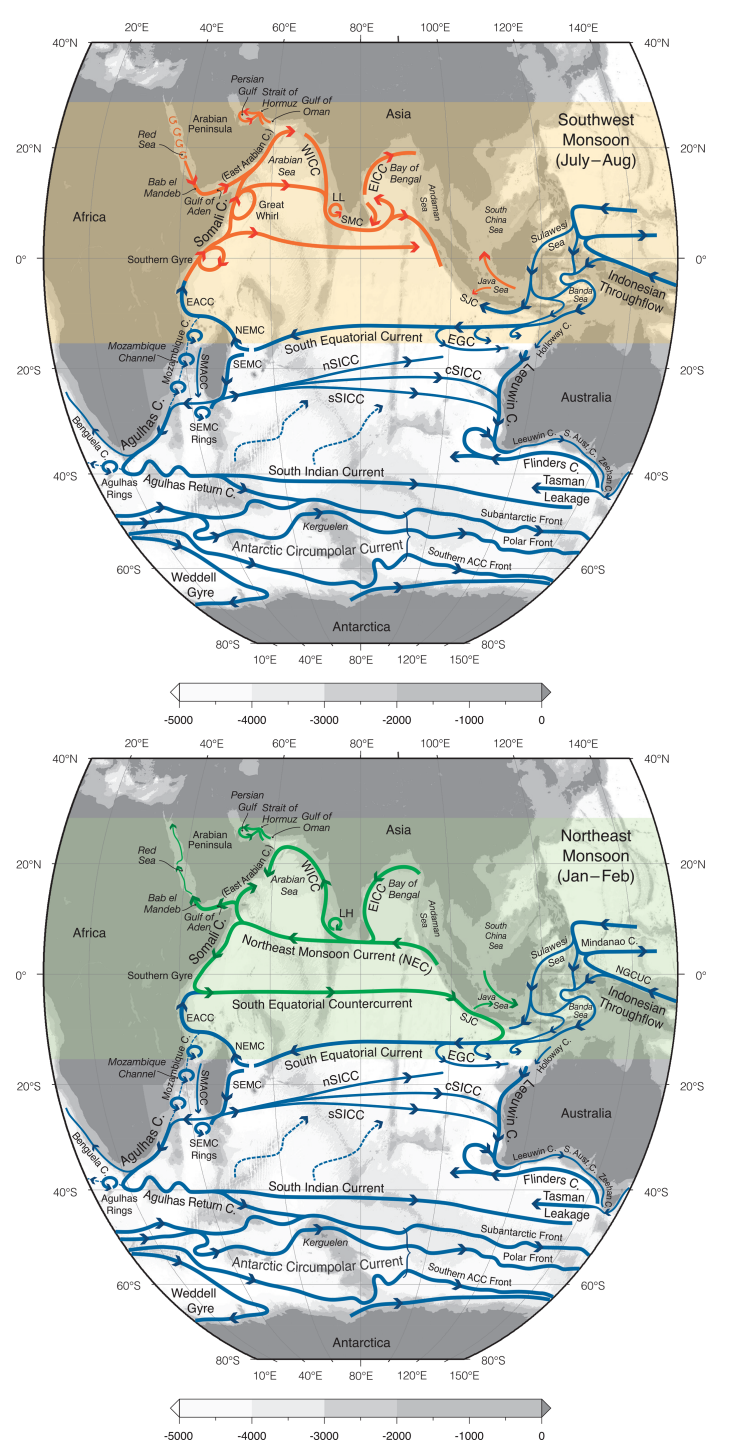

Figure 10. The top panel shows a schematic near-surface circulation during the southwest monsoon (July-August). Blue arrows indicate year-round mean flows with no seasonal reversals. Orange arrows indicate monsoonally reversing circulation (following Schott and McCreary, 2001). The Antarctic Circumpolar Current (ACC) fronts are taken directly from Orsi et al. (1995). Acronyms are as follows: EACC, East African Coastal Current; NEMC, Northeast Madagascar Current; SEMC, Southeast Madagascar Current; SMACC, Southwest Madagascar Coastal Current; WICC, West Indian Coastal Current; EICC, East Indian Coastal Current; LH and LL, Lakshwadeep high and low; SJC, South Java Current; EGC, Eastern Gyral Current; SICC, South Indian Countercurrent (south, central, and southern branches); NEC, Northeast Monsoon Current; SEC, Southwest Monsoon Current. Updated from Talley et al. (2011), originally based on Schott and McCreary (2001). The light grey shading shows seafloor bathymetry. The bottom panel shows a schematic near-surface circulation during the northeast monsoon (January-February) with the details being the same as the top panel. 
Between 50 and $80^{\circ} \mathrm{E}$ the SEC is coincident with the southern half of the Seychelles-Chagos Thermocline Ridge (SCTR, Vialard et al., 2009a). The SCTR is characterized by a relatively shallow thermocline and thin mixed layer $(\sim$ $30 \mathrm{~m})$ across the southern tropical Indian Ocean in the latitude band $5-15^{\circ} \mathrm{S}$. Between 50 and $80^{\circ} \mathrm{E}$ the SCTR and SEC are in a region of significant upwelling (Hermes and Reason, 2008; Vialard et al., 2009a; Resplandy et al., 2009; Dilmahamod, 2014), which affects biogeochemistry and even fisheries (Resplandy et al., 2009; Robinson et al., 2010; Dilmahamod, 2014).

In the eastern IO, the intraseasonal variation of the SEC is mostly attributed to the baroclinic instability of the mean current (Feng and Wijffels, 2002), which is important for the meridional heat transport in the region and contributes to the demise of Indian Ocean Dipole events (Ogata and Masumoto, 2011; Yang et al., 2015). Barotropic instability of the SEC has also been proposed to be a key mechanism for generating intraseasonal variability (Yu and Potemra, 2006). These intraseasonal signals propagate westward as Rossby waves, influencing the SEC variability in the western Indian Ocean (Zhou and Murtugudde, 2009).

Interannual variability in the ITF due to ENSO, IOD, and other influences is communicated into the interior Indian Ocean along the SEC and via Kelvin and Rossby waves (Godfrey and Weaver, 1989, 1996; Meyers et al., 1995; Meyers, 1996; Wijffels and Meyers, 2004). Pressure anomalies associated with ENSO and IOD are communicated through the Indonesian seas as Kelvin and Rossby waves. These anomalies propagate westward into the Indian Ocean as Rossby waves. At the same time, the pressure anomalies drive variations in ITF and SEC transport and induce temperature and salinity variability via advection. Geostrophic transport variability in the long-time repeat expendable bathythermograph (XBT) line IX1 shows that the SEC is stronger during La Niña and positive Indian Ocean Dipole events (Meyers, 1996; Liu et al., 2015). Similarly, the Pacific Decadal Oscillation alters the SEC and ITF transports and associated water properties (Sect. 6.1). During the climate change hiatus period of 2000-2011, the enhanced heat transport of the SEC/ITF was a key mechanism for the fast warming trend in the southern subtropical Indian Ocean (Sect. 6.1).

\subsubsection{Western boundary}

The Agulhas Current (Fig. 10) has long been known as one of the strongest western boundary currents in the global oceans, with an average transport of $75 \mathrm{~Sv}$ and current speeds in excess of $2 \mathrm{~m} \mathrm{~s}^{-1}$ (Beal et al., 2015, 2011). The Agulhas Current plays a vital role in the global thermohaline circulation, advecting warm, salty, subtropical water southwards, following the continental shelf of South Africa and meandering less than $150 \mathrm{~km}$ offshore (Gründlingh, 1983; Lutjeharms, 2006). The strength and warmth of the Agulhas Current in- fluences atmospheric storm tracks and storm development. The large moisture source of the warm Agulhas Current region contributes significantly to the frequency and strength of African precipitation, which significantly impacts rainfed subsistence farming (Hermes et al., 2019, and references therein).

South of the tip of Africa, the Agulhas Current retroflects eastwards into the southern Indian Ocean (Fig. 10). This retroflection area is highly variable, occluding rings that propagate into the southern Atlantic Ocean. The Agulhas variability is linked upstream to modes of variability including ENSO (Elipot and Beal, 2018; Trott et al., 2021) and downstream with the Atlantic meridional overturning circulation, providing an essential link between the Pacific, Indian, and Atlantic Oceans (Beal et al., 2011). Estimates of the rate of mass and heat exchange carried by Agulhas leakage south of Africa (and the number of rings shed per year) vary and are difficult to verify reliably (Weijer and van Sebille, 2014). Daher et al. (2020) recently used a combination of drifters and Argo floats to derive an estimate of Agulhas leakage of 20 Sv. Van Sebille et al. (2011) and Le Bars et al. (2014) suggested that upstream variability of the Agulhas Current has an effect on inter-ocean exchange between the southern Indian and southern Atlantic oceans, primarily by influencing the frequency of ring shedding at the Agulhas retroflection. However, a few recent papers suggest instead that its variability is driven by the Southern Hemisphere westerlies (Durgadoo et al., 2013; Loveday et al., 2014; Elipot and Beal, 2015).

The Agulhas Current has a seasonal cycle and is strongest in summer (Krug and Tournadre, 2012; Beal and Elipot, 2016) and tied to a baroclinic adjustment of near-field winds (Hutchinson et al., 2018). Seasonal changes in the Agulhas retroflection region (Lutjeharms and van Ballegooyen, 1988; Quartly and Srokosz, 1993) and in the southwest Indian Ocean (Ffield et al., 1997) have been suggested from hydrographic and satellite data (Krug and Tournadre, 2012), but with weak statistical significance due to a lack of a sufficiently long time series.

Although long-term observations in this region are limited, there are numerous recent studies that have further elucidated our understanding of the Agulhas Current. Beal and Elipot (2016) used 3 years of in situ data to show that, contrary to expectations, the Agulhas Current has not intensified since the early 1990s. Instead, it has broadened as a result of more eddy activity, driven by intensifying winds. Variability in the path and strength of the Agulhas Current has mostly been attributed to solitary Agulhas meanders within the current system (also known as Natal pulses) that drive upwelling and cross-shelf transports, affecting marine productivity, fisheries, and recruitment over the Agulhas Bank (Beal and Bryden, 1999; Roberts et al., 2010; Elipot and Beal, 2015). Recent work has highlighted the importance of sub-mesoscale eddies in the Agulhas Current frontal region 
driving an inshore edge flow reversal, which can have important consequences on fisheries (Krug et al., 2017).

The advance in models has also helped improve our understanding of the Agulhas Current, which is generally not well represented in global ocean models. Hutchinson et al. (2018) used idealized models to expose a link between the seasonality of the Agulhas Current and propagation of first baroclinic mode Rossby waves communicating the wind stress signal across the western portion of the southern Indian Ocean, with the signal from winds further east having little effect.

\subsubsection{Interior flows}

In the central-eastern southern Indian Ocean between 20 and $30^{\circ} \mathrm{S}$, the surface geostrophic flow is generally eastward, opposite to the prediction of both the Ekman and Sverdrup theories (Sharma, 1976; Sharma et al., 1978; Godfrey and Ridgway, 1985; Schott et al., 2009). This flow is driven by the large-scale, poleward drop in the dynamic height (steric height) near the sea surface (Godfrey and Ridgway, 1985; Schott et al., 2009) related to the meridional transition from the very fresh and warm SEC waters to the increasingly cooler, saltier, and denser waters to the south. The flow generally extends from the sea surface to $\sim 200-300 \mathrm{~m}$ (Domingues et al., 2007; Palastanga et al., 2007; Divakaran and Brassington, 2011; Menezes et al., 2014a). The mechanisms that determine the vertical extent of the interior eastward flow remain unclear, although this depth coincides with the depth of the shelf break at the eastern boundary and the bottom of the Leeuwin Current along that boundary. This correspondence may be achieved by the westward propagation of baroclinic Rossby waves (Weaver and Middleton, 1989; Furue et al., 2013). Below the near-surface eastward flows, the flow is weakly westward (Domingues et al., 2007; Schott et al., 2009; Furue et al., 2017).

Embedded in this general eastward flow are narrower eastward jets (Maximenko et al., 2009; Divakaran and Brassington, 2011; Menezes et al., 2014a), collectively known as the South Indian (Ocean) Countercurrent (SICC; Palastanga et al., 2007; Siedler et al., 2006; Menezes et al., 2014a). They start out as a single jet emanating from the southern tip of Madagascar around $25^{\circ} \mathrm{S}$, possibly fed by a partial retroflection of the SEMC (Palastanga et al., 2007; Siedler et al., 2006, 2009) and divide into separate jets around the Central Indian Ridge $\left(65-68^{\circ} \mathrm{E}\right)$ (Menezes et al., 2014a). Eastward flows exist in similar latitude bands in the northern and southern Pacific and northern and southern Atlantic (Yoshida and Kidokoro, 1967; Merle et al., 1969; Takeuchi, 1984; Kubokawa, 1999; Qiu and Chen, 2004; Kobashi and Kubokawa, 2012). However, the jets in these basins are weaker and shallower than the SICCs and do not extend all the way to the eastern boundary (Menezes, 2015).

Three main jets (Fig. 10a) are evident in geostrophic velocity calculated from both altimetric sea surface height and hydrography and are captured in OGCMs (Maximenko et al., 2009; Divakaran and Brassington, 2011; Menezes et al., 2014a). The stronger southern jet (3-4 Sv) crosses the basin around $26^{\circ} \mathrm{S}$ and has an associated thermal front at depths around 100-200 m (Sharma, 1976; Siedler et al., 2006; Menezes et al., 2014a; Palastanga et al., 2007). This front suggests that the southern SICC has physics similar to the Subtropical Countercurrents (STCCs) of the Pacific Ocean (Kubokawa, 1999; Kobashi and Kubokawa, 2012; Kubokawa and Inui, 1999; Menezes et al., 2014a). The location and strength of the SICC vary between studies, from well-defined jets (Siedler et al., 2006; Palastanga et al., 2007; Divakaran and Brassington, 2011; Menezes et al., 2014a) to a mean velocity structure (Jia et al., 2011a) or even absence of the SICC (Srokosz et al., 2015). Depending on the region and time in which its characteristics were determined, the SICC varies from a weak mean current of $2-3 \mathrm{~cm} \mathrm{~s}^{-1}$ (Jia et al., 2011a) to a strong jet of $50 \mathrm{~cm} \mathrm{~s}^{-1}$ eastward flow (Siedler et al., 2006).

The eastward flowing Eastern Gyral Current (EGC) is part of an anticyclonic recirculation centred at the IndonesianAustralian basin $\left(5-20^{\circ} \mathrm{S}\right.$ and $100-125^{\circ} \mathrm{E}$ ) (Domingues et al., 2007; Menezes et al., 2013, and references therein). Part of the northern SICC merges with the EGC around $15^{\circ} \mathrm{S}$, $100^{\circ} \mathrm{E}$ (Fig. 10a). The EGC supplies ITF-origin water to the Leeuwin Current (LC) and is an essential component of the LC dynamics (Domingues et al., 2007; Benthuysen et al., 2014b; Lambert et al., 2016; Furue et al., 2013, 2017; Yit Sen Bull and van Sebille, 2016). The geostrophic flow of the EGC is controlled by the meridional salinity gradient, making its dynamics distinct from the temperature-dominated SICC (Menezes et al., 2013). This salinity front is formed by the encounter of the fresh Indonesian Throughflow Water carried westward by the SEC and the salty subtropical underwater formed at the southern Indian Ocean subtropical salinity maximum. The seasonal cycles of the EGC and the SICC are also distinct: the EGC is stronger in austral winter $(3-5 \mathrm{~Sv})$ and weaker $(<0.5 \mathrm{~Sv})$ in summer with the cycle in phase with the Leeuwin Current (Feng et al., 2003; Menezes et al., 2013; Furue et al., 2017). The SICC is overall stronger in spring-summer and weaker in winter (Palastanga et al., 2007; Jia et al., 2011a; Menezes et al., 2014a) and experiences strong interannual variability, which peaks at biennial timescales and is decadally modulated (Menezes et al., 2016).

The multiple jets of the SICC are embedded in a zone of high eddy kinetic energy, with eddies generated by instabilities of the Leeuwin Current and of the SICC itself (Palastanga et al., 2007; Divakaran and Brassington, 2011; Huhn et al., 2012; Jia et al., 2011a, b; Menezes et al., 2014a, 2016; Siedler et al., 2006). By co-locating Argo floats and satellite data, Dilmahamod et al. (2018) described the passage of surface and subsurface southern Indian Ocean eddies (SIDDIES). These westward-propagating, long-lived features (> 3 months) originate in areas of high evaporation in the eastern Indian Ocean and prevail over a preferential latitude band, 
forming a permanent structure linking the eastern to the western Indian Ocean (the "SIDDIES Corridor"). This corridor of eddy passage allows the advection of water masses and biogeochemical properties across the basin (Dilmahamod et al., 2018).

\subsubsection{Eastern boundary}

Unlike any other eastern boundary current, the Leeuwin Current (LC; Figs. 10 and 11a) flows poleward along the shelf break of the west coast of Australia (Smith et al., 1991). Figure 11a presents the long-term average volume transport of the LC system from an observational climatology with similar structure found in a $1 / 10^{\circ}$ ocean general circulation model (Furue et al., 2017). The primary source waters for the LC are the interior eastward flows (Sect. 4.2.3) that turn southeastward as they approach the coast and merge with the LC (Fig. 11a; Domingues et al., 2007; D'Adamo et al., 2009; Menezes et al., 2013, 2014a; Furue et al., 2017; Furue, 2019). On average, the LC carries $0.3 \mathrm{~Sv}$ southward at $22^{\circ} \mathrm{S}$, gains $4.7 \mathrm{~Sv}$ from the Indian Ocean interior, loses $3.5 \mathrm{~Sv}$ through downwelling to the layer beneath, and carries $1.5 \mathrm{~Sv}$ at its southern limit. The LC is approximately 200$300 \mathrm{~m}$ deep, extends from $22^{\circ} \mathrm{S}$ (North West Cape) to $34^{\circ} \mathrm{S}$ (Cape Leeuwin) and exists throughout the year despite significant seasonality (Feng et al., 2003; Ridgway and Godfrey, 2015; Furue et al., 2017). The Holloway Current, which flows southwestward on the North West Shelf (D'Adamo et al., 2009; Bahmanpour et al., 2016), is another weaker source to the LC from the north. Inshore of the LC, there exist seasonal equatorward flows that recirculate waters of distinct water mass properties influenced by air-sea interaction over the continental shelf (Woo et al., 2006).

The mean state of the LC is driven by the meridional pressure gradient in the upper ocean (e.g. Godfrey and Ridgway, 1985; Godfrey and Weaver, 1989, 1991), evident as a large poleward decrease in sea surface height ( $\mathrm{SSH}$ ) balanced by an eastward surface geostrophic current (Sect. 4.2.3). The eastward flow approaches the eastern boundary, inducing downwelling and a surface poleward current (Fig. 11; Godfrey and Ridgway, 1985; McCreary et al., 1986; Thompson, 1987; Weaver and Middleton, 1989, 1990; Furue et al., 2013; Benthuysen et al., 2014b), in opposition to the prevailing southerly winds. As a poleward boundary current, the LC waters are relatively fresh and warm from tropical origins (Rochford, 1969; Andrews, 1977; Legeckis and Cresswell, 1981; Domingues et al., 2007; Woo and Pattiaratchi, 2008). Saltier Indian Central Water, the surface water of the subtropical South Indian Ocean, joins the LC as it flows poleward (Sect. 4.2.3) increasing the mean density of the LC. Surface cooling along the poleward path also contributes to the increase in density (Woo and Pattiaratchi, 2008; Furue, 2019).

The LC flows around the southwestern corner of Australia and continues to flow eastward along the shelf break of the south coast of Australia to reach the southern tip of Tasma- nia near $42^{\circ} \mathrm{S}, 140^{\circ} \mathrm{E}$ (Fig. 11b, Oliver et al., 2016; Oke et al., 2018; Duran et al., 2020). This $5500 \mathrm{~km}$ long boundary current was first documented as a continuous flow by Ridgway and Condie (2004). When the longshore current is weak, however, it tends to be somewhat fragmentary (Oke et al., 2018; Duran et al., 2020) and sometimes even reverses in places (Duran et al., 2020). For this reason, and additionally because of the scarcity of observational sampling, the current is not traditionally regarded as a single current. Along southern Australia, the boundary currents can be described following Ridgway and Condie's (2004) naming convention. The current's western sector is called the Leeuwin Current Extension, the central part, to the south of the Great Australian Bight, is called the South Australian Current, and the easternmost part along Tasmania is called the Zeehan Current. They are collectively known as the Shelf-Break Currents (SBCs) of the Southern Australia Current System (Duran et al., 2020). It is not clear whether the SBCs along the southern coast of Australia are, dynamically, an extension of the LC. The SBCs are at least consistent with the local northward Ekman drift (Ridgway and Condie, 2004; Duran et al., 2020) and hence would exist without the LC.

On seasonal timescales, the LC transport generally tends to be strongest in austral autumn and weakest in austral summer (McCreary et al., 1986; Smith et al., 1991; Feng et al., 2003; Furue et al., 2017). There are two theories to explain this seasonality. In one, the local winds, which generally induce an offshore Ekman drift and therefore tend to weaken the LC, reach their annual maximum or minimum when the LC transport reaches its minimum or maximum, respectively (McCreary et al., 1986; Furue et al., 2013). In the other, a seasonal pressure anomaly originates in the Gulf of Carpentaria and propagates anticlockwise along the shelf break, driving the seasonality of the LC and of the SBCs to the south of Australia (Ridgway and Godfrey, 2015). Like the LC, the SBCs tend to be strongest in austral autumn and weakest in austral summer (Ridgway and Condie, 2004; Oke et al., 2018; Duran et al., 2020). In particular, the eastern part of the South Australian Current is seen to reverse in summer (Duran et al., 2020). This variability is consistent with the anticlockwise propagation of pressure anomaly shown by Ridgway and Godfrey (2015) and also with the seasonality of the wind stress along the southern coast of Australia, with onshore (offshore) Ekman drift tending to drive eastward (westward) shelf-break flow (Duran et al., 2020).

On interannual timescales, the LC is modulated by the El Niño Southern Oscillation owing to the steric height anomalies in the western equatorial Pacific Ocean propagating through the Indonesian Seas and along Western Australia (Feng et al., 2003). During El Niño and La Niña periods, the LC transport weakens and strengthens, respectively, and is correlated with Fremantle sea level (Feng et al., 2003). During the strong 2010-2011 La Niña event, the LC reached record strength speeds (Feng et al., 2013) and the consequences of the unprecedented marine heat wave that re- 
(a)

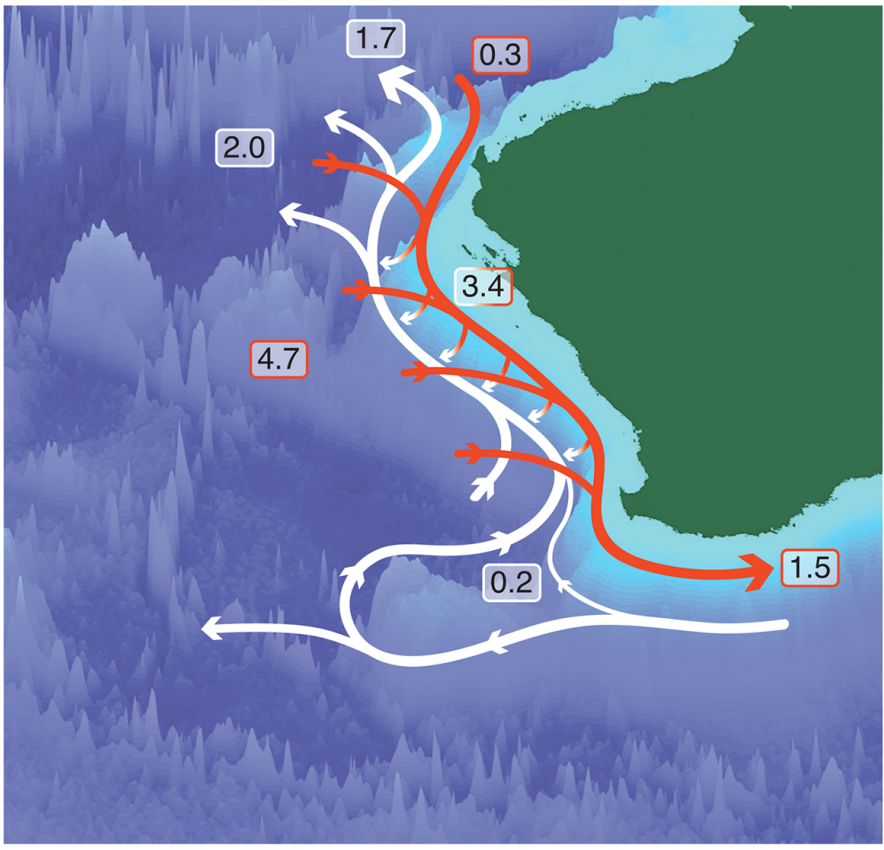

(b)

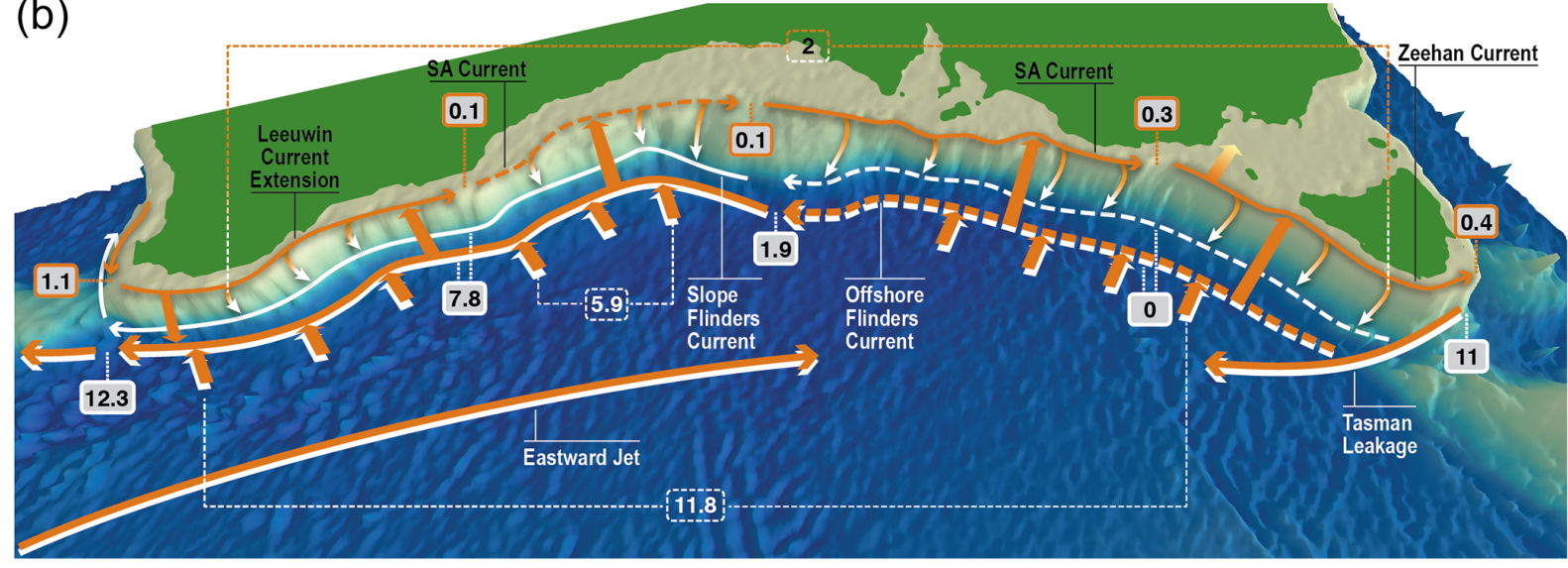

\begin{tabular}{|c|c|c|}
\hline$\longrightarrow$ Surface & 1.17 .8 & Long-shore transport \\
\hline $\begin{array}{l}\text { Sub-surface } \\
\text { Seasonally reversing }\end{array}$ & 20.5 & Transport exchanges \\
\hline
\end{tabular}

Figure 11. (a) Schematic summary of Australia's Leeuwin Current System three-dimensional transports (Sv). The red arrows and redoutlined numbers represent the upper-layer $(0-200 \mathrm{~m})$ meridional transport of the poleward Leeuwin Current and meridionally integrated zonal transport of the shallow eastward flows. The white arrows represent the lower-layer (200-900 m) flows of the Leeuwin Undercurrent. Taken from Furue et al. (2017). (C) American Meteorological Society. Used with permission. (b) Schematic summary of the Southern Australia Current System three-dimensional transports (Sv). Long-shore transport for the Shelf-Break Currents and Flinders Current in grey box with orange and white outlines, respectively. Integrated vertical and onshore flow transport in dashed outline box. Reprinted from Duran et al. (2020), with permission from Elsevier, Progress in Oceanography. Both schematics are based on a geostrophic calculation in the CARS $1 / 8^{\circ}$ climatology.

sulted are described in Sect. 6.4. On multidecadal timescales, the major boundary currents around Australia, including the LC, are reported to have strengthened during 1979-2014 in an eddy-resolving OGCM, also consistent with observations (Feng et al., 2016; see Sect. 6.1 for associated changes). At intraseasonal timescales, winds or heat anomalies in the
North West Shelf region due to MJO events lead to intraseasonal variability of the Holloway Current on the North West Shelf and then of the LC (Marshall and Hendon, 2014; Marin and Feng, 2019).

The LC is accompanied by mesoscale eddies that cause the LC to meander energetically (Pearce and Griffiths, 1991; 
Feng et al., 2005; Waite et al., 2007b; Meuleners et al., 2007). Those eddies are, at least partially, generated by barotropic, baroclinic, or mixed instability of the LC itself (Pearce and Griffiths, 1991; Feng et al., 2005; Meuleners et al., 2008). The eddy kinetic energy is greatest when the LC transport is strongest, in May-June (Fang and Morrow, 2003; Feng et al., 2005). Some of these eddies cause a large meander of the LC: a large anticyclonic eddy often forms at $28-29^{\circ} \mathrm{S}$ and at 31-32 ${ }^{\circ}$ S (Feng et al., 2003, 2007), steering the LC offshore to return to the continental shelf further south. This state typically starts during May-June and ends in July-August (Feng et al., 2007). Similarly, it is suggested that the eastern part of the SBCs becomes unstable in boreal autumn and winter, generating eddies, which subsequently propagate westward south of Australia (Oke et al., 2018). Turbulent mixing has been found to be enhanced in anticyclonic eddies near the surface and in cyclonic eddies at deeper levels (500-1000 m) due to the interaction of the eddies and near-inertial waves, which has implications for water mass modifications and the meridional overturning circulation (Cyriac et al., 2021).

Just below the Leeuwin Current is the equatorward Leeuwin Undercurrent (LUC; Thompson, 1984; Church et al., 1989; Smith et al., 1991; Fig. 11a). The LUC hugs the continental slope and extends from 200 to $900 \mathrm{~m}$ (Furue et al., 2017). The LUC begins at Cape Leeuwin $\left(34^{\circ} \mathrm{S}, 114^{\circ} \mathrm{E}\right)$ and is fed by a northward bend of a small fraction of the Flinders Current (FC; Figs. 10, 11; Furue et al., 2017). The remaining part of the FC continues westward but another small fraction of it appears to retroflect eastward and join and augment the LUC (Duran, 2015; Furue et al., 2017). Near $22^{\circ} \mathrm{S}$, most of the LUC volume leaves the continental slope and flows offshore (Duran, 2015), apparently following the southern flank of the Exmouth Plateau, although its bottom at $900 \mathrm{~m}$ is much shallower than the topographic feature (Fig. 11a).

To the south of Australia, an undercurrent has been recently identified below the Zeehan Current in a numerical simulation (Oke et al., 2018) and in a geostrophic calculation based on a gridded temperature and salinity (T-S) climatology (Duran et al., 2020). Traditionally this flow was identified as a branch of the FC (Cirano and Middleton, 2004; Rosell-Fieschi et al., 2013; Feng et al., 2016) because the former flows in the same direction as the latter, but the FC as the northern boundary current of the subtropical gyre cannot exist on an eastern boundary (Anderson and Gill, 1975; Philander and Yoon, 1982; McCreary et al., 1992), and it lacks the vertical structure of an undercurrent (Duran et al., 2020). This northwestward- or westward-flowing undercurrent appears to exist all the way from the west coast of Tasmania to Cape Leeuwin (the southwestern tip of Australia) but its separation from the FC is less clear to the south of the Great Australian Bight and further west, where the FC accelerates and tends to overwhelm the undercurrent (Duran et al., 2020). Below, we call this current "slope FC", following Duran et al. (2020).
The mechanisms responsible for the LUC and undercurrent off southern Australia remain an open question, although models have been developed to investigate potential processes. The linear, continuously stratified models of McCreary et al. (1986) and Kundu and McCreary (1986) produce a surface poleward and a subsurface equatorward current, resembling the LC and LUC, along the eastern boundary. This class of model, however, requires large vertical diffusivity to produce a realistic LC and LUC (Julian P. McCreary, personal communication, 2013). Along a continental slope, alongshore and cross-shelf buoyancy advection cause a shelf break front, forming a surface intensified poleward current, like the LC, and an equatorward undercurrent by thermal wind shear (Benthuysen et al., 2014b). Analytical shelf models have been extended to include cross-shelf buoyancy gradients to derive a poleward undercurrent like the LUC (Schloesser, 2014). These process-based analytical theories have not been tested in an eddy-resolving model.

The LUC and the slope FC are connected to the LC and the SBCs, respectively, by downwelling (Fig. 11; Furue et al., 2017; Duran et al., 2020), suggesting common (but as yet unexplained) dynamics. Note, however, that for the LC-LUC pair, the mean downwelling appears to occur along isopycnal surfaces, and hence the LC water mass is not found in the LUC (Furue, 2019). For the SBCs and the slope FC, the nature of the downwelling is not known. The seasonality of these undercurrents is not well known. No systematic seasonal variability of the LUC was evident in a hydrographic climatology and ocean general circulation model (Furue et al., 2017).

\subsubsection{Biogeochemical variability}

The ITF impacts both ocean currents and basin-scale biogeochemistry (Talley and Sprintall, 2005; George et al., 2013; van Sebille et al., 2014). Talley and Sprintall (2005) mapped silicate on the 31.96 potential density surface, revealing a striking silicate maximum associated with the SEC that extends westward to at least $60^{\circ} \mathrm{E}$, highlighting the broad reach of ITF nutrient influence into the Indian Ocean. Ayers et al. (2014) estimated the depth- and time-resolved nitrate, phosphate, and silicate fluxes at the three main exit passages of the ITF that feed into the SEC: Lombok Strait, Ombai Strait, and Timor Passage. They found that the nutrient flux is significant relative to basin-wide new production and that the majority of ITF nutrient supply to the Indian Ocean via the SEC is to thermocline waters, where it is likely to support primary production and significantly impact biogeochemical cycling.

Satellite chlorophyll and primary production estimates suggest that values in the SEC are considerably higher than those found in the Southern Hemisphere subtropical gyre to the south, with Chl $a$ from $\sim 0.10$ to $1.0 \mathrm{mg} \mathrm{m}^{-3}$ and primary production from $\sim 400$ to $1000 \mathrm{mg} \mathrm{C} \mathrm{m}^{-2} \mathrm{~d}^{-1}$ (Fig. 5; Figs. 5 and 6 in Hood et al., 2017). The highest concentra- 
tions and rates in the SEC are observed in the eastern Indian Ocean in July and August during austral winter, associated with the ITF nutrient sources and upwelling off Java. The lowest chlorophyll concentrations and rates are observed in January (austral summer).

Model results and satellite observations show that the SEC/SCTR region exhibits an annual cycle in surface Chl $a$ concentration and primary production, with the highest values in austral winter (June-August; $>0.20 \mathrm{mg} \mathrm{m}^{-3}$ and $>$ $600 \mathrm{mg} \mathrm{C} \mathrm{m}^{-2} \mathrm{~d}^{-1}$, respectively) due to the strong southeasterly winds that increase wind stirring and induce upwelling (Resplandy et al., 2009; Dilmahamod, 2014; Fig. 5; Figs. 5 and 6 in Hood et al., 2017). Vertical sections of the SEC and SCTR region also reveal a deep Chl $a$ maximum (George et al., 2013). Along $65^{\circ} \mathrm{E}$, this maximum shoals from $>100 \mathrm{~m}$ at $16^{\circ} \mathrm{S}$ to $\sim 50 \mathrm{~m}$ at $10^{\circ} \mathrm{S}$ due to upwelling. The increases in surface Chl $a$ concentrations in austral winter are associated with decreases in the subsurface Chl $a$ maximum (Resplandy et al., 2009; Dilmahamod, 2014). Surface freshening associated with the core of the SEC also influences the Chl $a$ distribution in the SCTR region by modulating the static stability and mixed-layer depth (George et al. (2013).

The SEC provides relatively oligotrophic (low nutrient, low chlorophyll, and low primary production) tropical source waters that feed into the EACC, NEMC, SEMC, and the Mozambique channel. Chlorophyll $a$ concentrations and production rates in Mozambique Channel surface waters are generally low ( $<0.4 \mathrm{mg} \mathrm{m}^{-3}$ and $<700 \mathrm{~g} \mathrm{C} \mathrm{m}^{-2} \mathrm{~d}^{-1}$, Fig. 5) and not significantly different in cyclonic and anticyclonic eddies (Lamont et al., 2014; Barlow et al., 2014; Figs. 5, 6 and 20 in Hood et al., 2017). Deep chlorophyll maxima are observed between 25 and $125 \mathrm{~m}$ depth depending on the proximity to the shelf and the influence of mesoscale eddies (Barlow et al., 2014; Lamont et al., 2014). Eddies in the Mozambique Channel also have a strong influence on the lateral transport of nutrients and chlorophyll from the coasts of Madagascar and Africa. Indeed, enhanced phytoplankton production within both cyclonic and anticyclonic eddies in the Mozambique Channel often occurs in response to lateral nutrient inputs into the euphotic zone by horizontal advection from the coasts of Madagascar and Africa rather than through eddy-induced upwelling and downwelling (José et al., 2014; Lamont et al., 2014; Roberts et al., 2014). In contrast, in the Southeast Madagascar Current, topographically induced coastal upwelling brings cold, nutrient-rich water up to the surface, which supports high rates of primary production (Lutjeharms and Machu, 2000; Ho et al., 2004; Quartly and Srokosz, 2004). This upwelling and its impacts are observed in both the austral summer and winter (Ho et al., 2004).

The Agulhas Current itself is warm and oligotrophic with sources derived from low-nutrient and low-chlorophyll surface waters from the Mozambique Channel, Southeast Madagascar Current, and the southwestern tropical Indian Ocean (Fig. 5; Lutjeharms, 2006). Chlorophyll $a$ concentrations and production rates in Agulhas Current surface waters are particularly low during austral summer $\left(<0.2 \mathrm{mg} \mathrm{m}^{-3}\right.$ and $<500 \mathrm{mg} \mathrm{C} \mathrm{m}^{-2} \mathrm{~d}^{-1}$ ), with higher concentrations and rates in the austral winter (Machu and Garçon, 2001; Figs. 5, 6 and 20 in Hood et al., 2017). The Agulhas Current can drive upwelling and elevate primary production in the coastal zone through meandering and topographic interactions, but it can also dramatically suppress primary production when it impinges onto the shelf (Schumann et al., 2005).

In general, chlorophyll concentrations and primary production are elevated in the coastal zone of southeastern Africa along the inshore side of the Agulhas Current (Fig. 5; Machu and Garçon, 2001; Goschen et al., 2012; Figs. 5, 6 and 20 in Hood et al., 2017). This enhancement is most pronounced in austral summer and further southward downstream, and it is associated with upwelling-favourable (easterly) winds and the aforementioned topographically induced upwelling.

The near-surface eastward flows are generally associated with very low (oligotrophic) nutrient and chlorophyll $a$ $(\mathrm{Chl} a)$ concentrations $\left(<0.1 \mathrm{mg} \mathrm{m}^{-3}\right)$ and also very low primary production $\left(<500 \mathrm{mg} \mathrm{C} \mathrm{m}^{-2} \mathrm{~d}^{-1}\right.$; Fig. 5 and Figs. 5 and 6 in Hood et al., 2017). A well-defined deep Chl $a$ maximum is observed between 50 and $150 \mathrm{~m}$ during the austral autumn along $55^{\circ} \mathrm{E}$ between 20 and $30^{\circ} \mathrm{S}$ (Coles et al., unpublished data). An exception to this, however, is the Southeast Madagascar bloom (SMB). The SMB occurs in nearsurface waters off the southeastern coast of Madagascar in the late austral summer and autumn (January-April). It was first described as a dendroid bloom by Longhurst (2001), owing to its branching shape that projects eastward (Fig. 12). The bloom can extend over a $2500 \mathrm{~km}^{2}$ area with Chl $a$ concentrations reaching 2-3 $\mathrm{mg} \mathrm{m}^{-3}$ (Longhurst, 2001), making it a "hotspot" for primary production in an otherwise oligotrophic region. Figure 12 illustrates the bloom's large spatial variability, with high $\mathrm{Chl} a$ filaments apparently co-occurring and being transported with mesoscale and sub-mesoscale eddies and jets.

Why the SMB flourishes in late austral summer is unclear. Longhurst (2001) attributed SMB development to mixedlayer deepening and entrainment of nutrients by the vigorous mesoscale eddy field. These nutrients could stimulate phytoplankton growth in the photic zone, with the eddies shaping the eastward propagation of the enhanced surface Chl $a$ concentrations. However, Uz (2007), Srokosz and Quartly (2013), and Dilmahamod et al. (2019) subsequently showed that the bloom occurs within a warm $\left(>26.5^{\circ} \mathrm{C}\right)$, shallow mixed layer $(\sim 30 \mathrm{~m})$ overlying a strong pycnocline. Furthermore, they suggested that diazotrophs known to inhabit the region (Poulton et al., 2009) might introduce new nitrogen $(\mathrm{N})$ from $\mathrm{N}_{2}$ fixation that could support the enhanced Chl $a$ concentration as observed elsewhere (Mulholland et al., 2014; Hood et al., 2004; Coles et al., 2004). Subsequent studies also highlight the role of mesoscale eddies (Fig. 12), that could advect, disperse, and co-mingle 

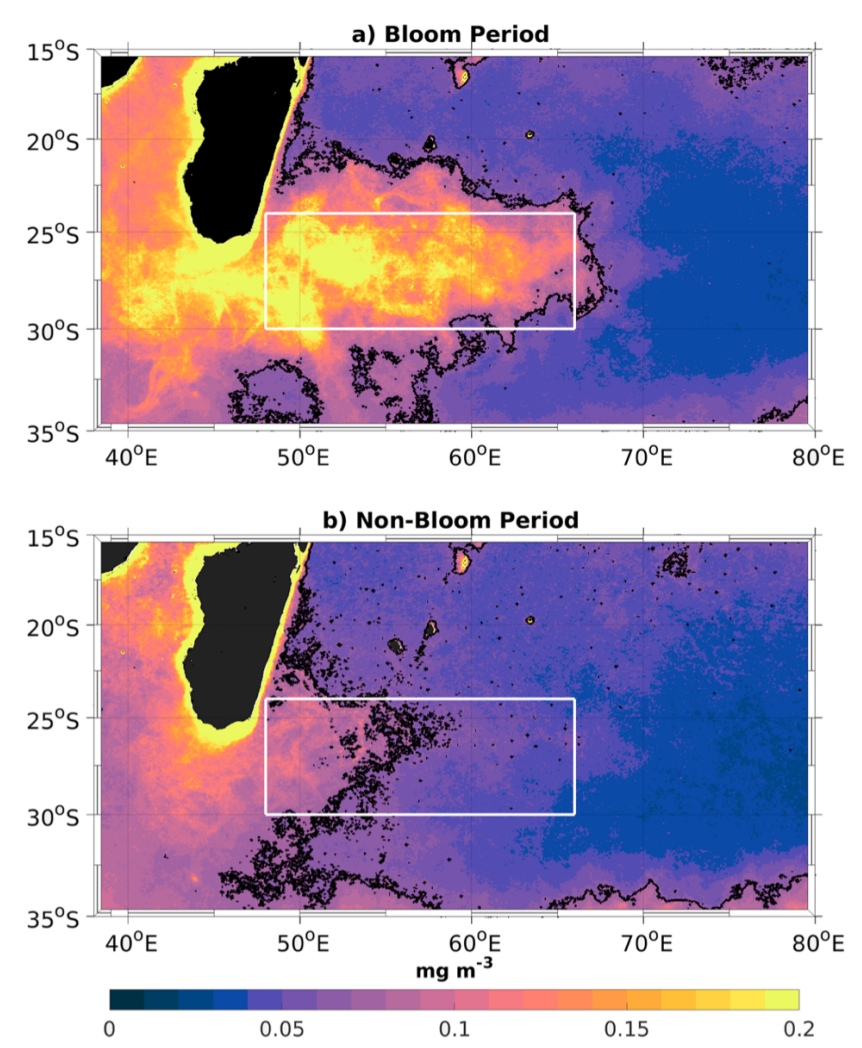

Figure 12. (a) Spatial maps of mean Chl $a$ concentration $\left(\mathrm{mg} \mathrm{m}^{-3}\right)$ during months of maximum austral summer bloom. (b) The same as (a) but during January showing the minimum Chl $a$ concentration in austral summer. The black contour denotes the $0.07 \mathrm{mg} \mathrm{m}^{-3}$ threshold used to distinguish between bloom and non-bloom years. From Dilmahamod et al. (2019).

nutrients and/or phytoplankton biomass (Dilmahamod et al., 2019; Huhn et al., 2012; Raj et al., 2010; Srokosz and Quartly, 2013; Srokosz et al., 2004, 2015; Uz, 2007).

A different explanation of the SMB and its eastward projection was proposed by Srokosz et al. (2004). In their proposed mechanism, the bloom initiates off Madagascar due to coastal processes that bring limiting nutrients to the photic zone, and phytoplankton are transported horizontally by mesoscale eddies, resulting in an eastward propagation of the bloom. Dilmahamod et al. (2020) extend this further using a model to suggest that, from a nutrient flux analysis, horizontal advection of low-salinity nutrient-rich Madagascan coastal waters can indeed trigger a phytoplankton bloom. Alternatively, the apparent eastward propagation of the SMB has recently been attributed to advection by the SICC (Fig. 10; Dilmahamod et al., 2019; Huhn et al., 2012; Wilson and Qiu, 2008). Indeed, Huhn et al. (2012) further suggested that the bloom is shaped by a meridional barrier of jet-like Lagrangian coherent structures associated with the SICC.

At the eastern boundary, the tropical source waters and downwelling tendency of the Leeuwin Current combine to create a warm, oligotrophic current with low productivity. Chl $a$ concentrations are usually $<30 \mathrm{mg} \mathrm{Chl} a \mathrm{~m}^{-2}$, and rates of primary production rates generally do not exceed $500 \mathrm{mg} \mathrm{C} \mathrm{m}^{-2} \mathrm{~d}^{-1}$ (Koslow et al., 2008; Lourey et al., 2006, 2013). Productivity in the Leeuwin Current is lowest during austral summer, when the water column is stratified. During summer, subsurface chlorophyll maxima are found between 50 and $120 \mathrm{~m}$ depth (Hanson et al., 2007), as observed in open-ocean subtropical oligotrophic waters (e.g. Venrick, 1991). However, rates of primary production in near-shore upwelling regions (e.g. off of the North West Cape during summer) can sometimes attain very high levels (3000$8000 \mathrm{mg} \mathrm{C} \mathrm{m}^{-2} \mathrm{~d}^{-1}$ ) as observed in other eastern boundary upwelling zones (Furnas, 2007).

In all seasons, meanders in the Leeuwin Current give rise to warm-core, anticyclonic eddies that carry moderately high-chlorophyll coastal water offshore. The elevated chlorophyll concentrations in these eddies are due to the presence of coastal diatom communities. These diatoms are transported offshore into cooler oligotrophic waters that are dominated by much smaller open-ocean phytoplankton species (Waite et al., 2007a; Paterson et al., 2008; Waite et al., 2016). These eddies, which can extend to more than $2000 \mathrm{~m}$ depth, are unusual because they are downwelling (anticyclonic) circulations that should inhibit the input of new nutrients from depth. Nonetheless, these eddies, and the elevated chlorophyll concentrations that are associated with them, persist for months (Feng et al., 2007; Moore et al., 2007; Dufois et al., 2014). It has been hypothesized that the diatom communities in these eddies are supported by internal nutrient recycling and/or lateral supply (Waite et al., 2007a; Paterson et al., 2013; Thompson et al., 2007, 2011).

Generation of these warm (and cold) core eddies by the Leeuwin Current is prolific between 20 and $35^{\circ} \mathrm{S}$ (Gaube et al., 2013). Most of these eddies move directly westward and some may be very long lived (Feng et al., 2005, 2007; Moore et al., 2007; Gaube et al., 2013; Dufois et al., 2014). The persistence and potential biogeochemical and ecological impacts of these eddies in the open ocean have not been investigated fully.

\subsection{Equatorial regime}

\subsubsection{Wyrtki Jets}

Owing to the seasonally reversing monsoon winds, the equatorial Indian Ocean (EIO) exhibits unique characteristics and is in contrast with the equatorial Atlantic and Pacific Oceans. Unlike the other basins, the annual winds along the EIO are very weak and mostly meridionally oriented except during the two intermonsoon seasons between boreal winter (AprilMay) and summer (October-November), when strong westerly wind bursts prevail along the EIO (see Schott and McCreary, 2001, and references therein). The semi-annual cycle in the zonal wind is well known observationally and was 
shown to be due to the meridional advection of easterly momentum by the cross-equatorial monsoon winds (Ogata and Xie, 2011). The westerly winds force strong eastward jets in the top $100 \mathrm{~m}$ along the Equator that are known as spring and autumn Wyrtki Jets, respectively (Wyrtki, 1973). These surface jets are usually confined within the top $100 \mathrm{~m}$ of the water column (Han et al., 1999; Iskander et al., 2011) and deepen (shoal) the thermocline and elevate (lower) the sea level in the east (west) (Rao et al., 1989; Schott and McCreary, 2001; Nagura and McPhaden, 2010a). These jets play a major role in zonal redistribution of mass, heat, salt, and other water properties at the Equator and in off-equatorial basins (Reppin et al., 1999; Murtugudde and Busalacchi, 1999; Han et al., 1999; McPhaden et al., 2015; Chatterjee et al., 2017). Long-term ADCP observations from the RAMA equatorial mooring suggest that the autumn jet in the central EIO is usually stronger with a maximum transport of $\sim 19.7 \mathrm{~Sv}$ compared to the spring jet, which shows maximum transport of $\sim 14.9 \mathrm{~Sv}$ with comparable standard deviations (McPhaden et al., 2015).

These eastward surface zonal currents tend to propagate westward during spring and eastward during autumn (Nagura and McPhaden, 2016). The westward phase propagation speed during spring is estimated to be on average between $0.7-1.5 \mathrm{~m} \mathrm{~s}^{-1}$ (Qiu et al., 2009; Nagura and McPhaden, 2010a) and driven primarily by the westward-propagating surface zonal winds associated with atmospheric deep convection that moves from the Maritime Continent to the northern Bay of Bengal during spring (Nagura and McPhaden, 2010b, 2016). Equatorial Rossby waves may also contribute to this westward propagation (Nagura and McPhaden, 2010a). In contrast, during autumn, as the deep convection moves southeastward, the surface equatorial zonal winds, and thus surface currents, propagate eastward.

The spring and autumn Wyrtki Jets also show considerable intraseasonal and interannual variability. While the intraseasonal variability of the Wyrtki Jets has been shown to be influenced by their own instability (Sengupta et al., 2001, 2007; Han et al., 2004) and local winds (Masumoto et al., 2005; Sengupta et al., 2007; Iskander et al., 2009; Prerna et al., 2019), the interannual variability of the Wyrtki Jets is mainly caused by the anomalous wind forcing along the EIO associated with ENSO (Murtugudde et al., 2000; Gnanaseelan et al., 2012; Joseph et al., 2012) and IOD (Nagura and McPhaden, 2010b; Nyadjro and McPhaden (2014); Prerna et al., 2019): IOD weakens (strengthens) the equatorial zonal winds during its positive (negative) phase. While IOD modulates the zonal winds along the entire Equator, the influence of ENSO is primarily limited to the eastern part of the EIO (Gnanaseelan et al., 2012). Moreover, it has been shown that these climate modes affect the boreal autumn jet more significantly than the boreal spring jet. Recent modelling studies suggest that MJO convection can lead to a stronger spring Wyrtki jet particularly in the eastern EIO. The interannual variability of MJO can, therefore, contribute to the observed interannual variability of this equatorial jet as well (Deshpande et al., 2017; Prerna et al., 2019).

\subsubsection{The 5-30 d ocean waves and instabilities}

Meridional velocity along the Equator shows prominent high-frequency variability at all depths, in the periodic band of 10-20 d with a peak at $\sim 15 \mathrm{~d}$ (referred to as biweekly variability) and in the $20-30 \mathrm{~d}$ band with a peak at $\sim 25 \mathrm{~d}$ (Masumoto et al., 2005; David et al., 2011; Chatterjee et al., 2013; Smyth et al., 2015). This variability is attributed to Yanai waves, first discovered in the atmosphere (also referred to as mixed Rossby-gravity waves; Yanai and Maruyama, 1966; Arzeno et al., 2020; Pujiana and McPhaden, 2021). Unlike Kelvin and Rossby waves, Yanai wave phases can propagate westward or eastward depending upon their frequency, but their group velocity is always eastward (Miyama et al., 2006). These waves lead to convergent meridional heat flux into the equatorial regime (Shinoda et al., 2009; Smyth et al., 2015). While these waves were first observed in the ocean in the late 1990s, the establishment of the equatorial RAMA moorings (McPhaden et al., 2009) over the last 2 decades has provided more insight into these processes. Biweekly $(10-20 \mathrm{~d})$ is shown to be forced by the direct meridional wind stress (Sengupta et al., 2004) and to some extent by the meridional gradient of the zonal wind stress (Miyama et al., 2006). The $20-30 \mathrm{~d}$ band can be excited by off-equatorial barotropic and baroclinic instabilities in addition to direct wind forcing. A detailed review of the biweekly variability is provided in Schott et al. (2009), and hence we focus on the $20-30 \mathrm{~d}$ variability in this review.

While the $20-30 \mathrm{~d}$ oscillation in meridional velocity is reported near the surface in the central EIO (David et al., 2011), in the eastern EIO these variabilities are seen only in subsurface layers (100-200 m depth) of the water column (Masumoto et al., 2005). This indicates a possible downward energy propagation of a vertical beam that carries energy to deeper depths. In the central EIO, these 20-30 d Yanai waves are excited by horizontal shear between the westwardflowing South Equatorial Current and the eastward-flowing Southwest Monsoon Current during IOD events (Fig. 10a; David et al., 2011). In the western EIO, these waves are primarily driven by cross-equatorial meridional winds (Chatterjee et al., 2013). During early boreal summer (June/July), when the Somali Current begins to cross the Equator along the western boundary of the basin, it bends offshore to conserve potential vorticity (Schott and McCreary, 2001) and forms a gyral circulation known as the Southern Gyre (Fig. 10a). Subsequently, these swift currents turn barotropically unstable and generate eddy flow that is advected southward to the Equator near the western boundary i.e. at $\sim 50-55^{\circ} \mathrm{E}$. They generate a westward-propagating crossequatorial flow with a wavelength set by the eddy field that is similar to the wavelength of 20-30 d Yanai waves and thus excites these frequencies efficiently (Chatterjee et al., 2013). 
The ocean response to convectively coupled Kelvin waves $(\mathrm{CCKW})$ in the atmosphere was investigated using ocean glider measurements from the CINDY/DYNAMO field experiment (Webber et al., 2014; Matthews et al., 2014). CCKW are atmospheric weather systems that propagate eastward along the Equator and are an important constituent of the MJO convection (Baronowski et al., 2016). CCKW enhance surface wind speed and latent heat flux during their passage, suppressing the diurnal cycle of SST and leading to sustained decrease in bulk SST of around $0.1^{\circ} \mathrm{C}$, one-third of the SST anomaly due to a single, average MJO event, suggesting the oceanographic impact could have a strong feedback on the MJO cycle (Baronowski et al., 2016). Using RAMA moored measurements of upper ocean and surface atmosphere variability, Pujiana and McPhaden (2018) demonstrated that CCKW force oceanic Kelvin waves, affect surface heat fluxes, and generate upper-ocean turbulence.

\subsubsection{Equatorial upwelling and downwelling}

In the Pacific and Atlantic Oceans, permanent easterlies drive permanent equatorial upwelling due to Ekman divergence, but in the Indian Ocean where the mean winds are weak and westerly, permanent upwelling does not exist (Schott and McCreary, 2001). Mean westerly winds along the Equator are favourable for downwelling, driving surface convergence and thermocline divergence, which has been observed and described with Argo and RAMA data (Wang and McPhaden, 2017). Instead of upwelling along the Equator, coastal upwelling along the coasts of Sumatra and Java is prominent. During June-October, southeasterly trade winds blow close to the Equator and drive the offshore Ekman transport away from the Sumatran-Javan coasts (Quadfasel and Cresswell, 1992; Sprintall et al., 1999; Susanto et al., 2001). The associated wind-driven upwelling intensifies as the monsoon progresses, reaching its peak by August and finally weakening by October as the monsoon winds wane. Recent studies suggest that when the easterly winds prevail during summer, upwelling favourable Kelvin waves also contribute to intensifying the equatorial upwelling (Iskander et al., 2009; Chen et al., 2016). During boreal winter-early spring (December-March), an intermittent and weaker subsurface thermocline shoaling is evident (Chen et al., 2016). Subsequently, the prevalence of westerly winds, which drive downwelling Kelvin waves, depress the thermocline in the east (Susanto et al., 2001; Prerna et al., 2019). Apart from this seasonal cycle, interannual climatic variability associated with ENSO and IOD events (Saji et al., 1999; Vinayachandran et al., 1999; Nyadjro and McPhaden, 2014) also influences the upwelling intensity in this region (Sect. 6.2).

\subsubsection{Equatorial undercurrents}

In the Pacific and Atlantic, easterly winds produce an eastward mean undercurrent in the thermocline but in the Indian
Ocean westerly winds do not produce a mean westward undercurrent. The reason is that non-linear momentum advection drives mean eastward currents in the thermocline that flow up the zonal pressure gradient (Nagura and McPhaden, 2014). The Indian Ocean Equatorial Undercurrent (EUC) is, therefore, a much weaker and seasonally varying transient feature driven by seasonally reversing monsoon winds (Reppin et al., 1999; Schott and McCreary, 2001). The equatorial RAMA moorings have recorded an eastward EUC with a core within the thermocline during boreal winter and spring (Chen et al., 2015, 2019) and occasionally in summer and autumn at a depth of 90-170 m (Iskandar and McPhaden, 2011). During winter, the eastward EUC is forced by the upwelling Kelvin and Rossby waves that are in turn forced by easterly winds along the Equator in that season. During summer, the westward EUC is primarily forced by the eastward pressure gradient generated by the downwelling Rossby waves reflected off the eastern boundary of the basin. On intraseasonal timescales of 30-70 d, the EUC variability is dominated by that of Kelvin and Rossby waves of lowerorder baroclinic modes (Iskander and McPhaden, 2011). The undercurrents also undergo significant interannual variations related to the IOD. These variations are important in the mass and heat balance on IOD timescales, with significant impacts on upwelling and SST (Zhang et al., 2014; Nyadjro and McPhaden, 2014).

\subsubsection{Cross-equatorial circulation}

The cross-equatorial circulation in the upper ocean is achieved by the Cross-Equatorial Cell (CEC), driven by Southern Hemisphere southeasterly winds and the seasonally reversing monsoon winds in the Northern Hemisphere (Miyama et al., 2003; Schott et al., 2002, 2004, 2009). Thermocline waters subducted in the subtropical southeastern Indian Ocean move equatorward and enter the Northern Hemisphere via the western boundary to upwell off Somalia and Oman. The return across the Equator, the surface branch of the CEC, is via the near-surface meridional flow in the interior Indian Ocean that is southward in the mean at nearly all longitudes (Miyama et al., 2003; Lee, 2004). This cell is unique to the Indian Ocean and is consistent with Sverdrup dynamics, being driven by the predominantly negative wind stress curl (Godfrey et al., 2001; Miyama et al., 2003; Wang and McPhaden, 2017). It carries most of the crossequatorial transport of mass and heat (Schott and McCreary, 2001) and helps to moderate the seasonal climate of the region. The seasonal cross-equatorial mass flux is oppositely directed along the western boundary and in the interior (Beal et al., 2013). Flow in the interior is directed from the summer to the winter hemisphere (Horii et al., 2013; Wang and McPhaden, 2017) consistent with monsoon wind-forced Ekman and Sverdrup dynamics as proposed in the model study of Miyama et al. (2003). 
In OGCMs, the southward flow of the CEC was found to occur just below the surface, beneath a northward surface current (Wacogne and Pacanowski, 1996; Miyama et al., 2003). This "equatorial roll", also unique to the Indian Ocean, is only of order $100 \mathrm{~m}$ depth and so has little impact on the cross-equatorial heat transport of the CEC. Horii et al. (2013) and Wang and McPhaden (2017) presented the first observational evidence for the equatorial roll.

The spatial structure and time evolution of the crossequatorial circulation is difficult to depict due to its dependence on the fluctuating monsoon winds. Consequently, the flow patterns obtained from an Eulerian average as in Fig. 10 cannot capture the monsoon-dependent streamlines that a flow will follow at a given moment. Lagrangian methods based on ocean drifter velocities (Laurindo et al., 2017) and real and simulated surface drifter trajectories identify path lines that connect the monsoonal Indian Ocean, revealing three cross-equatorial gyre pathways that connect the Somali Current with the interior flow north and south of the Equator (Fig. 7 in l'Hegaret et al., 2018).

\subsubsection{Biogeochemical variability}

Much of the current understanding of biogeochemical variability in the equatorial zone of the Indian Ocean is based on satellite ocean colour observations and models, augmented by some additional, relatively sparse, in situ measurements. Seasonal climatologies of near-surface chlorophyll concentrations and primary production show a significant seasonality in equatorial waters that is clearly associated with monsoon forcing (Fig. 5, Wiggert et al., 2006; Strutton et al., 2015; Figs. 5 and 6 in Hood et al., 2017). In general, Chl $a$ concentrations and primary production increase northward from the Equator with the lowest concentrations $(<$ $\left.0.1 \mathrm{mg} \mathrm{m}^{-3}\right)$ and rates $\left(<800 \mathrm{mg} \mathrm{C} \mathrm{m}^{-2} \mathrm{~d}^{-1}\right)$ occurring during the boreal spring intermonsoon period. During the southwest monsoon, Chl $a$ concentrations and rates of primary production increase in western equatorial waters in response to monsoon-forced mixing and upwelling. However, concentrations and rates in the central and eastern equatorial waters stay relatively low $\left(<0.5 \mathrm{mg} \mathrm{m}^{-3},<800 \mathrm{mg} \mathrm{C} \mathrm{m}^{-2} \mathrm{~d}^{-1}\right.$, respectively). Island wake effects can be seen advecting high chlorophyll water $\left(>0.5 \mathrm{mg} \mathrm{m}^{-3}\right.$ ) along the Equator from the Chagos-Laccadive ridge at $73^{\circ} \mathrm{E}$ eastward during the autumn intermonsoon period and westward during spring (see Fig. 1 in Strutton et al., 2015).

Well-developed deep Chl $a$ maxima have been observed in the equatorial Indian Ocean along $65^{\circ} \mathrm{E}$ centred at about $50 \mathrm{~m}$ depth in November-December (George et al., 2013) and along $80^{\circ} \mathrm{E}$ centred at about $75 \mathrm{~m}$ in August-September (Sorokin et al., 1985). It is unknown whether or not this subsurface Chl $a$ maximum exists along the Equator throughout the year, but it is probably present whenever the water column is stratified. Models predict the presence of a subsurface $(60 \mathrm{~m}) \mathrm{Chl} a$ maximum in eastern Indian Ocean equato- rial waters along $87^{\circ} \mathrm{E}$ (Wiggert et al., 2006) that is present throughout the year except during the southwest monsoon when high-chlorophyll surface water is advected into the region.

Physical processes at timescales from intraseasonal to interannual (i.e. Wyrtki Jets, MJO and IOD) have been shown to influence biogeochemistry. For example, IOD events can significantly increase chlorophyll concentrations and primary production in eastern Indian Ocean equatorial waters (Wiggert et al., 2009). In addition, relaxation of an IOD can deplete upper-ocean nutrients, decreasing biological productivity (Kumar et al., 2012). Biogeochemical responses to the IOD also have significant higher trophic level impacts (Marsac and Le Blanc, 1999).

Satellite observations and biophysical model simulations show how chlorophyll concentrations and primary production near the Seychelles-Chagos thermocline ridge can be increased by MJO-induced wind mixing and nutrient entrainment (Resplandy et al., 2009). They also concluded that IODdriven interannual variability of thermocline depth influences the biogeochemical response to MJO: the deepened nutricline following IOD events inhibits nutrient input into the mixed layer and thus decreases the biogeochemical response to MJO.

In model simulations, Wyrtki jets depress the thermocline and nitracline along the Equator on the eastern side of the basin and, as a result, lower equatorial primary production when they arrive in the spring and autumn (Wiggert et al., 2006). This pattern was observed in a $25 \mathrm{~d}$ time series study on the Equator at $80.5^{\circ} \mathrm{E}$ in late 2006 that showed a deepening of the surface layer, nutricline, and subsurface Chl $a$ maximum during the autumn Wyrtki jet period (Kumar et al., 2012).

Finally, Strutton et al. (2015) examined time series measurements of near-surface chlorophyll concentration from a mooring deployed in 2010 at $80.5^{\circ} \mathrm{E}$ in the equatorial Indian Ocean. These data revealed at least six spikes in chlorophyll from October through December, separated by approximately 2-week intervals and coinciding with the development of the autumn Wyrtki jets. The chlorophyll pulses were associated with increases in eastward surface winds and eastward currents in the mixed layer and inconsistent with upwelling dynamics because eastward winds that cause intensification of the Wyrtki jet should drive downwelling. Strutton et al. (2015) concluded that the chlorophyll spikes could be explained by two alternative mechanisms: (1) turbulent entrainment of nutrients and/or chlorophyll from across the base of the mixed layer by wind stirring or Wyrtki jetinduced shear instability or (2) enhanced southward advection of high chlorophyll concentrations into the equatorial zone associated with wind-forced biweekly Yanai waves. 


\subsection{Northern Indian Ocean}

The two main basins of the northern Indian Ocean, the Bay of Bengal (BoB) and the Arabian Sea (AS), are characterized at the surface by remarkably contrasting sea surface salinity with differences on the order of 3 psu (e.g. Chatterjee et al., 2012; Gordon et al., 2016; Hormann et al., 2019) decreasing from west to east (Fig. 4). The fresh surface layer of the $\mathrm{BoB}$ is maintained by large freshwater input deriving from direct rainfall over the ocean and river runoff, especially during the South Asian monsoon. The salt balance of the BoB is maintained by the subsurface supply of salt water via the Southwest Monsoon Current (Fig. 10, Vinayachandran et al., 2013). The saltier SSS of the AS is the consequence of an evaporative regime (e.g. Rao and Sivakumar, 2003; Sengupta et al., 2006). A reversing monsoonal near-surface circulation (Fig. 10a, b) plays a central role in the exchanges of freshwater and heat between the BoB and the AS (McCreary et al., 1993; Hormann et al., 2019).

Recent multi-year deployments of satellite-tracked surface drifters drogued at $15 \mathrm{~m}$ depth (Wijesekera et al., 2016a; Centurioni, 2018) have helped to better constrain the amplitude and structure of the circulation and the exchange processes between the two basins and to refine the findings reported by other authors (e.g. Schott and McCreary, 2001). Additionally, implementation of a moored buoy network along the slope and shelf of the Indian coast has helped significantly in enhancing our understanding of the East Indian Coastal Current (EICC) and West Indian Coastal Current (WICC) (Fig. 10, Mukherjee et al., 2014; Amol et al., 2014; Mukhopadhyay et al., 2020; Chaudhuri et al., 2020).

\subsubsection{Bay of Bengal}

In a climatological sense, the main features of the nearsurface circulation of the western BoB (Fig. 10a and b) are the reversing EICC, the Southwest Monsoon Current (SMC, also known as the Summer Monsoon Current) and Northeast Monsoon Current (NMC) and the seasonally variable Sri Lanka Dome. The eastern side of the BoB, extending into the Andaman Sea, is characterized by a sluggish circulation.

\section{Southwest Monsoon Current and Northeast Monsoon Current}

During the boreal summer SW monsoon, the Southwest Monsoon Current (SMC, Fig. 10a) flows eastward around the Indian subcontinent, supplying salty water from the Arabian Sea to the fresher Bay of Bengal (e.g. Jensen, 2001; Jensen et al., 2016; Vinayachandran et al., 2013; Wijesekera et al., 2015, 2016c). During the winter monsoon, the Northeast Monsoon Current (NMC, Fig. 10b) reverses the flow, carrying fresher water into the Arabian Sea. Figure 13 provides a snapshot from an operational forecast system, the Coupled Ocean-Atmosphere Mesoscale Prediction System
(COAMPS), of the NMC flow and a route for fresh water to enter the Arabian Sea (Wijesekera et al., 2015).

A more recent study has found that the origins of the Arabian Sea high-salinity water are specifically from the western Arabian Sea and western Equatorial Indian Ocean, and they reach the Bay of Bengal via a combination of the Indian Ocean EUC and the SMC (Sanchez-Franks et al., 2019; Sect. 8.2). Changes in the supply of salty water to the Bay of Bengal varies interannually due to the strength in the equatorial currents forced by the local wind field and ENSO (Sanchez-Franks et al., 2019) and is expected to influence the salinity budget of the Bay of Bengal (Vinayachandran et al., 2013) and thus modulate SST variability (Fig. 10a, Jensen, 2001; Jensen et al., 2016; Li et al., 2017a; Vinayachandran et al., 2013, 2018; Webber et al., 2018).

\section{East Indian Coastal Current (EICC)}

The EICC forms the western boundary current of the Bay of Bengal and plays an important role in the basin-scale heat and salt budget of the Indian Ocean and hence in determining the local climate (Shenoi et al., 2002), biological processes (Madhupratap et al., 2003; Vinayachandran et al., 2005; Naqvi et al., 2006; Dileepkumar, 2006; McCreary et al., 2009), and marine fisheries (Vivekanandan and Krishnakumar, 2010) of this region. It reverses its direction seasonally north of $10^{\circ} \mathrm{N}$ in response to a combination of local alongshore winds, remote alongshore winds in the eastern $\mathrm{BoB}$, remote forcing from the equatorial Indian Ocean, and the interior Ekman pumping of the basin (Shankar et al., 1996; McCreary et al., 1996; Vinayachandran et al., 1996; Mukherjee et al., 2018). The EICC is generally equatorward south of $10^{\circ} \mathrm{N}$ throughout the year. While local winds dominate the EICC forcing during summer and winter, remote forcing dominates during the inter-monsoon periods (Shankar et al., 1996; McCreary et al., 1996; Suresh et al., 2013).

Climatological ship-drift and hydrographic data suggest the EICC flows poleward during February-September (Shetye et al., 1993) and turns equatorward during November-January (Shetye et al., 1996; Fig. 10). While the annual cycle is driven by local alongshore winds and interior Ekman pumping, the semiannual cycle is the result of asymmetry in the monsoon and equatorial forcing (Mukherjee et al., 2018). During boreal spring (March-May), the EICC is strongest with a magnitude exceeding $1 \mathrm{~m} \mathrm{~s}^{-1}$ with unidirectional currents to about $150 \mathrm{~m}$, forming the western boundary current of a cyclonic basin-wide gyre of the BoB. The local alongshore winds are weakest and the stronger EICC is primarily forced by the interior anticyclonic Ekman pumping over the basin (McCreary et al., 1996; Shankar et al., 1996; Vinayachandran et al., 1996; Mukherjee et al., 2018). During boreal summer, the EICC is weaker and is restricted to within the top $70 \mathrm{~m}$ of the water column. The poleward flow is generally limited to the central part of the coast between 

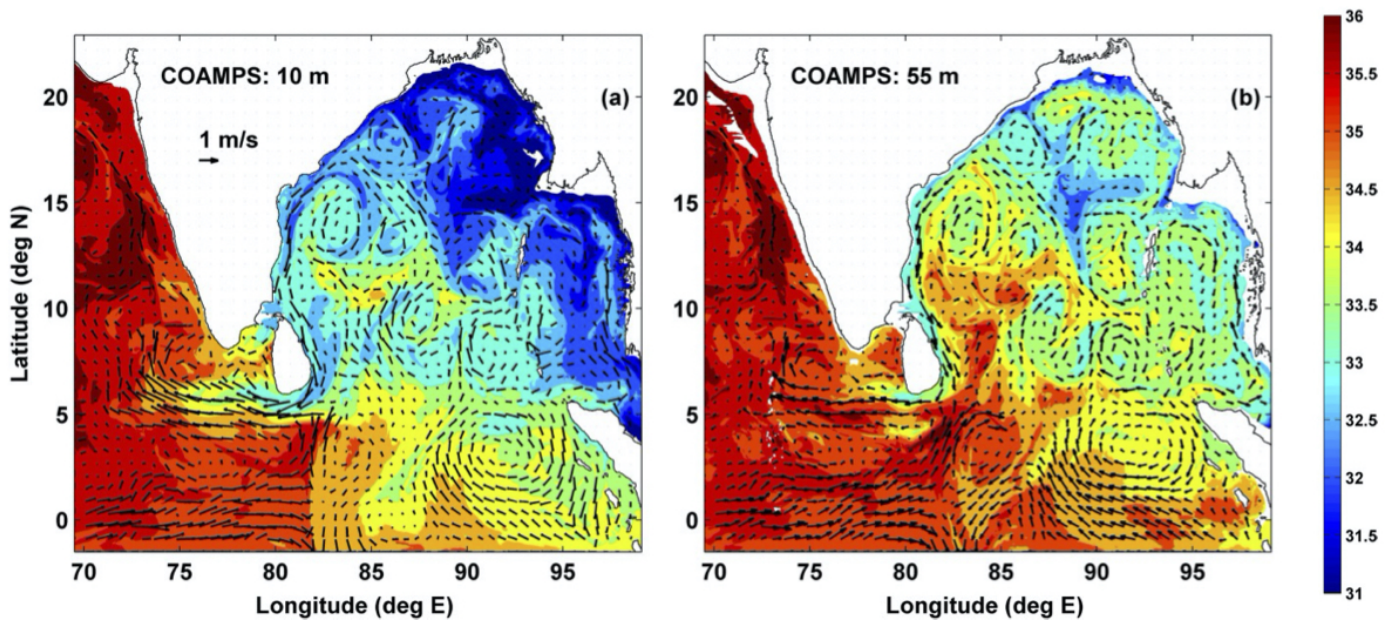

Figure 13. COAMPS velocity vectors (arrows) and salinity (psu, colour shading) at (a) $10 \mathrm{~m}$ and (b) $55 \mathrm{~m}$ on 18 December 2013 . Modified from Wijeskera et al. (2015).

$10-18^{\circ} \mathrm{N}$ and often switches to short pulses of poleward currents along the coast (Mukherjee et al., 2018; Francis et al., 2020). The poleward flow is driven by local winds, but the response of the interior cyclonic Ekman pumping and equatorial winds driving an opposite flow along the coast causes a weaker poleward EICC in summer than in spring (McCreary et al., 1996; Vinayachandran et al., 1996; Shankar et al., 2002). The basin-scale gyre also disappears in summer and the EICC then consists of several eddies along the coast. The EICC turns equatorward during November-January (Shetye et al., 1996).

Near-surface alongshore currents also display significant $120 \mathrm{~d}$ and intraseasonal variability. The magnitude of the $120 \mathrm{~d}$ variability is generally weaker than the semiannual period, particularly in the southern part of the coast. As for the annual period, upward phase propagation along the coast is also evident for the semiannual and $120 \mathrm{~d}$ period, except at Cuddalore where downward phase propagation is common during summer and winter months (Mukherjee et al., 2014; Mukhopadhyay et al., 2020). Further, unlike annual and semiannual periods, the $120 \mathrm{~d}$ and intraseasonal variability decorrelate along the coast, indicating that these high frequencies are dominated by local responses rather than remote forcing (Mukherjee et al., 2018; Mukhopadhyay et al., 2020).

\section{Undercurrents}

ADCP observations suggest that during summer and winter, when the near-surface current is shallow, the EICC often exhibits undercurrents along the continental slope. As the EICC is deeper in the north, the undercurrent is observed at a depth of 100-150 $\mathrm{m}$ and can extend up to $700 \mathrm{~m}$. However, in the south undercurrents are seen at relatively shallow depths of about 70-75 m (Francis et al., 2020). While these undercurrents are observed throughout the coast, they are much more prominent and more frequent at Cuddalore, the southernmost station on the coast (Fig. 14, Mukherjee et al., 2014; Mukhopadhyay et al., 2020).

The prominent upward phase propagation of the annual signal in the subsurface layers, particularly in the southern stations, suggests downward propagation of energy and is thereby attributed as one of the main causes of the undercurrents (Mukherjee et al., 2014). A recent modelling study suggests that the wintertime undercurrent off Cuddalore consists of two separate subsurface anticyclonic eddy circulations: a shallow small-scale circulation at a depth range of $100-200 \mathrm{~m}$ and a broader and deep flow below $500 \mathrm{~m}$ depth off the continental slope (Francis et al., 2020). The shallow subsurface anticyclonic eddy was found to spin off from the zonal shear of the mean near-surface EICC along the shelf break (Fig. 14). These eddies exhibit high-frequency fluctuations and have $20-30 \mathrm{~km}$ length scales. Since the zonal share of the EICC is primarily linked to the strength of the EICC itself, the variability and strength of this undercurrent is also linked with the EICC.

\section{Sri Lanka Dome}

The Sri Lanka Dome (SLD; Vinayachandran et al., 1999; Schott and McCreary, 2001; Wijesekera et al., 2016c; Cullen and Shroyer, 2019) is mainly visible as a closed anticyclonic (clockwise) eddy in the near-surface geostrophic current velocity field starting in May and lasting through October (Fig. 15c). It is a recurring upwelling dome that forms east of Sri Lanka at $5-10^{\circ} \mathrm{N}, 83-87^{\circ} \mathrm{E}$. The SLD is embedded within the Southwest Monsoon Current (SMC) system (Gadgil, 2003) and enhances the SMC exchange from the Arabian Sea to the Bay of Bengal (Anutaliya et al., 2017). Upwelling associated with the SLD influences the vertical exchange of water properties, enhances biological productiv- 
a) Surface

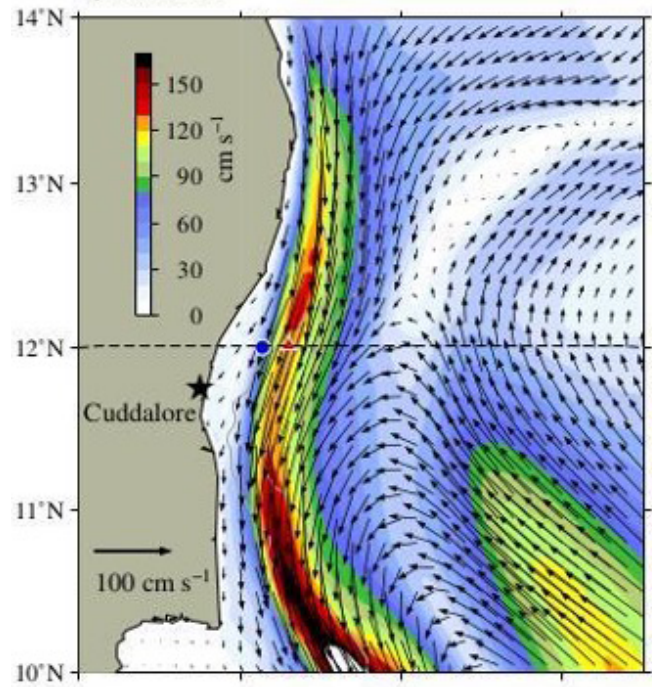

c) $1200 \mathrm{~m}$

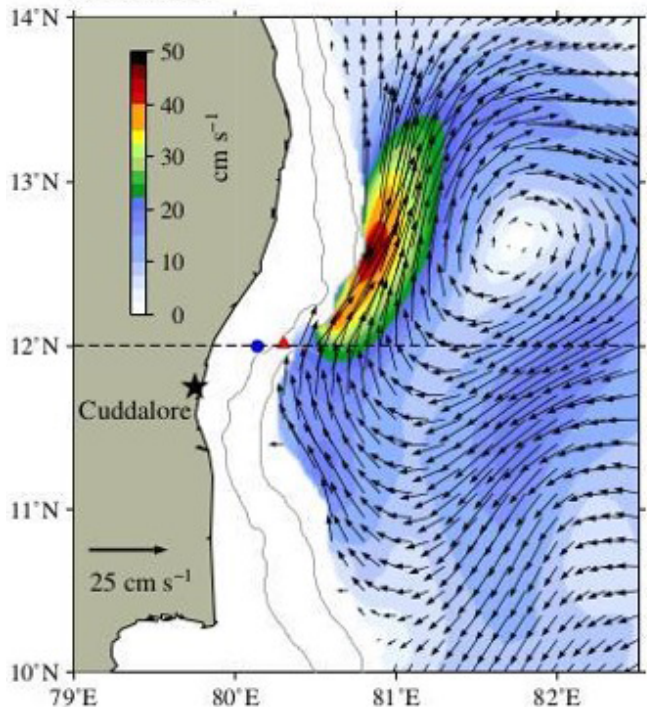

b) $200 \mathrm{~m}$

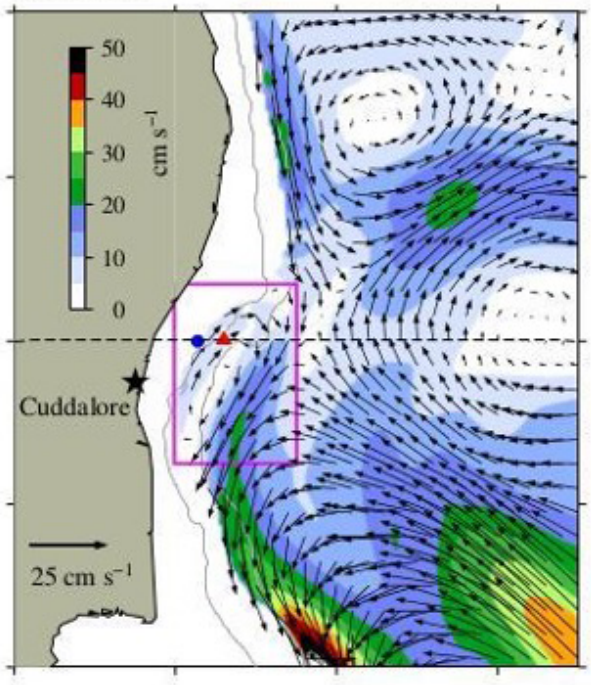

d) Cross-shore structure

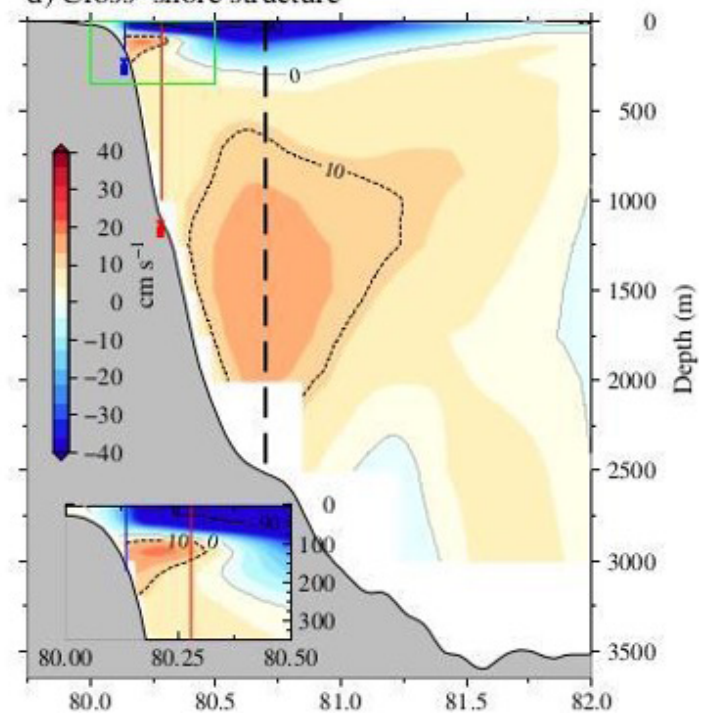

Figure 14. Circulation pattern in the southwestern Bay of Bengal at (a) surface, (b) $200 \mathrm{~m}$, and (c) $1200 \mathrm{~m}$ on 15 November 2014 . Vectors show the current direction, and overlaid is the current magnitude $\left(\mathrm{cm} \mathrm{s}^{-1}\right)$. Note that the scales of current vectors and colour bars are different for each subplot. The blue circle (red triangle) represents the location of ADCP deployed on the shelf (slope) off Cuddalore. The dashed black line represents the $12^{\circ} \mathrm{N}$ latitude. The continuous grey lines represent the 100 and $1000 \mathrm{~m}$ bathymetric contours. The rectangular box (magenta) indicates the subsurface eddy near the shelf break. (d) Cross-shore structure of alongshore currents across $12^{\circ} \mathrm{N}$. The dashed vertical black line shows the core of the undercurrent, and the red (blue) vertical lines show the location of ADCP mooring on the slope (shelf). The inset plot is the zoomed view of shelf break region indicated by a green box (reproduced from Francis et al., 2020).

ity, and cools sea surface temperature (SST), which affects local atmospheric convection (Vinayachandran et al., 2004; de Vos et al., 2014).

\subsubsection{Arabian Sea}

Like the BoB, AS near-surface circulation is also driven primarily by the seasonally reversing monsoon winds. The AS is connected to the BoB through the passage between the southern tip of India and the equatorial wave guide, and to the Southern Hemisphere by the cross equatorial flow via the Somali current system. The Somali current (Fig. 10) forms one of the western boundary currents of the AS. Another major boundary current system is along the western coast of India, the WICC (Fig. 10), which transports heat and salt from the northern Arabian Sea to the BoB, and vice-versa. Recent observations (Chatterjee et al., 2012) and modelling studies (Shankar et al., 2016; Vijith et al., 2016) indicate that the northern extent of the WICC reaches up to $20^{\circ} \mathrm{N}$ during 

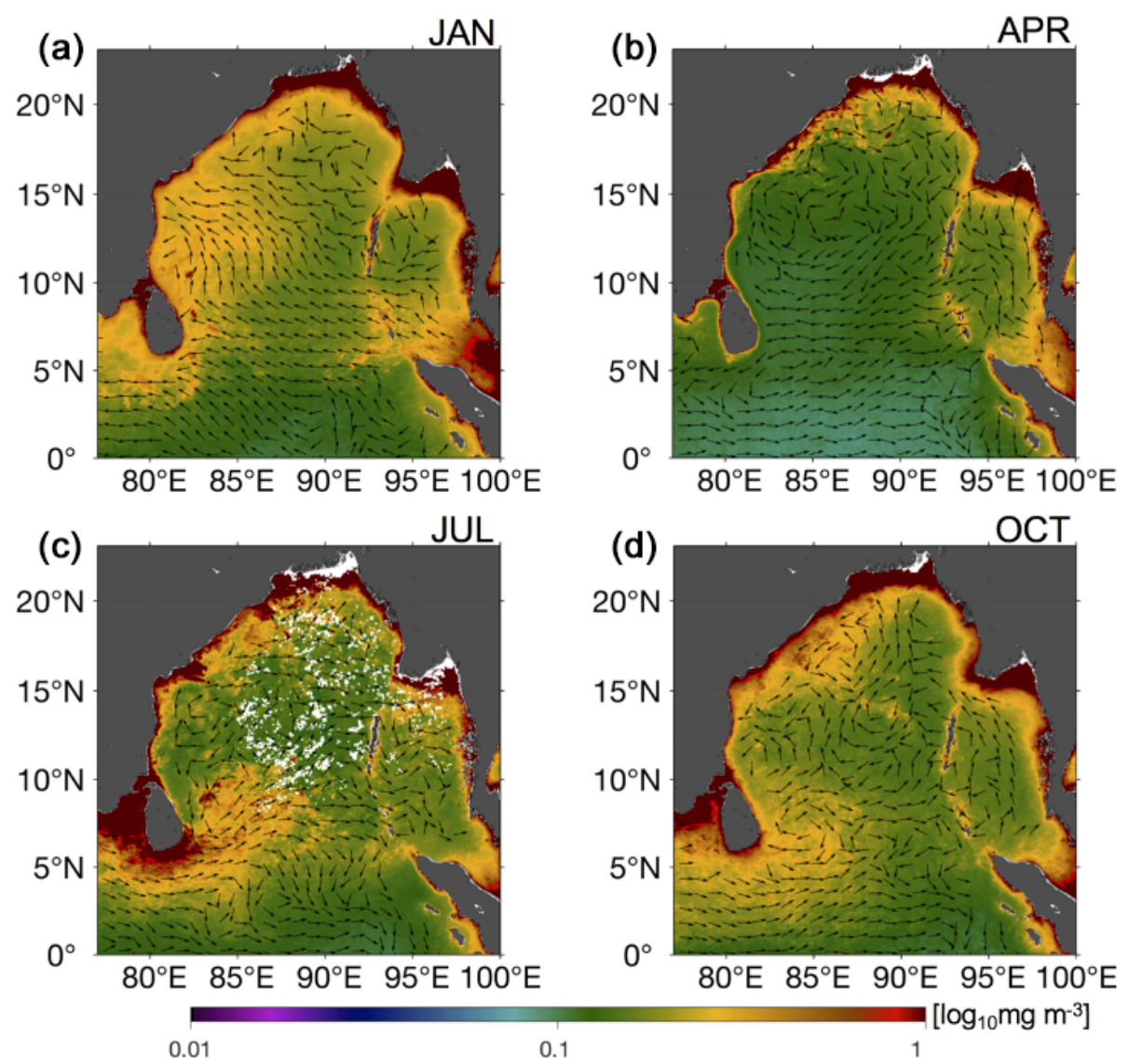

Figure 15. Climatology (2002-2018) of chlorophyll $a$ concentrations (colour map) and current velocities (arrows) in the Bay of Bengal for (a) January, (b) April, (c) July, and (d) October. Chlorophyll climatology was obtained from the MODIS-Aqua product, and current velocities were obtained from the third-degree Ocean Surface Current Analysis Real-time (OSCAR) product.

the winter monsoon, carrying fresher $\mathrm{BoB}$ water to the northern latitudes and modulating the wintertime convection there. In the last couple of decades, the strengthening of WICC and NMC has decreased the SSS in the eastern Arabian Sea (Varna et al., 2021).

\section{Somali Current system}

The Somali Current is a seasonally reversing western boundary current and is often composed of discontinuous nonlinear eddy-driven flows. During summer it flows poleward, and the upwelling here is nearly as large as for the eastern boundary upwelling regimes of the Pacific Ocean and Atlantic Ocean (see Schott and McCreary, 2001, for a detailed review). Unfortunately, owing to piracy, direct in situ observations are very rare in this region and mostly date back to the early 1960s and 1970s. Hence, the scientific community has mostly relied on numerical model simulations to enhance understanding of this region over the last few decades.

Recent modelling studies suggest that during the summer monsoon, unlike other western boundary currents, the Somali Current system can be divided into three dynami- cally distinctive regions (Wang et al., 2018; Chatterjee et al., 2019): northern (north of $\left.8^{\circ} \mathrm{N}\right)$, central $\left(3-8^{\circ} \mathrm{N}\right)$, and southern (south of $3^{\circ} \mathrm{N}$ ) parts. The northern and southern parts are driven by the large anticyclonic gyres called the Great Whirl (GW) and the southern Gyre (SG), respectively (Fig. 10a). Local southwesterly alongshore winds known as the Findlater Jet (Findlater, 1969) drives Ekman transport all along the Somali coast (Schott and McCreary, 2001) with varied magnitude that is strongest in the southern part and significantly weakens northward (Chatterjee et al., 2019). The wind stress forcing leads to Ekman pumping in the central Arabian Sea, setting up a bowl-shaped mixed layer and warming at the $100 \mathrm{~m}$ level. Ekman downwelling velocities are strongest in the northern part and likely contribute to the formation of the Great Whirl front, which upwells cold subsurface water in this part of the coast. The central part, in contrast, is mainly driven by the local winds and remotely forced Rossby waves. In fact, the annual Rossby waves radiated out of the southwestern coast of Sri Lanka seem to play a major role in the reversal of currents to poleward flow in the northern part of the Somali coast as early as mid-April. This reversal likely initiates the generation of the Great Whirl (Beal and Donohue, 
2013; Vic et al., 2014), a month before the strong northeastward Findlater Jet commences along the Somali coast. As the monsoon progresses, these downwelling favourable Rossby waves oppose the coastal Ekman upwelling and thereby start to weaken the upwelling all along the coast. Moreover, as the alongshore winds peak, this favours enhanced mixing at the bottom of the mixed layer, which deepens the thermocline further. This process is more conspicuous in the central part of the coast, where the depth of the $22^{\circ} \mathrm{C}$ isotherm deepens by about $30-40 \mathrm{~m}$ from June to August (Chatterjee et al., 2019). By this time, the upwelling becomes limited to the northern part of the coast along the Great Whirl front of the Somali region.

Climatological characteristics of the Somali Undercurrent (SUC) have been revealed by a new multi-decadal time series of temperature, salinity, and geostrophic velocity constructed from repeat XBT transects and Argo observations (Zang et al., 2021). They find that the SUC flows southeastward during the monsoon transition periods in boreal spring (AprilJune) and autumn (September-November), against the northeastward flow of the Somali Current. The depth of the SUC core is shallower during the spring transition $(\sim 500 \mathrm{dbar}$ in April) and has a maximum depth of $\sim 1200$ dbar in September. Core speeds are $2.5-4 \mathrm{~cm} \mathrm{~s}^{-1}$ in spring; in autumn the core speed strengthens from 0.2 to $10.6 \mathrm{~cm} \mathrm{~s}^{-1}$ from September to November and then disappears in December. Volume transport of the Somali Current and SUC (0-2000 dbar) has a maximum of $29.6 \mathrm{~Sv}$ northeastward in the summer monsoon and minimum of $13 \mathrm{~Sv}$ southwestward during the autumn transition when the SUC is strong.

\section{West India Coastal Current (WICC)}

The WICC reverses its direction annually, flowing equatorward (upwelling favourable) during the summer monsoon (May to September; Fig. 10a) and poleward (downwelling favourable) during the winter monsoon (November to February; Fig. 10b). The equatorward flow during the summer characterizes the WICC as a classical eastern boundary current (Shetye and Shenoi, 1988). Interestingly, as the monthly mean alongshore winds off the west coast of India are always equatorward throughout the year, the surface currents flow against the winds during the winter, driven by coastally trapped Kelvin waves forced remotely in the BoB and along the eastern coast of India (McCreary et al., 1993; Shankar and Shetye, 1997; Shankar et al., 2002; Suresh et al., 2016). Recent observations based on satellite data and alongshore ADCP moorings reveal strong interannual variability of this seasonal cycle. Vialard et al. (2009b), based on a short ADCP record during 2006-2008, reported an absence of seasonal cycle off Goa, and they attributed this absence to the radiation of Rossby waves south of the critical latitude. As the longer record of ADCP data became available, a clear seasonal cycle in the WICC became evident with weaker amplitudes in the south, stronger poleward (Amol et al., 2014).
The WICC also shows significant intraseasonal variability at times, particularly during boreal winter, exhibiting much stronger energy in the intraseasonal band than in the seasonal band (Vialard et al., 2009b; Amol et al., 2014). Unlike the seasonal cycle, intraseasonal variability is stronger in the south and weakens poleward. Vialard et al. (2009b) attributed this intraseasonal variability to the atmospheric MJO forcing. Recently, a modelling study suggested that interception of the intraseasonal equatorial Rossby waves by the southern tip of India and Sri Lanka excites coastal Kelvin waves that contribute significantly $(\sim 60 \%-70 \%)$ to the intraseasonal variability along the west coast (Suresh et al., 2013). A satellite sea level study by Dhage and Strub (2016) confirmed the model-based findings of Suresh et al. (2013) and revealed that large-scale winds from the south of India and Sri Lanka also contribute to the coastal signals along the west coast of India.

Another striking feature observed in these ADCP data is the clear signature of upward phase propagation in all timescales during both monsoon seasons. This upward phase propagation is more conspicuous for the seasonal period than for the intraseasonal. As a result, the phase of the surface currents often tends to be opposite that in the subsurface layers (Amol et al., 2014). Moreover, it is found that the strength of this undercurrent intensifies northward along the west coast with strongest undercurrent off Mumbai and the weakest off Kanyakumari (southernmost point of Indian mainland), indicating a possible downward propagation of energy along the ray path as suggested earlier by Nethery and Shankar (2007). Since the ray angle $(\theta)$ depends on the frequency $(\sigma)$ and stratification $\left(N_{\mathrm{b}}\right)$ according to $\theta=\sigma / N_{\mathrm{b}}$ (McCreary, 1984; Nethery and Shankar, 2007), the angle the beam makes from the horizontal is deeper for the intraseasonal band than for the seasonal. As a result, intraseasonal beams propagate energy deeper into the water column. Therefore, while the WICC shows some coherence along the coast in the seasonal timescale, it completely decorrelates horizontally for the intraseasonal period.

\subsubsection{Biogeochemical variability}

In the Bay of Bengal, the large freshwater input gives rise to enhanced stratification that inhibits upwelling and wind mixing and therefore nutrient supply to surface waters (Kumar et al., 2002; Vinayachandran et al., 2002; Madhupratap et al., 2003; Vinayachandran, 2009). Nonetheless, increased productivity is observed along the coast primarily in association with riverine nutrient inputs (Vinayachandran, 2009). These nutrients stimulate diatom blooms (Sasamal et al., 2005), leading to significant increases in Chl $a$ concentration $(\sim 30$

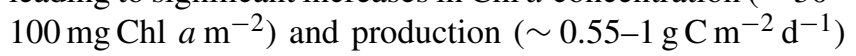
near the coast (Gomes et al., 2000; Fig. 15). This high-Chl $a$ river water flows either along the coast or offshore, up to several hundred kilometres, depending on the coastal current pattern (Vinayachandran, 2009). Along the Indian coast, the 
flow of Chl $a$-rich water is determined by the EICC, which flows northward during the spring intermonsoon period and southwest monsoon and southward during the autumn intermonsoon and northeast monsoon (Fig. 15). When the EICC meanders seaward from the Indian coast, it leads to offshore increases in high-chlorophyll water. During the spring intermonsoon and southwest monsoon the northward-flowing EICC is upwelling favourable, which may contribute to increases in Chl $a$ concentration and primary production along the coast (Hood et al., 2017).

Elevated productivity is observed further offshore in the southwestern Bay of Bengal during the northeast monsoon (Vinayachandran and Mathew, 2003; Vinayachandran, 2009). Modelling studies suggest that this is caused by winddriven entrainment of not only subsurface nutrients but also phytoplankton from the subsurface $\mathrm{Chl} a$ maximum that is present during the autumn intermonsoon period (Vinayachandran et al., 2005). In contrast, productivity near the coast is suppressed during the northeast monsoon when the EICC flows southward (Fig. 14). Presumably, this is due to a combination of the downwelling-favourable currents and winds. However, primary production over the shelf in the northern part of the bay increases during the northeast monsoon (Gomes et al., 2000; Fig. 15), possibly due to river nutrient inputs (Vinayachandran, 2009), wind stress, and buoyancy-driven nutrient entrainment as is observed in the northern Arabian Sea during the northeast monsoon (Wiggert et al., 2000, 2005; Hood et al., 2017).

Subsurface Chl a maxima are observed in the Bay of Bengal during all seasons whenever and wherever wind forcing and/or currents are insufficiently strong to upwell or entrain them into the surface layer (Sarma and Aswanikumar, 1991; Murty et al., 2000; Sarojini and Sarma, 2001; Kumar et al., 2007). During the intermonsoon periods the Bay of Bengal transitions to more oligotrophic conditions with relatively low surface chlorophyll concentrations $\left(<0.6 \mathrm{mg} \mathrm{m}^{-3}\right.$; Fig. 15) and production rates $(<$ $700 \mathrm{mg} \mathrm{C} \mathrm{m}^{-2} \mathrm{~d}^{-1}$; see Fig. 6 in Hood et al., 2017). Trichodesmium erythraeum blooms have been observed during the intermonsoon periods, along with high abundances of Synechococcus and heterotrophic dinoflagellates (Sarojini and Sarma, 2001; Jyothibabu et al., 2008). In offshore waters, subsurface chlorophyll maxima are generally located between 40 and $70 \mathrm{~m}$ in autumn and 60 and $90 \mathrm{~m}$ in spring (Kumar et al., 2007). These deep Chl $a$ maxima tend to shoal near the coast (Sarma and Aswanikumar, 1991; Murty et al., 2000) and their depth and chlorophyll concentrations are strongly influenced by eddies (Kumar et al., 2007).

Strong upwelling also occurs along the southern coast of Sri Lanka during the southwest monsoon (Vinayachandran et al., 2004, 2009; de Vos et al., 2014). Satellite SST and chlorophyll images reveal dramatic eastward advection of cool $\left(<28^{\circ} \mathrm{C}\right)$ chlorophyll-rich upwelled water by the SMC (Vinayachandran et al., 2004, 2009; de Vos et al., 2014). Chlorophyll-rich waters from the southwest- ern coast of India are also advected by the SMC towards Sri Lanka during the southwest monsoon (Vinayachandran et al., 2004, 2009; Strutton et al., 2015). Surface chlorophyll concentrations and rates of primary production along the southern coast of Sri Lanka during the southwest monsoon can exceed $10 \mathrm{mg} \mathrm{Chl} a \mathrm{~m}^{-3}$ (de Vos et al., 2014) and $1000 \mathrm{mg} \mathrm{C} \mathrm{m}^{-2} \mathrm{~d}^{-1}$ (Fig. 6 in Hood et al., 2017), respectively, compared to much lower concentrations and rates during the northeast monsoon when the NMC flows westward (de Vos et al., 2014; Hood et al., 2017). Vinayachandran et al. $(2004,2009)$ attribute the productivity response during the southwest monsoon to nutrient enrichment from coastal upwelling driven by monsoon winds. Presumably, these high chlorophyll concentrations and production rates are associated with diatom blooms. This elevated productivity extends to the east of Sri Lanka during the peak of the southwest monsoon (Vinayachandran et al., 1999; Vinayachandran et al., 2004, 2009). This eastward extension into the southern Bay of Bengal occurs along the path of the SMC (Vinayachandran et al., 1999) and is associated with upward Ekman pumping east of Sri Lanka. This Ekman pumping also leads to the formation of the aforementioned Sri Lanka Dome (Vinayachandran and Yamagata, 1998).

The western side of the northern Indian Ocean transitions during the southwest monsoon to a eutrophic coastal upwelling system in response to the upwelling-favourable winds and currents (Wiggert et al., 2005; Hood et al., 2017, and references cited therein; Fig. 5; Figs. 5 and 6 in Hood et al., 2017; Lakshmi et al., 2020). These changes can be seen in ocean colour data as substantial increases in Chl $a$ concentrations along the coasts of Somalia, Yemen, and Oman (e.g. Brock and McClain, 1992; Banse and English, 2000; Kumar et al., 2000; Lierheimer and Banse, 2002; Wiggert et al., 2005; George et al., 2013; Hood et al., 2017). Chlorophyll $a$ concentrations in the western Arabian Sea can exceed $40 \mathrm{mg} \mathrm{Chl} a \mathrm{~m}^{-2}$ during the southwest monsoon with production rates $>2.5 \mathrm{~g} \mathrm{C} \mathrm{m}^{-2} \mathrm{~d}^{-1}$ (Marra et al., 1998; Fig. 6 in Hood et al., 2017). However, the environmental conditions vary significantly between the eutrophic coastal zones to the west and the oligotrophic open ocean waters offshore that are influenced by wind-curl-induced downwelling to the southwest of the Findlater Jet (Lee et al., 2000; Lakshmi et al., 2020). The surface nitrate and Chl $a$ concentrations decline dramatically from $>10$ to $<0.02 \mu \mathrm{M}$ and from $>1.0$ to $<0.2 \mathrm{mgChl} a \mathrm{~m}^{-3}$, respectively, from the west coast to open ocean in the Arabian Sea (Brown et al., 1999; Wiggert et al., 2005; Hood et al., 2017). In general, the phytoplankton community structure transitions to larger cells (diatoms) during the southwest monsoon in the western Arabian Sea (Brown et al., 1999; Tarran et al., 1999; Shalapyonok et al., 2001; Lakshmi et al., 2020). However, small primary producers remain important, even in areas strongly influenced by coastal upwelling (Brown et al., 1999; Lakshmi et al., 2020). In contrast, during the oligotrophic spring and autumn intermonsoon periods, surface waters in the western Arabian Sea 
are dominated by picoplankton (Garrison et al., 2000). Subsurface Chl $a$ maxima are observed between 40 and $140 \mathrm{~m}$ in the central southeastern Arabian Sea during all seasons (Gundersen et al., 1998; Goericke et al., 2000; Ravichandran et al., 2012) at times occurring in layers below the oxyclines of the oxygen minimum zone (Goericke et al., 2000). These features are strongly influenced by mesoscale features (Gundersen et al., 1998).

During the southwest monsoon off Oman and Somalia, the presence of the topographically locked eddies generate strong offshore flows that advect high-nutrient waters, highChl $a$ concentrations, and coastal phytoplankton communities hundreds of kilometres offshore (Keen et al., 1997; Latasa and Bidigare, 1998; Manghnani et al., 1998; Gundersen et al., 1998; Hitchcock et al., 2000; Lee et al., 2000; Kim et al., 2001). These advective effects can be seen, for example, in association with the Great Whirl off the coast of northern Somalia (Hitchcock et al., 2000) and in the filaments that develop off the Arabian Peninsula during the southwest monsoon (Wiggert et al., 2005; Hood et al., 2017). In contrast, during the northeast monsoon, the circulation and winds transition to being favourable to downwelling. During the northeast monsoon, cold, dry northeasterly winds from southern China and the Tibetan Plateau flow across the northern Arabian Sea. The shear from these winds, combined with surface cooling and buoyancy-driven convection, drive mixing and entrainment of nutrients that, in turn, promote modest increases in chlorophyll and primary production over the northern Arabian Sea (Wiggert et al., 2000, 2005; Fig. 5; Figs. 5 and 6 in Hood et al., 2017). These increases in Chl $a$ have been associated with increased diatom abundance (Banse and McClain, 1986; Sawant and Madhupratap, 1996). In the last decade, however, there appears to have been a shift in the composition of winter phytoplankton blooms in the northern and central Arabian Sea from diatom dominance to blooms of a large, green mixotrophic dinoflagellate, i.e. Noctiluca scintillans (Gomes et al., 2014; Goes et al., 2020).

During the southwest monsoon, the upwelling-favourable WICC induces upwelling along the western coast of India, which increases Chl $a$ concentrations by more than $70 \%$ compared to the central Arabian Sea (Kumar et al., 2000; Naqvi et al., 2000; Luis and Kawamura, 2004; Hood et al., 2017). The increased Chl $a$ concentrations near the coast are associated with increases in diatom abundance (Sawant and Madhupratap, 1996). However, these increases in Chl $a$ and their offshore extent are modest compared to the western Arabian Sea (Fig. 5; Fig. 5 in Hood et al., 2017). In contrast, during the northeast monsoon the WICC is favourable to downwelling and tends to suppress primary production off the southwestern coast of India. The depletion of nutrients in this region during the northeast monsoon coincides with blooms of Trichodesmium and dinoflagellate species (Parab et al., 2006; Matondkar et al., 2007), resulting in the extremely high rates of nitrogen fixation (Gandhi et al., 2011; Kumar et al., 2017). However, as discussed above, further north and offshore, nutrient entrainment enhances phytoplankton biomass and primary production during the northeast monsoon (Wiggert et al., 2000; McCreary et al., 2001; Luis and Kawamura, 2004; Gomes et al., 2014; Goes et al., 2020; Fig. 5). Near-surface Chl $a$ and primary production off the western coast of India (estimated from satellite ocean colour measurements) increases from $\sim 9$ to $24 \mathrm{mg} \mathrm{Chl} a \mathrm{~m}^{-2}$ and from $\sim 1$ to $2.25 \mathrm{~g} \mathrm{C} \mathrm{m}^{-2} \mathrm{~d}^{-1}$, respectively, from winter to the summer monsoon (Luis and Kawamura, 2004; Fig. 5; Figs. 5 and 6 in Hood et al., 2017). The elevated productivity during the southwest monsoon is modulated by the coastal Kelvin waves that originate from the Bay of Bengal and propagate along the West Indian Shelf, modifying circulation patterns and upwelling (Luis and Kawamura, 2004).

\section{Inter-ocean exchange}

\subsection{Indonesian Throughflow}

\subsubsection{General features}

The Indonesian Throughflow (ITF) transfers low-salinity tropical waters from the Pacific to the Indian Ocean via the Indonesian seas (Fig. 10). The ITF is the only tropical oceanic pathway that links ocean basins and plays an important role in the global ocean circulation and climate system (Sprintall et al., 2014, 2019). The simultaneous measurements in the exit channels of the ITF from the International Nusantara Stratification and Transport (INSTANT) programme during 2004-2006 (Gordon et al., 2008; Sprintall et al., 2009) suggested that the ITF has a mean transport of $15 \mathrm{~Sv}$ into the Indian Ocean. The ITF pathway is composed of many narrow channels within the Indonesian seas, among which about $80 \%$ of the total ITF is through the Makassar Strait (Fig. 10, Gordon et al., 2008, 2010). The remaining passages include the Maluku Sea, Lifamatola Passage, Karimata Strait, and Sibutu Passage (Fang et al., 2010; Gordon et al., 2012; Susanto et al., 2013).

\subsubsection{Variability, dynamics, and influence}

The interannual variability of the ITF is mainly dictated by the ENSO-related wind forcing through the Pacific waveguide with stronger transport during La Niña years (Meyers, 1996; England and Huang, 2005; Wijffels et al., 2008; Hu and Sprintall, 2016), but the IOD occasionally offsets the Pacific ENSO influences through the Indian Ocean wind variability and Indian Ocean waveguide (Sprintall and Révelard, 2014; Liu et al., 2015; Feng et al., 2018). For the strong negative IOD event in 2016, the Indian Ocean influence overwhelmed that of the Pacific, leading to record low ITF volume transports because of the reduction in the interbasin pressure gradient (Pujiana et al., 2019). Strong wind forcing over the equatorial Indian Ocean triggers equatorial 
Kelvin waves and influences the ITF variability on intraseasonal, semi-annual, and interannual timescales (Drushka et al., 2010; Pujiana et al., 2013; Shinoda et al., 2012). Kelvin waves through the Indian Ocean waveguide are suggested to influence the interannual variability in the tropical Pacific Ocean (Yuan et al., 2013; Pujiana and McPhaden, 2020).

The ENSO cycle also influences the outflowing ITF transport through the salinity effect in the downstream buoyant pool, contributing about $36 \%$ of the total ITF interannual transport variation (Hu and Sprintall, 2016; Sect. 6.1). Fresh anomalies in the buoyant pool during La Niña years can be as large as 0.2 in practical salinity averaged over the upper $180 \mathrm{~m}$ of the water column (Phillips et al., 2005). Such salinity anomalies can strengthen the volume transport of the LC through an increase in the zonal density gradient driving stronger southward flow (Feng et al., 2015a). The Inter-decadal Pacific Oscillation/Pacific Decadal Oscillation (IPO/PDO), through modulations of decadal wind stress in the tropical Pacific, have also directly influenced the strength of the ITF (Feng et al., 2011; Hu et al., 2015; Mayer et al., 2018). This has in turn influenced heat and freshwater transports, causing upper-ocean heat content to increase in the southern Indian Ocean (Feng et al., 2010; Schwarzkopf and Böning, 2011; Nidheesh et al., 2013; Sprintall et al., 2014; Lee et al., 2015; Nieves et al., 2015; Du et al., 2015; Ummenhofer et al., 2017) and produced interhemispheric contrasts in sea surface temperature (Dong and McPhaden, 2016). During the negative IPO phase, such as during the hiatus in warming of the globally averaged surface atmosphere (19982012), enhanced trade winds in the Pacific strengthened the ITF volume and heat transport into the Indian Ocean, driving a rapid warming trend in the southern Indian Ocean (England et al., 2014; Nieves et al., 2015; Lee et al., 2015; Liu et al., 2015; Y. Zhang et al., 2018). Contributions from air-sea exchanges (Jin et al., 2018a, b) have also been suggested to be important, as has a reduction in the oceanic heat exported from the Indian Ocean at its southern boundary (Lisa Beal, personal communication, 2021).

Using a combination of theory, ocean reanalyses, OGCM simulations, and coupled climate model simulations, Jin et al. (2018a, b) found eastern and western Indian Ocean heat content to be affected by remote Pacific forcing through two distinct mechanisms: oceanic influences transmitted through the ITF and the atmospheric bridge. The intensified freshwater input within the Maritime Continent during the past decade was found to strengthen the ITF and its heat and freshwater transports into the Indian Ocean, causing significant warming and freshening trends and accelerated sea-level rise in the eastern Indian Ocean (Hu and Sprintall, 2017a, b; Y. Zhang et al., 2018; Jyoti et al., 2019). The decadal enhancement of the ITF transport has increased upper-ocean heat content anomalies in the southeastern Indian Ocean and increased the likelihood of marine heatwaves off the western coast of Australia (Feng et al., 2015b; Sect. 6.4).

\subsection{Agulhas leakage}

\subsubsection{General features}

At the tip of Africa, the southward-flowing Agulhas Current retroflects, with most of the flow heading eastwards along the northern edge of the ACC, recirculating back into the Indian Ocean (Fig. 10, Sect. 4.2.2). Around 20\%-30\% of the Agulhas Current enters the Atlantic Ocean as Agulhas leakage in the form of Agulhas rings and cyclones (van Sebille et al., 2010a). Agulhas leakage estimates are sensitive to the definition used to calculate the leakage, ranging between roughly 10 and $20 \mathrm{~Sv}$ (van Sebille et al., 2010b; Beron-Vera et al., 2013; Cheng et al., 2016; Holton et al., 2017). Le Bars et al. (2014) proposed an algorithm to measure Agulhas leakage anomalies using absolute dynamic topography data from satellites.

The division of flow between Agulhas leakage and Agulhas retroflection can be influenced by the upstream Agulhas Current. In a Lagrangian particle-tracking experiment, van Sebille et al. (2009) found that a weaker Agulhas Current, detaching farther downstream and generating anticyclonic vorticity, potentially leads to more Agulhas leakage and larger Indian-Atlantic inter-ocean exchange. However, eddy-resolving model results suggest that as model resolution increases, the sensitivity of the leakage to Agulhas Current transport anomalies is reduced (Loveday et al., 2014). In addition, the ITF potentially influences the Agulhas leakage (Le Bars et al., 2013) as model outputs suggest that the Indian Ocean contributes $12.6 \mathrm{~Sv}$ to the Agulhas leakage, half of which is from the ITF (Durgadoo et al., 2017).

\subsubsection{Variability, dynamics, and influence on climate}

The magnitude of the Agulhas leakage is controlled by wind forcing, including the trade winds and the Southern Hemisphere westerlies (e.g. Durgadoo et al., 2013). The poleward shift in the Southern Hemisphere westerlies associated with anthropogenic forcing induced a clear increase in the Agulhas leakage during 1995-2004, as shown in numerical simulations (Biastoch et al., 2009; Biastoch and Böning, 2013). Increased wind stress curl in the South Indian Ocean associated with the southward shift of westerlies led to significant warming in the Agulhas Current system since the 1980s (Rouault et al., 2009); however, further work showed that this is due to an increase in eddies leading to a broadening of the current as opposed to intensification (Beal and Elipot, 2016). Given the non-linear nature of Agulhas leakage, the difficulty of observing it, and ocean model biases in the region, quantifying Agulhas leakage is very challenging (Holton et al., 2017). At seasonal timescales, the Agulhas leakage variability is controlled by eddies; however, recent studies have shown that eddies might not contribute as significantly to leakage as was thought and that the non-eddy leakage transport is likely to be constrained by large-scale 
forcing at longer timescales (e.g. Y. Cheng et al., 2018). A recent study shows that the subsurface signal from the ENSO cycle influences the Agulhas leakage through Rossby waves with a time lag of 2 years (Paris et al., 2018).

The Agulhas leakage carries warm and saline water from the Indo-Pacific Ocean into the Atlantic Ocean. The Agulhas leakage has been suggested to influence the Atlantic Meridional Overturning Circulation strength (AMOC; Beal et al., 2011; Weijer and van Sebille, 2014; Biastoch et al., 2015) and modify the AMOC convective stability (e.g. Haarsma et al., 2011; Caley et al., 2012; Castellanos et al., 2017). It is suggested that the increases in the Agulhas leakage due to anthropogenic warming during the past decades would act to strengthen the Atlantic overturning circulation (e.g. Beal et al., 2011).

The Agulhas leakage is an important source of decadal variability in the AMOC through Rossby waves (Biastoch et al., 2008, 2015). Source waters from the Agulhas Current take more than 4 years and mostly 1 to 4 decades to arrive in the North Atlantic Ocean (van Sebille et al., 2011; Rühs et al., 2013). The increased Agulhas leakage during 1995-2004 has contributed to the salinification of the South Atlantic thermocline waters (Biastoch et al., 2009). Hindcast experiments suggest that the Agulhas leakage increased by about $45 \%$ during the 1960s-2000s, leading to the observed warming trend in the upper tropical Atlantic Ocean (Lübbecke et al., 2015).

\subsection{Supergyre connection to the South Pacific}

The extreme strong westerly wind stress in the Southern Hemisphere gives rise to a wide and energetic subtropical supergyre (Fig. 16), the Southern Hemisphere supergyre, that connects three ocean basins (e.g. Ridgway and Dunn, 2007; Speich et al., 2007; Lambert et al., 2016; Maes et al., 2018; Cessi, 2019). Although the near-surface circulation is eastward across the southern Indian Ocean, there are subsurface westward flows beneath (Sect. 4.2.3; Schott and McCreary, 2001; Domingues et al., 2007; Furue et al., 2017), and the depth-integrated circulation reveals the westward return flow of the equatorward side of the Indian Ocean's anticlockwise subtropical gyre. In Fig. 16, the southern side of the Indian Ocean subtropical gyre extends eastward south of Australia to connect with the western Pacific subtropical gyre. The return flow is accomplished via a pathway that includes the East Australian Current, the South Pacific's western boundary flow; the Tasman Leakage, a westward flow south of Tasmania that carries Pacific Ocean water back to the Indian Ocean (distinct from the Flinders Current that hugs the continental slope, Duran et al., 2020; Sect. 4.2.4); and northwestward flow in the eastern Indian Ocean to close the circulation. The ITF and Leeuwin Current are also part of the supergyre, connecting the Indian and Pacific Oceans through the Indonesian seas (e.g. Ridgway and Dunn, 2007).

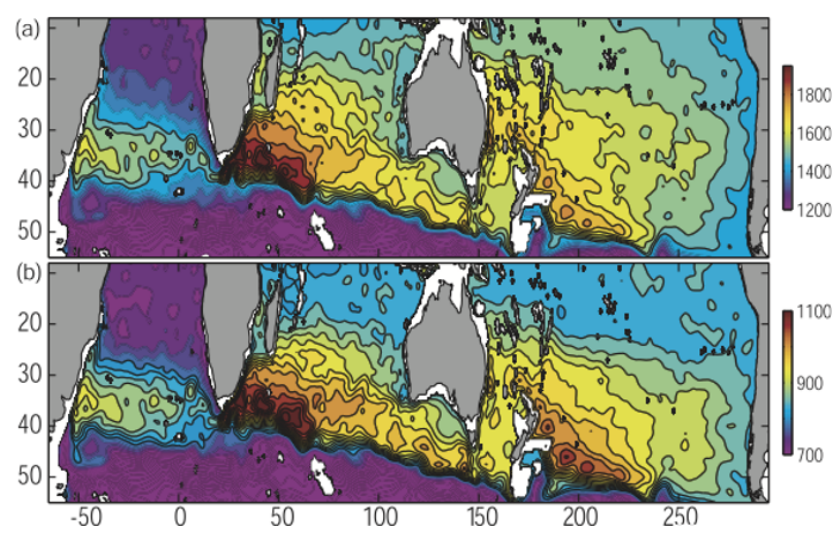

Figure 16. The interbasin supergyre system for the Pacific Ocean and Indian Ocean as shown by the depth-integrated steric heights (a) $P_{0 / 2000}$ and (b) $P_{400 / 2000}$ derived from the CARS climatological temperature and salinity fields. The contour interval in (a) is $50 \mathrm{~m}^{2}$, and it is $25 \mathrm{~m}^{2}$ in (b). Taken from Ridgway and Dunn (2007).

The supergyre is the subtropical gyre of the Southern Hemisphere. As such, its flow is primarily determined by the westward integration of wind stress curl from the eastern boundaries as determined by Sverdrup dynamics. The latitudinal position of the subtropical front at the southern edge of the supergyre is found to be controlled by strong bottom pressure torque due to the interaction between the ACC and the ocean floor topography (De Boer et al., 2013). According to one analysis in SODA (Simple Ocean Data Reanalysis), the water masses in the supergyre became cooler and fresher and shifted southward by about $2.5^{\circ}$ due to changes in the basin-scale wind forcing during 1958-2007 (Duan et al., 2013). A recent study using altimeter observations shows a clear strengthening of the Southern Hemisphere supergyre in all three oceans since 1993, as indicated in the large trends of sea surface height and their contrast. Argo observations and ECCO assimilations suggest that the strengthening extends to deeper than $2000 \mathrm{~m}$ (Qu et al., 2019). The spin-up of the Southern Hemisphere supergyre is attributed to the poleward shift and strengthening of westerly winds that are linked to an increasingly positive southern annular mode $(\mathrm{Qu}$ et al., 2019).

\subsection{Roles of salinity in inter-ocean exchange}

Ocean salinity is one of the basic variables that determines oceanic stratification, sea level change, and climate change (e.g. Llovel and Lee, 2015; Kido and Tozuka, 2017; Sprintall et al., 2019). However, the role of salinity in ocean circulation has been largely underestimated until the last decade, when in situ observations of subsurface and surface salinity from Argo and satellite salinity missions became available. These new observations have revolutionized our understanding of the influence of salinity on ocean circulation and dynamics (Vinogradova et al., 2019, and references therein). 
Four major processes control the salinity in the Indian Ocean: net air-sea fluxes (evaporation minus precipitation, Fig. 4), freshwater inflow from large rivers in the Bay of Bengal, inflow of relatively fresh waters from the Pacific Ocean via the Indonesian Throughflow, and inflow of saltier waters from the Red Sea and the Persian (or Arabian) Gulf. These different drivers combine to give the Indian Ocean salinity its unique flavour: a strong east-west gradient in the northern Indian Ocean (salty in the Arabian Sea and fresh in the Bay of Bengal) and strong north-south gradients in the southern Indian Ocean (fresh in the tropics, and salty in the subtropics) (Fig. 4, contours).

Salinity is a crucial variable to understand Indian Ocean dynamics. For instance, salinity has strong ties with the Indian Ocean Dipole (e.g. Du et al., 2015; Durand et al., 2013; Grunseich et al., 2011; Kido and Tozuka, 2017; Nyadjro and Subrahmanyam, 2014; Zhang et al., 2016; Sect. 6.2), the EGC (Menezes et al., 2013; Sect. 4.2.3), LC transport, the Ningaloo Niño and marine heatwaves off Western Australia (e.g. Feng et al., 2015a), and the El Niño-La Niña climate mode (e.g. Hu and Sprintall, 2016; Zhang et al., 2016). Salinity plays an essential role in the dynamics of the seasonal Wyrtki Jets in the equatorial zone (e.g. Masson et al., 2003), extra-equatorial Rossby waves (Heffner et al., 2008; Menezes et al., 2014b; Vargas-Hernandez et al., 2015; Banks et al., 2016), the Madden-Julian Oscillation and the Intraseasonal Oscillation (e.g. Grunseinch et al., 2011; Guan et al., 2014; Subrahmanyam et al., 2018), barrier-layer dynamics (e.g. Drushka et al., 2014; Felton et al., 2014), and the North Indian Ocean (e.g. D'Addezio et al., 2015; Fournier et al., 2017; Mahadevan et al., 2016b; Nyadjro et al., 2011, 2012, 2013; Wilson and Riser, 2016; Jaeger and Mahadevan, 2018).

Salinity variability within the Indonesian Seas has been shown to control the transport of the ITF. Andersson and Stigebrandt (2005) proposed that a downstream buoyancy pool in the outflowing ITF region acts to regulate the ITF transport. Gordon et al. $(2003,2012)$ pointed out that lowsalinity surface water from the South China Sea is drawn into the Java Sea. Combined with the monsoonal precipitation over the Maritime Continent and seasonal monsoon winds, this freshwater plug contributes to the seasonal fluctuation of the Makassar Strait Throughflow transport and inhibits the inflow of tropical Pacific surface water from the Mindanao Current (e.g. Gordon et al., 2012; Lee et al., 2019). Recently, $\mathrm{Hu}$ and Sprintall (2016) found that about $36 \%$ of the interannual ITF transport is attributable to the salinity effect associated with freshwater input anomalies due to the ENSO cycle. Jyoti et al. (2019) further examined this salinity effect and found that the unprecedented sea-level rise in the southern Indian Ocean since the beginning of the 21 st century is attributed to the accelerated heat and freshwater intrusion by the ITF. A significant strengthening of the ITF transport in the 2000s has given rise to a subsequent warming and freshening of the eastern Indian Ocean (e.g. Hu and Sprintall, 2017a, b, Sect. 6.1). The southeastern Indian Ocean is one of the few places in the global ocean where the halosteric component of sea level rise is as large as the thermosteric component (Llovel and Lee, 2015).

\section{Modes of interannual climate variability in the Indian Ocean}

\subsection{ENSO teleconnection and the Indian Ocean Basin mode}

ENSO influences the Indian Ocean circulation through the Pacific-to-Indian Ocean oceanic waveguide and atmospheric teleconnections. Through the atmospheric bridge, El Niño conditions in the Pacific Ocean induce an anticyclonic wind anomaly pattern in the southeast Indian Ocean (Xie et al., 2002), whereas La Niña induces a cyclonic wind anomaly pattern (Feng et al., 2013). The ENSO teleconnection also drives SST variability over the western Indian Ocean during ENSO development. The tropical Indian Ocean experiences prolonged warming (cooling) that peaks in the following boreal spring and persists into boreal summer, after the decay of El Niño (La Niña) events, the so-called Indian Ocean Basin (IOB) mode (Yang et al., 2007). The westward-propagating Rossby waves induced by ENSO may also help sustain the warming (cooling) of the tropical Indian Ocean (Xie et al., 2002), fuelled by regional air-sea coupling (Du et al., 2009). The IOB warming has a capacitor effect for El Niño to influence boreal summer climate, such as for the Indian monsoon (Zhou et al., 2019), and remote impacts in the northwestern Pacific (Xie et al., 2009, 2016), including China and Japan (Hu et al., 2019). Details of the Indo-Western North Pacific capacitor effect are summarized in Xie et al. (2016) and Kosaka et al. (2021). The relationship between ENSO and IOB varies on decadal timescales (e.g. Xie et al., 2010; Chowdary et al., 2012) and under global warming scenarios. The IOB warming tends to persist longer after El Niño events according to CMIP5 model simulations (Zheng et al., 2013).

The ITF variability lags ENSO by $8-9$ months, as found in ocean model results (England and Huang, 2005) and derived from the geostrophic transport across an AustraliaIndonesia XBT section (Liu et al., 2015). The variability of the ITF transport drives sea level and upper-ocean heat content anomalies in the southeast Indian Ocean. Through the waveguide, ENSO has a direct influence on the strength of the Leeuwin Current (Sect. 4.2.4), with a stronger poleward volume and heat transport during a La Niña event (Feng et al., 2008). A stronger Leeuwin Current during La Niña events leads to greater baroclinic instability of the current and enhanced generation of eddies that leads to interannual variability of the eddy kinetic energy in the southeastern Indian Ocean (Feng et al., 2005; Zheng et al., 2018). The increase of the ITF transport and enhancement of rainfall in the Indonesian Seas during strong La Niña events can drive up to $0.2-0.3$ psu freshening anomalies in the upper south- 
east Indian Ocean (Phillips et al., 2005; Feng et al., 2015a; Hu and Sprintall, 2017a; Sect. 5.1.2), which may have a compound effect in accelerating the Leeuwin Current (Feng et al., 2015a). Both ENSO and the IOD (see Sect. 6.2) influence the ITF and thus the exchange of heat from the Pacific into the Indian Ocean, but in concurrent IOD and ENSO events it appears that the influence from the IOD dominates (Sprintall and Révelard, 2014).

Due to the opposing effects of the winds and dissipation, ENSO-induced sea level and upper-ocean heat content anomalies in the southeast Indian Ocean do not propagate far into the western Indian Ocean; instead, wind anomalies generate sea level and heat content anomalies of opposite signs in the western Indian Ocean through Rossby wave propagations (Masumoto and Meyers, 1998; Xie et al., 2002; Zhuang et al., 2013; Ma et al., 2019; Volkov et al., 2020; Nagura and McPhaden, 2021). Thus, the joint forcing of the oceanic waveguide and atmospheric teleconnection results in variations of meridional overturning circulation and heat transport in the Indian Ocean on a multi-year timescale, in phase with the ITF variability (Ma et al., 2019).

\subsection{The Indian Ocean Dipole}

There is increasing evidence that positive IOD events are more frequent and intense during the 20th century (e.g. Abram et al., 2008; Cai et al., 2013; Abram et al., 2020a, b, and references therein). A rare occurrence of three consecutive positive IOD events took place in 2006-2008 (Cai et al., 2009b). The skewness towards more positive and fewer negative IOD events (Cai et al., 2009a) is potentially due to an anthropogenically driven shoaling thermocline in the eastern Indian Ocean (Cai et al., 2008). The three consecutive positive IOD events rarely occurred in Coupled Model Intercomparison phase 5 (CMIP5) models and the more recent frequent occurrence were consistent with regional Indo-Pacific Walker circulation trends (Cai et al., 2009c, d). An anthropogenic contribution was proposed since positive IOD events became more frequent over the period 1950-1999 in the CMIP5 models. Projected mean-state changes in the Indian Ocean with stronger easterly winds and a shoaling thermocline in the southeastern Indian Ocean during austral spring favour positive IOD development, with a reduction in skewness between positive and negative IOD events likely (Cai et al., 2013; Fig. 17), and a three-fold increase in frequency of extreme positive IOD events by 2100 compared to the previous century (Cai et al., 2014b). However, model biases in Indian Ocean mean-state and IOD variability challenge these projected changes: models with excessive IOD amplitude bias tend to project a strong IOD-like warming pattern and increase in extreme pIOD occurrences, consistent with an enhanced Bjerknes feedback, and hence the projected IOD changes could represent spurious artefacts of model biases (Li et al., 2016). Yet, paleoclimate evidence supports trends observed in recent decades: based on a millennial IOD recon- struction from corals, extreme positive IOD events, as were observed in 1997 and 2019, were historically rare (Abram et al., 2020b). In the reconstruction, only 10 extreme positive IOD events occurred, and yet 4 events occurred in the last 60 years (Abram et al., 2020b). The increase in event frequency and intensity highlights the need to improve preparedness in regions affected by IOD events to minimize future climate risks posed by them.

While model simulations and paleo-proxy records suggest changes in the frequency and magnitude of IOD events in a warming climate, there is less observational evidence from other sources. Given the short observational record in the Indian Ocean, the role of decadal to multi-decadal variability across the broader Indo-Pacific region has recently emerged as a compounding factor: the number and frequency of IOD events have been observed to vary on decadal timescales. Decadal variations in SST featuring an IOD-like out-ofphase pattern between the western and eastern tropical Indian Ocean have been linked to the PDO (Krishnamurthy and Krishnamurthy, 2016) or IPO (Dong et al., 2016). A combination of processes transmits the signal from the $\mathrm{Pa}$ cific to the Indian Ocean through both the atmospheric and oceanic bridges, leading to variations in the subsurface temperature structure in the Indian Ocean (X. Zhou et al., 2017; Jin et al., 2018b). Decadal modulations of the background state of the eastern Indian Ocean thermocline depth can thus pre-condition the Indian Ocean to more or fewer IOD events (Annamalai et al., 2005). Consequently, positive IOD events were unusually common in the 1960s and 1990s, with a relatively shallow eastern Indian Ocean thermocline, while the deeper thermocline in the 1970s and 1980s was associated with frequent negative IOD and rare positive IOD events (Ummenhofer et al., 2017). The Indian Ocean stands out as a region with high skill in decadal predictions (Guemas et al., 2013), and improved understanding of decadal modulation of IOD events can aid in decadal prediction efforts for the Indian Ocean region.

The relationship between ENSO and the IOD has been subject to ongoing debate. Recent research has shown that around two-thirds of IOD variability arises as a remote response to ENSO (Stuecker et al., 2017; Yang et al., 2015), with the remaining variability being independent of ENSO. Stuecker et al. (2017) argue that the ENSO-driven IOD can be seen as a combination of remotely driven wind and heat flux anomalies modulated by seasonally varying Bjerknes feedback in the Indian Ocean. Further, they suggest that the ENSO-independent IOD events arise out of white noise atmospheric forcing coupled to these feedbacks (Stuecker et al., 2017). Variability internal to the Indian Ocean basin and unrelated to ENSO, arising from ocean-atmosphere feedback processes, does modulate the evolution of IOD events and can lead to early termination of IOD events; as a result, including internal variability improves the predictability of the IOD (Yang et al., 2015). IOD variability internal to the Indian Ocean resembles recharge oscillator dynamics 


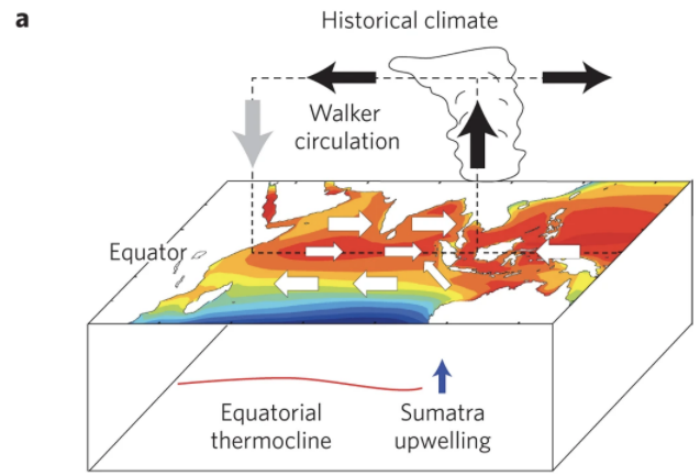

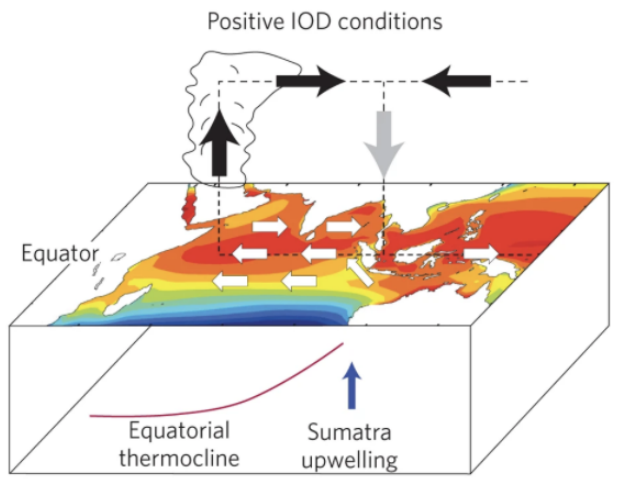

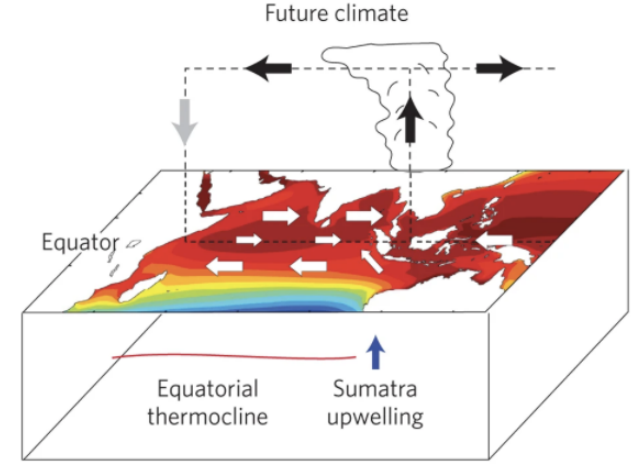

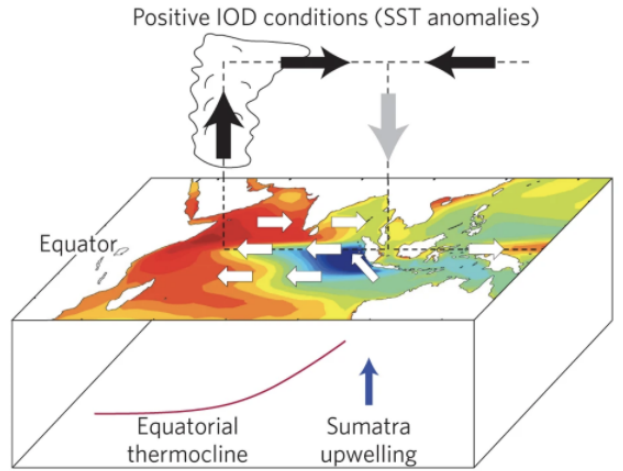

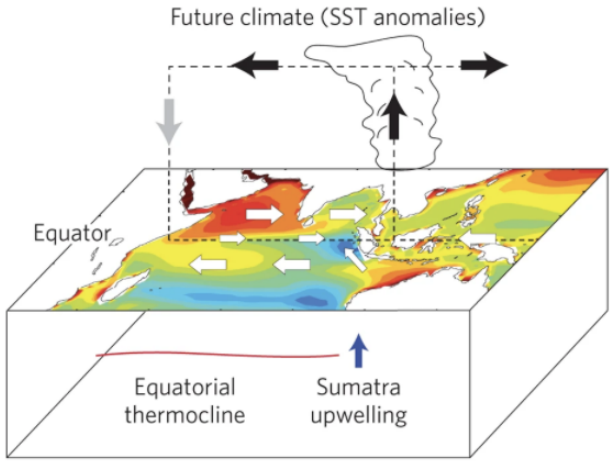

Figure 17. Historical austral spring mean climate and positive IOD conditions for the 20th century and future austral spring mean climate. (a) Historical mean climate, indicating SSTs, surface winds, the associated atmospheric Walker circulation, the mean position of convection, and the thermocline. In the western Indian Ocean, the descending branch is broad and not well defined, as indicated by a grey arrow. (b) Typical conditions during a positive IOD event. (c) Projected future mean climate based on a CMIP5 multi-model ensemble average. Diagrams with total SST fields are shown on the left; diagrams with SST anomalies referenced to the 1961-1999 mean for (b) and referenced to the basin mean for (c) are shown on the right. Reprinted from Cai et al. (2013) with permission from Springer Nature.

for ENSO, but equatorial heat content is less effective as a precursor for the IOD than for ENSO because of the strong impact of remote forcing from the Pacific on the IOD. Internal Indian Ocean dynamics may however contribute to the biennial nature of the IOD through the cycling of Kelvin and Rossby wave energy across the basin (McPhaden and Nagura, 2014). The relationship between ENSO and the IOD is not only one-way: IOD events have also been shown to influence the development of ENSO in the following year
(Izumo et al., 2010; Wang et al., 2019; Cai et al., 2019, and references therein).

Different types of IOD events have been described, each with distinct evolution and regional impacts (Du et al., 2013; Endo and Tozuka, 2016). Du et al. (2013) distinguished three types of IOD events according to the timing of their peak amplitude and overall duration: "unseasonable" events that develop and mature mostly within June-August (JJA), "normal" events that develop and mature mostly within September-November (SON), and "prolonged" events that 
develop in JJA and mature in SON, with the latter two described as the canonical IOD events (Du et al., 2013). The unseasonable IOD events have only been observed since the mid-1970s and have been suggested to be a response to the rapidly warming Indian Ocean SST and a weakened Walker circulation during austral winter (Du et al., 2013). The seasonal evolution and type of ENSO also seems to play a role in determining the IOD evolution and type, with atmospheric influences transmitted through variations in the Walker Circulation and oceanic ones through anomalous oceanic Rossby waves affecting timing and evolution of IOD events, especially during their developing phase (Guo et al., 2015; Zhang et al., 2015; Fan et al., 2017). However, Sun et al. (2015) suggested more IOD events independent of ENSO since the 1980s, along with higher correlations between the IOD and Indian summer monsoon activity, likely due to mean-state change in the tropical Indian Ocean due to weaker equatorial westerlies. The relationship between ENSO and the IOD has weakened in recent decades, linked to changes in the ENSO-induced rainfall anomalies over the Maritime Continent (Han et al., 2017).

Recent advances in understanding variability and change in IOD characteristics have implications for the relationships between SST and regional rainfall patterns in Indian Ocean rim countries. For example, different types of IOD events exhibit distinct regional impacts, with only the canonical events associated with enhanced rainfall over East Africa due to the low-level moisture convergence over the region (Endo and Tozuka, 2016). The effect of Indian Ocean SST on East African rainfall is most pronounced during the short rains (September-November), though Williams and Funk (2011) argued that warming Indian Ocean SST in recent decades was also associated with reduced long rains for the MarchJune season in Ethiopia and Kenya. Changes in the tropical atmospheric circulation across the Indo-Pacific on multidecadal timescales (Vecchi and Soden, 2007; L'Heureux et al., 2013) have further implications for the relationship between Indian Ocean SST and regional rainfall: when the Pacific Walker cell weakened and the Indian Ocean one strengthened post-1961, the East African short rains became more variable and wetter (Nicholson, 2015). Similarly, Manatsa and Behera (2013) described an epochal strengthening in the relationship between the IOD and East African rainfall post-1961, with $73 \%$ of short rain variability in East Africa explained by the IOD, up from $50 \%$ in previous decades. After 1997, this increased further to $82 \%$, explaining spatially coherent events across the region and frequent rainfall extremes (Manatsa and Behera, 2013). Recent observed and projected changes in frequency and intensity of IOD events highlight the increasing need for preparedness in vulnerable regions affected by these events. One such event is the recent 2019 positive IOD, the largest IOD on record since the 1960s (Du et al. 2020), which was linked to unusual hydroclimate around the Indian Ocean rim and further afield. It was linked to extreme rainfall and floods in East Africa (e.g.
Wainwright et al., 2021), an anomalously wet Indian monsoon season (Ratna et al., 2021), abnormally warm conditions in many parts of East Asia (Doi et al., 2020), and an unusually wet subsequent summer monsoon season in Japan and China due to downwelling Rossby waves that had affected the western Pacific SST (Takaya et al., 2020; Zhou et al., 2021) and was seen as a contributing factor to the severe bushfire season experienced in Australia in 2019/2020 (e.g. Wang and Cai, 2020). The 2019 IOD was unique in that it developed independently from any El Niño events and resulted from westward-propagating Rossby waves in the southwest tropical Indian Ocean (Du et al., 2020) and/or an interhemispheric pressure gradient over the Maritime continent ( $\mathrm{Lu}$ and Ren, 2020).

\section{Biogeochemical variability}

IOD events are associated with distinct changes in primary productivity, as measured by chlorophyll. During positive IOD events, increased chlorophyll indicative of phytoplankton blooms is apparent in the normally oligotrophic eastern Indian Ocean in autumn (Wiggert et al., 2009; Currie et al., 2013). Positive chlorophyll anomalies occur in the southeastern Bay of Bengal in boreal winter, while negative anomalies are observed over much of the Arabian Sea and southern tip of India. In a case study of the 2006 positive IOD event, Iskandar et al. (2010), using an eddy-resolving biophysical model, found the offshore chlorophyll signal in the southeastern Indian Ocean to be associated with regions of high eddy kinetic energy implying that cyclonic eddies injected nutrient-rich water into the upper layer, enabling the bloom. Currie et al. (2013) emphasize the importance of assessing the relative contributions of IOD events and remote impacts from ENSO on primary productivity in the Indian Ocean through their respective influence on upper-ocean properties for improved understanding and ultimately predictions of productivity, ecosystems, and fisheries within the basin. Little attention has been paid so far to resultant effects of these blooms on biogeochemical cycling (Wiggert et al., 2009).

\subsection{The subtropical Indian Ocean Dipole}

The subtropical Indian Ocean Dipole (SIOD) is a climate mode in the southern Indian Ocean, which tends to arise and peak in the austral summer (Behera and Yamagata, 2001). During the SIOD's positive phase, the climate mode has positive SST anomalies in the southwestern Indian Ocean and negative SST anomalies in the northeastern region (Behera and Yamagata, 2001; Suzuki et al., 2004; Hermes and Reason, 2005). During the positive phase, enhanced precipitation occurs over southern Africa (Behera and Yamagata, 2001; Reason, 2001, 2002). Recent studies have shown that the SIOD affects the Indian summer monsoon rainfall (Terray et al., 2003), rainfall over southwestern Australia (England 
et al., 2006), and tropical cyclone trajectories in the southern Indian Ocean (Ash and Matyas, 2012).

Initially, SST anomalies associated with the SIOD were considered to be generated directly by latent heat flux anomalies (Behera and Yamagata, 2001). However, recent studies (Morioka et al., 2010, 2012) based on a mixed-layer heat budget analysis revealed the importance of mixed-layer depth anomalies generated by latent heat flux anomalies. Wind anomalies associated with the anomalous Mascarene High suppress latent heat loss and shoal the mixed layer in the southwestern part, while latent heat release is enhanced and the mixed layer deepens anomalously in the northeastern part (Morioka et al., 2010, 2012). With these changes in the upper-ocean heat capacity, warming of the surface mixed layer by the climatological shortwave radiation is enhanced in the southwestern part and becomes less effective in the northeastern part. As a result, the dipole SST anomalies appear in the southern Indian Ocean.

Because the above mechanism operates more effectively as the thickness of the mixed layer becomes thinner, the return period of the SIOD is becoming shorter associated with the shoaling trend of the mixed layer (Yamagami and Tozuka, 2015). Whether this mechanism is associated with decadalto-interdecadal variations and/or global warming awaits further study. Many coupled models are relatively successful in simulating the SIOD with some biases in the location and structure of the SST anomaly (Kataoka et al., 2012). However, no study has examined if the SIOD is modulated by climate modes of variability with decadal-to-interdecadal timescales or changes with global ocean warming.

\subsection{Ningaloo Niño and marine heatwaves in the Indian Ocean}

The Ningaloo Niño (Niña) phenomenon is an interannual climate mode associated with anomalously warm (cold) water in the eastern Indian Ocean (Feng et al., 2013; see Fig. 18). This mode is seasonally phase-locked, with a peak during austral summer (Kataoka et al., 2014). The mode exerts significant impacts on rainfall over Australia (Kataoka et al., 2014) and affects marine ecosystems and fisheries (e.g. Pearce et al., 2011). The phenomenon can alter biological productivity, with negative chlorophyll anomalies during Ningaloo Niño (Narayanasetti et al., 2016). Ningaloo Niños can develop in response to remote ENSO forcing from the western Pacific transmitted as a coastally trapped wave (Kataoka et al., 2014). During the La Niña events, high sea level anomalies propagate poleward along the western coast of Australia, intensifying the Leeuwin Current and causing poleward advection of heat and anomalously warm waters (e.g. Benthuysen et al., 2014a; Sect. 4.2.4). Poleward transport of tropical, low-salinity waters can further enhance the total geostrophic transport of the Leeuwin Current (Feng et al., 2015a).
Atmospheric teleconnection can further enhance the development of Ningaloo Niño. A reduction in southerly winds over the shelf, which would strengthen the Leeuwin Current, can arise through a Gill-type response with low sea level pressure anomalies in the southeastern Indian Ocean owing to the Niño3.4 SST anomalies (Feng et al., 2013; Tozuka et al., 2014). Ningaloo Niños can arise from local air-sea interactions off Western Australia, through the windevaporation-SST feedback during its initial stage (Marshall et al., 2015) and coastal SST-wind-Leeuwin Current (Bjerknes) feedback (Kataoka et al., 2014). In the coastal feedback mechanism, positive SST anomalies lead to northerly alongshore wind anomalies and coastal downwelling anomalies, causing enhancement of the positive SST anomalies (Kataoka et al., 2014). During the Ningaloo Niño's development phase, estimates of air-sea heat flux contributions have been found to be dependent on products and their resolution and bulk flux algorithms (Feng and Shinoda, 2019). Since the late 1990s, Ningaloo Niño events have occurred more frequently (Feng et al., 2015b). This decadal increase is corroborated by coral proxy records of Leeuwin Current strength, with the most extreme SST anomalies associated with Ningaloo Niños occurring since 1980 (Zinke et al., 2014).

More generally, marine heatwaves refer to prolonged, extremely warm water events. Over the past decade, most studies of marine heatwaves in the Indian Ocean have focused on the eastern sector of the Indian Ocean. Major events in the Indian Ocean have been associated with phases of ENSO. Along the western coast of Australia, marine heatwaves have occurred predominantly at subtropical reefs during La Niña events due to increased heat transport (Zhang et al., 2017). The term "marine heatwave" was first coined owing to a $+5^{\circ} \mathrm{C}$ warm water event in 2011 off Western Australia during a strong La Niña (Pearce et al., 2011). The 2011 event was associated with the strongest recorded Leeuwin Current transport anomaly, bringing warm tropical waters south, and was partly due to air-sea heat fluxes (Feng et al., 2013; Benthuysen et al., 2014a).

Across Australia's North West Shelf, marine heatwaves have been found to occur at tropical coral reefs from El Niño due to solar radiation and a weakened monsoon (Zhang et al., 2017). During the strong El Niño of 2015-2016, the southeastern tropical Indian Ocean experienced the warmest and longest marine heatwave on record, with weakened monsoon activity and anomalously high air-sea heat flux into the ocean (Benthuysen et al., 2018). The anomalously warm water conditions persisted into winter, during one of the strongest negative IOD events (Benthuysen et al., 2018). The 2016 marine heatwave was associated with coral bleaching spanning from Australia's inshore Kimberley region to remote coral reef atolls (Gilmour et al., 2019). More broadly across the Indian Ocean during 2016, marine heatwaves have been studied in terms of their ecological impacts, such as coral bleaching in the western Indian Ocean (e.g. Gudka et al., 2018) and 


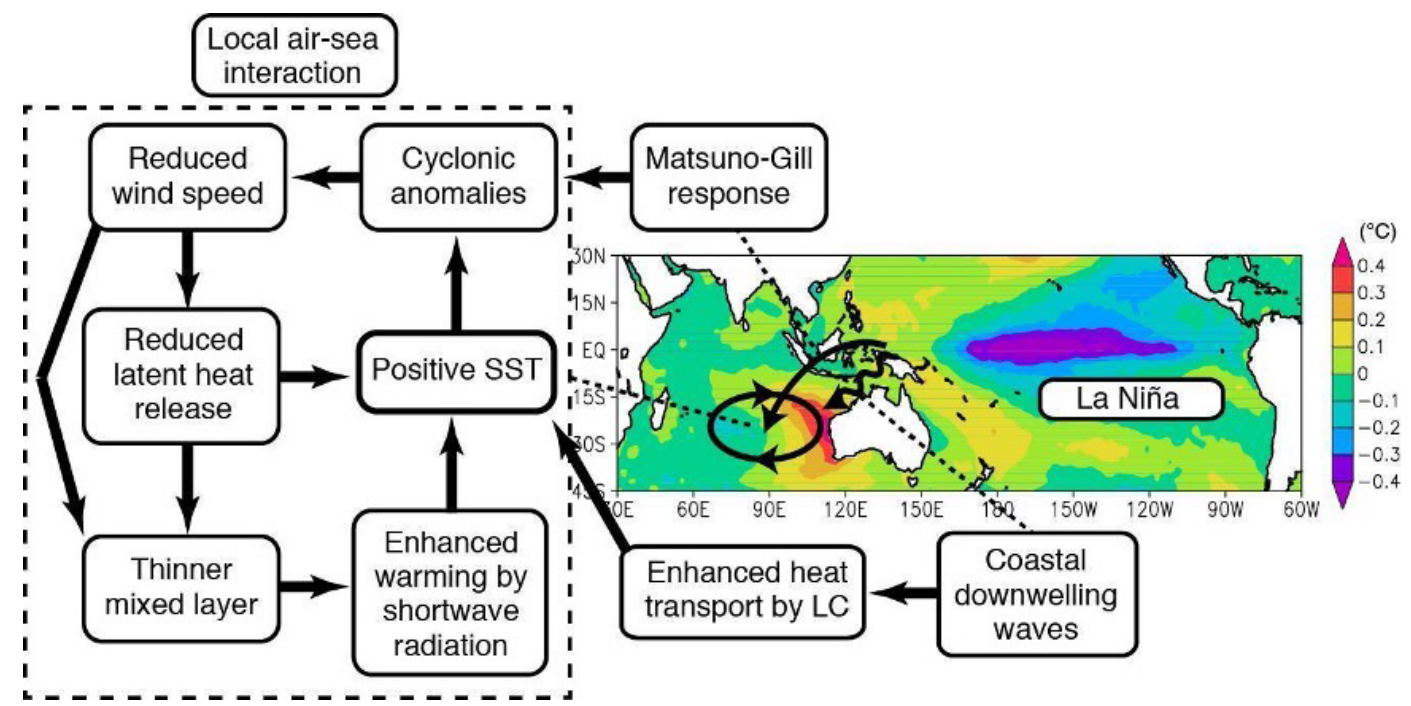

Figure 18. Schematic diagram illustrating generation mechanisms (i.e. local air-sea interaction, atmospheric teleconnection, and oceanic wave propagation) of the Ningaloo Niño. SST anomalies are regressed against the Ningaloo Niño Index to illustrate typical SST anomalies associated with the phenomenon.

the Maldives (e.g. Ibrahim et al., 2017) and consequences for fish in the Chagos Archipelago (Taylor et al., 2019).

Trends in marine heatwave metrics indicate widespread regions across the Indian Ocean where events have increased in frequency, based on SST from 1982-2016, especially in the central and southwestern sectors (Oliver et al., 2018). Over the same time period, the duration and intensity of marine heatwaves have increased in the Indian Ocean and globally (Oliver et al., 2018; Marin et al., 2021). Primary climate modes of variability correlated with an increased occurrence of marine heatwaves include the following phases: (1) the positive phase of the Dipole Mode Index for the northwestern sector, the tropical sector, and south to the Seychelles Islands; (2) the positive phase of the Niño3.4 index for the southern-central sector; and (3) the negative phase of the El Niño Modoki index, which measures the strength of the Central Pacific ENSO, for the eastern Indian Ocean (Holbrook et al., 2019). While the marine heatwaves in the eastern Indian Ocean have been well documented, there have been fewer studies into the physical mechanisms causing marine heatwaves across the basin and other regions and less confidence, for example in the Bay of Bengal, in the local processes causing reported events on a range of timescales (Holbrook et al., 2019). There are indications that increased extremes in El Niño (Cai et al., 2014a) and La Niña events (Cai et al., 2015) due to mean ocean warming trends increase the likelihood of marine heatwave occurrence in the southeastern Indian Ocean (Zhang et al., 2017).

\subsection{Monsoon variability and links to the Indian Ocean}

Several monsoon systems surround the Indian Ocean, notably the South Asian monsoon, the East Asian monsoon, and the Australian monsoon. These monsoon systems are remotely influenced by global coupled modes of variability such as ENSO, which is often associated with dry conditions in the South Asian monsoon (e.g. Rasmusson and Carpenter, 1983; Ropelewski and Halpert, 1987) and Australian monsoon (e.g. Risbey et al., 2009; Jourdain et al., 2013), although the relationship with the Indian monsoon has recently weakened (e.g. Kumar et al., 1999). In the Indian Ocean, the IOD has a strong influence on the Asian monsoon systems but is weak during the Australian monsoon period. The IOD tends to oppose the ENSO teleconnection to the South Asian monsoon by enhancing monsoon rainfall (e.g. Ashok et al., 2004; Chowdary et al., 2015; Krishnaswamy et al., 2015; Pokhrel et al., 2012). However, the exact combination of SST patterns between the Indian Ocean and the Pacific Ocean is crucial for determining the rainfall response in the Asian monsoons (e.g. Lau and Wu, 2001; Ratna et al., 2021; Yuan and Yang, 2012), and the relative strengths of the teleconnections have varied over time (Krishnaswamy et al., 2015). Furthermore, there is evidence that the Indian Ocean forcing of the South Asian monsoon may be primarily driven by ENSO, with pure IOD events only weakly influencing monsoon rainfall (Crétat et al., 2018).

The monsoon systems around the Indian Ocean tend to vary in phase and are also linked to the western North Pacific Monsoon (e.g. Gu et al., 2012). There is a biennial oscillation in the strength of the monsoon systems, with a strong Asian monsoon preceding a negative IOD and coinciding with cold eastern Pacific SSTs, followed by a strong Australian monsoon and subsequently by a reversal in the SST patterns (Loschnigg et al., 2003; Meehl and Arblaster, 2011). Thus, each monsoon system interacts with the ocean dynam- 
ics and thermodynamics and with the other monsoon systems through a complex set of teleconnections.

At a regional scale, upwelling in the Arabian Sea reduces rainfall along the Western Ghats of India during the monsoon due to a reduction in evaporation and water vapour transport (Izumo et al., 2008). Moisture fluxes across the Arabian Sea are crucial to accurate simulation of the Indian Monsoon, yet many models fail to accurately capture these (Levine and Turner, 2012). In the Bay of Bengal, the shallow surface mixed layer, supported by the vertical salinity gradient, leads to rapid variations in SST (e.g. Sengupta and Ravichandran, 2001; Vecchi and Harrison, 2002) that interact with intraseasonal oscillations (Gao et al., 2019) in the atmosphere and thus with the active and break cycles of the monsoon (e.g. Lucas et al., 2014). This strong and rapid variability in upper-ocean conditions in the Bay of Bengal, and the potential feedbacks on the monsoon, motivated multiple observational research programmes with field campaigns in the Bay of Bengal, as discussed in the next section.

\section{Multiscale upper-ocean processes in the Bay of Bengal}

Reflective of its name, the Bay of Bengal is in many ways analogous to a large-scale estuary with seasonally reversing winds and boundary currents that facilitate the transport, stirring, and mixing of water masses. To the north, the Ganga-Brahmaputra-Meghna watershed delivers on average $1300 \mathrm{~km}^{3}$ in annual runoff of freshwater with a seasonal peak in discharge from July to September (Sengupta et al., 2006). During the southwest monsoon (boreal summer), the Southwest Monsoon Current (SMC, Fig. 10) flows eastward advecting high-salinity waters from the Arabian Sea into the southern Bay of Bengal, balancing the bay's net outflow of freshwater. Instabilities and eddies result in mesoscale stirring of these different water types and create a strongly filamented and complex near-surface thermohaline structure. Lateral and vertical gradients in stratification are further modified by sub-mesoscale processes, instabilities, and mixing. The resultant shallow stratification allows for rapid coupling with the atmosphere. Collectively, these conditions present a natural laboratory to study multi-scale mixing processes and their link to air-sea interaction. This section discusses new understanding of physical processes in the bay from the large-scale to sub-mesoscale and finally at the smallest mixing scales.

Recent focus on the Bay of Bengal's upper-ocean structure has been prompted by the need to understand atmosphere and ocean coupling with the aim of ultimately informing monsoon forecasting efforts at the intraseasonal timescale and shorter. Several bilateral international collaborations (Lucas et al., 2014; Wijesekera et al., 2016a; Mahadevan et al., 2016; Vinayachandran et al., 2018; Gordon et al., 2019, 2020) have collectively supported multiple field campaigns, beginning in 2013 and concluding in 2019, using a combination of shipboard, moored, and autonomous platforms. These atmospheric and oceanic measurements have provided new insights into the BoB's structure and the processes that regulate that structure, particularly at fine lateral scales $(<5 \mathrm{~km})$.

Results from these combined efforts span from large scales, e.g. the quantification of coastal transport along the Sri Lankan coast (Lee et al., 2016) and the mesoscale stirring of freshwater (Sree Lekha et al., 2018), to intermediate scales, e.g. high-resolution (order $100 \mathrm{~m}$ ) frontal surveys that hint at the roles of sub-mesoscale (Ramachandran et al., 2018) and non-hydrostatic processes in setting stratification (Sarkar et al., 2016), to small scales with direct measurements of microstructure yielding new insights into the BoB's mixing regimes (Jinadasa et al., 2016; Thakur et al., 2019; Cherian et al., 2020).

\subsection{The bay's forcing and upper-ocean structure}

At the largest scales, the bay is forced by air-sea fluxes of buoyancy and momentum, which are strongly modulated by the monsoon and vice versa. Precipitation and multiple river systems, including the Ganga-Brahmaputra-Meghna system, contribute to freshwater input that creates a barrier layer in the surface Bay of Bengal, which is strongest in the northern bay and weakens toward the south. The bay's stratification, in particular its barrier layer, is unique in how it impacts the evolution of seasonal SST, in turn setting the lower boundary condition for the development of the monsoon (Li et al., 2017b). For this reason, recent emphasis has been placed on understanding processes that determine the bay's upper-ocean salinity and temperature structure.

The monsoon cycle of surface forcing plays a first-order role in controlling the bay's upper-ocean temperature structure. Direct flux measurements are a critical component in our ability to accurately capture, represent, and predict the magnitude and variability of monsoon air-sea coupling. Recent studies have shown that of the air-sea heat flux terms, shortwave radiation and latent heat flux are the largest drivers of variability to the total heat tendency. These variables are also those which reanalysis products struggle most to accurately represent, showing biases up to $75 \mathrm{~W} \mathrm{~m}^{-2}$ (SanchezFranks et al., 2018). High-quality air-sea surface flux measurements over the BoB historically have been limited to the few sites maintained by the RAMA array (McPhaden et al., 2009). However, regional measurement efforts have expanded, and baseline surface measurements are now collected and sustained through India's National Institute of Ocean Technology's MetOcean Buoy program (Venkatesan et al., 2018), as well as the recent transfer of an $18^{\circ} \mathrm{N}$ air-sea flux buoy from the Woods Hole Oceanographic Institution to the Indian National Centre for Ocean Information Services (Weller et al., 2016).

Precipitation and riverine discharge along the bay's margins contribute roughly $60 \%$ and $40 \%$, respectively, of 
the $0.14 \mathrm{~Sv}$ net freshwater delivered to the bay (Sengupta et al., 2006; Wilson and Riser, 2016). Precipitation peaks in early summer (June) with a value near $0.4 \mathrm{mmonth}^{-1}$, while discharge peaks slightly later in summer (August) with a value near $0.3 \mathrm{~m} \mathrm{month}^{-1}$. Evaporative loss (included in the net $0.14 \mathrm{~Sv}$ ) is relatively steady throughout the year at $0.1 \mathrm{~m} \mathrm{month}^{-1}$ (Wilson and Riser, 2016). Estimates of river discharge from gauged sources are known to have uncertainties (underestimates) related to unmonitored tributaries and streams. For large deltas, altimeter-based elevations offer a means of extrapolating gauge data over space and time. Papa et al. $(2010,2012)$ applied such an approach to the Ganga-Brahmaputra river system for the period 1998-2011. This time series allows for assessment of interannual variability over time ranges not spanned by gauged efforts. Papa et al. (2012) note a $12500 \mathrm{~m}^{3} \mathrm{~s}^{-1}$ standard deviation in interannual variability in the Ganga-Brahmaputra discharge. Importantly, such data sets are also easily accessible by the general public, facilitating progress and understanding by the scientific community.

The bay's upper-ocean temperature and salinity structure is an integrated representation of the sources summarized above and sinks of heat and freshwater, combined with the physical processes that redistribute these quantities. The thermohaline structure of the bay is remarkable in several regards: for shallow mixed-layer depths $(<5 \mathrm{~m}$, Sengupta and Ravichandran, 2001), for inversions of temperature (Shroyer et al., 2016, 2019; Thadathil et al., 2016), for large-scale coherent layering that spans $100 \mathrm{~km}$ (Shroyer et al., 2019), for its active mesoscale field, and for the strong influence of river discharge over the interior basin. The bay's salinity stratification is a critical, if not dominant, contributor to the upper-ocean density stratification. It supports the formation of barrier layers that are frequently observed to be warmer than the mixed layer, thereby providing a substantial subsurface heat reservoir with the potential to modify air-sea interaction (Girishkumar et al., 2011; Shroyer et al., 2016). For example, in conditions supportive of formation of a diurnal warm layer (low winds, strong insolation), subsurface turbulent fluxes can act to modulate the diurnal SST cycle by transporting (typically) warm barrier layer waters into the mixed layer at night while still cooling the base of the diurnal warm layer (DWL) during the day (Shroyer et al., 2016). A similar phenomenon, albeit on a much different scale, results with the passage of cyclones, which often show a salty wake even in the absence of a cool wake that is common for cyclones elsewhere (for e.g. Chaudhuri et al., 2019; Qiu et al., 2019). Below, we review recent progress on understanding of processes that determine the bay's upper-ocean thermohaline structure.

\subsection{Lateral processes}

\subsubsection{Stirring from the margins}

The BoB has an active mesoscale eddy field that stirs diverse source waters into the interior of the $\mathrm{BoB}$. The origins of these source waters are the Arabian Sea waters to the west, the Ganga-Brahmaputra-Meghna at the northern tip, Andaman Sea waters to the east, and equatorial waters to the south. This stirring effectively contributes to a quasistationary balance of the fresher waters from the north and the high-salinity waters from the west and south over time. Lateral advection is a fundamental contributor to the formation of the barrier layer (George et al., 2019) and the freshwater budget of the Bay (e.g. Sree Lekha et al., 2018). In the northern bay, the dispersal of water from the periphery into the interior depends critically on mesoscale stirring and the time-varying Ekman transport, as indicated from mooring (Sree Lekha et al., 2018) and ship-based surveys (Shroyer et al., 2019), and is constrained by modelling results (Sree Lekha et al., 2018). Here, the advection of freshwater by the mesoscale stirring also plays an important role in determining SST over the northern BoB (Buckley et al., 2020), as these waters are typically associated with relatively shallow mixed layers. In the southern bay, measurements have suggested the competing influences of mixing and advection of salty Arabian Sea water in the erosion and reformation of the barrier layer during the southwest monsoon (George et al., 2019; Vinayachandran et al., 2018). In particular, George et al. (2019) show that maintenance of the barrier layer and the associated maximum depth of mixing was critically dependent on horizontal advection through its impact on stratification. Surface freshwater input also has an impact on barrier layer evolution; several freshening events were captured at various stages of their seasonal evolution in the southern Bay of Bengal in recent observations (Vinayachandran et al., 2018). These events play a significant role in the formation of a thick barrier layer, showing that during the southwest monsoon the shoaling of the mixed layer in the southern BoB has a similar magnitude and behaviour to that in the northern BoB (Vinaychandran et al., 2018).

\subsubsection{Inter-basin exchange}

Inter-basin exchange is critical to the bay's salinity budget; since the bay receives net freshwater input, this freshwater must be balanced by salty water imported from either the Arabian Sea or the western equatorial Indian Ocean (Jensen et al., 2001; Sanchez-Franks et al., 2019), and turbulent transport of salt into the fresh water layer is necessary to maintain the BoB's long-term salinity balance. Observations show that intrusion of high-salinity water from the Arabian Sea enters the $\mathrm{BoB}$ between $80-90^{\circ} \mathrm{E}$ during the southwest monsoon (e.g. Murty et al., 1992; Vinayachandran et al., 2013) and has been found in several models (e.g. Vinayachandran et al., 
1999; Han and McCreary, 2001; Jensen, 2001). More recent observational and modelling studies show that both lateral and vertical transfer of heat and salt occur at multiple spatial scales and timescales. Seasonal currents play an important role in transporting heat and salt in and out of the BoB, but the role of mesoscale eddies on lateral transports is not well known.

Using unique year-long mixing measurements detailed in Sect. 7.3, Cherian et al. (2020) tentatively estimated a turbulent salt flux of $1.5 \times 10^{-6} \mathrm{psu} \mathrm{ms}^{-1}$ out of Arabian Sea water averaged between 85 and $88.5^{\circ} \mathrm{E}$ at $8^{\circ} \mathrm{N}$ through the 34.75 psu isohaline between August and January. Over those 6 months, this flux would increase the salinity of a $75 \mathrm{~m}$ layer of water by $0.3 \mathrm{psu}$, though much of this would be cancelled out by surface fluxes. The magnitude and timing of this salt flux roughly match that necessary to restore the bay's nearsurface salinity after the large freshwater input in August as estimated by a few modelling studies (Akhil et al., 2014; Benshila et al., 2014; Wilson and Riser, 2016). This is the first direct measurement of turbulence that supports the hypothesis of intrusion of high-salinity water from the Arabian Sea during the southwest monsoon (Vinayachandran et al., 2013).

\section{Andaman Sea exchange}

The Irrawady river drains into the Andaman Sea, a marginal sea at the eastern edge of the bay. Export from the Andaman Sea is then another source of freshwater for the bay, particularly at intermediate densities $\left(22-25 \mathrm{~kg} \mathrm{~m}^{-3}\right)$. A striking example of the interaction between strong surface forcing and an anticyclonic eddy can be found in the fortuitous crossing of an intra-thermocline eddy (ITE) in 2013 as reported by Gordon et al. (2017). The water mass characteristics clearly identify ITE waters from the Andaman Sea, and analysis of ancillary Argo data suggest a similar water type often penetrates westward into the bay extending from the three passages connecting the two basins. While at the time of transit the observed ITE had a very weak surface expression, a week prior to encountering the ITE a clear sea surface high $(>10 \mathrm{~cm})$ is evident in AVISO SSHA. Tropical Cyclone Lehar passed near the location of this sea surface high in the interim, and the working conjecture is that the winds associated with Lehar were sufficient to modify a typical mode-1 anticyclone into the observed ITE.

\section{Arabian Sea exchange}

Near-surface exchange from the Arabian Sea into the BoB is influenced by the Sri Lanka Dome (SLD), an upwelling thermal dome that recurs seasonally within the SMC in the wind shadow of Sri Lanka (Vinayachandran and Yamagata, 1998; de Vos et al., 2014; Burns et al., 2017). The SLD has long been recognized as a prominent circulation feature in the southwestern bay during the summer monsoon, and it has been noted as a region of enhanced productivity (Vinayachandran et al., 2004; de Vos et al., 2014), cool SST (Burns et al., 2017), and consequently depressed convection (Fig. 15). The SLD displays pronounced interannual variability (Cullen and Shroyer, 2019). In some years the SLD has a strong surface manifestation (amplitude of the low $\sim 30 \mathrm{~cm}$ ) that persists well beyond the southwest monsoon; in other years the SLD has a weak expression that is intermittent and short lived ( $\sim 1-2$ months). The SLD is not fixed in location despite its strong association with the wind stress curl. Its position varies from year to year and over the course of one season. Variations in its location and strength may influence the properties of waters entrained and upwelled within the SLD.

At intermediate depths $(<\sim 200 \mathrm{~m})$, the signature of the neighbouring Arabian Sea is notable across much of the basin (Gordon et al., 2016). During summer, Arabian Sea High-Salinity Water (ASHSW; density near 22-24 $\mathrm{kg} \mathrm{m}^{-3}$ ) is carried and advected into the Bay of Bengal as a "highsalinity core" via the SMC (Webber et al., 2018; SanchezFranks et al., 2019) and then spread north along the bay's central spine (Hormann et al., 2019). During this journey, salt is mixed upward into the near-surface fresh layer (Cherian et al., 2020; Sect. 7.3). A nearly 2-year-long moored current record in the southern BoB captured seasonally varying large eddies generated by the SMC and Northeast Monsoon Current. These eddies included a cyclonic eddy, the SLD, and an anticyclonic eddy south of the SLD (Wijesekera et al., 2016c). These observations revealed that the average transport over a nearly 2 -year period into the BoB was about $2 \mathrm{~Sv}$ $\left(1 \mathrm{~Sv}=10^{6} \mathrm{~m}^{3} \mathrm{~s}^{-1}\right)$ but likely exceeded $15 \mathrm{~Sv}$ during summer of 2014, which is consistent with the transport associated with the SMC (e.g. Schott et al., 2009; Webber et al., 2018). The observations further indicate that the water exchange away from coastal boundaries, in the interior of the BoB, may be largely influenced by the location and strength of the two eddies that modify the path of the SMC. The strength and location of the SMC itself is dependent on a combination of local and remote forcing (Webber et al., 2018).

As discussed above, several hypotheses have been suggested for cyclonic eddy (SLD) and anticyclonic eddy formation in the southern BoB. It has been suggested that the cyclonic wind stress curl over the southwestern BoB generates the SLD (McCreary at al., 1996; Vinayachandran and Yamagata, 1998; Schott and McCreary, 2001; Cullen and Shroyer, 2019). Based on numerical simulations, de Vos et al. (2014) argued that the separation of SMC from the (southern) boundary of Sri Lanka may lead to SLD, where a cyclonic vorticity is generated by lateral frictional effects. A mechanism for the anticyclonic eddy formation has been proposed by Vinayachandran and Yamagata (1998), where the interaction of the SMC with Rossby waves arriving from the eastern boundary leads to the anticyclonic eddy. Pirro et al. (2020a) proposed a new hypothesis wherein the anticyclonic eddy is generated by a topographically trapped 
Rossby wave response of the SMC to perturbations by the Sri Lankan coast. They reported that observations of the size, location, and origin of the SLD were broadly consistent with their hypothesis, based on a laboratory experiment designed to mimic natural flow in the BoB by creating an eastward jet (SMC) on a simulated $\beta$ plane.

High-resolution sampling of the interior BoB has provided a more detailed look at the lateral extent of typical "patches" of Arabian Sea water, which tend to remain well defined over scales of $10-50 \mathrm{~km}$, suggesting the importance of eddy activity in exchange (Shroyer et al., 2019). While many studies have traced origins of ASHSW from the eastern Arabian Sea, entering the BoB directly via the SMC (e.g. Jensen et al., 2016); a recent study suggests an equatorial pathway may also be relevant (Sanchez-Franks et al., 2019; Sect. 7.2.3). Highly salty and highly oxygenated waters from the Persian Gulf and the Red Sea have also been noted in the southern regions of the BoB (Jain et al., 2017). These waters are injected into the BoB via current systems (equatorial and the SMC) with important repercussions for the oxygen concentrations of the BoB oxygen minimum zone (Sheehan et al., 2020).

Velocity and hydrographic profiles from a shipboard survey in December 2013 combined with drifter observations, satellite altimetry, global ocean nowcast and forecast products, and coupled model simulations were used to examine the circulation in the southern Bay of Bengal during the northeast monsoon (Wijesekera et al., 2015). The observations captured the southward-flowing East India Coastal Current (EICC, e.g. Shetye et al., 1994) off southeast India and east of Sri Lanka. The EICC was approximately $100 \mathrm{~km}$ wide, with speeds exceeding $1 \mathrm{~m} \mathrm{~s}^{-1}$ in the upper $75 \mathrm{~m}$. East of the EICC, a subsurface-intensified $300 \mathrm{~km}$ wide, northward current was observed, with maximum speeds as high as $1 \mathrm{~m} \mathrm{~s}^{-1}$ between 50 and $75 \mathrm{~m}$. The EICC transported lowsalinity water out of the bay and the subsurface northward flow carried high-salinity water into the bay during typical northeast monsoon conditions (Wijesekera et al., 2015; Jensen et al., 2016).

\subsubsection{Equatorial connections}

The Equatorial Undercurrent (EUC) in the Indian Ocean is seasonally variable. The summer-autumn EUC tends to occur in the western basin in most years but exhibits evident interannual variability in the eastern basin (Chen et al., 2015), with different processes dominating its generation in the western and eastern basins. In the eastern basin, reflected Rossby waves from the eastern boundary play a crucial role in the EUC, whereas directly forced Kelvin and Rossby waves control the EUC in the western basin.

Equatorial Kelvin waves, commonly interpreted as Wyrtki (1973) jets, propagate eastward along the Equator during April/May and September/October. Upon reflection from the IO eastern boundaries, energy of Wyrtki jets is reflected back in part as long Rossby waves that disperse slowly during the following 2 months and reach the central-eastern BoB during July-August (Han et al., 1999, 2001; Han, 2005; Nagura and McPhaden, 2010a). The remaining energy is partitioned into two coastally trapped Kelvin waves travelling poleward (Moore, 1968), which excite long Rossby waves propagating westward. Therefore, it is suggested that planetary waves driven by remote forcing from the interior IO contribute significantly to the formation, strength, and intensity of the BoB circulation (Vinayachandran et al., 1998; Nagura and McPhaden, 2010b; Chen et al., 2015). A subset of these planetary waves are the mainstay of intraseasonal oscillations (ISOs), a sub-seasonal phenomenon of period less than $120 \mathrm{~d}$. The genesis of oceanic ISOs has been attributed to multiple mechanisms: external forcing (e.g. atmospheric ISOs and Ekman pumping; Duncan and Han, 2012) and internal processes (upper-ocean processes and instabilities, e.g. L. Zhang et al., 2018).

Observations in the IO have captured a range of variabilities in the 30-120 d frequency band (e.g. Girishkumar et al., 2013), and past research has identified roughly three distinct ISO bands in the context of the thermocline: 30-60, 6090, and $120 \mathrm{~d}$ (Han et al., 2001; Girishkumar et al., 2013). Pirro et al. (2020b) discussed interaction between 30-60 d ISOs and the SMC in the southern BoB using long-term moored observations. They estimated that the background mean flow acceleration resulting from the meridional divergence of wave momentum flux in the thermocline was about $10^{-8} \mathrm{~m} \mathrm{~s}^{-2}$. As a result, within a wave period, ISOs can enhance the eastward flow in the thermocline by about $25 \%$. The negative shear production computed for the same period is consistent with this finding, suggesting that the mean flow gained kinetic energy at the expense of the ISO band. The meridional heat flux divergence was $-10^{-7}{ }^{\circ} \mathrm{C} \mathrm{s}^{-1}$ and has a tendency for cooling the thermocline by about $0.5^{\circ} \mathrm{C}$ when ISOs are active (Pirro et al., 2020b). Observations have also captured energetic and consequential 5-20 d convectively coupled Kelvin waves in the atmosphere (Baranowski et al., 2016) that generate oceanic Kelvin waves, affect surface heat fluxes, and generate upper-ocean turbulence $(\mathrm{Pu}-$ jiana and McPhaden, 2018).

High-salinity waters from the western Arabian Sea and the western equatorial Indian Ocean can route to the Bay of Bengal via the Somali Current and the Indian Ocean EUC (Sanchez-Franks et al., 2019). Changes in the strength of the Bay of Bengal high-salinity core are linked to the convergence of the East Africa Coastal Current and the wintertime southward-flowing Somali Current, with anomalously strong Equatorial Undercurrent (Fig. 19). Because of the seasonal reversal of currents, two junctions form naturally, one in the western equatorial Indian Ocean (Somali Current) and another south of India (monsoon currents), which effectively act as "railroad switches" rerouting water masses to different basins in the Indian Ocean depending on the season (Fig. 19, Sanchez-Franks et al., 2019). 

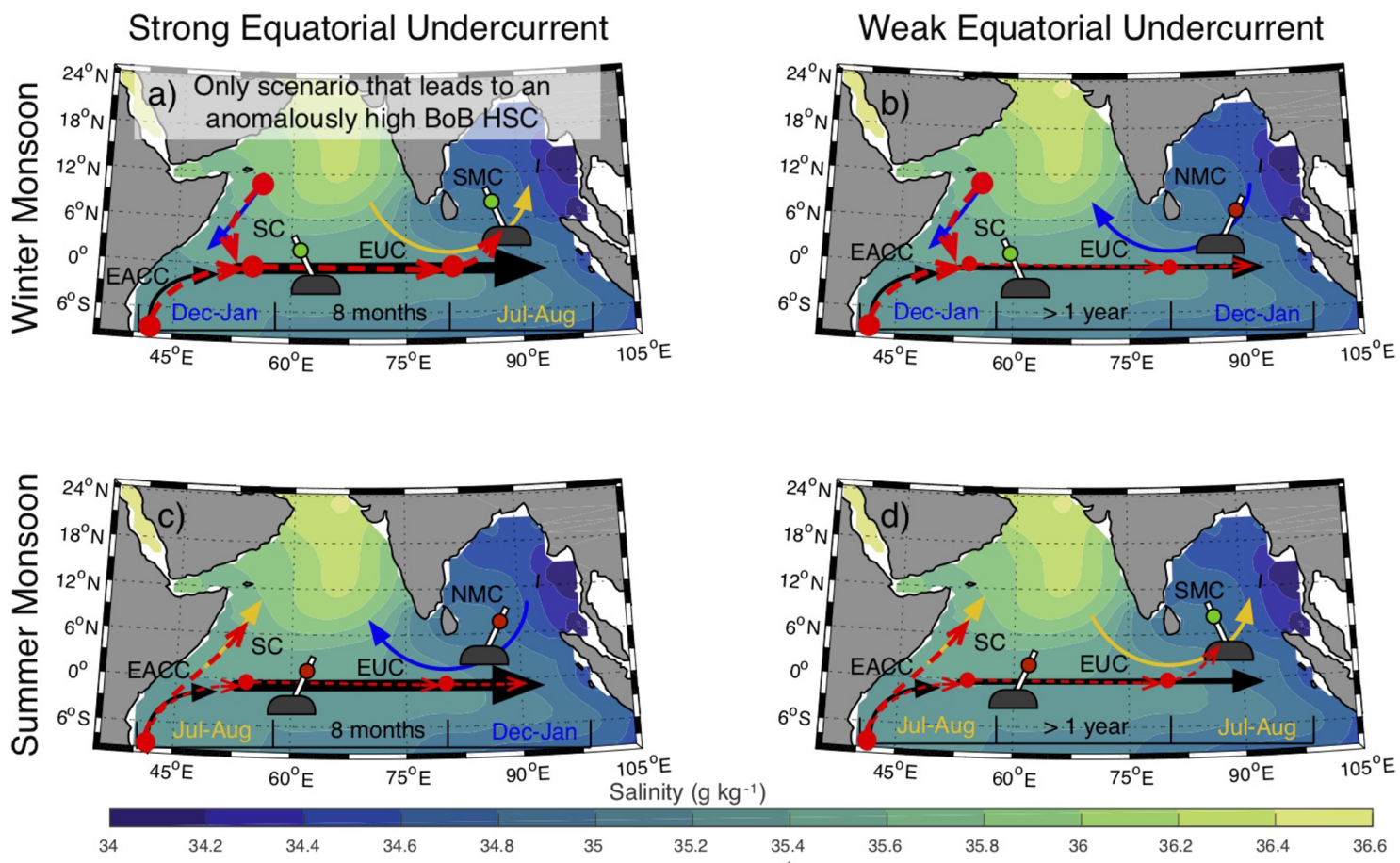

Figure 19. Seasonal circulation pathways in the northern Indian Ocean, or the railroad switch schematic, on subsurface (90 m) salinity climatology (psu; shaded) from the Argo optimally interpolated product for the four Equatorial Undercurrent scenarios: (a, b) winter monsoon and strong (weak) Equatorial Undercurrent and (c, d) summer monsoon and strong (weak) Equatorial Undercurrent. Dashed red arrows indicate high-salinity advection. BoB stands for Bay of Bengal, HSC stands for high-salinity core, SMC stands for Southwest Monsoon Current, SC stands for Somali Current, EUC stands for Equatorial Undercurrent, EACC stands for East African Coastal Current. Figure taken from Sanchez-Franks et al. (2019).

\subsection{Vertical mixing}

Strong stratification in the Bay of Bengal plays a critical role in setting the upper-ocean turbulence, notably leading to relatively weak mixing compared to other regions (e.g. Kunze et al., 2006). However, large-scale inferences suggest that mixing must play a key role in at least two regards. First, the net surface flux during the southwest monsoon on average is warming but the SST still cools (Shenoi et al., 2002). Second, the large-scale salt balance must be closed through upward mixing of high-salinity water carried into the bay via the Southwest Monsoon Current (Vinayachandran et al., 2013).

Recent year-long direct measurements of mixing in the bay have helped link the seasonal cycle of mixing to the seasonal cycle of winds, currents, and freshwater. These yearlong measurements were recorded by mixing meters called $\chi$ pods. $\chi$ pods consist of two temperature microstructure sensors and a suite of ancillary sensors necessary to infer the rate of dissipation of temperature variance at $1 \mathrm{~Hz}$ frequency for up to a year (Moum and Nash, 2009). $\chi$ pods have been deployed on moorings in three different regions of the bay (Fig. 20): the air-sea buoy at $18^{\circ} \mathrm{N}$, top $65 \mathrm{~m}$ (Thakur et al., 2019), RAMA moorings along $90^{\circ} \mathrm{E}$ (mixing measurements at 15, 30 and $45 \mathrm{~m}$; Warner et al., 2016), and the EBoB array in the south-central bay (mixing measurements spanning between 30 and $100 \mathrm{~m}$ at sites in the region $85-88^{\circ} \mathrm{E}, 5-8^{\circ} \mathrm{N}$, Cherian et al., 2020). Across the basin, turbulence within and near the base of the mixed layer shows strong seasonality that parallels the monsoon cycle in winds (Thakur et al., 2019, Warner et al., 2016). In the thermocline of the southcentral bay (EBoB array), mixing is correlated with packets of downward-propagating near-inertial waves implicating wind forcing. As depicted in Fig. 20, both near-surface and thermocline mixing are relatively high during the NE and SW monsoons (December-February, May-September) and relatively low during the transition (March, April). Cyclones during the post-monsoon months of October and November can drive a hundred-fold increase in near-surface mixing both locally and throughout the bay (Warner et al., 2016). Turbulence profiles collected by a fast thermistor on a CTD rosette during a basin-wide survey before and after the passage of Cyclone Madi (6-12 December 2013) show a basin-wide increase in diffusivity linked to near-inertial waves forced by the cyclone (Wijesekera et al., 2016b).

Indirect estimates of turbulent diffusivity and turbulent heat fluxes at the base of the mixed layer can be found as the residual of a mixed-layer heat budget whose terms are estimated using a combination of mooring and satellite mea- 
surements. Girishkumar et al. (2020) use this approach to indirectly estimate seasonal median turbulent diffusivities using decade-long RAMA mooring records at $90^{\circ} \mathrm{E}$. They find a robust seasonal cycle of mixing at 8,12 , and $15^{\circ} \mathrm{N}$ and strong latitudinal variability in turbulence, with larger diffusivities inferred at $8^{\circ} \mathrm{N}$ relative to 12 and $15^{\circ} \mathrm{N}$ in all seasons. When comparisons are possible, the indirect estimates compare well against the more direct but time-limited estimates of Warner et al. (2016) at $12^{\circ} \mathrm{N}, 90^{\circ} \mathrm{E}$.

The influence of freshwater is a critical caveat to the above generalizations: the arrival in August of the Ganga-Brahmaputra-Meghna freshwater plume at $18^{\circ} \mathrm{N}$ has been observed to suppress turbulence (diffusivity $K_{\mathrm{T}}<$ $10^{-5} \mathrm{~m}^{2} \mathrm{~s}^{-1}$ ) for multiple months (August-November) at depths of approximately 50-65 m (Fig. 20). This buoyant lens limited the vertical extent of the influence of Tropical Cyclone Komen as compared to a previous (weaker) storm (Chaudhuri et al., 2019; Thakur et al., 2019). Similar observations of extremely weak turbulence below strong, salinitystratified surface layers have been reported throughout the bay using data from a variety of platforms: ship-based microstructure (Jinadasa et al., 2016) profiling floats with a temperature microstructure sensor (Shroyer et al., 2016) and glider-based microstructure measurements (St. Laurent and Merrifield, 2017). Lucas et al. (2016) find that near-inertial shear was elevated at the base of the mixed layer but not elevated at the base of the barrier layer - direct evidence that salinity stratification can insulate deeper depths from the effects of near-surface forcing (downward-propagating nearinertial waves in this case). Li et al. (2017a) use a combination of observations and modelling results to demonstrate that barrier layers in the Bay of Bengal influence the amplitude of intraseasonal oscillations in SST and precipitation. However, a recent coarse-resolution coupled modelling study suggests that freshwater has little influence on SST or rainfall, since the SST tendency caused by a reduction in mixing is offset by changes in surface heat fluxes (Krishnamohan et al., 2019).

Surface freshwater advection can create subsurface reservoirs of heat and salt that can be accessed when the winds are strong enough, such as during cyclones that regularly form in the bay during October and November. In one dramatic example, Qiu et al. (2019) report up to 5 psu increases in SSS and only a smaller $0.5^{\circ} \mathrm{C}$ decrease in SST following the passage of Cyclone Phailin (2013). In this case, mooring records indicate that mixing was limited to the isothermal layer (Chaudhuri et al., 2019). Subsurface warm layers (i.e. temperature inversions stabilized by strong salinity stratification) are also observed, representing a reservoir of heat that can be accessed if a storm excites enough turbulence, as appears to have happened during the passage of Cyclone Hudhud (Warner et al., 2016). The influence of stratification in limiting the extent of vertical mixing and creating subsurface warm layers mean that cyclone-induced cooling is generally either weak or negligible in the bay, unlike in other ocean basins (Sengupta et al., 2008). Subsurface warm layers influence SST on longer timescales too: Girishkumar et al. (2013) find that the wintertime $\mathrm{SST}$ at $8^{\circ} \mathrm{N}, 90^{\circ} \mathrm{E}$ is quite sensitive to the thickness of the barrier layer and to the presence of temperature inversions (subsurface warm layers) in the barrier layer on intraseasonal and interannual timescales.

Long periods of near-molecular diffusivities (weeks to a month) were also inferred at multiple $\chi$ pods along $8^{\circ} \mathrm{N}$ between 50 and $100 \mathrm{~m}$ during transition months of March and April. Here freshwater insulation does not appear to be the major factor. Instead the period of weak turbulence may be linked to low levels of near-inertial energy (a consequence of weak wind forcing in March and April) and the absence of strong mean oceanic flows during these transition months (Cherian et al., 2020). Relatively weak diffusivities are also present in the LADCP fine-structure estimate of depth-integrated (thermocline to bottom) turbulent kinetic energy dissipation $\varepsilon$ (Kunze et al., 2006) and the Argo finestructure-based $250-500 \mathrm{~m}$ diffusivity estimates of Whalen et al. (2012). The extended presence of such weak turbulence suggests that the bay's internal wave field is weaker than might be expected from the Garrett-Munk internal wave spectrum at least during some months of the year. Another (related) question is the issue of representation of such weak background mixing in climate models and whether that matters to known biases in such models.

Published efforts so far have been directed towards understanding the modulation of turbulence by larger-scale variations in the wind, currents, and freshwater. Questions remain as to the impact of small-scale mixing on the largescale long-term T-S structure in the bay and the influence of subsurface mixing and the ensuing modification of SST on coupled ocean-atmosphere phenomena such as the MJO and the MISO (Sect. 3.2).

\subsection{Where vertical and lateral processes meet: the role of sub-mesoscale processes}

Freshwater inflow from the Ganga-Brahmaputra-Meghna (GBM) and the Irrawady river in the Bay of Bengal is stirred by the mesoscale eddies into sharp frontal gradients (in salinity and in density) at $\mathrm{O}(1-10 \mathrm{~km})$ scales with shallow vertical extent. These fronts are acted upon by winds seasonally, setting up complex sub-mesoscale structures with salinity differences $\mathrm{O}(1 \mathrm{psu})$ over $1-10 \mathrm{~km}$, developing bore-like features with $\mathrm{O}(0.5 \mathrm{psu})$ difference over a few metres horizontally (Nash et al., 2016; Fig. 21). Wavenumber spectra of temperature at $\mathrm{O}(1-10 \mathrm{~km})$ scale show a -2 slope in many regions of the bay (MacKinnon et al., 2016), a signature of frontogenesis in the bay at these scales. The BoB is thus replete with fronts which evidently slump at submesoscales due to both symmetric and baroclinic instabilities (Ramachandran et al., 2018) and shows higher stratification near fronts (Sree Lekha, 2020). 


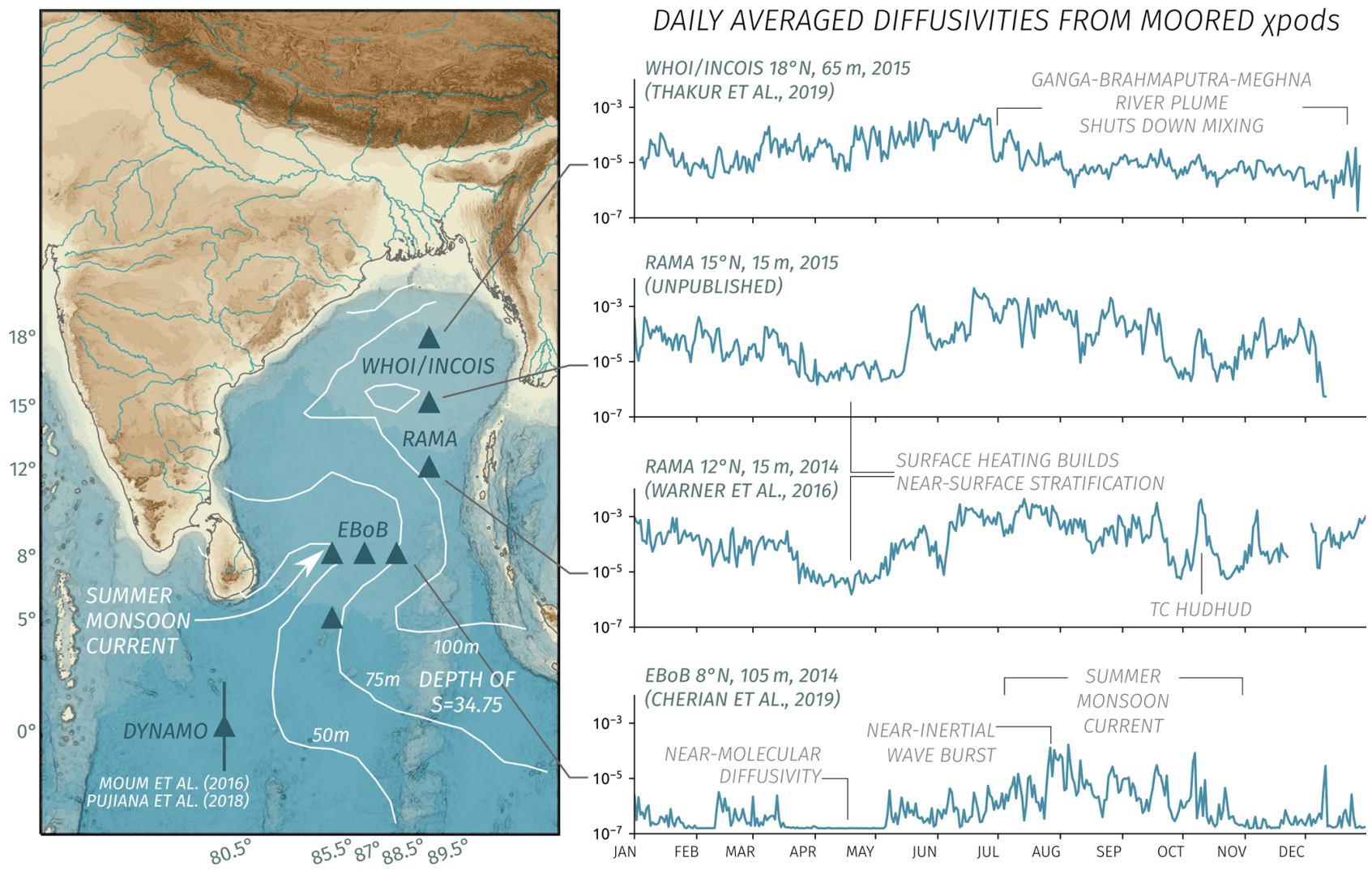

Figure 20. Annual cycle of daily averaged temperature diffusivities derived from $\chi$ pod measurements. The data are from 2 different years, 2014 and 2015 , depending on location. Note the similar wind-forced seasonal cycle at $12^{\circ} \mathrm{N}, 15 \mathrm{~m}$ and $15^{\circ} \mathrm{N}, 15 \mathrm{~m}$ and the dramatically different seasonal cycle at $8^{\circ} \mathrm{N}, 105 \mathrm{~m}$ (reflecting near-inertial wave activity) and at $18^{\circ} \mathrm{N}, 65 \mathrm{~m}$ (reflecting freshwater influence).

The fronts and filaments at $\mathrm{O}(1-10 \mathrm{~km})$, which are dominated by salinity gradients and weakly compensated, have strong implications for setting up the density stratification in the top 50-100 $\mathrm{m}$ in the BoB (Sect. 4.4.1). The stratification in this depth range often has multi-layered structure, with stratification varying at $\mathrm{O}(1-10 \mathrm{~km})$ scales (Lucas et al., 2016), showing evidence that the stratification in the bay cannot be explained simply in terms of vertical processes, and horizontal sub-mesoscale processes are intimately coupled with the vertical processes at these scales. Ramachandran et al. (2018) show that a mesoscale strained region with strong fronts $\left(\mathrm{O}\left(1 \mathrm{~kg} \mathrm{~m}^{-3}\right.\right.$ over $\left.\left.40 \mathrm{~km}\right)\right)$ and weak down-front wind shows multiple dynamical signatures of sub-mesoscale instabilities. Ageostrophic secondary circulations arising near the fronts and the accompanied sheared advection plays an important role in setting the stratification (Pham and Sarkar, 2019). Both observations and process modelling show $\mathrm{O}(1-$ $10 \mathrm{~km})$ patches of low potential vorticity consisting of subducted warm water patches due to a combination of baroclinic and forced symmetric instabilities, creating barrier layers with thicknesses that vary laterally at sub-mesoscales (Ramachandran and Tandon, 2020).
During winter, the temperature gradients in the horizontal compensate for the salinity gradients to reduce the density gradient, and the sub-mesoscale processes in BoB lead to a unique situation. Jaeger and Mahadevan (2018) show that surface cooling fluxes combined with sub-mesoscale instabilities of the haline fronts during wintertime lead to shallower mixed layers on the less saline (cooler) side. Therefore, cold SSTs in wintertime in the bay mark surface-trapped waters (Fig. 22), whereas in other regions of the world ocean, cold filaments mark upwelling of nutrient-rich waters. Further, since the shallow fresher mixed layers lead to larger drops in temperature, this develops the correlation between SST and SSS at $\mathrm{O}(1-10 \mathrm{~km})$ scales.

\subsection{Putting the pieces together}

\subsubsection{Coupled ocean-atmosphere phenomena}

Due to the presence of a barrier layer over much of the Bay of Bengal, entrainment and upwelling of waters from the thermocline are inhibited, and the evolution of SST is largely driven by net air-sea heat flux variability (Duncan and Han, 2009). However, the dependency of SST on surface fluxes is controlled by subsurface processes such as forma- 

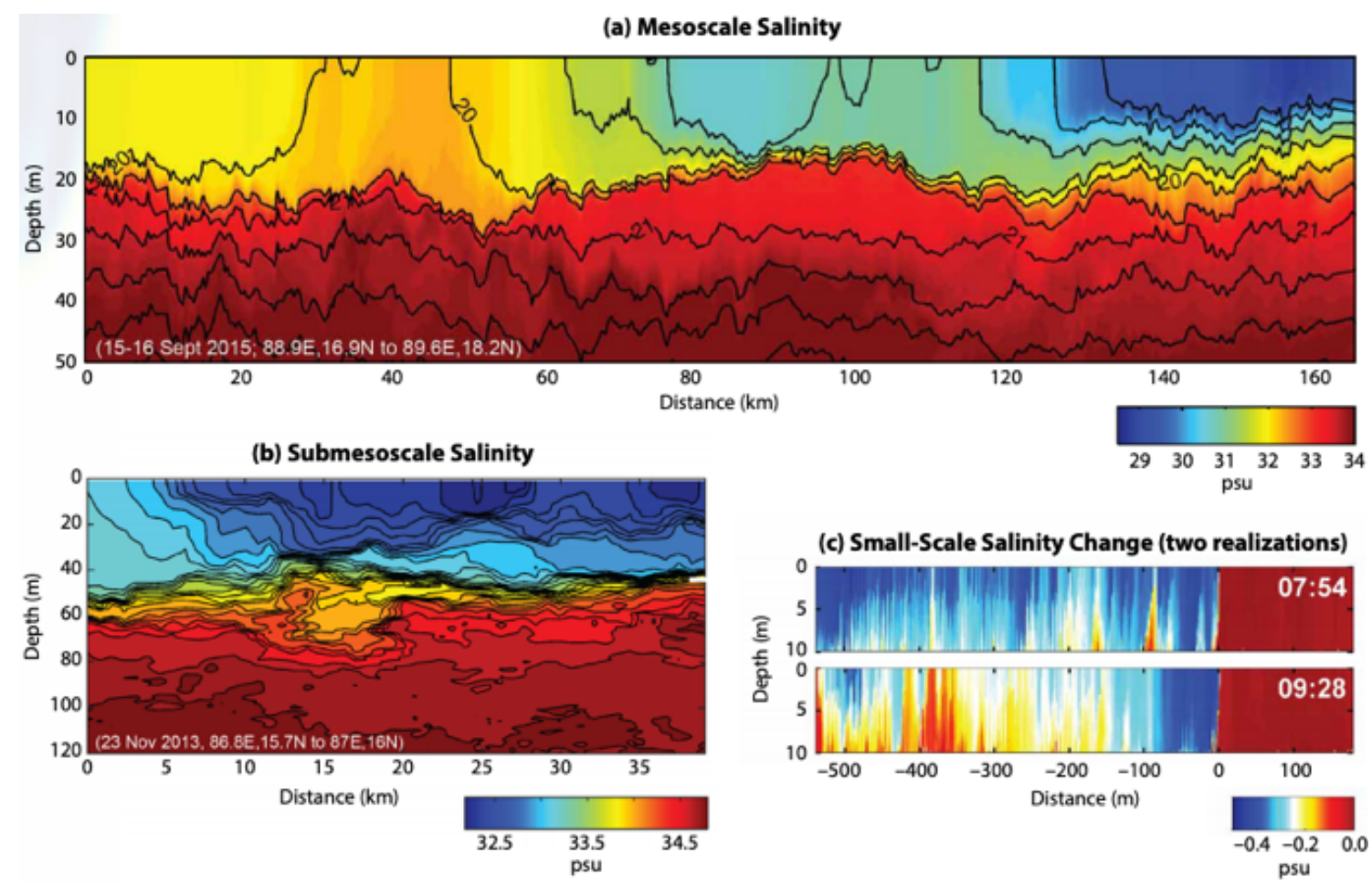

Figure 21. Observed salinity gradients at mesoscale, sub-mesoscale, and small horizontal scales in the Bay of Bengal (Nash et al., 2016).

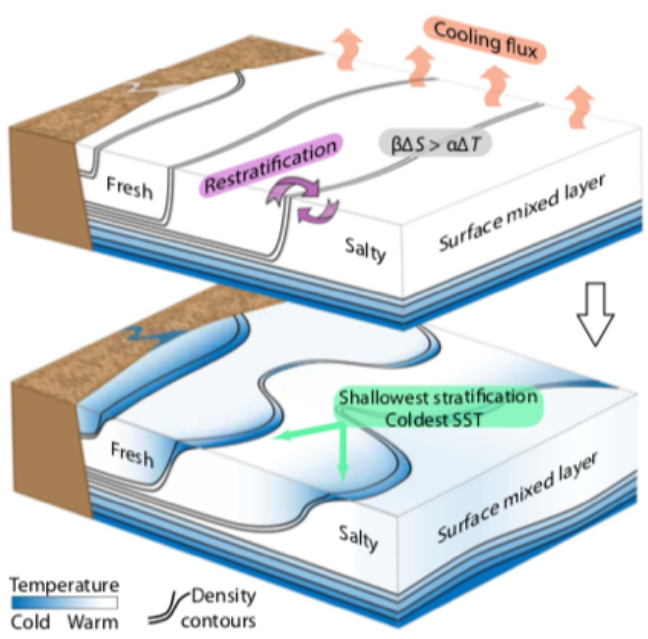

Density fronts controlled by salinity gradients:

Submesoscale circulation

Shallow vertical restratification (along front)

Atmosphere cools ocean Largest SST drop along front

Partial T-S compensation at frontal scale: Salty (deep) warm

Figure 22. Interaction of sub-mesoscale salinity gradients with atmospheric cooling leads to shallow cold regions (from Jaeger and Mahadevan, 2018).

tion of barrier layers, entrainment warming and cooling of the mixed layer, penetrative solar radiation, and zonal advection (Thangaprakash et al., 2016). Advection is important in influencing the SST as lateral variations in the mixedlayer depth alone can result in variations in air-sea fluxes of roughly $20 \mathrm{~W} \mathrm{~m}^{-2}$ over distances of kilometres (Adams et al., 2019). This magnitude is similar to uncertainty in air-sea flux products (Weller et al., 2016), thus implying that variations in sub-mesoscales are important for heat balance in the northern BoB. The coupling of the ocean-atmosphere over $\mathrm{BoB}$ at large scales implicates the air-sea interaction and the mixed-layer heat budget in the BoB (Rahaman et al., 2019), although at oceanic mesoscale and finer scales in the horizontal and at sub-seasonal timescales this coupling is a topic of active research.

\subsubsection{Implications for biogeochemistry in the bay}

Eddies in the central BoB arise not by the baroclinic instability of boundary currents but rather due to planetary wave dynamics off the Equator that triggers coastal Kelvin waves around the bay. The Kelvin waves then trigger southwestward-propagating Rossby waves, which result in large mesoscale structures in the bay (X. Cheng et al., 2018). The Andaman Islands and Nicobar Islands are also shown to be very important for the generation of these eddies; without these islands the number of eddies would have reduced to almost half in the western bay of Bengal (Mukherjee et al., 2019). These eddies provide much of the horizontal stretching and stirring of the tracers, including those relevant to the ecosystems.

Eddies have tremendous potential to influence ocean biogeochemistry by providing "new" nutrients to the ocean's euphotic layer (Stramma et al., 2013). However, we do not fully understand the spatial distribution of nutrients within 
the eddy surface area - e.g. there is a debate whether nutrients upwell at the core and downwell at the edge of the eddy or vice versa. Further, such discrepancy also continues in the type of eddies - i.e. whether upwelling occurs in cyclonic and downwelling occurs in anticyclonic eddies and vice versa (Mahadevan, 2014; Mahadevan et al., 2012; Martin and Richards, 2001). However, there is a consensus that eddies do impact biogeochemistry (McGillicuddy et al., 2007).

There have been only a handful of studies on the role of eddies in biological productivity in this region (Kumar et al., 2004, 2007; Singh et al., 2015). Kumar et al. (2007) observed an increase in surface nutrients in the bay through eddies during both autumn 2002 and spring 2003 followed by higher biomass. Despite being highly eutrophic, biological activity did not increase following cyclonic eddies during summer 2003 in the northern bay (Muraleedharan et al., 2007). However, primary production switched from "regenerated" to "new" production during summer 2003. In a ${ }^{15} \mathrm{~N}$ based new production estimate to assess the role of cyclonic eddies in enhancing primary production, Singh et al. (2015) carried out measurements of primary production at four stations in the Bay of Bengal (around a cyclonic eddy close to $17.8^{\circ} \mathrm{N}, 87.5^{\circ} \mathrm{E}$ ) during winter 2007 . The measurements sampled one cyclonic eddy during the campaign. The highest surface productivity $\left(2.71 \mu \mathrm{MCd}^{-1}\right)$ and chlorophyll $a$ $\left(0.18 \mu \mathrm{g} \mathrm{L}^{-1}\right)$ were observed within the eddy due to intrusion of nutrients from subsurface waters. Given new nitrogen input via vertical mixing, river discharge, or aerosol deposition, the additional primary production due to this new nutrient input and its contribution to the total production increased from $40 \%$ to $70 \%$. Eddies could be a reason for the otherwise unexplained high new production rates in the Bay of Bengal (Singh and Ramesh, 2015). Eddies also seem to have a potential for transferring a high fraction of fixed carbon to the deep. A couple of recent studies have highlighted the role of mesoscale eddies in changing the elemental proportions of carbon: nitrogen: phosphorus in the organic and nutrient pools in the euphotic layer of the bay (Sahoo et al., 2020, 2021).

\section{Summary and open questions}

This paper summarizes a suite of new studies in the Indian Ocean that have been made possible through national, bilateral, and international programmes, including the IIOE-2. An increase in high-quality observations (both increased spatial resolution and the acquisition of longer time series) has led to a substantial increase in our understanding of processes and interactions. These in situ observations, in combination with remote sensing, detailed syntheses, and modelling have increased our knowledge of the surface circulation and its complex implications for biological production, along with an increased understanding of air-sea interaction in the Indian Ocean.

There are, however, a number of outstanding questions that require prioritized efforts. Compared to the Atlantic and Pacific, where the important boundary currents are now being monitored with a suite of gliders with repeated and sustained sections (Todd et al., 2019), the boundary currents and their variability in the Indian Ocean remain poorly constrained. Given the anomalous warming of the Indian Ocean, the frequency of heatwaves, and the population supported by the Indian Ocean and monsoons, the air-sea fluxes and the coupled atmosphere-ocean exchange in this ocean remain poorly understood at many scales. Understanding of the intermediate, deep, and abyssal layer circulation and the vertical overturning cells that connect these layers in the Indian Ocean is lacking.

There are still many gaps in current understanding of Indian Ocean biogeochemical cycles, which we have presented here in the context of the physical processes that affect them. Although the characterization of the temporal and spatial variability in chlorophyll concentration and primary production has greatly improved as a result of recent in situ measurements and satellite remote sensing, there are still many areas where there is little or no information about how this relates to changes in planktonic food web structure and particulate organic matter export to the deep ocean. Although nutrient limitation patterns were not discussed in this review, it should be pointed out that the importance of nitrogen versus iron and silica limitation in the Arabian Sea and elsewhere in the Indian Ocean is still a subject of debate - more nutrient and trace metal measurements are needed, along with nutrient limitation bioassays throughout the Indian Ocean.

The number of nitrogen fixation rate measurements in the Indian Ocean has increased significantly over the last decade, but the importance of this process as a source of new nitrogen to the surface ocean has been quantified in only a few regions (e.g. off northwestern Australia), and its contribution to bloom formation (e.g. the Madagascar Bloom) is still uncertain. From a spatial standpoint, the quantification of biogeochemical variability in the northern Indian Ocean (Arabian Sea and Bay of Bengal) has benefited, in particular, from numerous shipboard measurements, moorings, and biogeochemical Argo float deployments in the last decade. Many questions still remain, for example, related to the influence of freshwater inputs on biogeochemical cycles in the Bay of Bengal. Remarkably, the biogeochemical and ecological impacts of the Indonesian Throughflow have been examined in only a handful of studies. Similarly, there are very few studies that focus on the biogeochemical and ecological impacts of the Seychelles-Chagos Thermocline Ridge (SCTR). The ITF and the SCTR are unique features of the Indian Ocean, yet the understanding of their biogeochemical and ecological impacts is rudimentary at best. Finally, the quantification of biogeochemical variability in the Leeuwin Current, Agulhas Current, and adjacent waters has also benefited from recent 
measurements, though it is important to point out that the biogeochemical impacts of boundary currents in the Indian Ocean are still poorly understood compared to the Atlantic and Pacific.

There are still large uncertainties in air-sea fluxes. Even in the regional basin of the Bay of Bengal where there have been focused international efforts, the river discharge and rain need to be better represented in models, as do the processes that set the shallow salinity stratification. These have important feedbacks on the SST, which impacts atmospheric convection with a global reach. At longer timescales, the salinity feedbacks to climate at interannual to decadal timescales need to be investigated in further detail. The decadal variability of the Indian Ocean Dipole and its link to the Pacific decadal variability also needs to be better understood, particularly given events like the record breaking 2019 positive IOD that developed independently from ENSO conditions. Marine heatwaves are an increasing threat to marine ecosystems fuelled by increasing mean temperatures in the ocean and atmosphere. There are still large gaps in our understanding of the Indian Ocean dynamics that lead to these extremes, and consequently in our ability to predict the onset, intensity, and frequency of extreme weather such as rainfall, flooding, and heatwaves, associated with anomalously strong climatic-mode events that have major socioeconomic impacts.

Modelling and observational efforts have both pointed to the increased role of air-sea coupling at higher frequencies to improve the predictions of sub-seasonal monsoon forecasts. Observations and models indicate that MISOs may be slowing down because of the warming in the Indian Ocean (e.g. Sabeerali et al., 2013), which needs to be understood better for providing reliable monsoon predictions and projections in this climate vulnerable region.

On the influence of small-scale mixing, increased measurements of ocean mixing both along the Equator and new long-term measurements in the Bay of Bengal have shown intensively enhanced mixing during the passage of eddies and during cyclones. However, there are still significant uncertainties in subsurface ocean mixing in setting the largescale balance in the Indian ocean.

It has been proposed that the hiatus in warming of the surface atmosphere may have ceased as the Pacific Ocean enters an El Niño-like state (Cha et al., 2018). However, the secular trends in the Pacific Ocean trade winds are expected to continue to affect the Indo-Pacific Ocean heat content through the Indonesian Throughflow (Maher et al., 2018). The Indian Ocean thus remains a critical component of the Earth's global response to the continued anthropogenic forcing and the ocean's role as a clearing house for distributing heat to modulate global warming.

Code availability. No original data analyses were undertaken as part of this review paper.
Data availability. No original data analyses were undertaken as part of this review paper. All data presented in this paper have been previously published and are available from sources identified in the original publications.

Author contributions. HEP and AT designed the review and wrote the introductory and concluding parts and sections in their areas of expertise. HEP and AT reviewed the contributions of the authors and made editorial adjustments. RH wrote the sections on biogeochemical variability in Sect. 4. All co-authors contributed to the writing of sections relevant to their areas of expertise and responded to reviewer questions. All authors contributed to refining the manuscript for submission. RF, CCU, JAB, BW, ASF, JH, and RM contributed editorial advice.

Competing interests. The authors declare that they have no conflict of interest.

Disclaimer. Publisher's note: Copernicus Publications remains neutral with regard to jurisdictional claims in published maps and institutional affiliations.

Special issue statement. This article is part of the special issue "Understanding the Indian Ocean system: past, present and future (BG/ACP/OS/SE inter-journal SI)". It is not associated with a conference.

Acknowledgements. The authors acknowledge the sustained efforts of researchers and funding agencies in observing and modelling the oceanic and atmospheric processes that control climate variability in the Indian Ocean region. These contributions during the International Indian Ocean Expeditions (I and II) and in the intervening years through national and international programmes, such as CLIVAR and GOOS, are fundamental to improving our knowledge of these systems and increasing our skill at forecasting variability and extreme events. We thank the IIOE-2 leadership team (https: //iioe-2.incois.gov.in/, last access: 22 October 2021) for their unwavering efforts to share new discoveries and promote understanding of the importance of the Indian Ocean to the climate system and Earth's inhabitants. We are very grateful to Michael McPhaden, Lisa Beal, and an anonymous reviewer for their encouraging and constructive comments that have led to a more comprehensive and balanced synthesis of recent advances. Helen E. Phillips acknowledges support from the Earth Systems and Climate Change Hub and Climate Systems Hub of the Australian Government's National Environmental Science Programme and the ARC Centre of Excellence for Climate Extremes. Amit Tandon acknowledges the US Office of Naval Research. This is INCOIS contribution no. 437.

Review statement. This paper was edited by Hermann Bange and reviewed by Michael McPhaden and one anonymous referee. 


\section{References}

Abram, N. J., Gagan, M. K., Cole, J. E., Hantoro, W. S., and Mudelsee, M.: Recent intensification of tropical climate variability in the Indian Ocean, Nat. Geosci., 1, 849-853, https://doi.org/10.1038/ngeo357, 2008.

Abram, N. J., Hargreaves, J. A., Wright, N. M., Thirumalai, K., Ummenhofer, C. C., and England, M. H.: Palaeoclimate perspectives on the Indian Ocean Dipole, Quat. Sci. Rev., 237, 106302, https://doi.org/10.1016/j.quascirev.2020.106302, 2020a.

Abram, N. J., Wright, N. M., Ellis, B., Dixon, B. C., Wurtzel, J. B., England, M. H., Ummenhofer, C. C., Philibosian, B., Cahyarini, S. Y., Yu, T.-L., Shen, C.-C., Cheng, H., Edwards, R. L., and Heslop, D.: Coupling of Indo-Pacific climate variability over the last millennium, Nature, 579, 385-392, https://doi.org/10.1038/s41586-020-2084-4, 2020 b.

Adams, K., MacKinnon, J., Lucas, A. J., Nash, J., Shroyer, E., and Farrar, J. T.: Multi-platform observations of small-scale lateral mixed layer variability in the northern Bay of Bengal, Deep-Sea Res. Pt. II, 168, 104629, https://doi.org/10/ggdzdw, 2019.

Akhil, V. P., Durand, F., Lengaigne, M., Vialard, J., Keerthi, M. G., Gopalakrishna, V. V., Deltel, C., Papa, F., and De Boyer Montégut, C.: A modeling study of the processes of surface salinity seasonal cycle in the Bay of Bengal, J. Geophys. Res.-Oceans, 119, 3926-3947, https://doi.org/10.1002/2013JC009632, 2014.

Alory, G., Wijffels, S., and Meyers, G.: Observed temperature trends in the Indian Ocean over 1960-1999 and associated mechanisms, Geophys. Res. Lett., 34, L02606, https://doi.org/10.1029/2006GL028044, 2007.

Amol, P., Shankar, D., Fernando, V., Mukherjee, A., Aparna, S. G., Fernandes, R., Michael, G. S., Khalap, S. T., Satelkar, N. P., Agarvadekar, Y., Gaonkar, M. G., Tari, A. P., Kankonkar, A., and Vernekar, S. P.: Observed intraseasonal and seasonal variability of the West India Coastal Current on the continental slope, J. Earth Syst. Sci., 123 1045-1074, https://doi.org/10.1007/s12040-014-0449-5, 2014.

Anderson, D. L. T. and Gill, A. E.: Spin-up of a stratified ocean, with applications to upwelling, Deep-Sea Res., 22, 583-596, https://doi.org/10.1016/0011-7471(75)90046-7, 1975.

Andersson, H. C. and Stigebrandt, A.: Regulation of the Indonesian throughflow by baroclinic draining of the North Australian Basin, Deep-Sea Res. Pt. I, 52, 2214-2233, https://doi.org/10.1016/j.dsr.2005.06.014, 2005.

Andrews, J. C.: Eddy structure and the West Australian current, Deep-Sea Res., 24, 1133-1148, https://doi.org/10.1016/01466291(77)90517-3, 1977.

Annamalai, H., Potemra, J., Murtugudde, R., and McCreary, J. P.: Effect of preconditioning on the extreme climate events in the tropical Indian Ocean, J. Climate, 18, 3450-3469, https://doi.org/10.1175/JCLI3494.1, 2005.

Antonov, J. I., Seidov, D., Boyer, T. P., Locarnini, R. A., Mishonov, A. V., and Garcia, H. E.: World Ocean Atlas 2009, Volume 2: Salinity. NOAA Atlas NESDIS 69, NOAA, U.S. Government Printing Office, Washington D.C., 2010.

Anutaliya, A., Send, U., McClean, J. L., Sprintall, J., Rainville, L., Lee, C. M., Jinadasa, S. U. P., Wallcraft, A. J., and Metzger, E. J.: An undercurrent off the east coast of Sri Lanka, Ocean Sci., 13, 1035-1044, https://doi.org/10.5194/os-13-1035-2017, 2017.

Arzeno, I. B., Giddings, S. N., Pawlak, G., and Pinkel, R.: Generation of Quasi Biweekly Yanai Waves in the Equato- rial Indian Ocean, Geophys. Res. Lett., 47, e2020GL088915. https://doi.org/10.1029/2020GL088915, 2020.

Ash, K. D. and Matyas, C. J.: The influences of ENSO and the Subtropical Indian Ocean Dipole on tropical cyclone trajectories in the South Indian Ocean, Int. J. Climatol., 32, 41-56, https://doi.org/10.1002/joc.2249, 2012.

Ashok, K., Guan, Z., Saji, N. H., and Yamagata, T.: Individual and Combined Influences of ENSO and the Indian Ocean Dipole on the Indian Summer Monsoon, J. Climate, 17, 3141-3155, https://doi.org/10.1175/15200442(2004)017<3141:IACIOE>2.0.CO;2, 2004.

Ayers, J. M., Strutton, P. G., Coles, V. J., Hood, R. R., and Matear, R. J.: Indonesian throughflow nutrient fluxes and their potential impact on Indian Ocean productivity, Geophys. Res. Lett., 41, 5060-5067, https://doi.org/10.1002/2014GL060593, 2014.

Bahmanpour, M. H., Pattiaratchi, C., Wijeratne, E. M. S., Steinberg, C., and D'Adamo, N.: Multi-year observation of Holloway Current along the shelf edge of North Western Australia, J. Coast. Res., 517-521, https://doi.org/10.2112/SI75-104.1, 2016.

Banks, C. J., Srokosz, M. A., Cipollini, P., Snaith, H. M., Blundell, J. R., Gommenginger, C. P., and Tzortzi, E.: Reduced ascending/descending pass bias in SMOS salinity data demonstrated by observing westward-propagating features in the South Indian Ocean, Remote Sens. Environ., 180, 154-163, https://doi.org/10.1016/j.rse.2016.02.035, 2016.

Banse, K. and English, D. C.: Geographical differences in seasonality of CZCS-derived phytoplankton pigment in the Arabian Sea for 1978-1986, Deep-Sea Res. Pt. II, 47, 1623-1677, https://doi.org/10.1016/S0967-0645(99)00157-5, 2000.

Banse, K. and McClain, C.: Winter blooms of phytoplankton in the Arabian Sea as observed by the Coastal Zone Color Scanner, Mar. Ecol. Prog. Ser., 34, 201-211, https://doi.org/10.3354/meps034201, 1986.

Baranowski, D. B., Flatau, M. K., Flatau, P. J., and Matthews, A. J.: Impact of atmospheric convectively coupled equatorial kelvin waves on upper ocean variability, J. Geophys. Res.-Atmos., 121, 2045-2059, https://doi.org/10.1002/2015jd024150, 2016.

Barlow, R., Lamont, T., Morris, T., Sessions, H., and van den Berg, M.: Adaptation of phytoplankton communities to mesoscale eddies in the Mozambique Channel, Deep-Sea Res. Pt. II, 100, 106118, https://doi.org/10.1016/j.dsr2.2013.10.020, 2014.

Beal, L. M. and Bryden, H. L.: The velocity and vorticity structure of the Agulhas Current at $32^{\circ} \mathrm{S}$, J. Geophys. Res.-Oceans, 104, 5151-5176, https://doi.org/10.1029/1998jc900056, 1999.

Beal, L. M. and Donohue, K. A.: The Great Whirl: Observations of its seasonal development and interannual variability, J. Geophys. Res.-Oceans, 118, 1-13, https://doi.org/10.1029/2012JC008198, 2013.

Beal, L. and Elipot, S.: Broadening not strengthening of the Agulhas Current since the early 1990s, Nature, 540, 570-573, https://doi.org/10.1038/nature19853, 2016.

Beal, L. M., De Ruijter, W. P. M., Biastoch, A., Zahn, R., Cronin, M., Hermes, J., Lutjeharms, J., Quartly, G., Tozuka, T., BakerYeboah, S., Bornman, T., Cipollini, P., Dijkstra, H., Hall, I., Park, W., Peeters, F., Penven, P., Ridderinkhof, H., and Zinke, J.: On the role of the Agulhas system in ocean circulation and climate, Nature, 118, 1-13, https://doi.org/10.1038/nature09983, 2011. 
Beal, L. M., Hormann, V., Lumpkin, R., and Foltz, G. R.,: The Response of the Surface Circulation of the Arabian Sea to Monsoonal Forcing, J. Phys. Oceanogr., 43, 2008-2022, 2013.

Beal, L. M., Elipot, S., Houk, A., and Leber, G. M.: Capturing the Transport Variability of aWestern Boundary Jet: Results from the Agulhas Current Time-Series Experiment (ACT)*, J. Phys. Oceanogr., 45, 1302-1324, https://doi.org/10.1175/jpo-d14-0119.1, 2015.

Beal, L. M., Vialard, J., Roxy, M. K., and lead authors: IndOOS-2: A roadmap to sustained observations of the Indian Ocean for 2020-2030, CLIVAR-4/2019, GOOS-237, 204 pp., https://doi.org/10.36071/clivar.rp.4.2019, 2019.

Beal, L. M., Vialard, J., Roxy, M. K., Li, J., Andres, M., Annamalai, H., Feng, M., Han, W., Hood, R., Lee, T., Lengaigne, M., Lumpkin, R., Masumoto, Y., McPhaden, M. J., Ravichandran, M., Shinoda, T., Sloyan, B. M., Strutton, P. G., Subramanian, A. C., Tozuka, T., Ummenhofer, C. C., Unnikrishnan, A. S., Wiggert, J., Yu, L., Cheng, L., Desbruyères, D. G., and Parvathi, V.: A Road Map to IndOOS-2: Better Observations of the Rapidly Warming Indian Ocean, B. Am. Meteorol. Soc., 101, E1891E1913, 2020.

Behera, S. K. and Yamagata, T.: Subtropical SST dipole events in the southern Indian Ocean, Geophys. Res. Lett., 28, 327-330, https://doi.org/10.1029/2000GL011451, 2001.

Bellon, G., Sobel, A. H., and Vialard, J.: Ocean-atmosphere coupling in the monsoon intraseasonal oscillation: A simple model study, J. Climate, 21, 5254-5270, https://doi.org/10.1175/2008JCLI2305.1, 2008.

Benshila, R., Durand, F., Masson, S., Bourdalle-Badie, R., de Boyer Montégut, C., Papa, F., and Madec, G.: The upper Bay of Bengal salinity structure in a high-resolution model, Ocean Model., 74, 36-52, https://doi.org/10.1016/j.ocemod.2013.12.001, 2014.

Benthuysen, J., Feng, M., and Zhong, L.: Spatial patterns of warming off Western Australia during the 2011 Ningaloo Niño: quantifying impacts of remote and local forcing, Continental Shelf Res., 91, 232-246, https://doi.org/10.1016/j.csr.2014.09.014, 2014a.

Benthuysen, J., Furue, R., McCreary, J. P., Bindoff, N. L., and Phillips, H. E.: Dynamics of the Leeuwin Current: Part 2. Impacts of mixing, friction, and advection on a buoyancy-driven eastern boundary current over a shelf, Dyn. Atmos. Oceans, 65, 39-63, https://doi.org/10.1016/j.dynatmoce.2013.10.004, 2014b.

Benthuysen, J. A., Oliver, E. C. J., Feng, M., and Marshall, A. G.: Extreme marine warming across tropical Australia during austral summer 2015-2016, J. Geophys. Res.-Oceans, 123, 1301-1326, https://doi.org/10.1002/2017JC013326, 2018.

Bergman, J. W., Hendon, H. H., and Weickmann, K. M.: Intraseasonal air-sea interactions at the onset of El Nino, J. Climate, 14, 1702-1719, 2001.

Beron-Vera, F. J., Wang, Y., Olascoaga, M. J., Goni, G. J., and Haller, G.: Objective detection of oceanic eddies and the Agulhas leakage, J. Phys. Oceanogr., 43, 1426-1438, https://doi.org/10.1175/JPO-D-12-0171.1, 2013.

Biastoch, A. and Böning, C. W.: Anthropogenic impact on Agulhas leakage, Geophys. Res. Lett., 40, 1138-1143, https://doi.org/10.1002/grl.50243, 2013.

Biastoch, A., Böning, C. W., and Lutjeharms, J. R. E.: Agulhas leakage dynamics affects decadal variability in
Atlantic overturning circulation, Nature, 456, 489-492, https://doi.org/10.1038/nature07426, 2008.

Biastoch, A., Böning, C. W., Schwarzkopf, F. U., and Lutjeharms, J. R. E.: Increase in Agulhas leakage due to poleward shift of Southern Hemisphere westerlies, Nature, 462, 495-498, https://doi.org/10.1038/nature08519, 2009.

Biastoch, A., Durgadoo, J. V., Morrison, A. K., Van Sebille, E., Weijer, W., and Griffies, S. M.: Atlantic multi-decadal oscillation covaries with Agulhas leakage, Nat. Commun., 6, 10082, https://doi.org/10.1038/ncomms10082, 2015.

Brock, J. C. and McClain, C. R.: Interannual variability in phytoplankton blooms observed in the northwestern Arabian Sea during the southwest monsoon, J. Geophys. Res., 97, 733-750, https://doi.org/10.1029/91JC02225, 1992.

Brown, S. L., Landry, M. R., Barber, R. T., Campbell, L., Garrison, D. L., and Gowing, M. M.: Picophytoplankton dynamics and production in the Arabian Sea during the 1995 Southwest Monsoon, Deep-Sea Res. Pt. II, 46, 1745-1768, https://doi.org/10.1016/S0967-0645(99)00042-9, 1999.

Bryden, H. and Beal, L.: Role of the Agulhas Current in Indian Ocean circulation and associated heat and freshwater fluxes, Deep-Sea Res. Pt. I, 48, 1821-1845, 2001.

Buckley, J., Mingels, B., and Tandon, A.: The impact of lateral advection on SST and SSS in the northern Bay of Bengal during 2015, Deep-Sea Res. Pt. II, 172, 104653, https://doi.org/10.1016/j.dsr2.2019.104653, 2020.

Burns, J., Bulusu, S., and Murty, V. S. N.: On the dynamics of the Sri Lanka Dome in the Bay of Bengal, J. Geophys. Res.-Oceans, 122, 7737-7750, https://doi.org/10.1002/2017jc012986, 2017.

Cai, W., Sullivan, A., and Cowan, T.: Shoaling of the offequatorial south Indian Ocean thermocline: Is it driven by anthropogenic forcing?, Geophys. Res. Lett., 35, L12711, https://doi.org/10.1029/2008GL034174, 2008.

Cai, W., Cowan, T., and Sullivan, A.: Recent unprecedented skewness towards positive Indian Ocean Dipole occurrences and their impact on Australian rainfall, Geophys. Res. Lett., 36, L11705, https://doi.org/10.1029/2009GL037604, 2009a.

Cai, W., Pan, A., Roemmich, D., Cowan, T., and Guo, X.: Argo profiles a rare occurrence of three consecutive positive Indian Ocean Dipole events, 2006-2008, Geophys. Res. Lett., 36, L08701, https://doi.org/10.1029/2008GL037038, 2009b.

Cai, W., Sullivan, A., and Cowan, T.: Climate change contributes to more frequent consecutive positive Indian Ocean Dipole events, Geophys. Res. Lett., 36, L23704, https://doi.org/10.1029/2009GL040163, 2009c.

Cai, W., Sullivan, A., and Cowan, T.: How rare are the 2006 2008 positive Indian Ocean Dipole events? An IPCC AR4 climate model perspective, Geophys. Res. Lett., 36, L08702, https://doi.org/10.1029/2009GL037982, 2009d.

Cai, W., Zheng, X.-T. , Weller, E., Collins, M., Cowan, T., Lengaigne, M., Yu, W., and Yamagata, T.: Projected response of the Indian Ocean Dipole to greenhouse warming, Nat. Geosci., 6, 999-1007, https://doi.org/10.1038/ngeo2009, 2013.

Cai, W., Borlace, S., Lengaigne, M., van Rensch, P., Collins, M., Vecchi, G., Timmermann, A., Santoso, A., McPhaden, M. J., Wu, L., and England, M. H.: Increasing frequency of extreme El Niño events due to greenhouse warming, Nat. Clim. Change, 4, 111116, https://doi.org/10.1038/nclimate2100, 2014a. 
Cai, W., Santoso, A., Wang, G., Weller, E., Wu, L., Ashok, K., Masumoto, Y., and Yamagata, T.: Increased frequency of extreme Indian Ocean Dipole events due to greenhouse warming, Nature, 510, 254-258, https://doi.org/10.1038/nature13327, 2014b.

Cai, W. Wang, G., Santoso, A., McPhaden, M. J., Wu, L., Jin, F. F., Timmermann, A., Collins, M., Vecchi, G., Lengaigne, M., and England, M. H.: Increased frequency of extreme La Niña events under greenhouse warming, Nat. Clim. Change, 5, 132137, https://doi.org/10.1038/nclimate2492, 2015.

Cai, W., Wu, L., Lengaigne, M., Li, T., McGregor, S., Kug, J.-S., Yu, J.-Y., Stuecker, M. F., Santoso, A., Li, X., Ham, Y.-G., Chikamoto, Y., Ng, B., McPhaden, M. J., Du, Y., Dommenget, D., Jia, F., Kajtar, J. B., Keenlyside, N., Lin, X., Luo, J.-J., Martín-Rey, M., Ruprich-Robert, Y., Wang, G., Xie, S.-P., Yang, Y., Kang, S. M., Choi, J.-Y., Gan, B., Kim, G.-I., Kim, C.-E., Kim, S., Kim, J.-H., and Chang, P.: Pantropical climate interactions, Science, 363, 944, https://doi.org/10.1126/science.aav4236, 2019.

Caley, T., Giraudeau, J., Malaizé, B., Rossignol, L., and Pierre, C.: Agulhas leakage as a key process in the modes of Quaternary climate changes, P. Natl. Acad. Sci. USA, 109, 6835-6839, https://doi.org/10.1073/pnas.1115545109, 2012.

Castellanos, P., Campos, E. J. D., Piera, J., Sato, O. T., and Silva Dias, M. A. F.: Impacts of Agulhas leakage on the tropical Atlantic western boundary systems, J. Climate, 30, 6645-6659, https://doi.org/10.1175/JCLI-D-15-0878.1, 2017.

Centurioni, L. R.: Drifter Technology and Impacts for Sea Surface Temperature, Sea Level Pressure, and Ocean Circulation Studies, in: Observing the Oceans in Real Time, edited by: Venkatesan, R., Tandon, A., D'Asaro, E., and Atmanand, M. A., 37-57, Springer International Publishing, Cham, 2018.

Cessi, P.: The Global Overturning Circulation, Annu. Rev. Marine Sci., 11, 249-270, https://doi.org/10.1146/annurev-marine010318-095241, 2019

Cha, S.-C., Moon, J.-H., and Song, Y. T.: A recent shift toward an El Niño-like ocean state in the tropical Pacific and the resumption of ocean warming, Geophys. Res. Lett., 45, 11885-11894, https://doi.org/10.1029/2018GL080651, 2018.

Chatterjee, A., Shankar, D., Shenoi, S. S. C., Reddy, G. V., Michael, G. S., Ravichandran, M., Gopalkrishna, V. V., Rao, E. P. R., Bhaskar, T. V. S. U., and Sanjeevan, V. N.: A new atlas of temperature and salinity for the North Indian Ocean, J. Earth Syst. Sci., 121, 559-593, https://doi.org/10.1007/s12040-012-0191-9, 2012.

Chatterjee, A., Shankar, D., McCreary, J. P., and Vinayachandran, P. N.: Yanai waves in the western equatorial Indian Ocean, J. Geophys. Res.-Oceans, 118, 1556-1570, https://doi.org/10.1002/jgrc.20121, 2013.

Chatterjee, A., Shankar, D., McCreary, J. P., Vinayachandran, P. N., and Mukherjee, A.: Dynamics of Andaman Sea circulation and its role in connecting the equatorial Indian Ocean to the Bay of Bengal, J. Geophys. Res.-Oceans, 122, 3200-3218, https://doi.org/10.1002/2016JC012300, 2017.

Chatterjee, A., Kumar, B. P., Prakash, S., and Singh, P.: Annihilation of the Somali upwelling system during summer monsoon, Sci. Rep-UK, 9, 7598, https://doi.org/10.1038/s41598-019-44099-1, 2019.

Chaudhuri, D., Sengupta, D., D’Asaro, E., Venkatesan, R., and Ravichandran, M.: Response of the salinity-stratified bay of
Bengal to Cyclone Phailin, J. Phys. Oceanogr., 49, 1121-1140, https://doi.org/10.1175/JPO-D-18-0051.1, 2019.

Chaudhuri, A., Shankar, D., Aparna, S. G., Amol, P., Fernando, V., Kankonkar, A., Micheal, G. S., Satelkar, N. P., Khalap, S. T., Tari, A. P., Gaonkar, M. G., Ghatkar, S., and Khedekar, R. R.: Observed variability of the West India Coastal Current on the continental slope from 2009-2018, J. Earth Syst. Sci., 129, 57, https://doi.org/10.1007/s12040-019-1322-3, 2020.

Chen, G., Han, W., Li, Y., Wang, D., and McPhaden, M. J.: Seasonal-to-interannual time-scale dynamics of the equatorial undercurrent in the Indian Ocean, J. Phys. Oceanogr., 45, 1532 1553, https://doi.org/10.1175/JPO-D-14-0225.1, 2015.

Chen, G., Han, W., Shu, Y., Li, Y., Wang, D., and Xie, Q.: The role of Equatorial Undercurrent in sustaining the Eastern Indian Ocean upwelling, Geophys. Res. Lett., 43, 6444-6451, https://doi.org/10.1002/2016GL069433, 2016.

Chen, G., Han, W., Li, Y., Yao, J., and Wang, D.: Intraseasonal Variability of the Equatorial Undercurrent in the Indian Ocean, J. Phys. Oceanogr., 49, 85-101, 2019.

Cheng, X., McCreary, J. P., Qiu, B., Qi, Y., Du, Y., and Chen, X.: Dynamics of Eddy Generation in the Central Bay of Bengal, J. Geophys. Res.-Oceans, 123, 6861-6875, https://doi.org/10.1029/2018JC014100, 2018.

Cheng, Y., Putrasahan, D., Beal, L., and Kirtman, B.: Quantifying Agulhas leakage in a high-resolution climate model, J. Climate, 29, 6881-6892, https://doi.org/10.1175/JCLI-D-150568.1, 2016.

Cheng, Y., Beal, L. M., Kirtman, B. P., and Putrasahan, D.: Interannual Agulhas Leakage Variability and Its Regional Climate Imprints, J. Climate, 31, 10105-10121, 2018.

Cherian, D. A., Shroyer, E. L., Wijesekera, H. W., and Moum, J. N.: The Seasonal Cycle of Upper-Ocean Mixing at $8^{\circ} \mathrm{N}$ in the Bay of Bengal, J. Phys. Oceanogr., 50, 323-342, https://doi.org/10.1175/jpo-d-19-0114.1, 2020.

Chi, N.-H., Lien, R.-C., D'Asaro, E. A., and Ma, B. B. The surface mixed layer heat budget from mooring observations in the central Indian Ocean during Madden-Julian Oscillation events, J. Geophys. Res.-Oceans, 119, 4638-4652, https://doi.org/10.1002/2014JC010192, 2014

Chowdary, J. S., Xie, S., Tokinaga, H., Okumura, Y. M., Kubota, H., Johnson, N., and Zheng, X.: Interdecadal variations in ENSO teleconnection to the Indo-Western Pacific for 1870-2007, J. Climate, 25, 1722-1744, 2012.

Chowdary, J. S., Bandgar, A. B., Gnanaseelan, C., and Luo, J. J.: Role of tropical Indian Ocean air-sea interactions in modulating Indian summer monsoon in a coupled model, Atmos. Sci. Lett., 16, 170-176, https://doi.org/10.1002/as12.561, 2015.

Church, J. A., Cresswell, G. R., and Godfrey, J. S.: The Leeuwin Current, in: Poleward Flows Along Eastern Ocean Boundaries, Coastal and Estuarine Studies (formerly Lecture Notes on Coastal and Estuarine Studies), vol 34, edited by: Neshyba, S. J., Mooers, C. N. K., Smith, R. L., and Barber, R. T., Springer, New York, 230-254, https://doi.org/10.1007/978-1-4613-89637_16, 1989.

Cirano, M. and Middleton, J. F.: Aspects of the mean wintertime circulation along Australia's southern shelves: Numerical studies, J. Phys. Oceanogr., 34, 668-684, https://doi.org/10.1175/2509.1, 2004. 
Coles, V. J., Wilson, C., and Hood, R. R.: Remote sensing of new production fuelled by nitrogen fixation, Geophys. Res. Lett., 31, L06301, https://doi.org/10.1029/2003g1019018, 2004.

Crétat, J., Terray, P., Masson, S., and Sooraj, K. P.: Intrinsic precursors and timescale of the tropical Indian Ocean Dipole: insights from partially decoupled numerical experiment, Clim. Dynam., 51, 1311-1332, https://doi.org/10.1007/s00382-017-39567, 2018.

Cullen, K. E. and Shroyer, E. L.: Seasonality and interannual variability of the Sri Lanka dome, Deep-Sea Res. Pt. II, 168, 104642, https://doi.org/10.1016/j.dsr2.2019.104642, 2019.

Currie, J. C., Lengaigne, M., Vialard, J., Kaplan, D. M., Aumont, O., Naqvi, S. W. A., and Maury, O.: Indian Ocean Dipole and El Niño/Southern Oscillation impacts on regional chlorophyll anomalies in the Indian Ocean, Biogeosciences, 10, 6677-6698, https://doi.org/10.5194/bg-10-6677-2013, 2013.

Cuypers, Y., Le Vaillant, X., Bouruet-Aubertot, P., Vialard, J., and McPhaden, M. J.: Tropical storm-induced near-inertial internal waves during the Cirene experiment: energy fluxes and impact on vertical mixing, J. Geophys. Res., 118, 358-380, https://doi.org/10.1029/2012JC007881, 2013.

Cyriac, A., McPhaden, M., Phillips, H., Bindoff, N., and Feng, M.: Surface layer heat balance in the subtropical Indian Ocean, J. Geophys. Res.-Oceans, 124, 6459-6477, https://doi.org/10.1029/2018JC014559, 2019.

Cyriac, A., Phillips, H. E., Bindoff, N. L., Mao, H., and Feng, M.: Observational estimates of turbulent mixing in the southeast Indian Ocean, J. Phys. Oceanogr., 51, 2103-2128, https://doi.org/10.1175/jpo-d-20-0036.1, 2021.

D'Adamo, N., Fandry, C., Buchan, S., and Domingues, C.: Northern sources of the Leeuwin Current and the "Holloway Current" on the North West Shelf, J. Roy. Soc. Western Australia, 92, 53-66, 2009.

D’Addezio, J. M., Subrahmanyam, B., Nyadjro, E. S., and Murty, V. S. N.: Seasonal Variability of Salinity and Salt Transport in the Northern Indian Ocean, J. Phys. Oceanogr., 45, 1947-1966, 2015.

Daher, H., Beal, L. M., and Schwarzkopf, F. U.: A new improved estimation of Agulhas Leakage using observations and simulations of Lagrangian floats and drifters, J. Geophys. Res.-Oceans, 125, e2019JC015753, https://doi.org/10.1029/2019JC015753, 2020.

David, D. T., Kumar, S. P., Byju, P., Sarma, M. S. S., Suryanarayana, A., and Murty, V. S. N.: Observational evidence of lower-frequency Yanai waves in the central equatorial Indian Ocean, J. Geophys. Res., 116, C06009, https://doi.org/10.1029/2010JC006603, 2011.

De Boer, A. M., Graham, R. M., Thomas, M. D., and Kohfeld, K. E.: The control of the Southern Hemisphere Westerlies on the position of the Subtropical Front, J. Geophys. Res.-Oceans, 118, 5669-5675, https://doi.org/10.1002/jgrc.20407, 2013.

DeMott, C. A., Klingaman, N. P., and Woolnough, S. J.: Atmosphere-ocean coupled processes in the MaddenJulian oscillation, Rev. Geophys., 53, 1099-1154, https://doi.org/10.1002/2014RG000478, 2015.

Desbruyères, D. G., McDonagh, E. L., King, B. A., and Thierry, V.: Global and Full-Depth Ocean Temperature Trends during the Early Twenty-First Century from Argo and Repeat Hydrography, J. Climate, 30, 1985-1997, https://doi.org/10.1175/JCLI-D-160396.1, 2017.
Deshpande, A., Gnanaseelan, C., Chowdary, J., and Rahul, S.: Interannual spring Wyrtki jet variability and its regional impacts, Dyn. Atmos. Oceans, 78, 26-37, 2017.

de Vos, A., Pattiaratchi, C. B., and Wijeratne, E. M. S.: Surface circulation and upwelling patterns around Sri Lanka, Biogeosciences, 11, 5909-5930, https://doi.org/10.5194/bg-11-59092014, 2014.

Dhage, L. and Strub, P. T.: Intra-seasonal sea level variability along the west coast of India, J. Geophys. Res.-Oceans, 121, 81728188, https://doi.org/10.1002/2016JC011904, 2016.

Dileepkumar, M.: Biogeochemistry of the North Indian Ocean; IGBP-WCRP-SCOPE Rep. Ser. 1, Indian Nat. Sci. Acad., New Delhi, India, 2006.

Dilmahamod, A. F.: Links between the Seychelles-Chagos thermocline ridge and large scale climate modes and primary productivity and the annual cycle of chlorophyll-a, PhD thesis, University of Cape Town, 2014.

Dilmahamod, A. F., Aguiar-González, B., Penven, P., Reason, C. J. C., De Ruijter, W. P. M., Malan, N., and Hermes, J. C.: SIDDIES corridor: A major east-west pathway of longlived surface and subsurface eddies crossing the subtropical south indian ocean, J. Geophys. Res.-Oceans, 123, 5406-5425, https://doi.org/10.1029/2018JC013828, 2018.

Dilmahamod, A. F., Penven, P., Aguiar-González, B., Reason, C. J. C., and Hermes, J. C.: A new definition of the South-East Madagascar Bloom and analysis of its variability, J. Geophys. Res.-Oceans, 124, 1717-1735, https://doi.org/10.1029/2018JC014582, 2019.

Dilmahamod, A., Penven, P., Aguiar-Gonzalez, B., Reason, C. J. C., and Hermes, J. C.: A model investigation of the influences of the South-East Madagascar Current on the South-East Madagascar Bloom, J. Geophys. Res., 125, e2019JC015761, https://doi.org/10.1029/2019JC015761, 2020.

Divakaran, P., and Brassington, G. B.: Arterial ocean circulation of the southeast Indian Ocean, Geophys. Res. Lett., 38, L01802, https://doi.org/10.1029/2010GL045574, 2011.

Doi, T., Behera, S. K., and Yamagata, T.: Wintertime impacts of the 2019 super IOD on East Asia, Geophys. Res. Lett., 47, e2020GL089456, https://doi.org/10.1029/2020GL089456, 2020.

Domingues, C. M., Wijffels, S. E., Maltrud, M. E., Church, J. A., and Tomczak, M.: Role of eddies in cooling the Leeuwin Current, Geophys. Res. Lett., 33, L05603, https://doi.org/10.1029/2005GL025216, 2006.

Domingues, C. M., Maltrud, M. E., Wijffels, S. E., Church, J. A., Tomczak, M.: Simulated Lagrangian pathways between the Leeuwin Current System and the upper-ocean circulation of the southeast Indian Ocean, Deep-Sea Res. Pt. II, 54, 797-817, https://doi.org/10.1016/j.dsr2.2006.10.003, 2007.

Dong, L. and McPhaden, M. J.: Interhemispheric SST gradient trends in the Indian Ocean prior to and during the recent global warming hiatus, J. Climate, 29, 9077-9095, 2016.

Dong, L., Zhou, T., Dai, A., Song, F., Wu, B., and Chen, X.: The footprint of the inter-decadal Pacific oscillation in Indian Ocean sea surface temperatures, Sci. Rep.-UK, 6, 21251, https://doi.org/10.1038/srep21251, 2016.

Drushka, K., Sprintall, J., Gille, S. T., and Brodjonegoro, I.: Vertical structure of Kelvin waves in the Indonesian throughflow exit passages, J. Phys. Oceanogr., 40, 1965-1987, https://doi.org/10.1175/2010JPO4380.1, 2010. 
Drushka, K., Sprintall, J., Gille, S. T., and Wijffels, S.: In situ observations of Madden-Julian oscillation mixed layer dynamics in the Indian and western Pacific Oceans, J. Climate, 25, 2306-2328, https://doi.org/10.1175/JCLI-D-11-00203.1, 2012.

Drushka, K., Sprintall, J., and Gille, S. T.: Subseasonal variations in salinity and barrier-layer thickness in the eastern equatorial Indian Ocean, J. Geophys. Res.-Oceans, 119, 805-823, https://doi.org/10.1002/2013JC009422, 2014.

Du, Y., Xie, S.-P., Huang, G., and Hu, K.: Role of airsea interaction in the long persistence of El Niño-induced north Indian Ocean warming, J. Clim., 22, 2023-2038, https://doi.org/10.1175/2008JCLI2590.1, 2009.

Du, Y., Cai, W., and Wu, Y.: A new type of the Indian Ocean dipole since the mid-1970s, J. Climate, 26, 959-972, https://doi.org/10.1175/JCLI-D-12-00047.1, 2013.

Du, Y., Zhang, Y., Feng, M., Wang, T., Zhang, N., and Wijffels, S. S.: Decadal trends of the upper ocean salinity in the tropical Indo-Pacific since mid-1990s, Sci. Rep.-UK, 5, 16050, https://doi.org/10.1038/srep16050, 2015.

Du, Y., Zhang, Y., Zhang, L.-Y., Tozuka, T., Ng, B., and Cai, W.: Thermocline warming induced extreme Indian Ocean dipole in 2019, Geophys. Res. Lett., 47, e2020GL090079, https://doi.org/10.1029/2020GL090079, 2020.

Duan, Y., Hou, Y., Liu, H., and Liu, Y.: The water mass variability and southward shift of the Southern Hemisphere mid-depth supergyre, Acta Oceanologica Sinica, 32, 74-81, 2013.

Dufois, F., Hardman-Mountford, N. J., Greenwood, J., Richardson, A. J., Feng, M., Herbette, S., and Matear, R.: Impact of eddies on surface chlorophyll in the South Indian Ocean, J. Geophys. Res.-Oceans, 119, 8061-8077, https://doi.org/10.1002/2014JC010164, 2014.

Duncan, B. and Han, W.: Indian Ocean intraseasonal sea surface temperature variability during boreal summer: Madden-Julian Oscillation versus submonthly forcing and processes, J. Geophys. Res.-Oceans, 114, C05022, https://doi.org/10.1029/2008JC004958, 2009.

Duncan, B. and Han, W.: Influence of atmospheric intraseasonal oscillations on seasonal and interannual variability in the upper Indian Ocean, J. Geophys. Res.-Oceans, 117, 1-24, https://doi.org/10.1029/2012JC008190, 2012.

Duran, E. R.: An investigation of the Leeuwin Undercurrent source waters and pathways. Honours thesis, University of Tasmania, 2015.

Duran, E. R., Phillips, H. E., Furue, R., Spence, P., and Bindoff, N. L.: Southern Australia Current System based on a gridded hydrography and a high-resolution model, Prog. Oceanogr., 181, 102254, https://doi.org/10.1016/j.pocean.2019.102254, 2020.

Durand, F., Alory, G., Dussin, R., and Reul, N.: SMOS reveals the signature of Indian Ocean dipole events, Ocean Dynam., 63, 1203-1212, https://doi.org/10.1007/s10236-013-0660-y, 2013.

Durgadoo, J. V., Loveday, B. R., Reason, C. J. C., Penven, P., and Biastoch, A.: Agulhas leakage predominantly responds to the southern hemisphere westerlies, J. Phys. Oceanogr., 43, 21132131, https://doi.org/10.1175/JPO-D-13-047.1, 2013.

Durgadoo, J. V., Rühs, S., Biastoch, A., and Böning, C. W. B.: Indian Ocean sources of Agulhas leakage, J. Geophys. Res.-Oceans, 122, 3481-3499, https://doi.org/10.1002/2016JC012676, 2017.
Elipot, S. and Beal, L. M.: Characteristics, energetics, and origins of Agulhas current meanders and their limited influence on ring shedding, J. Phys. Oceanogr., 45, 2294-2314, https://doi.org/10.1175/JPO-D-14-0254.1, 2015.

Elipot, S. and Beal, L. M.: Observed Agulhas Current Sensitivity to Interannual and Long-Term Trend Atmospheric Forcings, J. Climate, 31, 3077-3098, https://doi.org/10.1175/JCLI-D-170597.1, 2018.

Endo, S. and Tozuka, T.: Two flavors of the Indian Ocean dipole, Clim. Dynam., 46, 3371-3385, https://doi.org/10.1007/s00382015-2773-0, 2016.

England, M. H. and Huang, F.: On the interannual variability on the Indonesian Throughflow and its linkage with ENSO, J. Climate, 18, 1435-1444, https://doi.org/10.1175/JCLI3322.1, 2005.

England, M. H., Ummenhofer, C. C., and Santoso, A.: Interannual rainfall extremes over southwest Western Australia linked to Indian Ocean climate variability, J. Climate, 9, 1948-1969, https://doi.org/10.1175/JCLI3700.1, 2006.

England, M., McGregor, S., Spence, P., Meehl, G., Timmerman, A., Cai, W., Sen Gupta, A., McPhaden, M., Purich, A., and Santoso, A.: Recent intensification of wind-driven circulation in the Pacific and the ongoing warming hiatus, Nat. Clim. Change, 4, 222-227, https://doi.org/10.1038/nclimate2106, 2014.

Fan, L., Liu, Q., Wang, C., and Guo, F.: Indian Ocean dipole modes associated with different types of ENSO development, J. Climate, 30, 2233-2249, https://doi.org/10.1175/JCLI-D-160426.1, 2017.

Fang, F. and Morrow, R.: Evolution, movement and decay of warmcore Leeuwin Current eddies, Deep-Sea Res. Pt. II, 50, 2245 2261, https://doi.org/10.1016/S0967-0645(03)00055-9, 2003.

Fang, G., Susanto, R. D., Wirasantosa, S., Qiao, F., Supangat, A., Fan, B., Wei, Z., Sulistiyo, B., and Li, S.: Volume, heat, and freshwater transports from the South China Sea to Indonesian seas in the boreal winter of 2007-2008, J. Geophys. Res.-Oceans, 115, C12020, https://doi.org/10.1029/2010JC006225, 2010.

Felton, C. S., Subrahmanyam, B., Murty, V. S. N., and Shriver, J. F.: Estimation of the barrier layer thickness in the Indian Ocean using Aquarius Salinity, J. Geophys. Res.-Oceans, 119, 42004213, https://doi.org/10.1002/2013JC009759, 2014.

Feng, M. and Wijffels, S.: Intraseasonal variability in the South Equatorial Current of the East Indian Ocean, J. Phys. Oceanogr., 32, 265-277, 2002.

Feng, M., Meyers, G., Pearce, A., and Wijffels, S.: Annual and interannual variations of the Leeuwin Current at $32^{\circ} \mathrm{S}$, J. Geophys. Res., 108, 3355, https://doi.org/10.1029/2002JC001763, 2003.

Feng, M., Wijffels, S., Godfrey, S., and Meyers, G.: Do eddies play a role in the momentum balance of the Leeuwin Current? J. Phys. Oceanogr., 35, 964-975, https://doi.org/10.1175/JPO2730.1, 2005.

Feng, M., Majewski, L. J., Fandry, C. B., and Waite, A. M.: Characteristics of two counter-rotating eddies in the Leeuwin Current system off the Western Australian coast, Deep-Sea Res. Pt. II, 54, 961-980, https://doi.org/10.1016/j.dsr2.2006.11.022, 2007.

Feng, M., Biastoch, A., Böning, C., Caputi, N., and Meyers, G.: Seasonal and interannual variations of upper ocean heat balance off the west coast of Australia, J. Geophys. Res., 113, C12025, https://doi.org/10.1029/2008JC004908, 2008.

Feng, M., McPhaden, M. J., and Lee, T.: Decadal variability of the Pacific subtropical cells and their influence on the 
southeast Indian Ocean, Geophys. Res. Lett., 37, L09606, https://doi.org/10.1029/2010GL042796, 2010.

Feng, M., Böning, C. W., Biastoch, A., Behrens, E., Weller, E., and Masumoto, Y.: The reversal of the multi-decadal trends of the equatorial Pacific easterly winds, and the Indonesian Throughflow and Leeuwin Current transports, Geophys. Res. Lett., 38, L11604, https://doi.org/10.1029/2011GL047291, 2011.

Feng, M., McPhaden, M. J., Xie, S. P., and Hafner, J.: La Niña forces unprecedented Leeuwin Current warming in 2011, Sci. Rep-UK, 3, 1277, https://doi.org/10.1038/srep01277, 2013.

Feng, M., Benthuysen, J., Zhang, N., and Slawinski, D.: Freshening anomalies in the Indonesian throughflow and impacts on the Leeuwin Current during 2010-2011, Geophys. Res. Lett., 42, 8555-8562, https://doi.org/10.1002/2015GL065848, 2015a.

Feng, M., Hendon, H. H., Xie, S.-P., Marshall, A. G., Schiller, A., Kosaka, Y., Caputi, N., and Pearce, A.: Decadal increase in Ningaloo Niño since the late 1990s, Geophys. Res. Lett., 42, 104-112, https://doi.org/10.1002/2014GL062509, 2015 b.

Feng, M., Zhang, X., Oke, P., Monselesan, D., Chamberlain, M., Matear, R., and Schiller, A.: Invigorating ocean boundary current systems around Australia during 19792014: As simulated in a near-global eddy-resolving ocean model. J. Geophys. Res.-Oceans, 121, 3395-3408, https://doi.org/10.1002/2016JC011842, 2016.

Feng, M., Zhang, N., Liu, Q., and Wijffels, S.: The Indonesian throughflow, its variability and centennial change, Geosci. Lett., 5, 3, https://doi.org/10.1186/s40562-018-0102-2, 2018.

Feng, X. and Shinoda, T.: Air-sea heat flux variability in the southeast Indian Ocean and its relation with Ningaloo Niño. Front. Mar. Sci., 6, 266, https://doi.org/10.3389/fmars.2019.00266, 2019.

Ffield, A., Toole, J., and Wilson, D.: Seasonal circulation in the South Indian Ocean, Geophys. Res. Lett., 24, 2773-2776, 1997.

Findlater, J.: A major low-level air current near the Indian Ocean during the northern summer, Q. J. Roy. Meteor. Soc., 95, 362380, 1969 .

Foltz, G. R., Vialard, J., Kumar, B. P., and Mcphaden, M. J.: Seasonal mixed layer heat balance of the southwestern tropical Indian Ocean, J. Climate, 23, 947-965, https://doi.org/10.1175/2009JCLI3268.1, 2010.

Fournier, S., Vialard, J., Lengaigne, M., Lee, T., Gierach, M. M., and Chaitanya, A. V. S.: Modulation of the Ganges-Brahmaputra river plume by the Indian Ocean dipole and eddies inferred from satellite observations, J. Geophys. Res.-Oceans, 122, 9591-9604, https://doi.org/10.1002/2017JC013333, 2017.

Fox-Kemper, B., Hewitt, H. T., Xiao, C., Aðalgeirsdóttir, G., Drijfhout, S. S., Edwards, T. L., Golledge, N. R., Hemer, M., Kopp, R. E., Krinner, G., A. Mix, A., Notz, D., Nowicki, S. Nurhati, I. S., Ruiz, L., Sallée, J-B., Slangen, A. B. A., and Yu, Y.: Ocean, Cryosphere and Sea Level Change, in: Climate Change 2021: The Physical Science Basis. Contribution of Working Group I to the Sixth Assessment Report of the Intergovernmental Panel on Climate Change, edited by: Masson-Delmotte, V., Zhai, P., Pirani, A., Connors, S. L., Péan, C., Berger, S., Caud, N., Chen, Y., Goldfarb, L., Gomis, M. I., Huang, M., Leitzell, K., Lonnoy, E., Matthews, J. B. R., Maycock, T. K., Waterfield, T., Yelekçi, O., Yu, R., and Zhou, B., Cambridge University Press, in press, 2021.
Francis, P. A., Jithin, A. K., Effy, J. B., Chatterjee, A., Chakraborty, K., Paul, A., Balaji, B., Shenoi, S. S. C., Biswamoy, P., Mukherjee, A., Singh, P., Deepsankar, B., Siva Reddy, S., Vinayachandran, P. N., Girish Kumar, M. S., Udaya Bhaskar, T. V. S., Ravichandran, M., Unnikrishnan, A. S., Shankar, D., Prakash, A., Aparna, S. G., Harikumar, R., Kaviyazhahu, K., Suprit, K., Shesu, R. V., Kiran Kumar, N., Srinivasa Rao, N., Annapurnaiah, K., Venkatesan, R., Rao, A. S., Rajagopal, E. N., Prasad, V. S., Gupta, M. D., Balakrishnan Nair, T. M., Rao, E. P. R., and Satyanarayana, B. V.: High-resolution operational ocean forecast and reanalysis system for the Indian Ocean, B. Am. Meteorol. Soc., 101, E1340-E1356, 2020.

Furnas, M.: Intra-seasonal and inter-annual variations in phytoplankton biomass, primary production and bacterial production at North West Cape, Western Australia: Links to the 1997-1998 El Niño event, Cont. Shelf Res., 27, 958-980, https://doi.org/10.1016/j.csr.2007.01.002, 2007.

Furue, R., McCreary, J. P., Benthuysen, J., Phillips, H. E., and Bindoff, N. L.: Dynamics of the Leeuwin Current: Part 1. Coastal flows in an inviscid, variabledensity, layer model, Dyn. Atmos. Oceans, 63, 24-59, https://doi.org/10.1016/j.dynatmoce.2013.03.003, 2013.

Furue, R., Guerreiro, K., Phillips, H. E., McCreary, J. P., and Bindoff, N. L.: On the Leeuwin Current System and its linkage to zonal flows in the South Indian Ocean as inferred from a gridded hydrography, J. Phys. Oceanogr., 47, 583-602, https://doi.org/10.1175/JPO-D-16-0170.1, 2017.

Furue, R.: The three-dimensional structure of the Leeuwin Current System in density coordinates in an eddy-resolving OGCM, Ocean Model., 138, 36-50, https://doi.org/10.1016/j.ocemod.2019.03.001, 2019.

Gadgil, S.: The Indian Monsoon and Its Variability, Annu. Rev. Earth Planet. Sci., 31, 429-467, https://doi.org/10.1146/annurev.earth.31.100901.141251, 2003.

Gadgil, S., Joseph, P., and Joshi, N.: Ocean-atmosphere coupling over monsoon regions, Nature, 312, 141-143, https://doi.org/10.1038/312141a0, 1984.

Gandhi, N., Singh, A., Prakash, S., Ramesh, R., Raman, M., Sheshshayee, M. and Shetye, S.: First direct measurements of $\mathrm{N}_{2}$ fixation during a Trichodesmium bloom in the eastern Arabian Sea, Global Biogeochem. Cycles, 25, GB4014, https://doi.org/10.1029/2010GB003970, 2011.

Gao, Y., Hsu, P.-C., and Li, T.: Effects of high-frequency activity on latent heat flux of MJO, Clim. Dynam., 52, 1471-1485, https://doi.org/10.1007/s00382-018-4208-1, 2019.

Garrison, D. L., Gowing, M. M., Hughes, M. P., Campbell, L., Caron, D. A., Dennett, M. R., Shalapyonok, A., Olson, R. J., Landry, M. R., Brown, S. L., Liu, H. Bin, Azam, F., Steward, G. F., Ducklow, H. W., and Smith, D. C.: Microbial food web structure in the Arabian Sea: A US JGOFS study, Deep-Sea Res. Pt. II, 47, 1387-1422, https://doi.org/10.1016/S0967-0645(99)001484, 2000.

Gaube, P., Chelton, D. B., Strutton, P. G., and Behrenfeld, M. J.: Satellite observations of chlorophyll, phytoplankton biomass, and Ekman pumping in nonlinear mesoscale eddies, J. Geophys. Res.-Oceans, 118, 6349-6370, https://doi.org/10.1002/2013JC009027, 2013.

George, J. V., Nuncio, M., Chacko, R., Anilkumar, N., Noronha, S. B., Patil, S. M., Pavithran, S., Alappattu, D. 
P., Krishnan, K. P., and Achuthankutty, C. T.: Role of physical processes in chlorophyll distribution in the western tropical Indian Ocean, J. Mar. Syst., 113-114, 1-12, https://doi.org/10.1016/j.jmarsys.2012.12.001, 2013.

George, J. V., Vinayachandran, P. N., Vijith, V., Thusaraa, V., Nayaka, A. A, Pargaonkara, S. K., Amol, P., Vijaykumar, K., and Matthews, A. J.: Mechanisms of barrier layer formation and erosion from in situ observations in the Bay of Bengal, J. Phys. Oceanogr., 49, 1183-1200, https://doi.org/10.1175/JPOD-18-0204.1, 2019.

Giddings, J., Heywood, K. J., Matthews, A. J., Joshi, M. M., Webber, B. G. M., Sanchez-Franks, A., King, B. A., and Vinayachandran, P. N.: Spatial and temporal variability of solar penetration depths in the Bay of Bengal and its impact on sea surface temperature (SST) during the summer monsoon, Ocean Sci., 17, 871890, https://doi.org/10.5194/os-17-871-2021, 2021.

Gilmour, J. P., Cook, K. L., Ryan, N. M., Puotinen, M. L., Green, R. H., Shedrawi, G., Hobbs, J.-P. A., Thmson, D.P., Babcock, R.C., Buckee, J., Foster, T., Richards, Z. T., Wilson, S. K., Barnes, P. B., Coutts, T. B., Radford, B. T., Piggott, C. H., Depczynski, M., Evans, S. N., Schoepf, V., Evans, R. D., Halford, A. H., Nutt, C. D., Bancroft, K. P., Heyward, A. J., and Oades, D.: The state of Western Australia's coral reefs, Coral Reefs, 38, 651-667, https://doi.org/10.1007/s00338-019-01795-8, 2019.

Girishkumar, M. S., Ravichandran, M., McPhaden, M. J., and Rao, R. R.: Intraseasonal variability in barrier layer thickness in the south central Bay of Bengal, J. Geophys. Res., 116, https://doi.org/10.1029/2010JC006657, 2011.

Girishkumar, M. S., Ravichandran, M., and McPhaden, M. J.: Temperature inversions and their influence on the mixed layer heat budget during the winters of 2006-07 and 2007-08 in the Bay of Bengal, J. Geophys. Res., 118, 118, 2426-2437, https://doi.org/10.1002/jgrc.20192, 2013.

Girishkumar, M. S., Joseph, J., Thangaprakash, V. P., Pottapinjara, V., and McPhaden, M. J.: Mixed Layer Temperature Budget for the Northward Propagating Summer Monsoon Intraseasonal Oscillation (MISO) in the Central Bay of Bengal, J. Geophys. Res.-Oceans, 122, 8841-8854, https://doi.org/10.1002/2017JC013073, 2017.

Girishkumar, M. S., Ashin, K., McPhaden, M. J., Balaji, B., and Praveenkumar, B.: Estimation of vertical heat diffusivity at the base of the mixed layer in the Bay of Bengal, J. Geophys. Res., 125, e2019JC015402, https://doi.org/10.1029/2019JC015402, 2020.

Gnanaseelan, C., Deshpande, A., and McPhaden, M. J.: Impact of Indian Ocean Dipole and El Nio/Southern Oscillation windforcing on the Wyrtki jets, J. Geophys. Res.-Oceans, 117, C08005, https://doi.org/10.1029/2012JC007918, 2012.

Godfrey, J. S.: The effect of the Indonesian throughflow on ocean circulation and heat exchange with the atmosphere: A review, J. Geophys. Res., 101, 12217-12237, 1996.

Godfrey, J. S. and Ridgway, K. R.: The large-scale environment of the poleward-flowing Leeuwin Current, Western Australia: longshore steric height gradients, wind stresses and geostrophic flow, J. Phys. Oceanogr., 15, 481-495, https://doi.org/10.1175/15200485(1985)015<0481:TLSEOT>2.0.CO;2, 1985.

Godfrey, J. S. and Weaver, A.: Why are there such strong steric height gradients off Western Australia? In: Proceedings of the Western Pacific International Meeting and Workshop on
TOGA COARE, 24-30 May 1989, Noumea, New Caledonia, 215-222, available at: https://www.documentation.ird.fr/hor/fdi: 30209 (last access: 20 October 2021), 1989.

Godfrey, J. S. and Weaver, A. J.: Is the Leeuwin Current driven by Pacific heating and winds?, Prog. Oceanogr., 27, 225-272, https://doi.org/10.1016/0079-6611(91)90026-I, 1991.

Godfrey, J. S., Johnson, G. C., McPhaden, M. J., Reverdin, G., and Wijffels, S.: The tropical ocean circulation, Ocean Circulation and Climate, edited by: Siedler, G., Church, J., and Gould, W. J., Academic Press, 77, 215-246, https://doi.org/10.1016/S00746142(01)80121-2, 2001.

Goericke, R., Olson, R. J., and Shalapyonok, A.: A novel niche for Prochlorococcus sp. in low-light suboxic environments in the Arabian Sea and the Eastern Tropical North Pacific, DeepSea Res. Pt. I, 47, 1183-1205, https://doi.org/10.1016/S09670637(99)00108-9, 2000.

Goes, J. I., Tian, H., Gomes, H. do R., Anderson, O. R., Al-Hashmi, K., deRada, S., Luo, H., Al-Kharusi, L., Al-Azri, A., and Martinson, D. G.: Ecosystem state change in the Arabian Sea fuelled by the recent loss of snow over the Himalayan-Tibetan Plateau region, Sci. Rep.-UK, 10, 7422, https://doi.org/10.1038/s41598020-64360-2, 2020.

Gomes, H., Goes, J. I., and Saino, T.: Influence of physical processes and freshwater discharge on the seasonality of phytoplankton regime in the Bay of Bengal, Cont. Shelf Res., 20, 313 330, 2000.

Gomes, H. D., Goes, J. I., Matondkar, S. G. P., Buskey, E. J., Basu, S., Parab, S., and Thoppil, P.: Massive outbreaks of Noctiluca scintillans blooms in the Arabian Sea due to spread of hypoxia, Nat. Commun., 5, 4862, https://doi.org/10.1038/ncomms5862, 2014.

Gordon, A., Shroyer, E., and Murty, V: An Intrathermocline Eddy and a tropical cyclone in the Bay of Bengal, Sci. Rep.-UK, 7, 46218, https://doi.org/10.1038/srep46218, 2017.

Gordon, A. L., Susanto, R. D., and Vranes, K.: Cool Indonesian throughflow as a consequence of restricted surface layer flow, Nature, 425, 824-828, https://doi.org/10.1038/nature02038, 2003.

Gordon, A. L., Susanto, R. D., Ffield, A., Huber, B. A., Pranowo, W., and Wirasantosa, S.: Makassar Strait throughflow, 2004 to 2006, Geophys. Res. Lett., 35, L24605, https://doi.org/10.1029/2008GL036372, 2008.

Gordon, A. L., Sprintall, J., Van Aken, H. M., Susanto, R. D., Wijffels, S., Molcard, R., Ffield, A., Pranowo, W., and Wirasantosa, S.: The Indonesian throughflow during 2004-2006 as observed by the INSTANT program, Dyn. Atmos. Ocean., 50, 115-128, https://doi.org/10.1016/j.dynatmoce.2009.12.002, 2010.

Gordon, A. L., Huber, B. A., Metzger, E. J., Susanto, R. D., Hurlburt, H. E. and Adi, T. R.: South China Sea throughflow impact on the Indonesian throughflow, Geophys. Res. Lett., 39, L11602, https://doi.org/10.1029/2012GL052021, 2012.

Gordon, A. L., Shroyer, E. L., Mahadevan, A., Sengupta, D., and Freilich, M.: Bay of Bengal: 2013 Northeast monsoon upper-ocean circulation, Oceanography, 29, 82-91, https://doi.org/10.5670/oceanog.2016.41, 2016.

Gordon, A. L., Shroyer, E. L., Fernando, H. J. S., Tandon, A., Mathur, M., and Udaya Priyantha Jinadasa, S.: Introduction to "Atmosphere-Ocean Dynamics of Bay of 
Bengal" volume 1, Deep-Sea Res. Pt. II, 168, 104670, https://doi.org/10.1016/j.dsr2.2019.104670, 2019.

Gordon, A. L., Shroyer, E. L., Fernando, H. J. S., Tandon, A., Mathur, M., and Udaya Priyantha Jinadasa, S.: Introduction to "Atmosphere-Ocean Dynamics of Bay of Bengal"-Volume 2, Deep-Sea Res. Pt. II, 172, 104724, https://doi.org/10.1016/j.dsr2.2019.104724, 2020.

Goschen, W. S., Schumann, E. H., Bernard, K. S., Bailey, S. E., and Deyzel, S. H. P.: Upwelling and ocean structures off Algoa Bay and the south-east coast of South Africa, African J. Mar. Sci., 34, 525-536, https://doi.org/10.2989/1814232X.2012.749810, 2012.

Goswami, B. N.: South Asian monsoon, in: Intraseasonal Variability in the Atmosphere-Ocean Climate System, edited by: Lau, W. K. M. and Waliser, D. E., Springer Praxis Books. Springer, Berlin, Heidelberg, https://doi.org/10.1007/978-3-64213914-7_2, 2012.

Goswami, B. B., Mukhopadhyay, P., Khairoutdinov, M., and Goswami, B. N.: Simulation of Indian summer monsoon intraseasonal oscillations in a superparameterized coupled climate model: Need to improve the embedded cloud resolving model, Clim. Dynam., 41, 1497-1507, https://doi.org/10.1007/s00382012-1563-1, 2013.

Goswami, B. N., Rao, S. A., Sengupta, D., and Chakravorty, S.: Monsoons to mixing in the Bay of Bengal: Multiscale air-sea interactions and monsoon predictability, Oceanography, 29, 1827, https://doi.org/10.5670/oceanog.2016.35, 2016.

Gründlingh, M. L.: On the Course of the Agulhas Current, S. Afr. Geogr. J., 65, 49-57, https://doi.org/10.1080/03736245.1983.10559671, 1983.

Grunseich, G., Subrahmanyam, B., Murty, V. S. N., and Giese, B. S.: Sea surface salinity variability during the Indian Ocean dipole and ENSO events in the tropical Indian Ocean, J. Geophys. Res., 116, C11013, https://doi.org/10.1029/2011JC007456, 2011.

Gu, W., Li, W. J., Chen, L. J., and Jia, X. L.: Interannual variations of autumn precipitation in China and their relations to the distribution of tropical Pacific sea surface temperature, Clim. Environ. Res., 17, 467-480, 2012.

Guan, B., Waliser, D. E., Lee, T., and Halkides, D. J.: Influence of the Madden-Julian oscillation on the Indian Ocean crossequatorial heat transport, Geophys. Res. Lett., 41, 7314-7322, https://doi.org/10.1002/2014GL061789, 2014.

Gudka, M., Obura, D., Mwaura, J., Porter, S. Yahya, S., and Mabwa, R.: Impact of the 3rd Global Coral Bleaching Event on the Western Indian Ocean in 2016, Global Coral Reef Monitoring Network (GCRMN)/Indian Ocean Commission, pp. 67, available at: https://wedocs.unep.org/handle/20.500.11822/25700 (last access: 22 October 2021), 2018.

Guemas, V., Corti, S., Garcia-Serrano, J., Doblas-Reyes, F. J., Balmaseda, M., and Magnusson, L.: The Indian Ocean: The region of highest skill worldwide in decadal climate prediction, J. Climate, 26, 726-739, 2013.

Gundersen, J. S., Gardner, W. D., Richardson, M. J., and Walsh, I. D.: Effects of monsoons on the seasonal and spatial distributions of POC and chlorophyll in the Arabian Sea, Deep-Sea Res. Pt. II, 45, 2103-2132, https://doi.org/10.1016/S0967-0645(98)000654, 1998.

Guo, F., Liu, Q., Sun, S., and Yang, J.: Three types of Indian Ocean dipoles, J. Climate, 28, 3073-3092, 2015.
Haarsma, R. J., Campos, E. J. D., Drijfhout, S., Hazeleger, W., and Severijns, C.: Impacts of interruption of the Agulhas leakage on the tropical Atlantic in coupled ocean-atmosphere simulations, Clim. Dynam., 36, 989-1003, https://doi.org/10.1007/s00382009-0692-7, 2011.

Halkides, D. J., Waliser, D. E., Lee, T., Menemenlis, D., and Guan, B.: Quantifying the processes controlling intraseasonal mixed-layer temperature variability in the tropical Indian Ocean, J. Geophys. Res.-Oceans, 120, 692-715, https://doi.org/10.1002/2014JC010139, 2015.

Han, W. Q.: Origins and dynamics of the 90-day and 30-60-day variations in the equatorial Indian Ocean, J. Phys. Oceanogr., 35, 708-728, 2005.

Han, W. and McCreary, J. P.: Modeling salinity distributions in the Indian Ocean, J. Geophys. Res.-Oceans, 106, 859-877, https://doi.org/10.1029/2000JC000316, 2001.

Han, W., McCreary, J. P., Anderson, D. L. T., and Mariano, A. J.: Dynamics of the eastern surface jets in the equatorial Indian Ocean, J. Phys. Oceanogr., 29, 2191-2209, https://doi.org/10.1175/15200485(1999)029<2191:DOTESJ>2.0.CO;2, 1999.

Han, W. Q., Lawrence, D. M., and Webster, P. J.: Dynamical response of equatorial Indian Ocean to intraseasonal winds: zonal flow, Geophys. Res. Lett., 28, 4215-4218, 2001.

Han, W., Webster, P., Lukas, R., Hacker, P., and $\mathrm{Hu}$, A.: Impact of atmospheric intraseasonal variability in the Indian Ocean: Low-frequency rectification in equatorial surface current and transport, J. Phys. Oceanogr., 34, 1350-1372, https://doi.org/10.1175/15200485(2004)034<1350:IOAIVI>2.0.CO;2, 2004.

Han, W., Yuan, D., Liu, W. T., and Halkides, D. J.: Intraseasonal variability of Indian Ocean sea surface temperature during boreal winter: Madden-Julian Oscillation versus submonthly forcing and processes, J. Geophys. Res.-Oceans, 112, 1-20, https://doi.org/10.1029/2006JC003791, 2007.

Han, W., Vialard, J., McPhaden, M. J., Lee, T., Masumoto, Y., Feng, M., and De Ruijter, W. P. M.: Indian ocean decadal variability: A review, B. Am. Meteorol. Soc., 95, 1679-1703, https://doi.org/10.1175/BAMS-D-13-00028.1, 2014.

Han, W., Meehl, G. A., Hu, A., Zheng, J., Kenigson, J., Vialard, J., and Rajagopalan, B.: Decadal Variability of the Indian and Pacific Walker Cells since the 1960s: Do They Covary on Decadal Time Scales?, J. Climate, 30, 8447-8468, 2017.

Hanson, C. E., Waite, A. M., Thompson, P. A., and Pattiaratchi, C. B.: Phytoplankton community structure and nitrogen nutrition in Leeuwin Current and coastal waters off the Gascoyne region of Western Australia, Deep-Sea Res. Pt. II, 54, 902-924, https://doi.org/10.1016/j.dsr2.2006.10.002, 2007.

Hazra, A., Chaudhari, H. S., Saha, S. K., Pokhrel, S., and Goswami, B. N.: Progress Towards Achieving the Challenge of Indian Summer Monsoon Climate Simulation in a Coupled OceanAtmosphere Model, J. Adv. Model. Earth Syst., 9, 2268-2290, https://doi.org/10.1002/2017MS000966, 2017.

Heffner, D. M., Subrahmanyam, B., and Shriver, J. F.: Indian Ocean Rossby waves detected in HYCOM sea surface salinity, Geophys. Res. Lett., 35, L03605, https://doi.org/10.1029/2007GL032760, 2008.

Hermes, J. C. and Reason, C. J. C.: Ocean model diagnosis of interannual coevolving SST variability in the South In- 
dian and South Atlantic Oceans, J. Climate, 18, 2864-2882, https://doi.org/10.1175/JCLI3422.1, 2005.

Hermes, J. C. and Reason, C. J. C.: Annual cycle of the South Indian Ocean (Seychelles-Chagos) thermocline ridge in a regional ocean model, J. Geophys. Res., 113, C04035, https://doi.org/10.1029/2007JC004363, 2008.

Hermes, J. C., Masumoto, Y., Beal, L. M., Roxy, M. K., Vialard, J., Andres, M., Annamalai, H., Behera, S., D'Adamo, N., Doi, T., Feng, M., Han, W., Hardman-Mountford, N., Hendon, H., Hood, R., Kido, S., Lee, C., Lee, T., Lengaigne, M., Li, J., Lumpkin, R., Navaneeth, K. N., Milligan, B., McPhaden, M. J., Ravichandran, M., Shinoda, T., Singh, A., Sloyan, B., Strutton, P. G., Subramanian, A. C., Thurston, S., Tozuka, T., Ummenhofer, C. C., Unnikrishnan, A. S., Venkatesan, R., Wang, D., Wiggert, J., Yu, L., and Yu, W.: A Sustained Ocean Observing System in the Indian Ocean for Climate Related Scientific Knowledge and Societal Needs, Front. Marine Sci., 6, 1-21, https://doi.org/10.3389/fmars.2019.00355, 2019.

Hernández-Guerra, A. and Talley, L. D.: Meridional overturning transports at $30^{\circ} \mathrm{S}$ in the Indian and Pacific Oceans in 2002-2003 and 2009, Prog Oceanogr., 146, 89-120, 2016.

Hitchcock, G. L., Key, L. E., and Masters, J.: The fate of upwelled waters in the Great Whirl, August 1995, Deep-Sea Res. Pt. II, 47, 1605-1621, https://doi.org/10.1016/S0967-0645(99)001563, 2000.

Ho, C. R., Zheng, Q., and Kuo, N. J.: SeaWiFs observations of upwelling south of Madagascar: Long-term variability and interaction with East Madagascar Current, Deep-Sea Res. Pt. II, 51, 59-67, https://doi.org/10.1016/j.dsr2.2003.05.001, 2004.

Holbrook, N. J., Scannell, H. A., Sen Gupta, A., Benthuysen, J. A., Feng, M., Oliver, E. C. J., Alexander, L. V., Burrow, M. T., Donat, M. G., Hobday, A. J., Moore, P. J., Perkins-Kirkpatrick, S. E., Smale, D. A., Straub, S. C., and Wernberg, T.: A global assessment of marine heatwaves and their drivers, Nat. Commun., 10, 2624, https://doi.org/10.1038/s41467-019-10206-z, 2019.

Holloway, P. E.: Leeuwin current observations on the Australian North West Shelf, May-June 1993, Deep-Sea Res. Pt. I, 42, 285305, https://doi.org/10.1016/0967-0637(95)00004-P, 1995.

Holloway, P. E. and Nye, H. C.: Leeuwin current and wind distributions on the southern part of the australian north west shelf between january 1982 and july 1983, Mar. Freshw. Res., 36, 123137, https://doi.org/10.1071/MF9850123, 1985.

Holton, L., Deshayes, J., Backeberg, B. C., Loveday, B. R., Hermes, J. C., and Reason, C. J. C.: Spatio-temporal characteristics of Agulhas leakage: a model inter-comparison study, Clim. Dynam., 48, 2107-2121, 2017.

Hood, R. R., Coles, V. J., and Capone, D. G.: Modeling the distribution of Trichodesmium and nitrogen fixation in the Atlantic Ocean, J. Geophys. Res.-Oceans, 109, C06006, https://doi.org/10.1029/2002JC001753, 2004.

Hood, R. R., Bange, H. W., Beal, L., Beckley, L. E., Burkill, P., Cowie, G. L., D'Adamo, N., Ganssen, G., Hendon, H., Hermes, J., Honda, M., McPhaden, M., Roberts, M., Singh, S., Urban, E., and Yu, W.: Science Plan of the Second International Indian Ocean Expedition (IIOE-2): A Basin-Wide Research Program, Scientific Committee on Oceanic Research, Newark, Delaware, USA, 2015.
Hood, R. R., Beckley, L. E., and Wiggert, J. D.: Biogeochemical and ecological impacts of boundary currents in the Indian Ocean, Prog. Oceanogr., 156, 290-325, 2017.

Horii, T., Mizuno, K., Nagura, M., Miyama, T., and Ando, K.: Seasonal and interannual variation in the cross-equatorial meridional currents observed in the eastern Indian Ocean, J. Geophys. Res., 118, 6658-6671, https://doi.org/10.1002/2013JC009291, 2013.

Hormann, V., Centurioni, L. R., and Gordon, A. L.: Freshwater export pathways from the Bay of Bengal, Deep-Sea Res. Pt. II, 168, 104645, https://doi.org/10.1016/j.dsr2.2019.104645, 2019.

Howden, S. D. and Murtugudde, R.: Effects of river inputs into the Bay of Bengal, J. Geophys. Res.-Oceans, 106, 19825-19843, https://doi.org/10.1029/2000jc000656, 2001.

Hu, D., Wu, L., Cai, W., Sen Gupta, A., Ganachaud, A., Qiu, B., Gordon, A. L., Lin, X., Chen, Z., Hu, S., Wang, G., Wang, Q., Sprintall, J., Qu, T., Kashino, Y., Wang, F., and Kessler, W. S.: Pacific western boundary currents and their roles in climate, Nature, 522, 299-308, https://doi.org/10.1038/nature14504, 2015.

Hu, K., Huang, G., Xie, S.-P., and Long, S. M.: Effect of the mean flow on the anomalous anticyclone over the Indo-northwest Pacific in post-El Niño summers, Clim. Dynam., 53, 5725-5741, 2019.

$\mathrm{Hu}, \mathrm{S}$. and Sprintall, J.: Interannual variability of the Indonesian Throughflow: The salinity effect, J. Geophys. Res.-Oceans, 121, 2596-2615, https://doi.org/10.1002/2015JC011495, 2016.

$\mathrm{Hu}, \mathrm{S}$. and Sprintall, J.: Observed strengthening of interbasin exchange via the Indonesian Seas due to rainfall Intensification, Geophys. Res. Lett., 44, 1448-1456, 2017a.

$\mathrm{Hu}, \mathrm{S}$. and Sprintall, J.: A stronger Indonesian Throughflow related to enhanced regional rainfall, CLIVAR Exchanges, 71, 21-25, $2017 b$.

Huang, K., McPhaden, M., Wang, D., Wang, W., and Xie, Q.: Vertical Propagation of Middepth Zonal Currents Associated With Surface Wind Forcing in the Equatorial Indian Ocean, J. Geophys. Res.-Oceans, 123, 7290-7307, 2018.

Huhn, F., von Kameke, A., Pérez-Muñuzuri, V., Olascoaga, M. J., and Beron-Vera, F. J.: The impact of advective transport by the South Indian Ocean countercurrent on the Madagascar bloom, Geophys. Res. Lett., 39, L06602, https://doi.org/10.1029/2012GL051246, 2012.

Hutchinson, K., Beal, L. M., Penven, P., Ansorge, I., and Hermes, J.: Seasonal phasing of Agulhas Current transport tied to a baroclinic adjustment of near-field winds, J. Geophys. Res.-Oceans, 123, 123, 7067-7083, https://doi.org/10.1029/2018JC014319, 2018.

Ibrahim, N., Mohamed, M., Basheer, A., Ismail, H., Nistharan, F., Schmidt, A., Naeem, R., Abdulla, A., and Grimsditch, G.: Status of Coral Bleaching in the Maldives in 2016, Marine Research Centre, Malé, Maldives, 47 pp., available at: https://portals.iucn. org/library/node/46803 (last access: 21 November 2021), 2017.

Iskandar, I. and McPhaden, M. J.: Dynamics of wind-forced intraseasonal zonal current variations in the equatorial Indian Ocean, J. Geophys. Res.-Oceans, 116, 1-16, https://doi.org/10.1029/2010JC006864, 2011.

Iskandar, I., Masumoto, Y., and Mizuno, K.: Subsurface equatorial zonal current in the eastern Indian Ocean, J. Geophys. Res.Oceans, 114, C06005, https://doi.org/10.1029/2008JC005188, 2009. 
Iskandar, I., Sasaki, H., Sasai, Y., Masumoto, Y., and Mizuno, K.: A numerical investigation of eddy-induced chlorophyll bloom in the southeastern tropical Indian Ocean during Indian Ocean Dipole - 2006, Ocean Dynam., 60, 731-742, 2010.

Izumo, T., de Boyer Montegut, C., Luo, J. J., Behera, S. K., Masson, S., and Yamagata, T.: The role of the western Arabian Sea upwelling in Indian monsoon rainfall variability, J. Climate, 21, 5603-5623, https://doi.org/10.1175/2008JCLI2158.1, 2008.

Izumo, T., Vialard, J., Lengaigne, M., de Boyer Montegut, C., Behera, S. K., Luo, J.-J., Cravatte, S., Masson, S., and Yamagata, T.: Influence of the state of the Indian Ocean Dipole on the following year's El Niño, Nat. Geosci., 3, 168-172, https://doi.org/10.1038/ngeo760, 2010.

Jaeger, G. S. and Mahadevan, A.: Submesoscale-selective compensation of fronts in a salinity-stratified ocean, Sci. Adv., 4, e1701504, https://doi.org/10.1126/sciadv.1701504, 2018.

Jain, V., Shankar, D., Vinayachandran, P. N., Kankonkar, A., Chatterjee, A., Amol, P., Almeida, A. M., Michael, G. S., Mukherjee, A., Chatterjee, M., Fernandes, R., Luis, R., Kamble, A., Hegde, A. K., Chatterjee, S., Das, U., and Neema, C. P.: Evidence for the existence of Persian Gulf Water and Red Sea Water in the Bay of Bengal, Clim. Dynam., 48, 3207-3226, https://doi.org/10.1007/s00382-016-3259-4, 2017.

Jayakumar, A., Vialard, J., Lengaigne, M., Gnanaseelan, C., McCreary, J. P., and Kumar, B. P.: Processes controlling the surface temperature signature of the Madden-Julian Oscillation in the thermocline ridge of the Indian Ocean, Clim. Dynam., 37, 2217-2234, https://doi.org/10.1007/s00382-010-0953-5, 2011.

Jayakumar, A., Turner, A. G., Johnson, S. J., Rajagopal, E. N., Mohandas, S., and Mitra, A. K.: Boreal summer sub-seasonal variability of the South Asian monsoon in the Met Office GloSea5 initialized coupled model, Clim. Dynam., 49, 20352059, https://doi.org/10.1007/s00382-016-3423-x, 2017.

Jensen, T. G.: Arabian Sea and Bay of Bengal exchange of salt and tracers in an ocean model, Geophys. Res. Lett., 28, 3967-3970, https://doi.org/10.1029/2001GL013422, 2001.

Jensen, T. G., Wijesekera, H. W., Nyadjro, E. S., Thoppil, P. G., Shriver, J., Sandeep, K. K., and Pant, V.: Modeling Salinity Exchanges Between the Equatorial Indian Ocean and the Bay of Bengal, Oceanography, 29, 92-101, https://doi.org/10.5670/oceanog.2016.42, 2016.

Jia, F., Wu, L., and Qiu, B.: Seasonal modulation of eddy kinetic energy and its formation mechanism in the southeast Indian Ocean, J. Phys. Oceanogr., 41, 657-665, https://doi.org/10.1175/2010JPO4436.1, 2011a.

Jia, F., Wu, L., and Qiu, B.: Interannual modulation of eddy kinetic energy in the southeast Indian ocean by Southern Annular Mode, J. Geophys. Res., 116, C02029, https://doi.org/10.1029/2010JC006699, 2011b.

Jin, D., Waliser, D. E., Jones, C., and Murtugudde, R.: Modulation of tropical ocean surface chlorophyll by the Madden-Julian Oscillation, Clim. Dynam., 40, 39-58, https://doi.org/10.1007/s00382-012-1321-4, 2013a.

Jin, D., Murtugudde, R. G., and Waliser, D. E.: Intraseasonal atmospheric forcing effects on the mean state of ocean surface chlorophyll, J. Geophys. Res.-Oceans, 118, 184-196, https://doi.org/10.1029/2012JC008256, 2013b.

Jin, X., Kwon, Y.-O., Ummenhofer, C. C., Seo, H., Kosaka, Y., and Wright, J. S.: Distinct mechanisms of decadal subsurface heat content variations in the eastern and western Indian Ocean modulated by tropical Pacific SST, J. Climate, 31, 7751-7769, 2018a. Jin, X., Kwon, Y.-O., Ummenhofer, C. C., Seo, H., Schwarzkopf, F. U., Biastoch, A., Böning, C. W., and Wright, J. S.: Influences of Pacific climate variability on decadal subsurface ocean heat content variations in the Indian Ocean, J. Climate, 31, 4157-4174, $2018 b$.

Jinadasa, S. U. P., Lozovatsky, I., Planella-Morató, J., Nash, J. D., MacKinnon, J. A., Lucas, A. J., Wijesekera, H. W., and Fernando, H. J. S.: Ocean turbulence and mixing around Sri Lanka and in adjacent waters of the northern Bay of Bengal, Oceanography, 29, 170-179, https://doi.org/10.5670/oceanog.2016.49, 2016.

Jochum, M. and Murtugudde, R.: Internal Variability of Indian Ocean SST, J. Climate, 18, 3726-3738, 2005.

Johnson, G. C., Purkey, S. G., and Bullister, J. L.: Warming and freshening in the abyssal southeastern Indian Ocean, J. Climate, 21, 5351-5363, https://doi.org/10.1175/2008JCLI2384.1, 2008.

José, Y. S., Aumont, O., Machu, E., Penven, P., Moloney, C. L., and Maury, O.: Influence of mesoscale eddies on biological production in the Mozambique Channel: Several contrasted examples from a coupled ocean-biogeochemistry model, Deep-Sea Res. Pt II, 100, 79-93, https://doi.org/10.1016/j.dsr2.2013.10.018, 2014.

Joseph, S., Wallcraft, A. J., Jensen, T. G., Ravichandran, M., Shenoi, S. S. C., and Nayak, S.: Weakening of spring Wyrtki jets in the Indian Ocean during 2006-2011, J. Geophys. Res.-Oceans, 117, C04012, https://doi.org/10.1029/2011JC007581, 2012.

Jourdain, N. C., Gupta, A. S., Taschetto, A. S., Ummenhofer, C. C., Moise, A. F., and Ashok, K.: The Indo-Australian monsoon and its relationship to ENSO and IOD in reanalysis data and the CMIP3/CMIP5 simulations, Clim. Dynam., 41, 3073-3102, 2013.

Jyothibabu, R., Madhu, N. V., Maheswaran, P. A., Jayalakshmy, K. V., Nair, K. K. C., and Achuthankutty, C. T.: Seasonal variation of microzooplankton $(20-200 \mu \mathrm{m})$ and its possible implications on the vertical carbon flux in the western Bay of Bengal, Cont. Shelf Res., 28, 737-755, https://doi.org/10.1016/j.csr.2007.12.011, 2008.

Jyoti, J., Swapna, P., Krishnan, R., and Naidu, C. V.: Pacific modulation of accelerated south Indian Ocean sea level rise during the early 21st Century, Clim. Dynam., 53, 4413-4432, https://doi.org/10.1007/s00382-019-04795-0, 2019.

Kataoka, T., Tozuka, T., Masumoto, Y., and Yamagata, T.: The Indian Ocean subtropical dipole mode simulated in the CMIP3 models, Clim. Dynam., 39, 1385-1399, https://doi.org/10.1007/s00382-011-1271-2, 2012.

Kataoka, T., Tozuka, T., Behera, S., and Yamagata, T.: On the Ningaloo Niño/Niña, Clim. Dynam., 43, 1463-1482, https://doi.org/10.1007/s00382-013-1961-z, 2014.

Kato, S., Loeb, N. G., Rose, F. G., Doelling, D. R., Rutan, D. A., Caldwell, T. E., Yu, L., and Weller, R. A.: Surface irradiances consistent with CERES-derived top-of-atmosphere shortwave and longwave irradiances, J. Climate, 26, 2719-2740, https://doi.org/10.1175/JCLI-D-12-00436.1, 2013.

Keen, T. R., Kindle, J. C., and Young, D. K.: The interaction of southwest monsoon upwelling, advection and primary production in the northwest Arabian Sea, J. Mar. Syst., 13, 61-82, https://doi.org/10.1016/S0924-7963(97)00003-1, 1997. 
Keerthi, M. G., Lengaigne, M., Drushka, K., Vialard, J., Montegut, C. D. B., Pous, S., Levy, M., and Muraleedharan, P. M.: Intraseasonal variability of mixed layer depth in the tropical Indian Ocean, Clim. Dynam., 46, 2633-2655, https://doi.org/10.1007/s00382-015-2721-z, 2016.

Kessler, W. S., McPhaden, M. J., and Weickmann, K. M.: Forcing of intraseasonal Kelvin Waves in the equatorial Pacific, J. Geophys. Res., 100, 10613-10631, 1995.

Kido, S. and Tozuka, T.: Salinity Variability Associated with the Positive Indian Ocean Dipole and Its Impact on the Upper Ocean Temperature, J. Climate, 30, 7885-7907, 2017.

Kim, H. S., Flagg, C. N., and Howden, S. D.: Northern Arabian Sea variability from TOPEX/Poseidon altimetry data: An extension of the US JGOFS/ONR shipboard ADCP study, DeepSea Res. Pt II, 48, 1069-1096, https://doi.org/10.1016/S09670645(00)00131-4, 2001.

Kindle, J. C. and Thompson, J. D.: The 26- and 50-day oscillations in the western Indian Ocean: Model results, J. Geophys. Res., 94, 4721-4736, https://doi.org/10.1029/JC094iC04p04721, 1989.

Kobashi, F. and Kubokawa, A.: Review on North Pacific Subtropical Countercurrents and Subtropical Fronts: role of mode waters in ocean circulation and climate, J. Oceanogr., 68, 21-43, https://doi.org/10.1007/s10872-011-0083-7, 2012.

Kosaka, Y. and Xie, S. P.: Recent global-warming hiatus tied to equatorial Pacific surface cooling, Nature, 501, 403-407, https://doi.org/10.1038/nature12534, 2013.

Kosaka, Y., Takaya, Y., and Kamae, Y.: The Indo-western Pacific Ocean capacitor effect, in: Tropical and Extratropical Air-Sea Interactions, Elsevier, Amsterdam, 141-169, 2021.

Koslow, J. A., Pesant, S., Feng, M., Pearce, A., Fearns, P., Moore, T., Matear, R., and Waite, A.: The effect of the Leeuwin Current on phytoplankton biomass and production off Southwestern Australia, J. Geophys. Res.-Oceans, 113, C07050, https://doi.org/10.1029/2007JC004102, 2008.

Krishnamohan, K. S., Vialard, J., Lengaigne, M., Masson, S., Samson, G., Pous, S., Neetu, S., Durand, F., Shenoi, S. S. C., and Madec, G.: Is there an effect of Bay of Bengal salinity on the northern Indian Ocean climatological rainfall?, Deep-Sea Res. Pt. II, 166, 19-33, https://doi.org/10.1016/j.dsr2.2019.04.003, 2019.

Krishnamurthy, L. and Krishnamurthy, V.: Decadal and interannual variability of the Indian Ocean SST. Clim. Dynam., 46, 57-70, 2016.

Krishnaswamy, J., Vaidyanathan, S., Rajagopalan, B., Bonell, M., Sankaran, M., Bhalla, R. S., and Badiger, S.: Non-stationary and non-linear influence of ENSO and Indian Ocean Dipole on the variability of Indian monsoon rainfall and extreme rain events, Clim. Dynam., 45, 175-184, https://doi.org/10.1007/s00382014-2288-0, 2015.

Krug, M. and Tournadre, J. : Satellite observations of an annual cycle in the Agulhas Current, Geophys. Res. Lett., 39, L15607, https://doi.org/10.1029/2012GL052335, 2012.

Krug, M., Swart, S., and Gula, J.: Submesoscale cyclones in the Agulhas current, Geophys. Res. Lett., 44, 346-354, https://doi.org/10.1002/2016GL071006, 2017.

Kubokawa, A.: Ventilated thermocline strongly affected by a deep mixed layer: A theory for subtropical countercurrent. J. Phys. Oceanogr., 29, 1314-1333, https://doi.org/10.1175/15200485(1999)029<1314:VTSABA>2.0.CO;2, 1999.
Kubokawa, A. and Inui, T.: Subtropical countercurrent in an idealized ocean GCM, J. Phys. Oceanogr., 29, 1303-1313, https://doi.org/10.1175/15200485(1999)029<1303:SCIAIO>2.0.CO;2, 1999.

Kumar, K. K., Rajagopalan, B., and Cane, M. A.: On the weakening relationship between the Indian monsoon and ENSO, Science, 284, 2156-2159, https://doi.org/10.1126/science.284.5423.2156, 1999.

Kumar, S. P., Madhupratap, M., Dileep Kumar, M., Gauns, M., Muraleedharan, P. M., Sarma, V. V. S. S., and De Souza, S. N.: Physical control of primary productivity on a seasonal scale in central and eastern Arabian Sea, Proc. Indian Acad. Sci. Earth Planet. Sci., 109, 433-441, https://doi.org/10.1007/bf02708331, 2000.

Kumar, S. P., Muraleedharan, P. M., Prasad, T. G., Gauns, M., Ramaiah, N., De Souza, S. N., Sardesai, S., and Madhupratap, M. Why is the Bay of Bengal less productive during summer monsoon compared to the Arabian Sea?, Geophys. Res. Lett., 29, 2235, https://doi.org/10.1029/2002GL016013, 2002.

Kumar, S. P., Nuncio, M., Narvekar, J., Kumar, A., Sardesai, S., De Souza, S. N., Gauns, M., Ramaiah, N., and Madhupratap, M.: Are eddies nature's trigger to enhance biological productivity in the Bay of Bengal?, Geophys. Res. Lett., 31, https://doi.org/10.1029/2003GL019274, 2004.

Kumar, S. P., Nuncio, M., Ramaiah, N., Sardesai, S., Narvekar, J., Fernandes, V., and Paul, J. T.: Eddy-mediated biological productivity in the Bay of Bengal during fall and spring intermonsoons, Deep-Sea Res. Pt. I, 514, 1619-1640, https://doi.org/10.1016/j.dsr.2007.06.002, 2007.

Kumar, S. P., David, T. D., Byju, P., Narvekar, J., Yoneyama, K., Nakatani, N., Ishida, A., Horii, T., Masumoto, Y., and Mizuno, K.: Bio-physical coupling and ocean dynamics in the central equatorial Indian Ocean during 2006 Indian Ocean Dipole, Geophys. Res. Lett., 39, https://doi.org/10.1029/2012GL052609, 2012.

Kumar, P., Singh, A., Ramesh, R., and Nallathambi, T.: $\mathrm{N}_{2}$ Fixation in the Eastern Arabian Sea: Probable Role of Heterotrophic Diazotrophs, Front. Marine Sci., 4, 80, https://doi.org/10.3389/fmars.2017.00080, 2017.

Kundu, P. K. and McCreary, J. P.: On the dynamics of the throughflow from the Pacific into the Indian Ocean, J. Phys. Oceanogr., 16, 2191-162198, https://doi.org/10.1175/15200485(1986)016<2191:OTDOTT>2.0.CO;2, 1986.

Kunze, E., Firing, E., Hummon, J. M., Chereskin, T. K., and Thurnherr, A. M.: Global Abyssal Mixing Inferred from Lowered ADCP Shear and CTD Strain Profiles, J. Phys. Oceanogr., 36, 1553-1576, https://doi.org/10.1175/JPO2926.1, 2006.

Lakshmi, R. S., Chatterjee, A., Prakash, S., and Mathew, T.: Biophysical interactions in driving the summer monsoon chlorophyll bloom off the Somalia coast, J. Geophys. Res.-Oceans, 125, e2019JC015549, https://doi.org/10.1029/2019JC015549, 2020.

Lambert, E., Le Bars, D., and de Ruijter, W. P. M.: The connection of the Indonesian Throughflow, South Indian Ocean Countercurrent and the Leeuwin Current, Ocean Sci., 12, 771-780, https://doi.org/10.5194/os-12-771-2016, 2016.

Lamont, T., Barlow, R. G., Morris, T., and van den Berg, M. A.: Characterisation of mesoscale features and phytoplankton variability in the Mozambique Channel, Deep-Sea Res. Pt. II, 100, 94-105, https://doi.org/10.1016/j.dsr2.2013.10.019, 2014. 
Latasa, M. and Bidigare, R. R.: A comparison of phytoplankton populations of the Arabian Sea during the Spring Intermonsoon and Southwest Monsoon of 1995 as described by HPLC-analyzed pigments, Deep-Sea Res. Pt. II, 45, 2133-2170, https://doi.org/10.1016/S0967-0645(98)00066-6, 1998.

Lau, W. K.-M. and Waliser, D. E.: Intraseasonal Variability in the Atmosphere-Ocean Climate System, Springer, https://doi.org/10.1007/978-3-642-13914-7, 2012.

Lau, K.-M. and Wu, H. T.: Intrinsic coupled ocean-atmosphere modes of the Asian summer monsoon: A reassessment of monsoon-ENSO relationships, J. Climate, 14, 2880-2895, 2001.

Laurindo, L. C., Mariano, A. J., and Lumpkin, R.: An improved near-surface velocity climatology for the global ocean from drifter observations, Deep-Sea Res. Pt. I, 124, 73-92, https://doi.org/10.1016/j.dsr.2017.04.009, 2017.

Le Bars, D., Dijkstra, H. A., and De Ruijter, W. P. M.: Impact of the Indonesian Throughflow on Agulhas leakage, Ocean Sci., 9, 773-785, https://doi.org/10.5194/os-9-773-2013, 2013.

Le Bars, D., Durgadoo, J. V., Dijkstra, H. A., Biastoch, A., and De Ruijter, W. P. M.: An observed 20-year time series of Agulhas leakage, Ocean Sci., 10, 601-609, https://doi.org/10.5194/os-10601-2014, 2014.

Lee, C. M., Jones, B. H., Brink, K. H., and Fischer, A. S.: The upper-ocean response to monsoonal forcing in the Arabian Sea: Seasonal and spatial variability, Deep-Sea Res. Pt. II, 47, $1177-$ 1226, https://doi.org/10.1016/S0967-0645(99)00141-1, 2000.

Lee, C. M., Jinadasa, S. U. P., Anutaliya, A., Centurioni, L. R., Fernando, H. J. S., Hormann, V., Lankhorst, M., Rainville, L., Send, U., and Wijesekera, H. W.: Collaborative observations of boundary currents, water mass variability, and monsoon response in the southern Bay of Bengal, Oceanography, 29, 102-111, https://doi.org/10.5670/oceanog.2016.43, 2016.

Lee, J. Y., Wang, B., Wheeler, M. C., Fu, X., Waliser, D. E., and Kang, I. S.: Real-time multivariate indices for the boreal summer intraseasonal oscillation over the Asian summer monsoon region, Clim. Dynam., 40, 493-509, https://doi.org/10.1007/s00382012-1544-4, 2013.

Lee, S. K., Park, W., Baringer, M. O., Gordon, A. L., Huber, B., and Liu, Y.: Pacific origin of the abrupt increase in Indian Ocean heat content during the warming hiatus, Nat. Geosci., 8, 445449, https://doi.org/10.1038/NGEO2438, 2015.

Lee, T.: Decadal weakening of the shallow overturning circulation in the South Indian Ocean, Geophys. Res. Lett., 31, L18305, https://doi.org/10.1029/2004GL020884, 2004.

Lee, T. and McPhaden, M. J.: Decadal phase change in largescale sea level and winds in the Indo-Pacific region at the end of the 20th century, Geophys. Res. Lett., 35, L01605, https://doi.org/10.1029/2007GL032419, 2008.

Lee, T., Fournier, S., Gordon, A. L., and Sprintall, J.: Maritime Continent water cycle regulates low-latitude chokepoint of global ocean circulation, Nat. Commun., 10, 2103, https://doi.org/10.1038/s41467-019-10109-z, 2019.

Legeckis, R. and Cresswell, G.: Satellite observations of seasurface temperature fronts off the coast of western and southern Australia, Deep-Sea Res. Pt. I, 28, 297-306, https://doi.org/10.1016/0198-0149(81)90069-8, 1981.

Levine, R. C. and Turner, A. G.: Dependence of Indian monsoon rainfall on moisture fluxes across the Arabian Sea and the impact of coupled model sea surface temperature biases, Clim. Dy- nam., 38, 2167-2190, https://doi.org/10.1007/s00382-011-1096$\mathrm{z}, 2012$.

Lewandowsky, S., Cowtan, K., Risbey, S., Mann, M., Steinman, B., Oreskes, N., and Rahmstorf, S.: The 'pause' in global warming in historical context: (II). Comparing models to observations, Environ. Res. Lett., 13, 123007, https://doi.org/10.1088/17489326/aaf372, 2018.

L'Hégaret, P., Beal, L. M., Elipot, S., and Laurindo, L.: Shallow cross-equatorial gyres of the Indian Ocean driven by seasonally reversing monsoon winds, J. Geophys. Res.-Oceans, 123, 89028920, https://doi.org/10.1029/2018JC014553, 2018.

L'Heureux, M. L., Lee, S., and Lyon, B.: Recent multidecadal strengthening of the Walker circulation across the tropical Pacific, Nat. Clim. Change, 3, 571-576, 2013.

Li, G., Xie, S., and Du, Y.: A robust but spurious pattern of climate change in model projections over the tropical Indian Ocean, J. Climate, 29, 5589-5608, 2016.

Li, Y., Han, W., Ravichandran, M., Wang, W., Shinoda, T., and Lee, T.: Bay of Bengal salinity stratification and Indian summer monsoon intraseasonal oscillation: 1. Intraseasonal variability and causes, J. Geophys. Res.-Oceans, 122, 4291-4311, https://doi.org/10.1002/2017JC012691, 2017a.

Li, Y., Han, W., Wang, W., Ravichandran, M., Lee, T., and Shinoda, T.: Bay of Bengal salinity stratification and Indian summer monsoon intraseasonal oscillation: 2. Impact on SST and convection, J. Geophys. Res.-Oceans, 122, 4312-4328, https://doi.org/10.1002/2017JC012692, 2017b.

Li, Y., Han, W., Hu, A., Meehl, G. A., and Wang, F.: Multidecadal changes of the upper Indian ocean heat content during 19652016, J. Climate, 31, 7863-7884, https://doi.org/10.1175/JCLID-18-0116.1, 2018a.

Li, Y., Han, W., Wang, W., Zhang, L., and Ravichandran, M.: The Indian summer monsoon intraseasonal oscillations in CFSv2 forecasts: Biases and importance of improving air-sea interaction processes, J. Climate, 31, 5351-5370, https://doi.org/10.1175/JCLI-D-17-0623.1, 2018b.

Lierheimer, L. J. and Banse, K.: Seasonal and interannual variability of phytoplankton pigment in the Laccadive (Lakshadweep) Sea as observed by the Coastal Zone Color Scanner, Proc. Indian Acad. Sci., 111, 163-185, 2002.

Liu, Q.-Y., Feng, M., Wang, D., and Wijffels, S.: Interannual variability of the Indonesian Throughflow transport: A revisit based on 30 year expendable bathythermograph data, J. Geophys. Res.-Oceans, 120, 8270-8282, https://doi.org/10.1002/2015JC011351, 2015.

Llovel, W. and Lee, T.: Importance and origin of halosteric contribution to sea level change in the southeast Indian Ocean during 2005-2013, Geophys. Res. Lett., 42, 1148-1157, https://doi.org/10.1002/2014GL062611, 2015.

Longhurst, A.: A major seasonal phytoplankton bloom in the Madagascar Basin, Deep-Sea Res. Pt. I, 48, 2413-2422, https://doi.org/10.1016/S0967-0637(01)00024-3, 2001.

Loschnigg, J., Meehl, G. A., Webster, P. J., Arblaster, J. M., and Compo, G. P.: The Asian monsoon, the tropospheric biennial oscillation, and the Indian Ocean zonal mode in the NCAR CSM, J. Climate, 16, 1617-1642, https://doi.org/10.1175/15200442(2003)016<1617:TAMTTB>2.0.CO;2, 2003.

Lotliker, A. A., Omand, M. M., Lucas, A. J., Laney, S. R., Mahadevan, A., and Ravichandran, M.: Penetrative radia- 
tive flux in the Bay of Bengal, Oceanography, 29, 214-221, https://doi.org/10.5670/oceanog.2016.53, 2016.

Lourey, M. J., Dunn, J. R., and Waring, J.: A mixed-layer nutrient climatology of Leeuwin Current and Western Australian shelf waters: Seasonal nutrient dynamics and biomass, J. Mar. Syst., 59, 25-51, https://doi.org/10.1016/j.jmarsys.2005.10.001, 2006.

Lourey, M. J., Thompson, P. A., McLaughlin, M. J., Bonham, P., and Feng, M.: Primary production and phytoplankton community structure during a winter shelf-scale phytoplankton bloom off Western Australia, Mar. Biol., 160, 355-369, https://doi.org/10.1007/s00227-012-2093-4, 2013.

Loveday, B. R., Durgadoo, J. V., Reason, C. J. C., Biastoch, A., and Penven, P.: Decoupling of the Agulhas leakage from the Agulhas Current, J. Phys. Oceanogr., 44, 1776-1797, https://doi.org/10.1175/JPO-D-13-093.1, 2014.

$\mathrm{Lu}$, B. and Ren, H. L.: What caused the extreme Indian Ocean Dipole event in 2019?, Geophys. Res. Lett., 47, e2020GL087768, https://doi.org/10.1029/2020GL087768, 2020.

Lübbecke, J. F., Durgadoo, J. V., and Biastoch, A.: Contribution of increased agulhas leakage to tropical Atlantic warming, J. Climate, 28, 9697-9706, https://doi.org/10.1175/JCLI-D-150258.1, 2015.

Lucas, A. J., Shroyer, E. L., Wijesekera, H. W., Fernando, H. J. S., D’Asaro, E., Ravichandran, M., Jinadasa, S. U. P., MacKinnon, J. A., Nash, J. D., Sharma, R., Centurioni, L., Farrar, J. T., Weller, R., Pinkel, R., Mahadevan, A., Sengupta, D., and Tandon, A.: Mixing to monsoons: air-sea interactions in the Bay of Bengal, EOS, Transactions American Geophysical Union, 95, 269-270, https://doi.org/10.1002/2014EO300001, 2014.

Lucas, A., Nash, J., Pinkel, R., MacKinnon, J., Tandon, A., Mahadevan, A., Omand, M., Freilich, M., Sengupta, D., Ravichandran, M., and Le Boyer, A.: Adrift Upon a Salinity-Stratified Sea: A view of upper-ocean processes in the Bay of Bengal during the Southwest Monsoon, Oceanography, 29, 134-145, https://doi.org/10.5670/oceanog.2016.46, 2016.

Luis, A. J. and Kawamura, H.: Air-sea interaction, coastal circulation and primary production in the eastern Arabian Sea: A review, J. Oceanogr., 60, 205-218, https://doi.org/10.1023/B:JOCE.0000038327.33559.34, 2004.

Lumpkin, R. and Speer, K.: Global ocean meridional overturning, J. Phys. Oceanogr., 37, 2550-2562, https://doi.org/10.1175/JPO3130.1, 2007.

Lutjeharms, J. R. E.: The Agulhas Current, Springer: Berlin, Heidelbert, New York, 2006.

Lutjeharms, J. R. E. and Machu, E.: An upwelling cell inshore of the East Madagascar Current, Deep-Sea Res. Pt. I, 47, 2405-2411, https://doi.org/10.1016/S0967-0637(00)00026-1, 2000.

Lutjeharms, J. R. E. and Van Ballegooyen, R. C.: The retroflection of the Agulhas Current, J. Phys. Oceanogr., 18, 1570-1583, 1988.

Ma, J., Feng, M., Sloyan, B. M., and Lan, J.: Pacific influences on the meridional temperature transport of the Indian Ocean, J. Climate, 32, 1047-1061, https://doi.org/10.1175/JCLI-D-180349.1, 2019.

Machu, E. and Garçon, V.: Phytoplankton seasonal distribution from sea WiFS data in the Agulhas current system, J. Mar. Res., 59, 795-812, https://doi.org/10.1357/002224001762674944, 2001.
MacKinnon, J., Nash, J., Alford, M., Lucas, A., Mickett, J., Shroyer, E., Waterhouse, A., Tandon, A., Sengupta, D., Mahadevan, A., Ravichandran, M., Pinkel, R., Rudnick, D., Whalen, C., Alberty, M., Lekha, J. S., Fine, E., Chaudhuri, D., and Wagner, G.: A Tale of Two Spicy Seas, Oceanography, 29, 50-61, https://doi.org/10.5670/oceanog.2016.38, 2016.

Madden, R. A. and Julian, P. R.: Detection of a 40-50 Day Oscillation in the Zonal Wind in the Tropical Pacific, J. Atmos. Sci., 28, 702-708, https://doi.org/10.1175/15200469(1971)028<0702:DOADOI>2.0.CO;2, 1971.

Madden, R. A. and Julian, P. R.: Description of Global-Scale Circulation Cells in the Tropics with a 40-50 Day Period, J. Atmos. Sci., 29, 1109-1123, https://doi.org/10.1175/15200469(1972)029<1109:dogscc>2.0.co;2, 1972.

Madhupratap, M., Gauns, M., Ramaiah, N., Prasanna Kumar, S., Muraleedharan, P. M., De Sousa, S. N., Sardessai, S., and Muraleedharan, U.: Biogeochemistry of the Bay of Bengal: Physical, chemical and primary productivity characteristics of the central and western Bay of Bengal during summer monsoon 2001, DeepSea Res. Pt II, 50, 881-896, https://doi.org/10.1016/S09670645(02)00611-2, 2003.

Maes, C., Grima, N., Blanke, B., Martinez, E., Paviet-Salomon, T., and Huck, T.: A Surface "Superconvergence" Pathway Connecting the South Indian Ocean to the Subtropical South Pacific Gyre, Geophys. Res. Lett., 45, 1915-1922, https://doi.org/10.1002/2017GL076366, 2018.

Mahadevan, A.: Eddy effects on biogeochemistry, Nature, 506, 168-169, https://doi.org/10.1038/nature13048, 2014.

Mahadevan, A., D'Asaro, E., Lee, C., and Perry, M. J.: Eddy-driven stratification initiates North Atlantic spring phytoplankton blooms, Science, 80, 54-58, https://doi.org/10.1126/science.1218740, 2012.

Mahadevan, A., Paluszkiewicz, T., Ravichandran, M., Sengupta, D., and Tandon, A.: Introduction to the Special Issue on the Bay of Bengal: From Monsoons to Mixing, Oceanography, 29, 14-17, https://doi.org/10.5670/oceanog.2016.34, 2016a.

Mahadevan, A., Spiro Jaeger, G., Freilich, M., Omand, M., Shroyer, E., and Sengupta, D.: Freshwater in the Bay of Bengal: Its Fate and Role in Air-Sea Heat Exchange, Oceanography, 29, 72-81, https://doi.org/10.5670/oceanog.2016.40, 2016 b.

Maher, N., England, M. H., Gupta, A. S., and Spence, P.: Role of Pacific trade winds in driving ocean temperatures during the recent slowdown and projections under a wind trend reversal, Clim. Dynam., 51, 321-336, https://doi.org/10.1007/s00382-017-3923-3, 2018.

Manatsa, D. and Behera, S. K.: On the epochal strengthening in the relationship between rainfall of East Africa and IOD, J. Climate, 26, 5655-5673, https://doi.org/10.1175/JCLI-D-12$00568.1,2013$.

Manghnani, V., Morrison, J. M., Hopkins, T. S., and Böhm, E.: Advection of upwelled waters in the form of plumes off Oman during the Southwest Monsoon, Deep-Sea Res. Pt II, 45, 2027 2052, https://doi.org/10.1016/S0967-0645(98)00062-9, 1998.

Marra, J., Dickey, T. D., Ho, C., Kinkade, C. S., Sigurdson, D. E., Weller, R. A., and Barber, R. T.: Variability in primary production as observed from moored sensors in the central Arabian Sea in 1995, Deep-Sea Res. Pt II, 45, 2253-2267, https://doi.org/10.1016/S0967-0645(98)00070-8, 1998. 
Marsac, F. and Le Blanc, J.: Oceanographic changes during the 1997-1998 El Niño in the Indian Ocean and their impact on the purse seine fishery, IOTC Proc. no. 2, 1999.

Marin, M. and Feng, M.: Intra-annual variability of the North West Shelf of Australia and its impact on the Holloway Current: Excitement and propagation of coastally trapped waves, Cont. Shelf Res., 186, 88-103, https://doi.org/10.1016/j.csr.2019.08.001, 2019.

Marin, M., Feng, M., Phillips, H. E., and Bindoff, N. L.: A global, multiproduct analysis of coastal marine heatwaves: distribution, characteristics, and long-term trends, J. Geophys. Res.-Oceans, 126, e2020JC016708, https://doi.org/10.1029/2020JC016708, 2021.

Marshall, A. G. and Hendon, H. H.: Impacts of the MJO in the Indian Ocean and on the Western Australian coast, Clim. Dynam., 42, 579-595, https://doi.org/10.1007/s00382-012-1643-2, 2014.

Marshall, A. G., Hendon, H. H., Feng, M., and Schiller, A.: Initiation and amplification of the Ningaloo Niño, Clim. Dynam., 45, 2367-2385, https://doi.org/10.1007/s00382-015-2477-5, 2015.

Martin, A. P. and Richards, K. J.: Mechanisms for vertical nutrient transport within a North Atlantic mesoscale eddy, DeepSea Res. Pt II, 48, 757-773, https://doi.org/10.1016/S09670645(00)00096-5, 2001.

Masson, S., Menkes, C., Delecluse, P., and Boulanger, J.-P.: Impacts of salinity on the eastern Indian Ocean during the termination of the fall Wyrtki Jet, J. Geophys. Res., 108, 3067, https://doi.org/10.1029/2001JC000833, 2003.

Masumoto, Y. and Meyers, G.: Forced Rossby waves in the southern tropical Indian Ocean, J. Geophys. Res.-Oceans, 103, 2758927602, https://doi.org/10.1029/98JC02546, 1998.

Masumoto, Y., Hase, H., Kuroda, Y., Matsuura, H., and Takeuchi, K.: Intraseasonal variability in the upper layer currents observed in the eastern equatorial Indian Ocean, Geophys. Res. Lett., 32, L02607, https://doi.org/10.1029/2004GL021896, 2005.

Matondkar, P. S. G., Gomes, H. D., Parab, S. G., Pednekar, S., and Goes, J. I.: Phytoplankton Diversity, Biomass and Production, in: The Mandovi and Zuari Estuaries, edited by: Shetye, S. R., Kumar, D., and Shankar, D., National Institute of Oceanography, Dona Paula, India, 2007.

Matthews, A. J., Singhruck, P., and Heywood, K. J.: Deep ocean impact of a Madden-Julian oscillation observed by Argo floats, Science, 318, 1765-1769, https://doi.org/10.1126/science.1147312, 2007.

Matthews, A. J., Baranowski, D. B., Heywood, K. J., Flatau, P. J., and Schmidtko, S.: The surface diurnal warm layer in the Indian Ocean during CINDY/DYNAMO, J. Climate, 27, 9101-9122, https://doi.org/10.1175/JCLI-D-14-00222.1, 2014.

Maximenko, N., Niiler, P., Centurioni, L., Rio, M.-H., Melnichenko, O., Chambers, D., Zlotnicki, V., and Galperin, B.: Mean dynamic topography of the ocean derived from satellite and drifting buoy data using three different techniques, J. Atmos. Ocean. Tech. 26, 1910-1919, https://doi.org/10.1175/2009JTECHO672.1, 2009.

Mayer, M., Alonso Balmaseda, M., and Haimberger, L.: Unprecedented 2015/2016 Indo-Pacific Heat Transfer Speeds Up Tropical Pacific Heat Recharge, Geophys. Res. Lett., 45, 3274-3284, https://doi.org/10.1002/2018GL077106, 2018.

McCreary, J. P.: Equatorial beams, J. Marine Res., 42, 395-430, https://doi.org/10.1357/002224084788502792, 1984.
McCreary, J. P., Fukamachi, Y., and Lu, P.: A nonlinear mechanism for maintaining coastally trapped eastern boundary currents, J. Geophys. Res., 97, 5677-5692, https://doi.org/10.1029/92JC00035, 1992.

McCreary, J. P., Kundu, P. K., and Molinari, R. L.: A numerical investigation of dynamics, thermodynamics, and mixed layer processes in the Indian Ocean, Prog. Oceanogr., 31, 181-224, 1993.

McCreary, J. P., Han, W., Shankar, D., and Shetye, S. R.: Dynamics of the East India Coastal Current 2. Numerical solutions; J. Geophys. Res., 101, 13993-14010, 1996.

McCreary, J. P., Shetye, S. R., and Kundu, P. K.: Thermohaline forcing of eastern boundary currents: With application to the circulation off the west coast of Australia, J. Mar. Res., 44, 71-92, https://doi.org/10.1357/002224086788460184, 1986.

McCreary, J. P., Kohler, K. E., Hood, R. R., Smith, S., Kindle, J., Fischer, A. S., and Weller, R. A.: Influences of diurnal and intraseasonal forcing on mixed-layer and biological variability in the central Arabian Sea, J. Geophys. Res.-Oceans, 106, 71397155, https://doi.org/10.1029/2000jc900156, 2001.

McCreary, J. P., Murtugudde, R., Vialard, J., Vinayachandran, P. N., Wiggert, J. D., Hood, R. R., Shankar, D., and Shetye, S.: Biophysical Processes in the Indian Ocean, in: Indian Ocean Biogeochemical Processes and Ecological Variability, edited by: Wiggert, J. D., Hood, R. R., Naqvi, S. A., Brink, K. H., and Smith, S. L., American Geophysical Union, https://doi.org/10.1029/2008GM000768, 2009.

McCreary, J. P., Yu, Z., Hood, R. R., Vinayachandran P. N., Furue, R., Ishida, A., and Richards, K. J.: Dynamics of the Indian-Ocean oxygen minimum zones, Prog. Oceanogr., 112, 15-37, 2013.

McDonagh, E. L., Bryden, H. L., King, B. A., and Sanders, R. J.: The circulation of the Indian Ocean at $32^{\circ} \mathrm{S}$, Prog. Oceanogr., 79, 20-36, 2008.

McGillicuddy, D. J., Anderson, L. A., Bates, N. R., Bibby, T., Buesseler, K. O., Carlson, C. A., Davis, C. S., Ewart, C., Falkowski, P. G., Goldthwait, S. A., Hansell, D. A., Jenkins, W. J., Johnson, R., Kosnyrev, V. K., Ledwell, J. R., Li, Q. P., Siegel, D. A., and Steinberg, D. K.: Eddy/Wind interactions stimulate extraordinary mid-ocean plankton blooms, Science, 316, 1021-1026, https://doi.org/10.1126/science.1136256, 2007.

McPhaden, M. J.: Genesis and evolution of the 1997-98 El Niño, Science, 283, 950-954, 1999.

McPhaden, M. J. and Foltz, G. R.: Intraseasonal variations in the surface layer heat balance of the central equatorial Indian Ocean: The importance of zonal advection and vertical mixing, Geophys. Res. Lett., 40, 2737-2741, https://doi.org/10.1002/grl.50536, 2013.

McPhaden, M. J. and Nagura, M.: Indian Ocean Dipole interpreted in terms of Recharge Oscillator theory, Clim. Dynam., 42, 15691586, https://doi.org/10.1007/s00382-013-1765-1, 2014.

McPhaden, M. J., Meyers, G., Ando, K., Masumoto, Y., Murty, V. S. N., Ravichandran, M., Syamsudin, F., Vialard, J., Yu, L., and Yu, W.: RAMA: The Research Moored Array for African-AsianAustralian Monsoon Analysis and Prediction, B. Am. Meteorol. Soc., 90, 459-480, 2009.

McPhaden, M. J., Wang, Y., and Ravichandran, M.: Volume transports of the Wyrtki jets and their relationship to the Indian Ocean dipole, J. Geophys. Res.-Oceans, 120, 5302-5317, 2015. 
Meehl, G. A. and Arblaster, J. M.: Decadal variability of AsianAustralian monsoon-ENSO-TBO relationships, J. Climate, 24, 4925-4940, https://doi.org/10.1175/2011JCLI4015.1, 2011.

Menezes, V. V.: The structure and dynamics of the eastward flows of the South Indian Ocean, PhD Thesis, University of Tasmania, 244 pp., available at: http://eprints.utas.edu.au/23392/ (last access: 7 November 2019), 2015.

Menezes, V. V., Phillips, H. E., Schiller, A., Domingues, C. M., and Bindoff, N. L.: Salinity dominance on the Indian Ocean Eastern Gyral current, Geophys. Res. Lett., 40, 5716-5721, https://doi.org/10.1002/2013GL057887, 2013.

Menezes, V. V., Phillips, H. E., Schiller, A., Bindoff, N. L., Domingues, C. M., and Vianna, M. L.: South Indian Countercurrent and associated fronts, J. Geophys. Res.-Oceans, 119, 67636791, https://doi.org/10.1002/2014JC010076, 2014a.

Menezes, V. V., Vianna, M. L., and Phillips, H. E.: Aquarius sea surface salinity in the South Indian Ocean: Revealing annualperiod planetary waves, J. Geophys. Res.-Oceans, 119, 38833908, https://doi.org/10.1002/2014JC009935, 2014b.

Menezes, V. V., Phillips, H. E., Vianna, M. L., and Bindoff, N. L.: Interannual variability of the South Indian Countercurrent, J. Geophys. Res.-Oceans, 121, 3465-3487, https://doi.org/10.1002/2015JC011417, 2016.

Menezes, V. V., Farrar, J. T., and Bower, A. S.: Evaporative Implications of Dry-Air Outbreaks Over the Northern Red Sea, J. Geophys. Res.-Atmos., 124, 4829-4861, https://doi.org/10.1029/2018JD028853, 2019.

Merle, J., Rotschi, H., and Voituriez, B.: Zonal circulation in the tropical western South Pacific at $170^{\circ}$ E. Bull. Japan Soc. Fish. Oceanogr., Special Issue (Prof. Uda's Commemorative Papers), 91-98, 1969.

Meuleners, M. J., Pattiaratchi, C. B., and Ivey, G. N.: Numerical modelling of the mean flow characteristics of the Leeuwin Current System, Deep-Sea Res. Pt. II, 54, 837-858, https://doi.org/10.1016/j.dsr2.2007.02.003, 2007.

Meuleners, M. J., Ivey, G. N., and Pattiaratchi, C. B.: A numerical study of the eddying characteristics of the Leeuwin Current System, Deep-Sea Res. Pt. I, 55, 261-276, https://doi.org/10.1016/j.dsr.2007.12.004, 2008.

Meyers, G.: Variation of Indonesian throughflow and the El Niño Southern Oscillation, J. Geophys. Res., 101, 12255-12263, https://doi.org/10.1029/95JC03729, 1996.

Meyers, G., Bailey, R. J., and Worby, A. P.: Geostrophic transport of Indonesian Throughflow, Deep-Sea Res. Pt. I, 42, 1163-1174, 1995.

Miyama, T., McCreary, J. P., Jensen, T. G., Loschnigg, J. L., Godfrey, S., and Ishida, A.: Structure and dynamics of the IndianOcean cross-equatorial cell, Deep-Sea Res. Pt. II, 50, 2023 2047, https://doi.org/10.1016/S0967-0645(03)00044-4, 2003.

Miyama, T., McCreary, J. P., Sengupta, D., and Senan, R.: Dynamics of biweekly oscillations in the equatorial Indian Ocean, J. Phys. Oceanogr., 36, 827-846, https://doi.org/10.1175/JPO2897.1, 2006.

Moore, D. W.: Planetary-gravity waves in an equatorial ocean, $\mathrm{PhD}$ Thesis, Harvard Univ., Cambridge, Mass., 207 pp., 1968.

Moore, T. S., Matear, R. J., Marra, J., and Clementson, L.: Phytoplankton variability off the Western Australian Coast: Mesoscale eddies and their role in cross-shelf exchange, Deep-Sea Res.
Pt II, 54, 943-960, https://doi.org/10.1016/j.dsr2.2007.02.006, 2007.

Morel, A. and Antoine, D.: Heating Rate within the Upper Ocean in Relation to its Bio-optical State, J. Phys. Oceanogr., 24, 1652-1665, https://doi.org/10.1175/15200485(1994)024<1652:HRWTUO>2.0.CO;2, 1994.

Morioka, Y., Tozuka, T., and Yamagata, T.: Climate variability in the southern Indian Ocean as revealed by self-organizing maps, Clim. Dynam., https://doi.org/10.1007/s00382-010-0843$\mathrm{x}, 2010$.

Morioka, Y., Tozuka, T., Masson, S., Terray, P., Luo, J. J., and Yamagata, T.: Subtropical dipole modes simulated in a coupled general circulation model, J. Climate, 25, 4029-4047, https://doi.org/10.1175/JCLI-D-11-00396.1, 2012.

Moum, J. N. and Nash, J. D.: Mixing Measurements on an Equatorial Ocean Mooring, J. Atmos. Ocean. Tech., 26, 317-336, https://doi.org/10.1175/2008jtecho617.1, 2009.

Moum, J. N., de Szoeke, S. P., Smyth, W. D., Edson, J. B., DeWitt, H. L., Moulin, A. J., Thompson, E. J., Zappa, C. J., Rutledge, S. A., Johnson, R. H., and Fairall, C. W.: Air-Sea Interactions from Westerly Wind Bursts During the November 2011 MJO in the Indian Ocean, B. Am. Meteorol. Soc., 95, 1185-1199, https://doi.org/10.1175/BAMS-D-12-00225.1, 2014.

Moum, J. N., Pujiana, K., Lien, R. C., and Smyth, W. D.: Ocean feedback to pulses of the Madden-Julian Oscillation in the equatorial Indian Ocean, Nat. Commun., 7, 1-7, https://doi.org/10.1038/ncomms13203, 2016.

Mukherjee, A., Shankar, D., Fernando, V., Amol, P., Aparna, S. G., Fernandes, R., Michael, G. S., Khalap, S. T., Satelkar, N. P., Agarvadekar, Y., Gaonkar, M. G., Tari, A. P., Kankonkar, A., and Vernekar, S.: Observed seasonal and intraseasonal variability of the East India Coastal Current on the continental slope, J. Earth Syst. Sci., 123, 1197-1232, https://doi.org/10.1007/s12040-0140471-7, 2014.

Mukherjee, A., Shankar, D., Chatterjee, A., and Vinayachandran, P. N.: Numerical simulation of the observed near surface East India Coastal Current on the continental slope, Clim. Dynam., 50, 3949-3980, https://doi.org/10.1007/s00382-017-3856-x, 2018.

Mukherjee, A., Chatterjee, A., and Francis, P.: Role of Andaman and Nicobar Islands in eddy formation along western boundary of the Bay of Bengal, Sci. Rep.-UK, 9, 10152, https://doi.org/10.1038/s41598-019-46542-9, 2019.

Mukhopadhyay, S. Shankar, D., Aparna, S. G., Mukherjee, A., Fernando, V., Kankonkar, A., Khalap, S. T., Satelkar, N. P., Gaonkar, M. G., Tari, A. P., Khedekar, R. R., and Ghatkar, S.: Observed variability of the East India Coastal Current on the continental slope during 2009-2018, J. Earth Syst. Sci., 129, 77, https://doi.org/10.1007/s12040-020-1346-8, 2020.

Mulholland, M. R., Bernhardt, P. W., Ozmon, I., Procise, L. A., Garrett, M., O’Neil, J. M., Heil, C. A., and Bronk, D. A.: Contribution of diazotrophy to nitrogen inputs supporting Karenia brevis blooms in the Gulf of Mexico, Harmful Algae, 38, 20-29, https://doi.org/10.1016/j.hal.2014.04.004, 2014.

Muraleedharan, K. R., Jasmine, P., Achuthankutty, C. T., Revichandran, C., Dinesh Kumar, P. K., Anand, P., and Rejomon, G.: Influence of basin-scale and mesoscale physical processes on biological productivity in the Bay of Bengal during the summer monsoon, Prog. Oceanogr., 72, 364-383, https://doi.org/10.1016/j.pocean.2006.09.012, 2007. 
Murtugudde, R. and Busalacchi, A. J.: Interannual variability of the dynamics and thermodynamics of the tropical Indian Ocean, J. Climate, 12, 2300-2326, https://doi.org/10.1175/15200442(1999)012<2300:ivotda>2.0.co;2, 1999.

Murtugudde, R., McCreary, J. P., and Busalacchi, A. J.: Oceanic processes associated with anomalous events in the Indian Ocean with relevance to 1997-1998, J. Geophys. Res.-Oceans, 105, 3295-3306, https://doi.org/10.1029/1999JC900294, 2000.

Murtugudde, R., Beauchamp, J., McClain, C. R., Lewis, M., and Busalacchi, A. J.: Effects of penetrative radiation of the upper tropical ocean circulation, J. Climate, 15, 470-486, https://doi.org/10.1175/15200442(2002)015<0470:EOPROT>2.0.CO;2, 2002.

Murty, V. S. N., Sarma, Y. V. B., Rao, D. P., and Murty, C. S.: Water characteristics, mixing and circulation in the Bay of Bengal during southwest monsoon, J. Marine Res., 50, 207-228, https://doi.org/10.1357/002224092784797700, 1992.

Murty, V. S. N., Gupta, G. V. M., Sarma, V. V., Rao, B. P., Jyothi, D., Shastri, P. N. M., and Supraveena, Y.: Effect of vertical stability and circulation on the depth of the chlorophyll maximum in the Bay of Bengal during May-June, 1996, Deep-Sea Res. Pt. I, 47, 859-873, https://doi.org/10.1016/S0967-0637(99)00071-0, 2000.

Nagura, M. and McPhaden, M. J.: Wyrtki jet dynamics: Seasonal variability, J. Geophys. Res.-Oceans, 115, 1-17, 2010a.

Nagura, M. and McPhaden, M. J.: Dynamics of zonal current variations associated with the Indian Ocean dipole, J. Geophys. Res.Oceans, 115, 1-12, 2010b.

Nagura, M. and McPhaden, M. J.: The dynamics of wind-driven intraseasonal variability in the equatorial Indian Ocean, J. Geophys. Res.-Oceans, 117, 1-16, https://doi.org/10.1029/2011JC007405, 2012.

Nagura, M. and McPhaden, M. J.: Zonal momentum budget along the equator in the Indian Ocean from a high resolution ocean general circulation model, J. Geophys. Res., 119, 4444-4461, https://doi.org/10.1002/2014JC009895, 2014.

Nagura, M. and McPhaden, M. J.: Zonal Propagation of NearSurface Zonal Currents in Relation to Surface Wind Forcing in the Equatorial Indian Ocean, J. Phys. Ocean., 46, 3623-3638, https://doi.org/10.1175/JPO-D-16-0157.1, 2016.

Nagura, M. and McPhaden, M. J.: The Shallow Overturning Circulation in the Indian Ocean, J. Phys. Oceanogr., 48, 413-434, 2018.

Nagura, M. and McPhaden, M. J.: Interannual variability in sea surface height at Southern midlatitudes of the Indian Ocean, J. Phys. Oceanogr., 51, 1595-1609, 2021.

Naqvi, S. W., Narvekar, P. V., and Desa, E.: Coastal biogeochemical processes in the North Indian Ocean $(14, \mathrm{~S}-\mathrm{W})$, The Sea, 14, 723-780, 2006.

Naqvi, S. W. A., Jayakumar, D. A., Narvekar, P. V., Naik, H., Sarma, V. V. S. S., D’Souza, W., Joseph, S., and George, M. D.: Increased marine production of $\mathrm{N}_{2} \mathrm{O}$ due to intensifying anoxia on the Indian continental shelf, Nature, 408, 346-349, https://doi.org/10.1038/35042551, 2000.

Narayanasetti, S., Swapna, P., Ashok, K., Jadhav, J., and Krishnan, R.: Changes in biological productivity associated with Ningaloo Niño/Niña events in the southern subtropical Indian Ocean in recent decades, Sci. Rep.-UK, 6, 27467, https://doi.org/10.1038/srep27467, 2016.
Nash, J. D., Lucas, A. D., MacKinnon, J. A., Shroyer, E. L., Whalen, C. B., and Waterhouse, A. F., Multiscale Observations of NearSurface Salinity in the Bay of Bengal, Box1, Oceanography, 29, 148, https://doi.org/10.5670/oceanog.2016.47, 2016.

Nethery, D. and Shankar, D.: Vertical propagation of baroclinic Kelvin waves along the west coast of India, J. Earth. Syst. Sci., 116, 331-339, https://doi.org/10.1007/s12040-007-0030-6, 2007.

Nicholson, S. E.: Long-term variability of the East African "short rains" and its links to large-scale factors, Int. J. Climatol., 35, 3979-3990, https://doi.org/10.1002/joc.4259, 2015.

Nidheesh, A. G., Lengaigne, M., Vialard, J., Unnikrishnan, A. S., and Dayan, H.: Decadal and long-term sea level variability in the tropical Indo-Pacific Ocean, Clim. Dynam., 41, 381-402, 2013.

Nieves, V., Willis, J. K., and Patzert, W. C.: Recent hiatus caused by decadal shift in Indo-Pacific heating, Science, 349, 532-535, https://doi.org/10.1126/science.aaa4521, 2015.

Niiler, P. P., Maximenko, N. A., and McWilliams, J. C.: Dynamically balanced absolute sea level of the global ocean derived from near-surface velocity observations, Geophys. Res. Lett., 30, 2164, https://doi.org/10.1029/2003GL018628, 2003.

Nof, D. and Olson, D. B.: How do western abyssal currents cross the equator?, Deep-Sea Res. Pt. I, 40, 235-255, https://doi.org/10.1016/0967-0637(93)90002-K, 1993.

Nyadjro, E. and McPhaden, M. J.: Variability of zonal currents in the eastern equatorial Indian Ocean on seasonal to interannual time scales, J. Geophys. Res., 119, 7969-7986, https://doi.org/10.1002/2014JC010380, 2014.

Nyadjro, E. S. and Subrahmanyam, B.: SMOS salinity mission reveals salinity structure of the Indian Ocean Dipole, IEEE Geosci. Remote Sens. Lett., 11, 1564-1568, https://doi.org/10.1109/LGRS.2014.2301594, 2014.

Nyadjro, E. S., Subrahmanyam, B., and Shriver, J. F.: Seasonal Variability of Salt Transport During the Indian Ocean Monsoons, J. Geophys. Res.-Oceans, 116, C08036, https://doi.org/10.1029/2011JC006993, 2011.

Nyadjro, E. S., Subrahmanyam, B., Murty, V. S. N., and Shriver, J. F.: The role of salinity on the dynamics of the Arabian Sea mini warm pool, J. Geophys. Res., 117, C09002, https://doi.org/10.1029/2012JC007978, 2012.

Nyadjro, E. S., Subrahmanyam, B., and Giese, B. S.: Variability of Salt Flux in the Indian Ocean During 1960-2008, Remote Sens. Environ., 134, 175-193, https://doi.org/10.1016/j.rse.2013.03.005, 2013.

Ogata, T. and Masumoto, Y.: Interannual modulation and its dynamics of the mesoscale eddy variability in the southeastern tropical Indian Ocean, J. Geophys. Res., 116, C05005, https://doi.org/10.1029/2010JC006490, 2011.

Ogata, T. and Xie, S.-P.: Semiannual cycle in zonal wind over the equatorial Indian Ocean, J. Climate, 24, 6471-6485, https://doi.org/10.1175/2011JCLI4243.1, 2011.

Oke, P. R., Griffin, D. A., Rykova, T., and de Oliveira, H. B.: Ocean circulation in the Great Australian Bight in an eddyresolving ocean reanalysis: The eddy field, seasonal and interannual variability, Deep-Sea Res. Pt. II, 157-158, 11-26, https://doi.org/10.1016/j.dsr2.2018.09.012, 2018.

Oliver, E. C., Donat, M. G., Burrows, M. T., Moore, P. J., Smale, D. A., Alexander, L. V., Benthuysen, J. A., Feng, M., Sen Gupta, A., Hobday, A. J., Holbrook, N. J., Perkins-Kirkpatrick, S. E., Scan- 
nell, H. A., Straub, S. C., and Wernberg, T.: Longer and more frequent marine heatwaves over the past century, Nat. Commun., 9, 1324, https://doi.org/10.1038/s41467-018-03732-9, 2018.

Oliver, E. C. J. and Thompson, K. R.: Madden-Julian oscillation and sea level: Local and remote forcing, J. Geophys. Res.-Oceans, 115, 1-15, https://doi.org/10.1029/2009JC005337, 2010.

Oliver, E. C. J., Herzfeld, M., and Holbrook, N. J.: Modelling the shelf circulation offeastern Tasmania, Cont. Shelf Res., 130, 1433, 2016.

Orsi, A. H., Whitworth, T., and Nowlin, W. D.: On the meridional extent and fronts of the Antarctic Circumpolar Current, Deep-Sea Res., 42, 641-673, https://doi.org/10.1016/09670637(95)00021-W, 1995.

Palastanga, V., van Leeuwen, P. J., Schouten, M. W., and de Ruijter, W. P. M.: Flow structure and variability in the subtropical Indian Ocean: instability of the South Indian Ocean Countercurrent, J. Geophys. Res., 112, C01001, https://doi.org/10.1029/2005JC003395, 2007.

Palmer, T. N. and Mansfield, D. A.: Response of two atmospheric general circulation models to sea-surface temperature anomalies in the tropical east and west Pacific, Nature, 310, 483-488, 1984.

Papa, F., Durand, F., Rossow, W. B., A. Rahman, and Bala, S. K.: Satellite altimeter-derived monthly discharge of the Ganga-Brahmaputra River and its seasonal to interannual variations from 1993 to 2008, J. Geophys. Res., 115, C12013, https://doi.org/10.1029/2009JC006075, 2010.

Papa, F., Bala, S. K., Pandey, R. K., Durand, F., Gopalakrishna, V. V., Rahman, A., and Rossow, W. B.: Ganga-Brahmaputra river discharge from Jason-2 radar altimetry: An update to the longterm satellite-derived estimates of continental freshwater forcing flux into the Bay of Bengal, J. Geophys. Res.-Oceans, 117, https://doi.org/10.1029/2012JC008158, 2012.

Parab, S. G., Prabhu Matondkar, S. G., Gomes, H. do R., and Goes, J. I.: Monsoon driven changes in phytoplankton populations in the eastern Arabian Sea as revealed by microscopy and HPLC pigment analysis, Cont. Shelf Res., 26, 2538-2558, https://doi.org/10.1016/j.csr.2006.08.004, 2006.

Paris, M. L., Subrahmanyam, B., Trott, C. B., and Murty, V. S. N.: Influence of ENSO Events on the Agulhas Leakage Region, Remote Sens. Earth Syst. Sci., 1, 79-88, https://doi.org/10.1007/s41976-018-0007-z, 2018.

Paterson, H. L., Feng, M., Waite, A. M., Gomis, D., Beckley, L. E., Holliday, D., and Thompson, P. A.: Physical and chemical signatures of a developing anticyclonic eddy in the Leeuwin Current, eastern Indian Ocean, J. Geophys. Res.-Oceans, 113, C07049, https://doi.org/10.1029/2007JC004707, 2008.

Paterson, J. S., Nayar, S., Mitchell, J. G., and Seuront, L.: Population-specific shifts in viral and microbial abundance within a cryptic upwelling, J. Mar. Syst., 113-114, 52-61, https://doi.org/10.1016/j.jmarsys.2012.12.009, 2013.

Pathak, A., Ghosh, S., Kumar, P., and Murtugudde, R.: Role of Oceanic and Terrestrial Atmospheric Moisture Sources in Intraseasonal Variability of Indian Summer Monsoon Rainfall, Sci. Rep.-UK, 7, 12729, https://doi.org/10.1038/s41598-017-131157, 2017.

Pearce, A., Lenanton, R., Jackson, G., Moore, J., Feng, M., and Gaughan, D.: The "marine heat wave" off Western Australia during the summer of 2010/11, Fisheries Research Report No. 222, Department of Fisheries, Western Australia, 40 pp., available at: http://fish.wa.gov.au/Documents/research_reports/frr222.pdf (last access: 22 October 2021), 2011.

Pearce, A. F. and Griffiths, R. W.: The mesoscale structure of the Leeuwin Current: A comparison of laboratory model and satellite images, J. Geophys. Res., 96, 16730-16757, https://doi.org/10.1029/91JC01712, 1991.

Peatman, S. C. and Klingaman, N. P.: The Indian summer monsoon in MetUM-GOML2.0: effects of air-sea coupling and resolution, Geosci. Model Dev., 11, 4693-4709, https://doi.org/10.5194/gmd-11-4693-2018, 2018.

Pham, H. T. and Sarkar, S.: The role of turbulence in strong submesoscale fronts of the Bay of Bengal, Deep-Sea Res. Pt. II, 168 , 104644, https://doi.org/10.1016/j.dsr2.2019.104644, 2019.

Philander, S. G. H. and Yoon, J.-H.: Eastern boundary currents and coastal upwelling, J. Phys Oceanogr., 12, 862-879, https://doi.org/10.1175/15200485(1982)012<0862:EBCACU>2.0.CO;2, 1982.

Phillips, H. E., Wijffels, S. E., and Feng, M.: Interannual variability in the freshwater content of the IndonesianAustralian Basin, Geophys. Res. Lett., 32, L03603, https://doi.org/10.1029/2004GL021755, 2005.

Pirro, A., Fernando, H. J. S., Wijesekera, H. W., Jensen, T. G., Centurioni, L. R., and Jinadasa, S. U. P.: Eddies and currents in the Bay of Bengal during summer monsoons, Deep-Sea Res. Pt. II, 172, 104728, https://doi.org/10.1016/j.dsr2.2019.104728, 2020a.

Pirro, A., Wijesekera, H. W., Jarosz, E., and Fernando, H. J. S.: Dynamics of intraseasonal oscillations in the Bay of Bengal during summer monsoons captured by mooring observations, Deep-Sea Res. Pt. II, 172, 104718, https://doi.org/10.1016/j.dsr2.2019.104718, 2020b.

Pokhrel, S., Chaudhari, H. S., Saha, S. K., Dhakate, A., Yadav, R. K., Salunke, K., Mahapatra, S., and Rao, S. A.: ENSO, IOD and Indian summer monsoon in NCEP climate forecast system, Clim. Dynam., 39, 2143-2165, https://doi.org/10.1007/s00382012-1349-5, 2012.

Poulton, A. J., Stinchcombe, M. C., and Quartly, G. D.: High numbers of Trichodesmium and diazotrophic diatoms in the southwest Indian Ocean, Geophys. Res. Lett., 36, L15610, https://doi.org/10.1029/2009GL039719, 2009.

Prerna, S., Chatterjee, A., Mukherjee, A., Ravichandran, M., and Shenoi, S. S. C.: Wyrtki Jets: Role of intraseasonal forcing, J. Earth Syst. Sci., 128, 21, https://doi.org/10.1007/s12040-0181042-0, 2019.

Pujiana, K. and McPhaden, M. J.: Ocean's response to the convectively coupled Kelvin waves in the eastern equatorial Indian Ocean, J. Geophys. Res., 123, 5727-5741, https://doi.org/10.1029/2018JC013858, 2018.

Pujiana, K. and McPhaden, M. J.: Intraseasonal Kelvin Waves in the Equatorial Indian Ocean and Their Propagation into the Indonesian Seas, J. Geophys. Res.-Oceans, 125, 1-18, https://doi.org/10.1029/2019JC015839, 2020.

Pujiana, K. and McPhaden, M. J.: Biweekly mixed Rossby-Gravity waves in the equatorial Indian Ocean, J. Geophys. Res., 126, e2020JC016840, https://doi.org/10.1029/2020JC016840, 2021.

Pujiana, K., Gordon, A. L., and Sprintall, J.: Intraseasonal Kelvin wave in Makassar strait, J. Geophys. Res.-Oceans, 118, 20232034, https://doi.org/10.1002/jgrc.20069, 2013.

Pujiana, K., McPhaden, M. J., Gordon, A. L., and Napitu, A. M.: Unprecedented response of Indonesian throughflow to anoma- 
lous Indo-Pacific climatic forcing in 2016, J. Geophys. Res., 124, 3737-3754, https://doi.org/10.1029/2018JC014574, 2019.

Purkey, S. G. and Johnson, G. C.: Global contraction of Antarctic Bottom Water between the 1980s and 2000s, J. Climate, 25, 5830-5844, https://doi.org/10.1175/JCLI-D-11-00612.1, 2012.

Qiu, B. and Chen, S.: Seasonal modulations in the eddy field of the South Pacific Ocean, J. Phys. Oceanogr., 34, 1515-1527, https://doi.org/10.1175/15200485(2004)034<1515:SMITEF>2.0.CO;2, 2004.

Qiu, Y., Li, L., and Yu, W.: Behavior of the Wyrtki jet observed with surface drifting buoys and satellite altimeter, Geophys. Res. Lett., 36, L18607, https://doi.org/10.1029/2009GL039120, 2009.

Qiu, Y., Han, W., Lin, X., West, J., Li, Y., Xing, W., Zhang, X., Arulananthan, K., and Guo, X.: Upper-ocean response to the super tropical cyclone Phailin (2013) over the freshwater region of the Bay of Bengal, J. Phys. Oceanogr., 49, 1201-1228, https://doi.org/10.1175/JPO-D-18-0228.1, 2019.

Qu, T., Fukumori, I., and Fine, R. A.: Spin-Up of the Southern Hemisphere Super Gyre, J. Geophys. Res.-Oceans, 82, 217-229, https://doi.org/10.1029/2018JC014391, 2019.

Quadfasel, D. and Cresswell, G. R.: A note on the seasonal variability of the South Java Current, J. Geophys. Res., 97, 3685-3688, https://doi.org/10.1029/91JC03056, 1992.

Quartly, G. D. and Srokosz, M. A.: Seasonal variations in the region of the Agulhas retroflection: studies with Geosat and FRAM, J. Phys. Oceanogr., 23, 2107-2124, 1993.

Quartly, G. D. and Srokosz, M. A.: Eddies in the southern Mozambique Channel, Deep-Sea Res. Pt. II, 51, 69-83, https://doi.org/10.1016/j.dsr2.2003.03.001, 2004.

Rahaman, H., Bharath Raj, G. N., and Ravichandran, M.: Coupled Ocean-Atmosphere Summer Intraseasonal Oscillation over the Bay of Bengal, Pure Appl. Geophys., 176, 5415-5429, https://doi.org/10.1007/s00024-019-02275-4, 2019.

Raj, R. P., Peter, B. N., and Pushpadas, D.: Oceanic and atmospheric influences on the variability of phytoplankton bloom in the Southwestern Indian Ocean, J. Mar. Syst., 82, 217-229, https://doi.org/10.1016/j.jmarsys.2010.05.009, 2010.

Ramachandran, S. and Tandon, A.: Generation of Submesoscale Temperature Inversions Below Salinity Fronts in the Bay of Bengal, J. Geophys. Res.-Oceans, 125, e2020JC016278, https://doi.org/10/ghmsfn, 2020.

Ramachandran, S., Tandon, A., Mackinnon, J., Lucas, A. J., Pinkel, R., Waterhouse, A. F., Nash, J., Shroyer, E., Mahadevan, A., Weller, R. A., and Farrar, J. T.: Submesoscale processes at shallow, salinity fronts in the Bay of Bengal: Observations during the winter monsoon, J. Phys. Oceanogr., 48, 479-509, https://doi.org/10.1175/JPO-D-16-0283.1, 2018.

Rao, R. R. and Sivakumar, R.: Seasonal variability of sea surface salinity and salt budget of the mixed layer of the north Indian Ocean, J. Geophys. Res., 108, 3009, https://doi.org/10.1029/2001JC000907, 2003.

Rao, R. R., Molinari, R. L., and Festa, J. F.: Evolution of the climatological near-surface thermal structure of the tropical Indian Ocean. 1. Description of mean monthly mixed layer depth, and sea surface temperature, surface current, and surface meteorological fields, J. Geophys. Res., 94, 10801-10815, https://doi.org/10.1029/jc094ic08p10801, 1989.

Rasmusson, E. M. and Carpenter, T. H.: The Relationship between Eastern Equatorial Pacific Sea Surface Temperature and Rain- fall over India and Sri Lanka, Mon. Weather Rev., 111, 517-528, 1983.

Rathore, S., Bindoff, N. L., Phillips, H. E., and Feng, M.: Recent hemispheric asymmetry in global ocean warming induced by climate change and internal variability, Nat. Commun., 11, 2008, https://doi.org/10.1038/s41467-020-15754-3, 2020.

Ratna, S. B., Cherchi, A., Osborn, T. J., Joshi, M., and Uppara, U.: The extreme positive Indian Ocean Dipole of 2019 and associated Indian summer monsoon rainfall response, Geophys. Res. Lett., 48, e2020GL091497, https://doi.org/10.1029/2020GL091497, 2021.

Ravichandran, M., Girishkumar, M. S., and Riser, S.: Observed variability of chlorophyll-a using Argo profiling floats in the southeastern Arabian Sea, Deep-Sea Res. Pt. I, 65, 15-25, https://doi.org/10.1016/j.dsr.2012.03.003, 2012.

Reason, C. J. C.: Subtropical Indian Ocean SST dipole events and southern African rainfall, Geophys. Res. Lett., 28, 2225-2227, https://doi.org/10.1029/2000GL012735, 2001.

Reason, C. J. C.: Sensitivity of the southern African circulation to dipole sea-surface-temperature patterns in the south Indian Ocean, Int. J. Climatol., 22, 377-393, https://doi.org/10.1002/joc.744, 2002.

Reppin, J., Schott, F. A., Fischer, J., and Quadfasel, D.: Equatorial currents and transports in the upper central Indian Ocean: Annual cycle and interannual variability, J. Geophys. Res.-Oceans, 104, 15495-15514, https://doi.org/10.1029/1999jc900093, 1999.

Resplandy, L., Vialard, J., Lévy, M., Aumont, O., and Dandonneau, Y.: Seasonal and intraseasonal biogeochemical variability in the thermocline ridge of the southern tropical Indian Ocean, J. Geophys. Res.-Oceans, 114, C07024, https://doi.org/10.1029/2008JC005246, 2009.

Ridgway, K. R. and Condie, S. A.: The 5500-km-long boundary flow off western and southern Australia, J. Geophys. Res., 109, C04017, https://doi.org/10.1029/2003JC001921, 2004.

Ridgway, K. and Dunn, J. R.: Observational evidence for a Southern Hemisphere oceanic supergyre, Geophys. Res. Lett., 34, https://doi.org/10.1029/2007GL030392, 2007.

Ridgway, K. R. and Godfrey, J.: The source of the Leeuwin Current seasonality, J. Geophys. Res., 120, 6843-6864, https://doi.org/10.1002/2015JC011049, 2015.

Risbey, J. S., Pook, M. J., McIntosh, P. C., Wheeler, M. C., and Hendon, H. H.: On the Remote Drivers of Rainfall Variability in Australia, Mon. Weather Rev., 137, 3233-3253, 2009.

Rixen, T., Cowie, G., Gaye, B., Goes, J., do Rosário Gomes, H., Hood, R. R., Lachkar, Z., Schmidt, H., Segschneider, J., and Singh, A.: Reviews and syntheses: Present, past, and future of the oxygen minimum zone in the northern Indian Ocean, Biogeosciences, 17, 6051-6080, https://doi.org/10.5194/bg-176051-2020, 2020.

Roberts, M. J., van der Lingen, C. D., Whittle, C., and van den Berg, M.: Shelf currents, lee-trapped and transient eddies on the inshore boundary of the Agulhas Current, South Africa: their relevance to the KwaZulu-Natal sardine run, Afr. J. Marine Sci., 32, 423-447, https://doi.org/10.2989/1814232X.2010.512655, 2010.

Roberts, M. J., Ternon, J. F., and Morris, T.: Interaction of dipole eddies with the western continental slope of the Mozambique Channel, Deep-Sea Res. Pt. II, 100, 54-67, https://doi.org/10.1016/j.dsr2.2013.10.016, 2014. 
Robinson, J., Guillotreau, P., Jiménez-Toribio, R., Lantz, F., Nadzon, L., Dorizo, J., Gerry, C., and Marsac, F.: Impacts of climate variability on the tuna economy of Seychelles, Clim. Res., 43, 149-162, https://doi.org/10.3354/cr00890, 2010.

Rochford, D. J.: Seasonal interchange of high and low salinity surface waters off south-west Australia, Technical Paper, Division of Fisheries and Oceanography, CSIRO, Australia, available at: http://hdl.handle.net/102.100.100/321788?index=1 (last access: 22 October 2021), 1969.

Roemmich, D., Gould, W. J., and Gilson, J.: 135 years of global ocean warming between the Challenger expedition and the Argo Programme, Nat. Clim. Change, 2, 425-428, 2012.

Roman-Stork, H. L., Subrahmanyam, B., and Trott, C. B.: Monitoring intraseasonal oscillations in the Indian Ocean using satellite observations, J. Geophys. Res.-Oceans, 125, e2019JC015891, https://doi.org/10.1029/2019JC015891, 2020.

Ropelewski, C. F. and Halpert, M. S.: Global and Regional Scale Precipitation Patterns Associated with the El Nino/Southern Oscillation, Mon. Weather Rev., 115, 1606-1626, https://doi.org/10.1175/15200493(1987)115<1606:GARSPP>2.0.CO;2, 1987.

Rosell-Fieschi, M., Rintoul, S. R., Gourrion, J., and Pelegrí, J. L.: Tasman Leakage of intermediate waters as inferred from Argo floats, Geophys. Res. Lett., 40, 5456-5460, https://doi.org/10.1002/2013GL057797, 2013.

Roxy, M. and Tanimoto, Y.: Role of SST over the Indian Ocean in Influencing the Intraseasonal Variability of the Indian Summer Monsoon, J. Meteorol. Soc. Japan Ser. II, 85, 349-358, https://doi.org/10.2151/jmsj.85.349, 2007.

Roxy, M., Tanimoto, Y., Preethi, B., Terray, P., and Krishnan, R.: Intraseasonal SST-precipitation relationship and its spatial variability over the tropical summer monsoon region, Clim. Dynam., 41, 45-61, https://doi.org/10.1007/s00382-012-1547-1, 2013.

Roxy, M. K., Ritika, K., Terray, P., and Masson, S.: The curious case of Indian Ocean warming, J. Climate, 27, 8501-8509, https://doi.org/10.1175/JCLI-D-14-00471.1, 2014.

Roxy, M. K., Modi, A., Murtugudde, R., Valsala, V., Panickal, S., Prasanna Kumar, S., Ravichandran, M., Vichi, M., and Lévy, M.: A reduction in marine primary productivity driven by rapid warming over the tropical Indian Ocean, Geophys. Res. Lett., 43, 826-833, https://doi.org/10.1002/2015GL066979, 2016.

Roxy, M. K., Dasgupta, P., McPhaden, M. J., Suematsu, T., Zhang, C., and Kim, D.: Twofold expansion of the Indo-Pacific warm pool warps the MJO life cycle, Nature, 575, 647-651, https://doi.org/10.1038/s41586-019-1764-4, 2019.

Rouault, M., Penven, P., and Pohl, B.: Warming in the Agulhas Current system since the 1980's, Geophys. Res. Lett., 36, L12602, https://doi.org/10.1029/2009GL037987, 2009.

Rühs, S., Durgado, J. V., Behrens, E., and Biastoch, A.: Advective timescales and pathways of Agulhas Leakage, Geophys. Res. Lett., 40, 3997-4000, https://doi.org/10.1002/grl.50782, 2013.

Rydbeck, A. V. and Jensen, T. G.: Oceanic impetus for convective onset of the Madden-Julian oscillation in the western Indian ocean, J. Climate, 30, 4299-4316, https://doi.org/10.1175/JCLID-16-0595.1, 2017.

Rydbeck, A. V., Jensen, T. G., and Nyadjro, E. S.: Intraseasonal sea surface warming in the western Indian Ocean by oceanic equatorial Rossby waves, Geophys. Res. Lett., 44, 4224-4232, https://doi.org/10.1002/2017GL073331, 2017.
Sabeerali, C. T., Ramu Dandi, A., Dhakate, A., Salunke, K., Mahapatra, S., and Rao, S. A.: Simulation of boreal summer intraseasonal oscillations in the latest CMIP5 coupled GCMs, J. Geophys. Res.-Atmos., 118, 4401-4420, https://doi.org/10.1002/jgrd.50403, 2013.

Sabu, P., Subeesh, M. P., George, J. V., Anilkumar, N. P., and Ravichandran, M.: Enhanced subsurface mixing due to near-inertial waves: observation from SeychellesChagos Thermocline Ridge, Ocean Dynam., 71, 391-409, https://doi.org/10.1007/s10236-020-01430-z, 2021.

Sahoo, D., Saxena, H., Tripathi, N., Khan, A., Rahaman, A., Kumar, S., Sudheer, A., and Singh, A.: Non-Redfieldian C:N:P ratio in the inorganic and organic pools of the Bay of Bengal during the summer monsoon, Mar. Ecol. Prog. Ser., 653, 41-55, https://doi.org/10.3354/meps13498, 2020.

Sahoo, D., Saxena, H., Nazirahmed, S., Kumar, S., Sudheer, A., Bhushan, R., Sahay, A., and Singh, A.: Role of eddies and $\mathrm{N}_{2}$ fixation in regulating $C: N: P$ proportions in the Bay of Bengal, Biogeochemistry, 155, 413-429, https://doi.org/10.1007/s10533021-00833-4, 2021.

Saji, N. H., Goswami, B. N., Vinayachandran, P. N., and Yamagata, T.: A dipole mode in the tropical Indian Ocean, Nature, 401, 360363, https://doi.org/10.1038/43854, 1999.

Saji, N. H., Xie, S.-P., and Tam, C.-Y.: Satellite observations of intense intraseasonal cooling events in the tropical south Indian Ocean, Geophys. Res. Lett., 33, L14704, https://doi.org/10.1029/2006GL026525, 2006.

Sanchez-Franks, A., Kent, E. C., Matthews, A. J., Webber, B. G. M., Peatman, S. C., and Vinayachandran, P. N.: Intraseasonal variability of air-sea fluxes over the Bay of Bengal during the Southwest Monsoon, J. Climate, 31, 7087-7109, https://doi.org/10.1175/JCLI-D-17-0652.1, 2018.

Sanchez-Franks, A., Webber, B. G. M., King, B. A., Vinayachandran, P. N., Matthews, A. J., Sheehan, P. M. F., Behara, A., and Neema, C. P.: The railroad switch effect of seasonally reversing currents on the Bay of Bengal high salinity core, Geophys. Res. Lett., 46, 6005-6014, https://doi.org/10.1029/2019g1082208, 2019.

Sarkar, S., Pham, H. T., Ramachandran, S., Nash, J. D., Tandon, A., Buckley, J., Lotliker, A. A., and Omand, M. M.: The interplay between submesoscale instabilities and turbulence in the surface layer of the Bay of Bengal, Oceanography, 29, 146-157, https://doi.org/10.5670/oceanog.2016.47, 2016.

Sarma, V. V. and Aswanikumar, V.: Subsurface chlorophyll maxima in the north-western Bay of Bengal, J. Plankton Res., 13, 339352, https://doi.org/10.1093/plankt/13.2.339, 1991.

Sarojini, Y. and Sarma, N. S.: Vertical distribution of phytoplankton around Andaman and Nicobar Islands, Bay of Bengal, Indian J. Mar. Sci., 30, 65-69, 2001.

Sasamal, S. K., Panigrahy, R. C., and Misra, S.: Asterionella blooms in the northwestern Bay of Bengal during 2004, Int. J. Remote Sens., 26, 3853-3858, https://doi.org/10.1080/01431160500185391, 2005.

Sawant, S. and Madhupratap, M.: Seasonally and composition of phytoplankton in the Arabian Sea, Curr. Sci., 71, 869-873, 1996.

Schloesser, F.: A dynamical model for the Leeuwin Undercurrent, J. Phys. Oceanogr., 44, 1798-1810, https://doi.org/10.1175/JPOD-13-0226.1, 2014. 
Schmitz Jr., W. J.: On the interbasin-scale thermohaline circulation, Rev. Geophys., 33, 151-173, https://doi.org/10.1029/95RG00879, 1995.

Schott, F. A. and McCreary, J. P.: The monsoon circulation of the Indian Ocean, Progr. Oceanogr., 51, 1-123, 2001.

Schott, F., Dengler, M., and Schoenefeldt, R.: The shallow overturning circulation of the Indian Ocean, Prog. Oceanogr., 53, 57-103, 2002.

Schott, F. A., McCreary, J. P., and Johnson, G. C.: Shallow Overturning Circulations of the Tropical-Subtropical Oceans, in: Earth Climate: The Ocean-Atmosphere Interaction, edited by: Wang, C., Xie, S.-P., and Carton, J. A., 261-304. Geophysical Monograph, American Geophysical Union, Washington, D.C., https://doi.org/10.1029/147GM15, 2004.

Schott, F. A., Xie, S.-P., and McCreary, J. P.: Indian Ocean circulation and climate variability, Rev. Geophys., 47, RG1002, https://doi.org/10.1029/2007RG000245, 2009.

Schwarzkopf, F. U. and Böning, C. W.: Contribution of Pacific wind stress to multi-decadal variations in upper-ocean heat content and sea level in the tropical south Indian Ocean. Geophys. Res. Lett., 38, L12602, https://doi.org/10.1029/2011GL047651, 2011.

Schumann, E. H., Churchill, J. R. S., and Zaayman, H. J.: Oceanic variability in the western sector of Algoa Bay, South Africa, African J. Mar. Sci., 27, 65-80, https://doi.org/10.2989/18142320509504069, 2005.

Sengupta, D. and Ravichandran, M.: Oscillations of Bay of Bengal sea surface temperature during the 1998 Summer Monsoon, Geophys. Res. Lett., 28, 2033-2036, https://doi.org/10.1029/2000GL012548, 2001.

Sengupta, D., Senan, R., and Goswami, B. N.: Origin of intraseasonal variability of circulation in the tropical central Indian Ocean, Geophys. Res. Lett., 28, 1267-1270, https://doi.org/10.1029/2000GL012251, 2001.

Sengupta, D., Senan, R., Murty, V. S. N., and Fernando V.: A biweekly mode in the equatorial Indian Ocean, J. Geophys. Res., 109, C10003, https://doi.org/10.1029/2004JC002329, 2004.

Sengupta, D., Bharath Raj, G. N., and Shenoi, S. S. C.: Surface freshwater from Bay of Bengal runoff and Indonesian Throughflow in the tropical Indian Ocean, Geophys. Res. Lett., 33, L22609, https://doi.org/10.1029/2006GL027573, 2006.

Sengupta, D., Senan, R., Goswami, B. N., and Vialard, J.: Intraseasonal variability of equatorial Indian Ocean zonal currents, J. Climate, 20, 3036-3055, 2007.

Sengupta, D., Goddalehundi, B. R., and Anitha, D. S.: Cyclone-induced mixing does not cool SST in the postmonsoon north Bay of Bengal, Atmos. Sci. Lett., 9, 1-6, https://doi.org/10.1002/asl.162, 2008.

Seo, H., Murtugudde, R., Jochum, M., and Miller, A. J.: Modeling of mesoscale coupled ocean-atmosphere interaction and its feedback to ocean in the western Arabian Sea, Ocean Model., 25, 120-131, https://doi.org/10.1016/j.ocemod.2008.07.003, 2008.

Shalapyonok, A., Olson, R. J., and Shalapyonok, L. S.: Arabian Sea phytoplankton during Southwest and Northeast Monsoons 1995: Composition, size structure and biomass from individual cell properties measured by flow cytometry, Deep-Sea Res. Pt. II, 48, 1231-1261, https://doi.org/10.1016/S0967-0645(00)001375,2001
Shankar, D. and Shetye, S. R.: On the dynamics of the Lakshadweep high and low in southeastern Arabian Sea, J. Geophys. Res., 102, 12551-12562, 1997.

Shankar, D., McCreary, J. P., Han, W., and Shetye, S. R.: Dynamics of the East India Coastal Current 1. Analytic solutions forced by interior Ekman pumping and local alongshore winds, J. Geophys. Res., 101 13975-13991, 1996.

Shankar, D., Vinayachandran, P. N., and Unnikrishnan, A. S.: The monsoon currents in the north Indian Ocean, Prog. Oceanogr., 52, 63-120, https://doi.org/10.1016/S0079-6611(02)00024-1, 2002.

Shankar, D., Remya, R., Vinayachandran, P., Chatterjee, A., and Behera, A.: Inhibition of mixed-layer deepening during winter in the northeastern Arabian Sea by theWest India Coastal Current, Clim. Dynam., 47, 1049-1072, 2016.

Sharma, G. S.: Water characteristics and current structure at $65^{\circ} \mathrm{E}$ during the southwest monsoon, J. Oceanogr. Soc. Jpn., 32, 284 296, https://doi.org/10.1007/BF02107985, 1976.

Sharma, G. S., Gouveia, A. D., and Satyendranath, S.: Incursion of the Pacific Ocean Water into the Indian Ocean, Proc. Indian Acad. Sci., 87, 29-45, https://doi.org/10.1007/BF02839383, 1978.

Sharmila, S., Pillai, P. A., Joseph, S., Roxy, M., Krishna, R. P. M., Chattopadhyay, R., Abhilash, S., Sahai, A. K., and Goswami, B. N.: Role of ocean-atmosphere interaction on northward propagation of Indian summer monsoon intraseasonal oscillations (MISO), Clim. Dynam., 41, 1651-1669, https://doi.org/10.1007/s00382-013-1854-1, 2013.

Sheehan, P. M. F., Webber, B. G. M., Sanchez-Franks, A., Matthews, A. J., Heywood, K. J., and Vinayachandran, P. N.: Injection of Oxygenated Persian Gulf Water Into the Southern Bay of Bengal, Geophys. Res. Lett., 47, e2020GL087773, https://doi.org/10.1029/2020GL087773, 2020.

Shenoi, S., Shankar, D., and Shetye, S. R.: Differences in heat budgets of the near-surface Arabian Sea and Bay of Bengal: Implications for the summer monsoon, J. Geophys. Res., 107, C6, https://doi.org/10.1029/2000JC000679, 2002.

Shetye, S. R. and Shenoi, S. S. C.: Seasonal cycle of surface circulation in the coastal North Indian Ocean, Proc. Indian Acad. Sci., 97, 53-62, 1988.

Shetye, S. R., Gouveia, A. D., Shenoi, S. S. C., Sundar, D., Michael, G. S., and Nampoothiri, G.: The western boundary current of the seasonal subtropical gyre in the Bay of Bengal, J. Geophys. Res., 98, 945-954, 1993.

Shetye, S. R., Gouveia, A. D., and Shenoi, S. S. C.: Circulation and water masses of the Arabian Sea, Proc. Indian Acad. Sci., 103, 107-123, https://doi.org/10.1007/BF02839532, 1994.

Shetye, S. R., Gouveia, A. D., Shankar, D., Shenoi, S. S. C., Vinayachandran, P. N., Sundar, D., Michael, G. S., and Nampoothiri, G.: Hydrography and circulation in the western Bay of Bengal during the northeast monsoon, J. Geophys. Res.-Oceans, 101, 14011-14025, https://doi.org/10.1029/95JC03307, 1996.

Shinoda, T., Hendon, H. H., and Glick, J.: Intraseasonal Variability of Surface Fluxes and Sea Surface Temperature in the Tropical Western Pacific and Indian Oceans, J. Climate, 11, 1685-1702, 1998.

Shinoda, T., Kiladis, G. N., and Roundy, P. E.: Statistical representation of equatorial waves and tropical instabil- 
ity waves in the Pacific Ocean, Atmos. Res., 94, 37-44, https://doi.org/10.1016/j.atmosres.2008.06.002, 2009.

Shinoda, T., Han, W., Joseph Metzger, E., and Hurlburt, H. E.: Seasonal variation of the Indonesian throughflow in Makassar Strait, J. Phys. Oceanogr., 42, 1099-1123, https://doi.org/10.1175/JPOD-11-0120.1, 2012.

Shroyer, E., Rudnick, D., Farrar, J. T., Lim, B., Venayagamoorthy, S. K., St. Laurent, L., Garanaik, A., and Moum, J.: Modification of Upper-Ocean Temperature Structure by Subsurface Mixing in the Presence of Strong Salinity Stratification, Oceanography, 29, 62-71, https://doi.org/10.5670/oceanog.2016.39, 2016.

Shroyer, E. L., Gordon, A. L., Jaeger, G. S., Freilich, M., Waterhouse, A. F., and Farrar, J. T.: Upper layer thermohaline structure of the Bay of Bengal during the 2013 northeast monsoon, Deep-Sea Res. Pt. II, 172, 104630, https://doi.org/10.1016/j.dsr2.2019.07.018, 2019.

Siedler, G., Rouault, M., and Lutjeharms, J.: Structure and origin of the subtropical South Indian Ocean Countercurrent, Geophys. Res. Lett., 33, L24609, https://doi.org/10.1029/2006GL027399, 2006.

Siedler, G., Rouault, M., Biastoch, A., Backeberg, B. C., Reason, C. J. C., and Lutjeharms, J.: Modes of the southern extension of the East Madagascar Current, J. Geophys. Res., 114, C01005, https://doi.org/10.1029/2008JC004921, 2009.

Singh, A. and Ramesh, R.: Environmental controls on new and primary production in the northern Indian Ocean, Prog. Oceanogr., 4, 456-461, https://doi.org/10.1016/j.pocean.2014.12.006, 2015.

Singh, A., Gandhi, N., Ramesh, R., and Prakash, S.: Role of cyclonic eddy in enhancing primary and new production in the Bay of Bengal, J. Sea Res., 131, 138-145, https://doi.org/10.1016/j.seares.2014.12.002, 2015.

Singh, D., Tsiang, M., Rajaratnam, B., and Diffenbaugh, N. S.: Observed changes in extreme wet and dry spells during the south Asian summer monsoon season, Nat. Clim. Change, 4, 456-461, https://doi.org/10.1038/nclimate2208, 2014.

Smith, R. L., Huyer, A., Godfrey, J. S., and Church, J. A.: The Leeuwin Current off Western Australia, 1986-1987, J. Phys. Oceanogr., 21, 323-345, https://doi.org/10.1175/15200485(1991)021<0323:TLCOWA>2.0.CO;2, 1991.

Smyth, W. D., Durland, T. S., and Moum, J. N.: Energy and heat fluxes due to vertically propagating Yanai waves observed in the equatorial Indian Ocean, J. Geophys. Res.-Oceans, 120, 1-15, https://doi.org/10.1002/2014JC010152, 2015.

Song, Q., Gordon, A. L., and Visbeck, M.: Spreading of the Indonesian Throughflow in the Indian Ocean, J. Phys. Oceanogr., 34, 772-792, 2004.

Sorokin, Y., Kopylov, A., and Mamaeva, N.: Abundance and dynamics of microplankton in the central tropical Indian Ocean, Mar. Ecol. Prog. Ser., 97, 5-13, https://doi.org/10.3354/meps024027, 1985.

Speich, S., Blanke, B., and Cai, W.: Atlantic meridional overturning circulation and the Southern Hemisphere supergyre, Geophys. Res. Lett., 34, L23614, https://doi.org/10.1029/2007GL031583, 2007.

Sperber, K. R. and Annamalai, H.: Coupled model simulations of boreal summer intraseasonal (30-50 day) variability, Part 1: Systematic errors and caution on use of metrics, Clim. Dynam., 31, 345-372, https://doi.org/10.1007/s00382-008-0367-9, 2008.
Sprintall, J. and Révelard, A.: The Indonesian Throughflow response to Indo-Pacific climate variability, J. Geophys. Res.-Oceans, 119, 1161-1175, https://doi.org/10.1002/2013JC009533, 2014.

Sprintall, J., Chong, J., Syamsudin, F., Morawitz, W., Hautala, S., Bray, N., and Wijffels, S.: Dynamics of the South Java current in the Indo-Australian Basin, Geophys. Res. Lett., 26, 2493-2496, 1999.

Sprintall, J., Wijffels, S. E., Molcard, R., and Jaya, I.: Direct estimates of the Indonesian Throughflow entering the Indian Ocean: 2004-2006, J. Geophys. Res.-Oceans, 114, C07001, https://doi.org/10.1029/2008JC005257, 2009.

Sprintall, J., Gordon, A. L., Koch-Larrouy, A., Lee, T., Potemra, J. T., Pujiana, K., and Wijffels, S. E.: The Indonesian seas and their role in the coupled ocean-climate system, Nat. Geosci., 7, 487-492, https://doi.org/10.1038/ngeo2188, 2014.

Sprintall, J., Gordon, A. L., Wijffels, S. E., Feng, M., Hu, S., Koch-Larrouy, A., Phillips, H., Nugroho, D., Napitu, A., Pujiana, K., Dwi Susanto, R., Sloyan, B., Yuan, D., Riama, N. F., Siswanto, S., Kuswardani, A., Arifin, Z., Wahyudi, A. J., Zhou, H., Nagai, T., Ansong, J. K., Bourdalle-Badié, R., Chanut, J., Lyard, F., Arbic, B. K., Ramdhani, A., and Setiawan, A.: Detecting change in the Indonesian seas, Front. Mar. Sci., 6, 257, https://doi.org/10.3389/fmars.2019.00257, 2019.

Sree Lekha, J.: Space-time variability of near-surface salinity in the Bay of Bengal, $\mathrm{PhD}$ thesis, Indian Institute of Science, available at: https://etd.iisc.ac.in/handle/2005/4649 (last access: 19 November 2021), 2020.

Sree Lekha, J., Buckley, J. M., Tandon, A., and Sengupta, D.: Subseasonal Dispersal of Freshwater in the Northern Bay of Bengal in the 2013 Summer Monsoon Season, J. Geophys. Res.-Oceans, 123, 6330-6348, https://doi.org/10.1029/2018JC014181, 2018.

Srokosz, M. A. and Quartly, G. D.: The Madagascar bloom: A serendipitous study, J. Geophys. Res.-Oceans, 118, 14-25, https://doi.org/10.1029/2012JC008339, 2013.

Srokosz, M. A., Quartly, G. D., and Buck, J. J. H.: A possible plankton wave in the Indian Ocean, Geophys. Res. Lett., 31, L13301, https://doi.org/10.1029/2004GL019738, 2004.

Srokosz, M. A., Robinson, J., McGrain, H., Popova, E. E., and Yool, A.: Could the Madagascar bloom be fertilized by Madagascan iron?, J. Geophys. Res.-Oceans, 120, 5790-5803, https://doi.org/10.1002/2015JC011075, 2015.

St. Laurent, L. and Merrifield, S. T.: Measurements of Near-Surface Turbulence and Mixing from Autonomous Ocean Gliders, Oceanography, 30, 116-125, https://doi.org/10.5670/oceanog.2017.231, 2017.

Stramma, L., Bange, H. W., Czeschel, R., Lorenzo, A., and Frank, M.: On the role of mesoscale eddies for the biological productivity and biogeochemistry in the eastern tropical Pacific Ocean off Peru, Biogeosciences, 10, 7293-7306, https://doi.org/10.5194/bg-10-7293-2013, 2013.

Strutton, P. G., Coles, V. J., Hood, R. R., Matear, R. J., McPhaden, M. J., and Phillips, H. E.: Biogeochemical variability in the central equatorial Indian Ocean during the monsoon transition, Biogeosciences, 12, 2367-2382, https://doi.org/10.5194/bg-122367-2015, 2015.

Stuecker, M. F., Timmermann, A. , Jin, F. F., Chikamoto, Y., Zhang, W., Wittenberg, A. T., Widiasih, E., and Zhao, S.: Revisiting 
ENSO/Indian Ocean Dipole phase relationships, Geophys. Res. Lett., 44, 2481-2492, 2017.

Subrahmanyam, B., Trott, C. B., and Murty, V. S. N.: Detection of intraseasonal oscillations in SMAP salinity in the Bay of Bengal, Geophys. Res. Lett., 45, 7057-7065, https://doi.org/10.1029/2018GL078662, 2018.

Suhas, E., Neena, J. M., and Goswami, B. N.: An Indian monsoon intraseasonal oscillations (MISO) index for real time monitoring and forecast verification, Clim. Dynam., 40, 2605-2616, https://doi.org/10.1007/s00382-012-1462-5, 2013.

Sun, S., Lan, J., Fang, Y., Tana, and Gao, X.: A triggering mechanism for the Indian Ocean dipoles independent of ENSO, J. Climate, 28, 5063-5076, https://doi.org/10.1175/JCLI-D-14$00580.1,2015$.

Suresh, I., Vialard, J., Lengaigne, M., Han, W., McCreary, J., Durand, F., and Muraleedharan, P. M.: Origins of winddriven intraseasonal sea level variations in the north Indian Ocean coastal waveguide, Geophys. Res. Lett., 40, 5740-5744, https://doi.org/10.1002/2013GL058312, 2013.

Suresh, I., Vialard, J., Izumo, T., Lengaigne, M., Han, W., McCreary, J. P., and Muraleedharan, P. M.: Dominant role of winds near Sri Lanka in driving seasonal sea level variations along the west coast of India, Geophys. Res. Lett., 43, 7028-7035, https://doi.org/10.1002/2016GL069976, 2016.

Susanto, R. D., Gordon, A. L., and Zheng, Q. N.: Upwelling along the coasts of Java and Sumatra sand its relation to ENSO, Geophys. Res. Lett., 28, 1599-1602, 2001.

Susanto, R. D., Wei, Z., Adi, R. T., Fan, B., Li, S., and Fang, G.: Observations of the Karimata Strait throughflow from December 2007 to November 2008, Acta Oceanol. Sin., 32, 1-6, https://doi.org/10.1007/s13131-013-0307-3, 2013.

Suzuki, R., Behera, S. K., Iizuka, S., and Yamagata, T.: Indian Ocean subtropical dipole simulated using a coupled general circulation model, J. Geophys. Res.-Oceans, 109, C09001, https://doi.org/10.1029/2003JC001974, 2004.

Takaya, Y., Ishikawa, I., Kobayashi, C., Endo, H., and Ose, T.: Enhanced Meiyu-Baiu rainfall in early summer 2020: Aftermath of the 2019 super IOD event, Geophys. Res. Lett., 47, e2020GL090671, https://doi.org/10.1029/2020GL090671, 2020.

Takeuchi, K.: Numerical study of the Subtropical Front and the Subtropical Countercurrent, J. Oceanogr. Soc. Japan, 40, 371-381, https://doi.org/10.1007/BF02303341, 1984.

Talley, L. D.: Freshwater transport estimates and the global overturning circulation: Shallow, deep and throughflow components, Prog. Oceanogr., 78, 257-303, https://doi.org/10.1016/j.pocean.2008.05.001, 2008.

Talley, L. D.: Closure of the global overturning circulation through the Indian, Pacific, and Southern Oceans: Schematics and transports, Oceanography, 26, 80-97, https://doi.org/10.5670/oceanog.2013.07, 2013.

Talley, L. D. and Sprintall., J.: Deep expression of the Indonesian Throughflow: Indonesian Intermediate Water in the South Equatorial Current, J. Geophys. Res.-Oceans, 110, C10009, https://doi.org/10.1029/2004JC002826, 2005.

Talley, L. D., Pickard, G. L., Emery, W. J., and Swift, J. H.: Descriptive Physical Oceanography: An Introduction, 6th Edition, Academic Press, Elsevier Ltd., New York, 983 pp., 2011.

Talley, L. D., Feely, R. A., Sloyan, B. M., Wanninkhof, R., Baringer, M. O., Bullister, J. L., Carlson, C. A., Doney, S. C., Fine, R.
A., Firing, E., Gruber, N., Hansell, D. A., Ishii, M., Johnson, G. C., Katsumata, K., Key, R. M., Kramp, M., Langdon, C., Macdonald, A. M., Mathis, J. T., McDonagh, E. L., Mecking, S., Millero, F. J., Mordy, C. W., Nakano, T., Sabine, C. L., Smethie, W. M., Swift, J. H., Tanhua, T., Thurnherr, A. M., Warner, M. J., and Zhang, J.-Z.: Changes in ocean heat, carbon content, and ventilation: A review of the first decade of GO-SHIP global repeat hydrography, Annu. Rev. Mar. Sci., 8, 185-215, https://doi.org/10.1146/annurev-marine-052915-100829, 2016.

Talley, L., Johnson, G. C., Purkey, S., Feely, R. A., and Wanninkhof, R.: Global Ocean Ship-based Hydrographic Investigations Program (GO-SHIP) provides key climate-relevant deep ocean observations, US CLIVAR Variations, 15, 8-14, 2017.

Tarran, G. A., Burkill, P. H., Edwards, E. S., and Woodward, E. M. S.: Phytoplankton community structure in the Arabian Sea during and after the SW monsoon, 1994, Deep-Sea Res. Pt II, 46, 655-676, https://doi.org/10.1016/S0967-0645(98)001222, 1999.

Taylor, B. M., Benkwitt, C. E., Choat, H., Clements, K. D., Graham, N. A., and Meekan, M. G.: Synchronous biological feedbacks in parrotfishes associated with pantropical coral bleaching, Global Change Biol., 26, 1285-1294, https://doi.org/10.1111/gcb.14909, 2019.

Terray, P., Delecluse, P., Labattu, S., and Terray, L.: Sea surface temperature associations with the late Indian summer monsoon, Clim. Dynam., 21, 593-618, https://doi.org/10.1007/s00382003-0354-0, 2003.

Thadathil, P., Muraleedharan, P. M., Rao, R. R., Somayajulu, Y. K., Reddy, G. V., and Revichandran, C.: Observed seasonal variability of barrier layer in the Bay of Bengal, J. Geophys. Res.Oceans, 112, C02009, https://doi.org/10.1029/2006JC003651, 2007.

Thadathil, P., Suresh, I., Gautham, S., Prasanna Kumar, S., Lengaigne, M., Rao, R. R., Neetu, S., and Hegde, A.: Surface layer temperature inversion in the Bay of Bengal: Main characteristics and related mechanisms, J. Geophys. Res.-Oceans, 121, 5682-5696, https://doi.org/10.1002/2016JC011674, 2016.

Thakur, R., Shroyer, E. L., Govindarajan, R., Farrar, J. T., Weller, R. A., and Moum, J. N.: Seasonality and Buoyancy Suppression of Turbulence in the Bay of Bengal, Geophys. Res. Lett., 46, 43464355, https://doi.org/10/gf3w8j, 2019.

Thangaprakash, V. P., Girishkumar, M. S., Suprit, K., Kumar, N. S., Chaudhuri, D., Dinesh, K., Kumar, A., Shivaprasad, S., Ravichandran, M., Farrar, J. T., Sundar, R., and Weller, R.: What Controls Seasonal Evolution of Sea Surface Temperature in the Bay of Bengal? Mixed Layer Heat Budget Analysis Using Moored Buoy Observations Along $90^{\circ} \mathrm{E}$, Oceanography, 29, 202-213, https://doi.org/10.5670/oceanog.2016.52, 2016.

Thompson, P. A., Pesant, S., and Waite, A. M.: Contrasting the vertical differences in the phytoplankton biology of a dipole pair of eddies in the south-eastern Indian Ocean, Deep-Sea Res. Pt. II, 54, 1003-1028, https://doi.org/10.1016/j.dsr2.2006.12.009, 2007.

Thompson, P. A., Wild-Allen, K., Lourey, M., Rousseaux, C., Waite, A. M., Feng, M., and Beckley, L. E.: Nutrients in an oligotrophic boundary current: evidence of a new role for the Leeuwin Current, Prog. Oceanogr., 91, 345-359, 2011.

Thompson, R. O. R. Y.: Observations of the Leeuwin Current off Western Australia, J. Phys. 
Oceanogr., $\quad 14, \quad 623-628, \quad$ https://doi.org/10.1175/15200485(1984)014<0623:OOTLCO>2.0.CO;2, 1984.

Thompson, R. O. R. Y.: Continental-shelf-scale model of the Leeuwin Current, J. Mar. Res., 45, 813-827, https://doi.org/10.1357/002224087788327190, 1987.

Todd, R. E., Chavez, F. P., Clayton, S., Cravatte, S., Goes, M., Graco, M., Lin, X., Sprintall, J., Zilberman, N. V., Archer, M., Arístegui, J., Balmaseda, M., Bane, J. M., Baringer, M. O., Barth, J. A., Beal, L. M., Brandt, P., Calil, P. H. R., Campos, E., Centurioni, L. R., Chidichimo, M. P., Cirano, M., Cronin, M. F., Curchitser, E. N., Davis, R. E., Dengler, M., deYoung, B., Dong, S., Escribano, R., Fassbender, A. J., Fawcett, S. E., Feng, M., Goni, G. J., Gray, A. R., Gutiérrez, D., Hebert, D., Hummels, R., Ito, S., Krug, M., Lacan, F., Laurindo, L., Lazar, A., Lee, C. M., Lengaigne, M., Levine, N. M., Middleton, J., Montes, I., Muglia, M., Nagai, T., Palevsky, H. I., Palter, J. B., Phillips, H. E., Piola, A., Plueddemann, A. J., Qiu, B., Rodrigues, R. R., Roughan, M., Rudnick, D. L., Rykaczewski, R. R., Saraceno, M., Seim, H., Sen Gupta, A., Shannon, L., Sloyan, B. M., Sutton, A. J.,Thompson, L., van der Plas, A. K., Volkov, D., Wilkin, J., Zhang, D., and Zhang, L.: Global perspectives on observing ocean boundary current systems. OceanObs'19 white paper, Front. Marine Sci., 6, 423, https://doi.org/10.3389/fmars.2019.00423, 2019.

Tozuka, T., Kataoka, T., and Yamagata, T.: Locally and remotely forced atmospheric circulation anomalies of Ningaloo Niño/Niña, Clim. Dynam., 43, 2197-2205, https://doi.org/10.1007/s00382-013-2044-x, 2014.

Trott, C., Bulusu, S., and Washburn, C. E.: Investigating the response of temperature and salinity in the Agulhas Current region to ENSO events, Remote Sens., 13, 1829, https://doi.org/10.3390/rs13091829, 2021.

Turner, A. G., Joshi, M., Robertson, E. S., and Woolnough, S. J.: The effect of Arabian Sea optical properties on SST biases and the South Asian summer monsoon in a coupled GCM, Clim. Dynam., 39, 811-826, https://doi.org/10.1007/s00382-011-1254-3, 2012.

Ummenhofer, C. C., Biastoch, A., and Böning, C. W.: Multidecadal Indian Ocean variability linked to the Pacific and implications for preconditioning Indian Ocean dipole events, J. Climate, 30, 1739-1751, 2017.

Uz, B. M.: What causes the sporadic phytoplankton bloom southeast of Madagascar?, J. Geophys. Res.-Oceans, 112, C09010, https://doi.org/10.1029/2006JC003685, 2007.

Valsala, K. V. and Ikeda, M.: Pathways and effects of the Indonesian throughflow water in the Indian Ocean using particle trajectory and tracers in an OGCM, J. Climate, 20, 2994-3017, 2007.

Van Sebille, E., Biastoch, A., Van Leeuwen, P. J., and De Ruijter, W. P. M.: A weaker Agulhas current leads to more Agulhas leakage, Geophys. Res. Lett., 36, L03601, https://doi.org/10.1029/2008GL036614, 2009.

Van Sebille, E., Van Leeuwen, P. J., Biastoch, A., and De Ruijter, W. P. M.: On the fast decay of Agulhas rings, J. Geophys. Res.Oceans, 115, https://doi.org/10.1029/2009JC005585, 2010a.

Van Sebille, E., van Leeuwen, P. J., Biastoch, A., and de Ruijter, W. P. M.: Flux comparison of Eulerian and Lagrangian estimates of Agulhas leakage: A case study using a numerical model, Deep-Sea Res. Pt. I, 57, 319-327, https://doi.org/10.1016/j.dsr.2009.12.006, 2010b.
Van Sebille, E., Beal, L. M., and Johns, W. E.: Advective Time Scales of Agulhas Leakage to the North Atlantic in Surface Drifter Observations and the 3D OFES Model, J. Phys. Oceanogr., 41, 1026-1034, https://doi.org/10.1175/2011jpo4602.1, 2011.

Van Sebille, E., Sprintall, J., Schwarzkopf, F. U., Sen Gupta, A., Santoso, A., England, M. H., Biastoch, A., and Böning, C. W.: Pacific-to-Indian Ocean connectivity: Tasman leakage, Indonesian Throughflow, and the role of ENSO, J. Geophys. Res.-Oceans, 119, 1365-1382, https://doi.org/10.1002/2013JC009525, 2014.

Vargas-Hernandez, J. M., Wijffels, S., Meyers, G., and Holbrook, N. J.: Slow westward movement of salinity anomalies across the tropical South Indian Ocean, J. Geophys. Res.-Oceans, 120, 5436-5456, https://doi.org/10.1002/2015JC010933, 2015.

Varna, M., Singh, A., Sahoo, D., and Sengupta, D.: Strengthening of basin-scale ocean currents in winter drives decadal salinity decline in the eastern Arabian Sea, Geophys. Res. Lett., 48, e2021GL094516, https://doi.org/10.1029/2021GL094516, 2021.

Vecchi, G. A. and Harrison, D. E.: Monsoon Breaks and Subseasonal Sea Surface Temperature Variability in the Bay of Bengal, J. Climate, 15, 1485-1493, https://doi.org/10.1175/15200442(2002)015<1485:MBASSS>2.0.CO;2, 2002.

Vecchi, G. A. and Soden, B. J.: Global warming and the weakening of the tropical circulation, J. Climate, 20, 4316-4340, 2007.

Vecchi, G. A., Xie, S., and Fischer, A. S.: Ocean-Atmosphere Covariability in the Western Arabian Sea, J. Climate, 17, 12131224, 2004.

Venkatesan, R., Vedachalam, N., Arul Muthiah, M., Sundar, R., Kesavakumar, B., Ramasundaram, S., and Jossia Joseph, K.: Reliability metrics from two decades of Indian ocean moored buoy observation network, Mar. Technol. Soc. J., 52, 71-90, https://doi.org/10.4031/MTSJ.52.3.14, 2018.

Venrick, E. L.: Mid-ocean ridges and their influence on the large-scale patterns of chlorophyll and production in the North Pacific, Deep-Sea Res. Pt. I, 38, S83-S102, https://doi.org/10.1016/s0198-0149(12)80006-9, 1991.

Vialard, J., Foltz, G. R., McPhaden, M. J., Duvel, J. P., and de Boyer Montégut, C.: Strong Indian Ocean sea surface temperature signals associated with the Madden-Julian Oscillation in late 2007 and early 2008, Geophys. Res. Lett., 35, 1-5, https://doi.org/10.1029/2008GL035238, 2008.

Vialard, J., Duvel, J. P., Mcphaden, M. J., Bouruet-Aubertot, P., Ward, B., Key, E., Bourras, D., Weller, R., Minnett, P., Weill, A., Cassou, C., Eymard, L., Fristedt, T., Basdevant, C., Dandonneau, Y., Duteil, O., Izumo, T., de Boyer Montégut, C., Masson, S., Marsac, F., Menkes, C., and Kennan, S.: Cirene: Air-sea interactions in the Seychelles-Chagos thermocline ridge region, B. Am. Meteorol. Soc., 90, 45-62, https://doi.org/10.1175/2008BAMS2499.1, 2009a.

Vialard, J., Shenoi, S. S. C., McCreary, J. P., Shankar, D., Durand, F., Fernando, V., and Shetye, S. R.: Intraseasonal response of the northern Indian Ocean coastal waveguide to the Madden-Julian Oscillation, Geophys. Res. Lett., 36, 1-5, https://doi.org/10.1029/2009GL038450, 2009b.

Vialard, J., Jayakumar, A., Gnanaseelan, C., Lengaigne, M., Sengupta, D., and Goswami, B. N.: Processes of 30-90 days sea surface temperature variability in the northern Indian 
Ocean during boreal summer, Clim. Dynam., 38, 1901-1916, https://doi.org/10.1007/s00382-011-1015-3, 2012.

Vic, C., Roullet, G., Xavier, C., and Capet, X.: Mesoscale dynamics in the Arabian Sea and a focus on the Great Whirl life cycle: A numerical investigation using ROMS, J. Geophys. Res.-Oceans, 119, 6422-6443, https://doi.org/10.1002/2014JC009857, 2014.

Vijith, V., Vinayachandran, P., Thushara, V., Amol, P., Shankar, D., and Anil, A.: Consequences of inhibition of mixed-layer deepening by the West India Coastal Current for winter phytoplankton bloom in the northeastern Arabian Sea, J. Geophys. Res.-Oceans, 121, 6583-6603, https://doi.org/10.1002/2016JC012004, 2016.

Vinayachandran, P. N.: Impact of Physical Processes on Chlorophyll Distribution in the Bay of Bengal, Geophysical Monograph Series, AGU, Washington, D.C., 71-86, https://doi.org/10.1029/2008GM000705, 2009.

Vinayachandran, P. N. and Mathew, S.: Phytoplankton bloom in the Bay of Bengal during the northeast monsoon and its intensification by cyclones, Geophys. Res. Lett., 30, 1572, https://doi.org/10.1029/2002GL016717, 2003.

Vinayachandran, P. N. and Yamagata, T.: Monsoon Response of the Sea around Sri Lanka: Generation of Thermal Domes and antiCyclonic Vortices, J. Phys. Oceanogr., 28, 1946-1960, 1998.

Vinayachandran, P. N., Shetye, S. R., Sengupta, D., and Gadgil, S.: Forcing mechanisms of the Bay of Bengal circulation, Curr. Sci., 71, 753-763, 1996.

Vinayachandran, P. N., Saji, N. H., and Yamagata, T.: Response of the equatorial Indian Ocean to an anomalous wind event during 1994, Geophys. Res. Lett., 26, 1613-1615, 1999.

Vinayachandran, P. N., Murty, V. S. N., and Babu, V. R.: Observations of barrier layer formation in the Bay of Bengal during summer mon-soon, J. Geophys. Res., 107, 8018, https://doi.org/10.1029/2001JC000831, 2002.

Vinayachandran, P. N., Chauhan, P., Mohan, M., and Nayak, S.: Biological response of the sea around Sri Lanka to summer monsoon, Geophys. Res. Lett., 310, L01302, https://doi.org/10.1029/2003GL018533, 2004.

Vinayachandran, P. N., Kagimoto, T., Masumoto, T. Y., Chauhan, P., Nayak, S. R., and Yamagata, T.: Bifurcation of the East India Coastal Current east of Sri Lanka, Geophys. Res. Lett., 32, L15606, https://doi.org/10.1029/2005GL022864, 2005.

Vinayachandran, P. N., Shankar, D., Vernekar, S., Sandeep, K. K., Amol, P., Neema, C. P., and Chatterjee, A.: A summer monsoon pump to keep the Bay of Bengal salty, Geophys. Res. Lett., 40, 1777-1782, https://doi.org/10.1002/grl.50274, 2013.

Vinayachandran, P. N., Matthews, A. J., Vijay KuMar, K., SanchezFranks, A., Thushara, V., George, J., Vijith, V., Webber, B. G. M., Queste, B. Y., Roy, R., Sarkar, A., Baranowski, D. B., Bhat, G. S., Klingaman, N. P., Peatman, S. C., Parida, C., Heywood, K. J., Hall, R., King, B., Kent, E. C., Nayak, A. A., Neema, C. P., Amol, P., Lotliker, A., Kankonkar, A., Gracias, D. G., Vernekar, S., D’Souza, A. C., Valluvan, G., Pargaonkar, S. M., Dinesh, K., Giddings, J., and Joshi, M.: BoBBLE: Ocean-Atmosphere interaction and its impact on the South Asian monsoon, B. Am. Meteorol. Soc., 99, 1569-1587, https://doi.org/10.1175/BAMSD-16-0230.1, 2018.

Vinogradova, N., Lee, T., Boutin, J., Drushka, K., Fournier, S., Sabia, R., Stammer, D., Bayler, E., Reul, N., Gordon, A., Melnichenko, O., Li, L., Hackert, E., Martin, M., Kolodziejczyk, N., Hasson, A., Brown, S., Misra, S., and Lind- strom, E.: Satellite Salinity Observing System: Recent Discoveries and the Way Forward, Front. Marine Sci., 6, 243, https://doi.org/10.3389/fmars.2019.00243, 2019.

Vivekanandan, E. and Krishnakumar, P. K.: Spatial and temporal differences in the coastal fisheries along the east coast of India, Indian J. Marine Sci., 39, 380-387, 2010.

Volkov, D. L., Lee, S.-K., Gordon, A. L., and Rudko, M.: Unprecedented reduction and quick recovery of the South Indian Ocean heat content and sea level in 2014-2018, Sci. Adv., 6, eabc1151, https://doi.org/10.1126/sciadv.abc1151, 2020.

Wacongne, S. and Pacanowski, R. C.: Seasonal heat transport in a primitive equation model of the tropical Indian Ocean, J. Phys. Oceanogr., 26, 2666-2699, 1996.

Wainwright, C. M., Finney, D. L., Kilavi, M., Black, E., and Marsham, J. H.: Extreme rainfall in East Africa, October 2019January 2020 and context under future climate change, Weather, 76, 26-31, https://doi.org/10.1002/wea.3824, 2021.

Waite, A. M., Pesant, S., Griffin, D. A., Thompson, P. A., and Holl, C. M.: Oceanography, primary production and dissolved inorganic nitrogen uptake in two Leeuwin Current eddies, Deep-Sea Res. Pt. II, 54, 981-1002, https://doi.org/10.1016/j.dsr2.2007.03.001, 2007a.

Waite, A. M., Thompson, P. A., Pesant, S., Feng, M., Beckley, L. E., Domingues, C. M., Gaughan, D., Hanson, C. E., Holl, C. M., Koslow, T., Meuleners, M., Montoya, J. P., Moore, T., Muhling, B. A., Paterson, H., Rennie, S., Strzelecki, J., and Twomey, L.: The Leeuwin Current and its eddies: An introductory overview, Deep-Sea Res. Pt. II, 54, 789-796, https://doi.org/10.1016/j.dsr2.2006.12.008, 2007b.

Waite, A. M., Beckley, L. E., Guidi, L., Landrum, J. P., Holliday, D., Montoya, J., Paterson, H., Feng, M., Thompson, P. A., and Raes, E. J.: Cross-shelf transport, oxygen depletion, and nitrate release within a forming mesoscale eddy in the eastern Indian Ocean, Limnol. Oceanogr., 61, 103-121, https://doi.org/10.1002/lno.10218, 2016.

Waliser, D. E., Lau, K. M., and Kim, J.-H.: The influence of coupled sea surface temperatures on the Madden-Julian oscillation: A model perturbation experiment, J. Atmos. Sci., 56, 333-358, 1999.

Waliser, D. E., Murtugudde, R., and Lucas, L. E.: Indo-Pacific Ocean response to atmospheric intraseasonal variability: 1 . Austral summer and the Madden-Julian Oscillation, J. Geophys. Res., 108, 3160, https://doi.org/10.1029/2002JC001620, 2003.

Waliser, D. E., Murtugudde, R., Strutton, P., and Li, J.-L.: Subseasonal organization of ocean chlorophyll: prospects for prediction based on the Madden-Julian Oscillation, Geophys. Res. Lett., 32, https://doi.org/10.1029/2005GL024300, 2005.

Wang, B., Liu, F., and Chen, G.: A trio-interaction theory for Madden-Julian Oscillation, Geosci. Lett., 3, 34, https://doi.org/10.1186/s40562-016-0066-z, 2016.

Wang, G. and Cai, W.: Two-year consecutive concurrences of positive Indian Ocean Dipole and Central Pacific El Niño preconditioned the 2019/2020 Australian "black summer" bushfires, Geosci. Lett., 7, 19, https://doi.org/10.1186/s40562-020-001682, 2020.

Wang, H., McClean, J. L., Talley, L. D., and Yeager, S.: Seasonal cycle and annual reversal of the Somali Current in an eddyresolving global ocean model, J. Geophys. Res.-Oceans, 123, 6562-6580, https://doi.org/10.1029/2018JC013975, 2018. 
Wang, H., Kumar, A., Murtugudde, R., Narapusetty, B., and Selp, K. L.: Covariations between the Indian Ocean dipole and ENSO: a modeling study, Clim. Dynam., 53, 5743-5761, https://doi.org/10.1007/s00382-019-04895-x, 2019.

Wang, Y. and McPhaden, M. J.: Seasonal cycle of cross-equatorial flow in the Central Indian Ocean, J. Geophys. Res., 122, 38173827, https://doi.org/10.1002/2016JC012537, 2017.

Warner, S. J., Becherer, J., Pujiana, K., Shroyer, E. L., Ravichandran, M., Thangaprakash, V. P., and Moum, J. N.: Monsoon mixing cycles in the Bay of Bengal: A yearlong subsurface mixing record, Oceanography, 29, 158-169, https://doi.org/10.5670/oceanog.2016.48, 2016.

Weaver, A. J. and Middleton, J. H.: On the dynamics of the Leeuwin Current, J. Phys. Oceanogr., $\quad 19, \quad 626-648, \quad$ https://doi.org/10.1175/15200485(1989)019<0626:OTDOTL>2.0.CO;2, 1989.

Weaver, A. J. and Middleton, J. H.: An analytic model for the Leeuwin Current off western Australia, Cont. Shelf Res., 10, 105-122, https://doi.org/10.1016/0278-4343(90)90025-H, 1990.

Webber, B. G. M., Matthews, A. J., and Heywood, K. J.: A dynamical ocean feedback mechanism for the MaddenJulian Oscillation, Q. J. Roy. Meteor. Soc., 136, 740-754, https://doi.org/10.1002/qj.604, 2010.

Webber, B. G. M., Matthews, A. J., Heywood, K. J., and Stevens, D. P.: Ocean Rossby waves as a triggering mechanism for primary Madden-Julian events, Q. J. Roy. Meteor. Soc., 138, 514-527, https://doi.org/10.1002/qj.936, 2012a.

Webber, B. G. M., Stevens, D. P., Matthews, A. J., and Heywood, K. J.: Dynamical ocean forcing of the Madden-Julian oscillation at lead times of up to five months, J. Climate, 25, 2824-2842, https://doi.org/10.1175/JCLI-D-11-00268.1, 2012b.

Webber, B. G. M., Matthews, A. J., Heywood, K. J., Kaiser, J., and Schmidtko, S.: Seaglider observations of equatorial Indian Ocean Rossby waves associated with the MaddenJulian Oscillation, J. Geophys. Res.-Oceans, 119, 3714-3731, https://doi.org/10.1002/2013JC009657, 2014.

Webber, B. G. M., Matthews, A. J., Vinayachandran, P. N., Neema, C. P., Sanchez-Franks, A., Vijith, V., Amol, P., and Baranowski, D. B.: The Dynamics of the Southwest Monsoon Current in 2016 from High-Resolution In Situ Observations and Models, J. Phys. Oceanogr., 48, 2259-2282, https://doi.org/10.1175/JPOD-17-0215.1, 2018.

Webster, P. J., Moore, A., Loschnigg, J. P., and R., L. R.: Coupled oceanic-atmoshperic dynamics in the Indian Ocean during 19971998, Nature, 401, 356-360, 1999.

Weijer, W. and van Sebille, E.: Impact of Agulhas leakage on the Atlantic overturning circulation in the CCSM4, J. Climate, 27, 101-110, https://doi.org/10.1175/JCLI-D-12-00714.1, 2014.

Weller, R. A., Farrar, J. T., Buckley, J., Mathew, S., Venkatesan, R., Lekha, J. S., Chaudhuri, D., Suresh Kumar, N., and Praveen Kumar, B.: Air-sea interaction in the Bay of Bengal, Oceanography, 29, 28-37, https://doi.org/10.5670/oceanog.2016.36, 2016.

Whalen, C. B., Talley, L. D., and MacKinnon, J. A.: Spatial and temporal variability of global ocean mixing inferred from Argo profiles, Geophys. Res. Lett., 39, https://doi.org/10.1029/2012GL053196, 2012.

Wiggert, J. D., Jones, B. H., Dickey, T. D., Brink, K. H., Weller, R. A., Marra, J., and Codispoti, L. A.: The Northeast Monsoon's impact on mixing, phytoplankton biomass and nutrient cycling in the Arabian Sea, Deep-Sea Res. Pt. II, 47, 1353-1385, https://doi.org/10.1016/S0967-0645(99)00147-2, 2000.

Wiggert, J. D., Hood, R. R., Banse, K., and Kindle, J. C.: Monsoon-driven biogeochemical processes in the Arabian Sea, Prog. Oceanogr., 65, 176-213, https://doi.org/10.1016/j.pocean.2005.03.008, 2005.

Wiggert, J. D., Murtugudde, R. G., and Christian, J. R.: Annual ecosystem variability in the tropical Indian Ocean: Results of a coupled bio-physical ocean general circulation model, Deep-Sea Res. Pt. II, 53, 644-676, https://doi.org/10.1016/j.dsr2.2006.01.027, 2006.

Wiggert, J. D., Vialard, J., and Behrenfeld, M. J.: Basin-wide modification of dynamical and biogeochemical processes by the positive phase of the Indian Ocean Dipole during the SeaWiFS era, in: Indian Ocean biogeochemical Processes and Ecological Variability, Geophysical Monograph Series, 185, 385-407, https://doi.org/10.1029/2008GM000776, 2009.

Wijesekera, H. W., Jensen, T. G., Jarosz, E., Teague, W. J., Metzger, E. J., Wang, D. W., Jinadasa, S. U. P., Arulananthan, K., Centurioni, L. R., and Fernando, H. J. S.: Southern Bay of Bengal currents and salinity intrusions during the northeast monsoon, J. Geophys. Res.-Oceans, 120, 6897-6913, https://doi.org/10.1002/2015JC010744, 2015.

Wijesekera, H. W., Shroyer, E., Tandon, A., Ravichandran, M., Sengupta, D., Jinadasa, S. U. P., Fernando, H. J. S., Agrawal, N., Arulananthan, K., Bhat, G. S., Baumgartner, M., Buckley, J., Centurioni, L., Conry, P., Thomas Farrar, J., Gordon, A. L., Hormann, V., Jarosz, E., Jensen, T. G., Johnston, S., Lankhorst, M., Lee, C. M., Leo, L. S., Lozovatsky, I., Lucas, A. J., MacKinnon, J., Mahadevan, A., Nash, J., Omand, M. M., Pham, H., Pinkel, R., Rainville, L., Ramachandran, S., Rudnick, D. L., Sarkar, S., Send, U., Sharma, R., Simmons, H., Stafford, K. M., Laurent, L. S., Venayagamoorthy, K., Venkatesan, R., Teague, W. J., Wang, D. W., Waterhouse, A. F., Weller, R., and Whalen, C. B.: ASIRI: An ocean-atmosphere initiative for Bay of Bengal, B. Am. Meteorol. Soc., 97, 1859-1884, https://doi.org/10.1175/BAMS-D-1400197.1, 2016a.

Wijesekera, H., Teague, W., Jarosz, E., Wang, D., Jensen, T., Jinadasa, S. U. P., Fernando, H., Centurioni, L., Hallock, Z., Shroyer, E., and Moum, J.: Observations of Currents Over the Deep Southern Bay of Bengal - With a Little Luck, Oceanography, 29, 112-123, https://doi.org/10.5670/oceanog.2016.44, 2016 b.

Wijesekera, H. W., Teague, W. J., Wang, D. W., Jarosz, E., Jensen, T. G., Jinadasa, S. U. P., Fernando, H. J. S., and Hallock, Z. R.: Low-frequency currents from deep moorings in the southern bay of Bengal, J. Phys. Oceanogr., 46, 3209-3238, https://doi.org/10.1175/JPO-D-16-0113.1, 2016c.

Wijffels, S. and Meyers, G.: An intersection of oceanic waveguides: Variability in the Indonesian throughflow region, J. Phys. Oceanogr., 34, 1232-1253, 2004.

Wijffels, S., Meyers, G., and Godfrey, J. S.: A 20-yr average of the Indonesian throughflow: Regional currents and the interbasin exchange, J. Phys. Oceanogr., 38, 1965-1978, 2008.

Wijffels, S., Roemmich, D., Monselesan, D., Church, J., and Gilson, J.: Ocean temperatures chronicle the ongoing warming of Earth, Nat. Clim. Change, 6, 116-118, https://doi.org/10.1038/nclimate2924, 2016. 
Williams, A. P. and Funk, C.: A westward extension of the warm pool leads to a westward extension of the Walker circulation, drying eastern Africa, Clim. Dynam., 37, 2417-2435, 2011.

Wilson, C. and Qiu, X.: Global distribution of summer chlorophyll blooms in the oligotrophic gyres, Prog. Oceanogr., 78, 107-134, https://doi.org/10.1016/j.pocean.2008.05.002, 2008.

Wilson, E. A. and Riser, S. C.: An Assessment of the Seasonal Salinity Budget for the Upper Bay of Bengal, J. Phys. Oceanogr., 46, 1361-1376, 2016.

Woo, L. M. and Pattiaratchi, C. B.: Hydrography and water masses off the western Australian coast, Deep-Sea Res. Pt. I, 55, 10901104, https://doi.org/10.1016/j.dsr.2008.05.005, 2008.

Woo, M., Pattiaratchi, C., and Schroeder, W.: Summer surface circulation along the Gascoyne continental shelf, Western Australia, Cont. Shelf Res., 26, 132-152, 2006.

Wyrtki, K.: An equatorial jet in the Indian Ocean, Science, 181, 262-264, https://doi.org/10.1126/science.181.4096.262, 1973.

Xi, J., Zhou, L., Murtugudde, R., and Jiang, L.: Impacts of intraseasonal SST anomalies on precipitation during Indian summer monsoon, J. Climate, 28, 4561-4575, https://doi.org/10.1175/JCLI-D-14-00096.1, 2015.

Xie, S., Hu, K., Hafner, J., Tokinaga, H., Du, Y., Huang, G., and Sampe, T.: Indian Ocean Capacitor Effect on Indo-Western Pacific Climate during the Summer following El Niño, J. Climate, 22, 730-747, https://doi.org/10.1175/2008JCLI2544.1, 2009.

Xie, S.-P., Annamalai, H., Schott, F. A., and McCreary, J. P.: Structure and mechanisms of South Indian Ocean climate variability, J. Climate, 15, 864-878, 2002.

Xie, S.-P., Du, Y., Huang, G., Zheng, X.-T., Tokinaga, H., Hu, K. M., and Liu, Q. Y.: Decadal shift in El Niño influences on IndoWestern Pacific and East Asian climate in the 1970s, J. Climate, 23, 3352-3368, 2010.

Xie, S.-P., Kosaka, Y., Du, Y., Hu, K., Chowdary, J. S., and Huang, G.: Indo-western Pacific ocean capacitor and coherent climate anomalies in post-ENSO summer: A review, Adv. Atmos. Sci., 33, 411-432, https://doi.org/10.1007/s00376-015-5192-6, 2016.

Yamagami, Y. and Tozuka, T.: Interdecadal changes of the Indian Ocean subtropical dipole mode, Clim. Dynam., 44, 3057-3066, https://doi.org/10.1007/s00382-014-2202-9, 2015.

Yanai, M. and Maruyama, T.: Stratospheric wave disturbances propagating over the equatorial pacific, J. Meteorol. Soc. Jap., 44, 291-294, 1966.

Yang, J., Liu, Q., Xie, S.-P., Liu, Z., and Wu, L.: Impact of the Indian Ocean SST basin mode on the Asian summer monsoon, Geophys. Res. Lett., 34, L02708, https://doi.org/10.1029/2006GL028571, 2007.

Yang, L., Murtugudde, R., Zhou, L., and Liang, P.: A potential link between the Southern Ocean warming and the South Indian Ocean heat balance, J. Geophys. Res.-Oceans, 125, e2020JC016132, https://doi.org/10.1029/2020JC016132, 2020.

Yang, Y., Xie, S.-P., Wu, L., Kosaka, Y., Lau, N. C., and Vecchi, G. A.: Seasonality and predictability of the Indian Ocean dipole mode: ENSO forcing and internal variability, J. Climate, 28, 8021-8036, 2015.

Yit Sen Bull, C. and van Sebille, E.: Sources, fate, and pathways of Leeuwin Current water in the Indian Ocean and Great Australian Bight: A Lagrangian study in an eddyresolving ocean model, J. Geophys. Res.-Oceans, 121, 16261639, https://doi.org/10.1002/2015JC011486, 2016.
Yoshida, K. and Kidokoro, T.: A subtropical countercurrent II: A prediction of eastward flows at lower subtropical latitudes, J. Oceanogr. Soc. Japan, 23, 231-246, 1967.

Yu, L.: Global Air-Sea Fluxes of Heat, Fresh Water, and Momentum: Energy Budget Closure and Unanswered Questions, Annu. Rev. Mar. Sci., 11, 227-248, 2019.

Yu, Z. and Potemra, J.: Generation mechanism for the intraseasonal variability in the Indo-Australian basin, J. Geophys. Res., 111, C01013, https://doi.org/10.1029/2005JC003023, 2006.

Yu, L., Jin, X., and Weller, R. A.: Annual, seasonal, and interannual variability of air-sea heat fluxes in the Indian Ocean, J. Climate, 20, 3190-3209, 2007.

Yuan, Y. and Yang, S.: Impacts of different types of El Niño on East Asian climate: focus on ENSO cycles, J. Climate, 25, 77027722, https://doi.org/10.1175/JCLI-D-11-00576.1, 2012.

Yuan, D., Zhou, H., and Zhao, X.: Interannual climate variability over the tropical pacific ocean induced by the indian ocean dipole through the Indonesian Throughflow, J. Climate, 26, 2845-2861, https://doi.org/10.1175/JCLI-D-12-00117.1, 2013.

Zang, N., Sprintall, J., Ienny, R., and Wang, F.: Seasonality of the Somali Current/Undercurrent System, Deep-Sea Res. Pt. II, 191192, 104953, https://doi.org/10.1016/j.dsr2.2021.104953, 2021.

Zhang, C.: Madden-Julian Oscillation, Rev. Geophys., 43, RG2003, https://doi.org/10.1029/2004RG000158, 2005.

Zhang, D., McPhaden, M. J., and Lee, T.: Observed Interannual Variability of Zonal Currents in the Equatorial Indian Ocean Thermocline and Their Relation to Indian Ocean Dipole, Geophys. Res. Lett., 41, 7933-7941, https://doi.org/10.1002/2014GL061449, 2014.

Zhang, L., Han, W., Li, Y., and Maloney, E. D.: Role of North Indian Ocean air-sea interaction in summer monsoon intraseasonal oscillation, J. Climate, 31, 7885-7908, https://doi.org/10.1175/JCLI-D-17-0691.1, 2018.

Zhang, L., Han, W., Li, Y., and Lovenduski, N. S.: Variability of Sea Level and Upper-Ocean Heat Content in the Indian Ocean: Effects of Subtropical Indian Ocean Dipole and ENSO, J. Climate, 32, 7227-7245, 2019.

Zhang, N., Feng, M., Du, Y., Lan, J., and Wijffels, S. E.: Seasonal and interannual variations of mixed layer salinity in the southeast tropical Indian Ocean, J. Geophys. Res.-Oceans, 121, 47164731, https://doi.org/10.1002/2016JC011854, 2016.

Zhang, N., Feng, M., Hendon, H. H., Hobday, A. J., and Zinke, J.: Opposite polarities of ENSO drive distinct patterns of coral bleaching potentials in the southeast Indian Ocean, Sci. Rep.-UK, 7, 1-10, https://doi.org/10.1038/s41598-017-02688-y, 2017.

Zhang, W., Wang, Y., Jin, F.-F., Stuecker, M. F., and Turner, A. G.: Impact of different El Niño types on the El Niño/IOD relationship. Geophys. Res. Lett., 42, 8570-8576, 2015.

Zhang, Y., Feng, M., Du, Y., Phillips, H. E., Bindoff, N. L., McPhaden, M. J.: Strengthened Indonesian Throughflow drives decadal warming in the Southern Indian Ocean, Geophys Res. Lett., 45, 6167-6175, 2018.

Zheng, S., Feng, M., Du, Y., Meng, X., and Yu, W.: Interannual variability of eddy kinetic energy in the subtropical southeast Indian Ocean associated with the El NiñoSouthern Oscillation, J. Geophys. Res.-Oceans, 123, 1048-1061, https://doi.org/10.1002/2017JC013562, 2018. 
Zheng, X.-T., Xie, S.-P., Du, Y., Liu, L., Huang, G., and Liu, Q. Y.: Indian Ocean Dipole response to global warming in the CMIP5 multimodel ensemble, J. Climate, 26, 6067-6080, 2013.

Zhou, L. and Murtugudde, R.: Ocean-Atmosphere Coupling on Different Spatiotemporal Scales: A Mechanism for Intraseasonal Instabilities, J. Atmos. Sci., 66, 1834-1844, 2009.

Zhou, L., Murtugudde, R., Chen, D., and Tang, Y.: A Central Indian Ocean mode and heavy precipitation during Indian Summer Monsoon, J. Climate, 30, 2055-2067, https://doi.org/10.1175/JCLI-D-16-0347.1, 2017a.

Zhou, L., Murtugudde R., Chen, D., and Tang, Y.: Seasonal and interannual variabilities of the Central Indian Ocean, J. Climate, 30, 6505-6520, https://doi.org/10.1175/JCLI-D-160616.1, 2017b.

Zhou, X., Alves, O. Marsland, S. J., Bi, D., and Hirst, A. C.: Multidecadal variations of the south Indian Ocean subsurface temperature influenced by Pacific Decadal Oscillation, Tellus, 69A, 1308055, https://doi.org/10.1080/16000870.2017.1308055, 2017.
Zhou, Z.-Q., Zhang, R., and Xie, S.-P.: Interannual variability of summer surface air temperature over central India: Implications for monsoon onset, J. Climate, 32, 1693-1706, 2019.

Zhou, Z.-Q., Xie, S.-P., and Zhang, R,: Historic Yangtze flooding of 2020 tied to extreme Indian Ocean conditions, P. Natl. Acad. Sci. USA, 118, e2022255118, https://doi.org/10.1073/pnas.2022255118, 2021.

Zhuang, W., Feng, M., Du, Y., Schiller, A., and Wang, D.: Low-frequency sea level variability in the southern Indian Ocean and its impacts on the oceanic meridional transports, J. Geophys. Res.-Oceans, 118, 1302-1315, https://doi.org/10.1002/jgrc.20129, 2013.

Zinke, J., Rountrey, A., Feng, M., Xie, S.-P., Dissard, D., Rankenburg, K., Lough, J. M., and McCulloch, M. T. Corals record long-term Leeuwin current variability including Ningaloo Niño/Niña since 1795, Nat. Commun., 5, 3607 , https://doi.org/10.1038/ncomms4607, 2014. 